\title{
Course of disease, fatigue and health-related quality of life in inflammatory bowel disease
}

Citation for published version (APA):

Romberg-Camps, M. (2010). Course of disease, fatigue and health-related quality of life in inflammatory bowel disease. [Doctoral Thesis, Maastricht University]. Maastricht University. https://doi.org/10.26481/dis.20100708mr

Document status and date:

Published: 01/01/2010

DOI:

10.26481/dis.20100708mr

Document Version:

Publisher's PDF, also known as Version of record

\section{Please check the document version of this publication:}

- A submitted manuscript is the version of the article upon submission and before peer-review. There can be important differences between the submitted version and the official published version of record.

People interested in the research are advised to contact the author for the final version of the publication, or visit the DOI to the publisher's website.

- The final author version and the galley proof are versions of the publication after peer review.

- The final published version features the final layout of the paper including the volume, issue and page numbers.

Link to publication

\footnotetext{
General rights rights.

- You may freely distribute the URL identifying the publication in the public portal. please follow below link for the End User Agreement:

www.umlib.nl/taverne-license

Take down policy

If you believe that this document breaches copyright please contact us at:

repository@maastrichtuniversity.nl

providing details and we will investigate your claim.
}

Copyright and moral rights for the publications made accessible in the public portal are retained by the authors and/or other copyright owners and it is a condition of accessing publications that users recognise and abide by the legal requirements associated with these

- Users may download and print one copy of any publication from the public portal for the purpose of private study or research.

- You may not further distribute the material or use it for any profit-making activity or commercial gain

If the publication is distributed under the terms of Article $25 \mathrm{fa}$ of the Dutch Copyright Act, indicated by the "Taverne" license above, 
Course of disease, fatigue and health related

$$
\text { quality of life in }
$$

\section{Inflammatory Bowel Disease}

Results from a population based study in the Netherlands, the Inflammatory Bowel Disease Registry South Limburg 
(C) Mariëlle Romberg-Camps, Maastricht 2010

Cover design: Alice Wielinga

Layout: Tiny Wouters

Production: Datawyse BV

ISBN: 978-90-5278-936-1

An unrestricted educational grant was received from Schering-Plough and

Tramedico BV to enable data collection and analysis of the presented scientific work. Printing of this thesis was financially supported by ABBOTT Immunology, AstraZeneca, Ferring, Janssen-Cilag BV, Schering-Plough, Solvay Pharma BV, Tramedico BV, Zambon Nederland BV. 


\title{
Course of disease, fatigue and health related
}

\author{
quality of life in
}

\section{Inflammatory Bowel Disease}

Results from a population based study in the Netherlands, the Inflammatory Bowel Disease Registry South Limburg

\author{
PROEFSCHRIFT
}

ter verkrijging van de graad van doctor aan de Universiteit Maastricht, op gezag van de Rector Magnificus, Prof. mr. G.P.M.F. Mols, volgens het besluit van het College van Decanen, in het openbaar te verdedigen op donderdag 8 juli 2010 om 14.00 uur

door

Mariëlle Johanna Leonarda Romberg-Camps

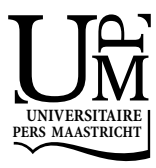




\section{Promotor:}

Prof. dr. R.W. Stockbrügger

\section{Copromotores:}

Dr. P.C. Dagnelie

Dr. M.G.V.M. Russel

\section{Beoordelingscommissie:}

Prof. dr. M. H. Prins, voorzitter

Prof. dr. J.M.J.P. van der Linden

Prof. dr. C. O' Morain (Trinity Centre for Health Sciences, Adelaide, Meath and National Childrens Hospital, Dublin)

Dr. B. Oldenburg (University Medical Center, Utrecht)

Prof. dr. J. J. van Os 


\section{Contents}

Chapter 1 General introduction and thesis outline

$\begin{array}{lll}\text { PART I Course of disease in IBD } & 25\end{array}$

Chapter 2 Inflammatory bowel disease in South Limburg (the 27

Netherlands) 1991-2002: Incidence, diagnostic delay, and seasonal variations in onset of symptoms

Chapter 3 Mortality in inflammatory bowel disease in the Netherlands 1991-2002

Chapter $4 \quad$ Influence of phenotype at diagnosis and of other potential prognostic factors on the course of inflammatory bowel disease

PART II Fatigue and Health Related Quality of Life in IBD

Chapter 5 Fatigue and health related quality of life in inflammatory bowel disease, results from a population based study in the Netherlands; the IBD South Limburg cohort

Chapter 6 The influence of disease course on fatigue and health related quality of life in inflammatory bowel disease.

Results from the population based IBD South Limburg cohort

Chapter 7 General discussion and conclusions

Summary

Samenvatting

Dankwoord

Curriculum Vitae

Appendix: patient questionnaire 



\section{Chapter 1}

General introduction and outline thesis 
8 Chapter 1 


\section{Introduction}

The majority of care in the Netherlands for patients having Inflammatory Bowel Disease (IBD) is performed by gastroenterologists. As it is a chronic disorder, follow-up of patients is over a long period of time. Apart from medical issues, disease activity and associated induction and remission therapy, psychosocial problems often arise during follow-up. Patients are mostly diagnosed at a young age, resulting in for example, work associated problems ${ }^{1}$, fertility and pregnancy related concerns and financial concerns with regard to life and medical insurance. ${ }^{2}$ In clinical practice, fatigue in IBD patients is frequently reported when asked for during consultation. The presence of fatigue has a major impact on the patients' daily functioning. However, as the seriousness of fatigue is difficult to measure and not visible for the environment, patients often do not feel understood.

\section{Inflammatory Bowel Disease}

\section{Definition and aetiology}

IBD is a group of inflammatory conditions of the intestine. The major types of IBD are Crohn's Disease (CD) and Ulcerative Colitis (UC). The main difference between CD and $U C$ is the location and nature of the inflammatory changes. CD can involve any part of the gastrointestinal tract from the oral cavity to the anus. UC is restricted to the colon. The term "IBD unclassified" (IBDU) is used for cases of IBD in which, after careful investigation, the differential diagnosis between $C D$ and $U C$ remained uncertain. ${ }^{3}$ The exact cause of IBD is unknown, but both genetic and environmental factors play a significant role in its aetiology and pathogenesis. ${ }^{4-6} A$ cure for IBD has still not been found. In the current therapy for CD and UC mesalazine (5-ASA), steroids and immunosuppressive medication are still most frequently used. In recent years the use of targeted medication influencing the innate and adaptive immune pathways, the "biologicals" has increased substantially. ${ }^{7}$ The search for new "biologicals" is still very actively ongoing. However their place in the treatment algorithms must be defined more carefully in the near future as it is not certain if biological therapies could carry a safety risk for patients in the future. Also a substantial number of patients, especially in $C D$, is still operated at diagnosis or at any time during their disease course. ${ }^{8-12}$ Although the percentage of operated patients in UC is lower than in $C D$, the overall colectomy rate in UC with a mean follow up of ten years is still around $10 \% .{ }^{13,14}$ 


\section{Incidence}

Increasing incidence in IBD has been suggested.

Recent publications show that the incidence of IBD is still increasing in the adult European population. ${ }^{15-18}$ Higher rates of IBD are seen in northern and industrialized countries $^{19}$, however, differences seem to get smaller. ${ }^{15,17,20,21}$ During recent years, diagnostic options in the field of IBD have significantly improved. This could possibly influence incidence rates by discovering sub-clinical disease and also by shortening the duration of time from first complaints until the diagnosis, i.e. the diagnostic lag time. Possibly also patients and doctors awareness with regard to IBD plays a role in earlier diagnosis. ${ }^{18}$

Population based data about the disease course of IBD are however scarce. In Table 1.1, an overview of published European incidence rates is given.

For $C D$, age distribution shows peak incidences at ages of $15-25$, especially in female patients, whereas in male UC patients a second peak in older age groups is found. ${ }^{22,23}$

\section{Mortality}

The debate whether IBD carries an elevated mortality risk is still ongoing. Results from the European Collaborative-IBD study group showed an elevated mortality risk for CD mainly due to gastro-intestinal causes, suggesting that mortality might be a surrogate marker for disease severity and phenotype at diagnosis. ${ }^{24}$ Other studies showed similar findings in CD patients. ${ }^{25,26}$ In UC, in contrast to older reports ${ }^{27-30}$, recent studies reported no elevated mortality risk. ${ }^{31-33}$

A recent meta-analysis showed a decline in overall IBD mortality over time ${ }^{34}$, other authors reported stable CD mortality rates. ${ }^{25,31,35}$ Because of the heterogeneity of IBD, specification of high-risk patients based on initial disease characteristics would be valuable, especially if obtained from an unselected patient population with uniform diagnostic criteria. In Table 1.2, a literature overview of mortality data with regard to $C D$ and UC is presented. 
Table 1.1 Incidence rates of CD, UC and IC per 100.000 inhabitants and year in Europe from the North to the South European countries.

\begin{tabular}{|c|c|c|c|c|c|c|}
\hline $\begin{array}{l}\text { Publication } \\
\text { year }\end{array}$ & $\begin{array}{l}\text { Time } \\
\text { period }\end{array}$ & Country area & First Author, reference & $C D$ & UC & IC \\
\hline 1988 & 1983-1984 & Norway western & Haug $^{36}$ & & 14.8 & \\
\hline 1990 & $1983-1986$ & Norway northern & Kildebo $^{37,38}$ & 5.8 & 12.8 & \\
\hline 1996 & $1990-1993$ & Norway Oslo & Moum $^{39,40}$ & 5.8 & 13.6 & \\
\hline 1991 & $1965-1983$ & Sweden Uppsala & Ekbom $^{41}$ & 6.6 & 11.5 & \\
\hline 1985 & $1955-1979$ & Sweden Stockholm & Nordenvall $^{42}$ & & $1.7 / 4.3$ & \\
\hline 1982 & $1962-1978$ & Denmark Copenhagen & Binder $^{43}$ & 2.7 & 8.1 & \\
\hline 1991 & $1962-1987$ & Denmark Copenhagen & $\begin{array}{l}\text { Langholz }^{44} \\
\text { Munkholm }^{45}\end{array}$ & 4.1 & 9.2 & \\
\hline 1996 & 1991-1993 & Denmark Copenhagen & Shivananda ${ }^{19}$ & $M / F 5.4 / 9.3$ & $M / F \quad 8.4 / 11.2$ & \\
\hline 2006 & 2003-2005 & Denmark Copenhagen & Vind $^{18}$ & $M / F 8.6 / 9.1$ & $\mathrm{M} / \mathrm{F} 13.4 / 13.3$ & $\mathrm{M} / \mathrm{F} 1.1 / 1.4$ \\
\hline 1996 & 1991-1993 & Ireland Dublin & Shivananda ${ }^{19}$ & $M / F 4.5 / 5.9$ & $M / F$ 18.6/11.6 & \\
\hline 1984 & 1968-1977 & UK South Glamorgan & Morris $^{46}$ & & 7.2 & \\
\hline 1988 & 1935-1954 & UK Cardiff & Rose $^{47}$ & 0.2 & & \\
\hline 1992 & 1968-1987 & UK Cardiff & Srivastava $^{48}$ & & 6.4 & \\
\hline 1995 & $1986-1990$ & UK Cardiff & Thomas $^{49}$ & 5.9 & & \\
\hline & & The Netherlands & & & & \\
\hline 1987 & $1979-1983$ & Leiden & Shivananda ${ }^{50,51}$ & $\mathrm{M} / \mathrm{F} 3.8 / 4.0$ & 6.8 & \\
\hline 1998 & 1990-1994 & South Limburg & Russel $^{52}$ & 6.9 & 10.0 & \\
\hline 1994 & $1980-1984$ & Germany Ruhr area & Dirks $^{53}$ & & 2.9 & \\
\hline 1994 & $1980-1984$ & Germany Ruhr area & Goebell $^{54}$ & 4.0 & & \\
\hline 1999 & $1980-1995$ & Germany ${ }^{\#}$ & Timmer $^{55}$ & & 5.0 & \\
\hline 2008 & 2004-2006 & Germany ${ }^{\#}$ & $\mathrm{Ott}^{56}$ & 6.6 & 3.9 & \\
\hline 1994 & $1988-1990$ & France Northern $\$$ & Gower Rousseau $^{57}$ & 3.2 & 4.9 & \\
\hline 2007 & $2002-2003$ & France Corsica & Abakar-Mahamat ${ }^{58}$ & 4.1 & 9.5 & \\
\hline 2003 & $1997-2001$ & Hungary Western & Lakatos $^{59}$ & 4.7 & 11.0 & 0.7 \\
\hline 2004 & $2002-2003$ & Romania & Gheorghe $^{60}$ & 0.5 & 1.0 & \\
\hline 1991 & 1980-1989 & Yugoslavia Zagreb & Vucelic $^{61,62}$ & 0.7 & 1.5 & \\
\hline 2006 & $2000-2004$ & $\begin{array}{l}\text { Croatia, } \\
\text { Primorsko-goranska }\end{array}$ & Sincic $^{17}$ & 7.0 & 4.3 & \\
\hline 1996 & $1990-1993$ & Italy Northern & Ranzi $^{63}$ & 3.4 & 7.0 & \\
\hline 1991 & 1978-1992 & Italy Florence & Trallori $^{64}$ & 1.5 & 4.0 & \\
\hline 1991 & $1987-1989$ & Sicily & Cottone $^{65}$ & 2.7 & & \\
\hline 2001 & $\begin{array}{l}\text { Review } \\
\text { article }\end{array}$ & Spain & Pajares $^{66}$ & 1.9 & 3.8 & \\
\hline 2003 & $1954-1997$ & Spain & Saro Gismera ${ }^{67}$ & 2.0 & 2.8 & 1.1 \\
\hline 2004 & $2000-2002$ & Spain Northern" & Rodrigo $^{20}$ & 7.5 & 9.1 & \\
\hline 2008 & $2001-2003$ & Spain Navarre & Arin Letamendia ${ }^{15}$ & 5.9 & 9.6 & 0.6 \\
\hline 2008 & $1993-2005$ & Malta ${ }^{\#}$ & Cachia $^{21}$ & $\mathrm{M} / \mathrm{F} 1 / 1.6$ & $\mathrm{M} / \mathrm{F} 8.2 / 7.6$ & \\
\hline 1996 & $1990-1994$ & Greece Crete $^{\#}$ & Manousos $^{68,69}$ & 3.0 & 8.9 & \\
\hline 2007 & 1983-2005 & Greece North-Western & Economou $^{16}$ & 0.9 & 2.7 & \\
\hline
\end{tabular}

\# Standardized incidence rates are presented using European Age Standardized Population (EASP) correction, $\$$ Standardized incidence rates using the World Standardized Population for age correction, $\mathrm{M}=$ male, $\mathrm{F}=$ Female 
Table 1.2 Mortality risks in Inflammatory Bowel Disease

\begin{tabular}{|c|c|c|c|c|c|}
\hline Publication year & Time period & Origin & Author & SMR CD $(95 \% \mathrm{Cl})$ & SMR UC $(95 \% \mathrm{Cl})$ \\
\hline 1981 & 1941-1976 & England & Prior $^{70}$ & $2.0(1.9-2.5)$ & \\
\hline 1980 & 1934-1976 & UK & Mayberry* ${ }^{71}$ & $2.2(1.5-2.9)$ & \\
\hline 1982 & $1969-1978$ & New Zealand & Eason* ${ }^{72}$ & & $0.8(0.4-1.4)$ \\
\hline 1982 & $1940-1976$ & England & Gyde ${ }^{27}$ & & 1.7 \\
\hline 1985 & $1955-1979$ & Sweden & Brostrom ${ }^{28}$ & & 2.0 \\
\hline 1990 & $1934-1984$ & Netherlands & Weterman ${ }^{73}$ & $2.2(1.8-2.9)$ & \\
\hline 1992 & $1965-1983$ & Sweden & Ekbom* ${ }^{74}$ & $1.6(1.4-1.9)$ & $1.4(1.2-1.5)$ \\
\hline 1992 & $1972-1989$ & UK & Probert $^{75}$ & $0.7(0.5-1.0)$ & \\
\hline 1993 & $1972-1989$ & UK & Probert* ${ }^{76}$ & & $0.9(0.8-1.1)$ \\
\hline 1995 & $1958-1990$ & Sweden & Stewenius* 77 & & $1.3(1.0-1.5)$ \\
\hline 1996 & $1955-1984$ & Sweden & Persson* ${ }^{29}$ & $1.5(1.3-1.8)$ & $1.4(1.2-1.5)$ \\
\hline 1996 & $1973-1993$ & Italy & Cottone $^{78}$ & $1.0(0.4-1.8)$ & \\
\hline 1996 & $1970-1990$ & Italy & Davoli $^{79}$ & & 1.0 \\
\hline 1998 & $1940-1993$ & USA & Loftus $^{80}$ & $1.3(1.1-1.6)$ & \\
\hline 1998 & 1978-1992 & Italy & Palli* ${ }^{81}$ & $1.4(0.9-2.0)$ & $0.6(0.4-0.8)$ \\
\hline 1999 & 1971-1994 & Japan & Ishibashi ${ }^{82}$ & $1.8(0.2-5.8)$ & $0.8(0.1-4.3)$ \\
\hline 2000 & $1940-1993$ & USA & Loftus $^{83}$ & & 1.0 \\
\hline 2002 & $1962-1987$ & Denmark & Jess* ${ }^{84}$ & $1.3(1.0-1.6)$ & \\
\hline 2001 & $1964-1997$ & Italy & Viscido $^{85}$ & & $1.0(0.8-1.2)$ \\
\hline 2001 & 1978-1993 & UK & Farokhyar* 86 & $0.9(0.6-1.4)$ & $1.0(0.8-1.4)$ \\
\hline 2003 & Unknown & UK & Card $^{30}$ & $1.7(1.5-2.0)$ & $1.4(1.3-1.6)$ \\
\hline 2003 & $1962-1997$ & Denmark & Winther* ${ }^{87}$ & & $1.1(0.9-1.2)$ \\
\hline 2004 & $1978-2001$ & Italy & Masala* ${ }^{88}$ & $1.5(1.1-2.1)$ & $0.7(0.6-0.9)$ \\
\hline 2005 & $1978-2003$ & Denmark & Jacobsen* 89 & & $1.1(0.9-1.3)$ \\
\hline 2005 & 1991-1993 & Europe & Wolters* ${ }^{24}$ & $1.9(1.3-2.6)$ & \\
\hline 2006 & $1940-2004$ & USA & Jess* ${ }^{90}$ & $1.2(0.9-1.6)$ & $0.8(0.6-1.0)$ \\
\hline 2007 & $1985-2004$ & England & Canavan ${ }^{25}$ & $1.3(1.1-1.5)$ & \\
\hline 2007 & 1991-1993 & Europe & Hoie ${ }^{33}$ & & $1.1(0.9-1.4)$ \\
\hline 2007 & $1962-2005$ & Denmark & Jess* ${ }^{26}$ & $1.3(1.1-1.6)$ & $1.1(1.0-1.2)$ \\
\hline
\end{tabular}

$\mathrm{SMR}=$ Standardized Mortality Ratio, $\mathrm{CD}=$ Crohn's disease, $\mathrm{Cl}=$ Confidence Interval, UC= Ulcerative Colitis. * population based studies.

\section{Course of disease}

The disease course in IBD is highly variable ${ }^{11,91}$ and seems to be difficult to predict on the basis of information acquired at the moment of diagnosis. ${ }^{8-10,14,92,93}$ However, for clinical purposes it would be useful to categorize patients at the onset of disease into low or high risk groups. In that way, specific therapeutic and preventive strategies might be chosen earlier in the disease course, and patients could be informed more precisely about their prognosis. Even more important, as recent data suggest that treating severe IBD "top-down" might change natural history of the disease. ${ }^{94}$ 


\section{Fatigue and Health Related Quality of Life}

The importance of fatigue and its negative impact on patients' HRQoL has been increasingly recognized and studied in several chronic diseases ${ }^{95-97}$ and in cancer. ${ }^{98,99}$ Persistent fatigue from chronic illness involves ongoing exhaustion that is disproportionate to exertion and not alleviated by rest. ${ }^{95}$ Fatigue is often the most debilitating part of the disease. ${ }^{95,98}$

Little is known about fatigue in IBD and its impact on the HRQoL. Worse fatigue scores are reported in IBD patients having active disease ${ }^{100}$, anaemic IBD patients ${ }^{101}$, patients with short bowel syndrome ${ }^{102,103}$ and in those with ileal-anal pouch anastomosis for UC. ${ }^{104}$ However, a high prevalence of fatigue (41\%) is also reported in IBD patients without disease activity. ${ }^{100} \mathrm{HRQOL}$ is better studied in IBD and is mainly negatively influenced by active disease ${ }^{105-109}$, also other variables, such as extra-intestinal manifestations ${ }^{110-112}$, Irritable Bowel (IBS) like symptoms ${ }^{113}$, anaemia ${ }^{101}$, short bowel syndrome, ileo anal pouch ${ }^{103,104}$ and higher age ${ }^{105}$ result in an impaired HRQoL. Concerning the course of disease and its effect on the HRQoL in IBD patients, treatment with systemic corticosteroid or immunosuppressive drugs, a relapsing disease course, and extra-intestinal manifestations were reported to be negative determinants of HRQoL. ${ }^{110,114}$ So far, there are no reports on disease course and fatigue in IBD, although in clinical practice patients frequently complain of fatigue, independent of disease activity.

\section{The IBD South Limburg study}

\section{Population and design}

In 1991 a population based Inflammatory Bowel Disease Registry was established in collaboration between the Departments of Gastroenterology/ Hepatology and the MEMIC (Centre for Data and Information Management of the University of Maastricht). The primary objective of the registry was to prospectively study the incidence of IBD and risk factors for disease severity and outcome within a welldefined area of the Netherlands, namely South Limburg (IBD-SL). ${ }^{115}$

South Limburg is located in the South East of the Netherlands between Germany and Belgium; its northern border with the rest of the Netherlands is narrow. The region had a population of about 645,000 between 1991 and 2003. ${ }^{116}$

All three hospitals in South Limburg, i.e. Maastricht University Medical Center in Maastricht and the General District Hospitals of Heerlen and Sittard, participated in the study.

Registration of IBD patients was based on endoscopic and/or radiological evidence, supported by mucosal biopsy and/or examination of a surgical specimen. For case definition of $C D$, the criteria of Lennard-Jones were applied. ${ }^{117}$ UC was defined as continuous mucosal inflammation without granulomata, affecting the rectum and/or 
some or all of the colon in continuity with the rectum. The term "IBD unclassified" (IBDU) was used for cases of IBD in which, after careful investigation, the differential diagnosis between $C D$ and $U C$ initially remained uncertain. ${ }^{3}$

All newly diagnosed patients (i.e. without prior history of IBD), registered between January $1^{\text {st }}, 1991$, and January $1^{\text {st }}, 2003$, were included in the present study. These patients were followed from inclusion until data collection for the present study, which took place between July 1, 2005, and January 1, 2006, or until a prior date in case of death or loss to follow-up (LTFU).

\section{Medical record data collection and definitions}

In all hospitals, the original written medical records as well as electronic patient files were reviewed. All collected data were instantly and uniformly registered in an Access database. Patients were characterized according to the Vienna classification at diagnosis. ${ }^{118}$ Definitions for "location" and "recurrence" were used according to an earlier publication of the European Collaborative study group on Inflammatory Bowel Disease (EC-IBD)..$^{10,119}$

All available laboratory data between June $1^{\text {st }}, 2005$, and December $1^{\text {st }}, 2005$, with regard to haemoglobin level were registered. Haemoglobin data were classified as; "no anaemia"; "anaemia" or "not determined".

\section{Questionnaire}

\section{Disease activity}

In $C D$, the Harvey Bradshaw Index $(\mathrm{HBI})^{120}$ was used for further analysis and to evaluate the accuracy of the $\mathrm{HBI}$, a subgroup of patients also scored disease activity using a validated diary developed by Sandler et al. ${ }^{121}$ In UC, the Colitis Activity Index $(C A I)^{122}$ was used. For IBDU, as the inflammation per definition is located in the colon, the CAl was used in further analysis.

\section{Subjective disease course}

In the composed questionnaire patients were asked to rate their disease course: "inactive since the IBD diagnosis" ("inactive"), "in most years since the IBD diagnosis no disease activity" ("most years no activity"), "in most years since the IBD diagnosis disease activity but not in every year" ("most years activity"), "disease activity in every year since the IBD diagnosis" ("every year activity"). Throughout the report we refer to this question as "subjective disease course". 


\section{Fatigue}

To measure fatigue, the validated Dutch Multidimensional Fatigue Inventory (MFI-20) was used. This is a 20-item instrument designed to measure five fatigue dimensions: general fatigue; physical fatigue; reduced activity; reduced motivation; mental fatigue. ${ }^{123,124}$ Each dimension contains four questions with a five point response format, resulting in a score range from 4-20 per dimension. A higher score indicates a higher degree of fatigue.

\section{Health Related Quality of Life}

The Inflammatory Bowel Disease Questionnaire (IBDQ) and the Short Form health survey (SF-36) were used to measure HRQoL. The IBDQ is a 32 item disease specific $\mathrm{HRQoL}$ questionnaire, including four health dimensions: bowel symptoms (10 questions); systemic symptoms (5 questions); emotional well-being (12 questions); social functioning (5 questions). ${ }^{125,126}$ Responses are graded on a 7-point Likert scale in which " 1 " represents a very severe problem and "7" represents no problem at al. In each dimension the mean value is calculated. Consequently, a higher score indicates a better quality of life. From the mean IBDQ sub-scores a total IBDQ score was computed per patient and used in the multivariate analysis.

The SF-36 includes multi-item scales measuring eight general health concepts: physical functioning (10 questions); role of limitations due to physical health problems (4 questions); bodily pain ( 2 questions); general health perception (5 questions); vitality (4 questions); social function ( 2 questions); role limitations due to personal or emotional problems ( 3 questions); mental health (5 questions). ${ }^{127,128}$ One question covers change in health status over the past year. This question is not counted in scoring in the eight dimensions. Translation into Dutch was carried out as part of an International Quality of Life assessment project. ${ }^{129}$ From the SF-36, individual "physical health" and "mental health" summary scores were computed. ${ }^{127,128}$ The "physical health" summary score is calculated using the dimensions: physical functioning; role of limitations due to physical health problems; bodily pain; general health perception. For the "mental health" summary score, social function, role limitations due to personal or emotional problems, and mental health is used. This calculation results in a score in which 50 (Standard Deviation 10) is the norm-based score found in the USA population. For example a higher score indicates a better quality of life compared to the average USA population.

\section{Anxiety and Depression}

Anxiety and depression were measured with the Hospital Anxiety and Depression Scale (HADS). The HADS is a self-assessment scale which is a reliable and valid screening instrument for anxiety and depression in the setting of a hospital medical outpatient clinic, consisting of seven items on anxiety (HADS-A) and seven items on depression (HADS-D). Possible scores on each item are from $0-3$, resulting in a summary score 
ranging from 0 to 21 for the HADS-A and HADS-D separately. ${ }^{130,131}$ On either subscale, a score above eight indicates the presence of anxiety or depression. ${ }^{132}$

\section{Outline of thesis}

First in PART I, chapter 2-4, the course of disease in IBD is described. In chapter 2, for South Limburg from 1991- 2002 the incidence, the diagnostic delay, and seasonal variations in onset of symptoms are described. In chapter 3, IBD mortality from 19912002 is presented. Standardized Mortality Ratios (SMRs) were calculated overall and with regard to causes of death, gender, as well as age, phenotype, smoking status at diagnosis and medication use. Causes of death, IBD or not IBD related are discussed into detail. In chapter 4, surgical and non-surgical recurrence is described and correlated to the phenotype at diagnosis. Moreover other potential prognostic factors influencing the course of IBD; age; gender; smoking; appendectomy; extra-intestinal manifestations; family history and educational level were looked at.

In PART II, chapter 5-6, results on fatigue and HRQoL are presented. In chapter 5, outcome of fatigue, HRQoL, depression and anxiety scores are described. Scores are presented overall and with regard to disease activity and the presence of anaemia. Related to norm values in literature, the prevalence of fatigue in our cohort is calculated.

In chapter 6, disease course as a predictor for fatigue and the HRQoL is described. Furthermore possible determinants of fatigue and HRQoL are reported.

In chapter 7, the major findings of all studies are reviewed and implications for future research are discussed. 


\section{References}

1. Boonen A, Dagnelie PC, Feleus A, Hesselink MA, Muris JW, Stockbrugger RW, Russel MG. The impact of inflammatory bowel disease on labor force participation: results of a population sampled case-control study. Inflamm Bowel Dis. 2002;8:382-389.

2. Russel MG, Ryan BM, Dagnelie PC, de Rooij M, Sijbrandij J, Feleus A, Hesselink M, Muris JW, Stockbrugger R. Insurance problems among inflammatory bowel disease patients: results of a Dutch population based study. Gut. 2003;52:358-362.

3. Geboes K, Colombel JF, Greenstein A, Jewell DP, Sandborn WJ, Vatn MH, Warren B, Riddell RH. Indeterminate colitis: a review of the concept--what's in a name? Inflamm Bowel Dis. 2008;14: 850-857.

4. Sartor RB. Pathogenesis and immune mechanisms of chronic inflammatory bowel diseases. Am J Gastroenterol. 1997;92:5S-11S.

5. Tsianos EV, Katsanos K. Do we really understand what the immunological disturbances in inflammatory bowel disease mean? World J Gastroenterol. 2009;15:521-525.

6. Noomen CG, Hommes DW, Fidder HH. Update on genetics in inflammatory disease. Best Pract Res Clin Gastroenterol. 2009;23:233-243.

7. Rutgeerts P, Vermeire S, Van Assche G. Biological therapies for inflammatory bowel diseases. Gastroenterology. 2009;136:1182-1197.

8. Henriksen M, Jahnsen J, Lygren I, Aadland E, Schulz T, Vatn MH, Moum B. Clinical course in Crohn's disease: results of a five-year population-based follow-up study (the IBSEN study). Scand J Gastroenterol. 2007;42:602-610.

9. Oostenbrug LE, van Dullemen HM, te Meerman GJ, Jansen PL, Kleibeuker JH. Clinical outcome of Crohn's disease according to the Vienna classification: disease location is a useful predictor of disease course. Eur J Gastroenterol Hepatol. 2006;18:255-261.

10. Wolters FL, Russel MG, Sijbrandij J, Ambergen T, Odes S, Riis L, Langholz E, Politi P, Qasim A, Koutroubakis I, Tsianos E, Vermeire S, Freitas J, van Zeijl G, Hoie O, Bernklev T, Beltrami M, Rodriguez D, Stockbrugger RW, Moum B. Phenotype at diagnosis predicts recurrence rates in Crohn's disease. Gut. 2006;55:1124-1130.

11. Munkholm P, Langholz E, Davidsen M, Binder V. Disease activity courses in a regional cohort of Crohn's disease patients. Scand J Gastroenterol. 1995;30:699-706.

12. Shivananda S, Hordijk ML, Pena AS, Mayberry JF. Crohn's disease: risk of recurrence and reoperation in a defined population. Gut. 1989;30:990-995.

13. Hoie O, Wolters FL, Riis L, Bernklev T, Aamodt G, Clofent J, Tsianos E, Beltrami M, Odes S, Munkholm P, Vatn M, Stockbrugger RW, Moum B. Low colectomy rates in ulcerative colitis in an unselected European cohort followed for 10 years. Gastroenterology. 2007;132:507-515.

14. Henriksen M, Jahnsen J, Lygren I, Sauar J, Kjellevold O, Schulz T, Vatn MH, Moum B. Ulcerative colitis and clinical course: results of a 5-year population-based follow-up study (the IBSEN study). Inflamm Bowel Dis. 2006;12:543-550.

15. Arin Letamendia A, Borda Celaya F, Burusco Paternain MJ, Prieto Martinez C, Martinez Echeverria A, Elizalde Apestegui I, Laiglesia Izquierdo M, Macias Mendizabal E, Tamburri Moso P, Sanchez Valverde F. [High incidence rates of inflammatory bowel disease in Navarra (Spain). Results of a prospective, population-based study]. Gastroenterol Hepatol. 2008;31:111-116.

16. Economou M, Filis G, Tsianou Z, Alamanos J, Kogevinas A, Masalas K, Petrou A, Tsianos EV. Crohn's disease incidence evolution in North-western Greece is not associated with alteration of NOD2/CARD15 variants. World J Gastroenterol. 2007;13:5116-5120.

17. Sincic BM, Vucelic B, Persic M, Brncic N, Erzen DJ, Radakovic B, Micovic V, Stimac D. Incidence of inflammatory bowel disease in Primorsko-goranska County, Croatia, 2000-2004: A prospective population-based study. Scand J Gastroenterol. 2006;41:437-444.

18. Vind I, Riis L, Jess T, Knudsen E, Pedersen N, Elkjaer M, Bak Andersen I, Wewer V, Norregaard P, Moesgaard F, Bendtsen F, Munkholm P. Increasing incidences of inflammatory bowel disease and decreasing surgery rates in Copenhagen City and County, 2003-2005: a population-based study from the Danish Crohn colitis database. Am J Gastroenterol. 2006;101:1274-1282. 
19. Shivananda S, Lennard Jones J, Logan R, Fear N, Price A, Carpenter L, van Blankenstein M. Incidence of inflammatory bowel disease across Europe: is there a difference between north and south? Results of the European Collaborative Study on Inflammatory Bowel Disease (EC-IBD). Gut. 1996;39:690-697.

20. Rodrigo L, Riestra S, Nino P, Cadahia V, Tojo R, Fuentes D, Moreno M, Gonzalez Ballina E, Fernandez E. A population-based study on the incidence of inflammatory bowel disease in Oviedo (Northern Spain). Rev Esp Enferm Dig. 2004;96:296-305.

21. Cachia E, Calleja N, Aakeroy R, Degaetano J, Vassallo M. Incidence of inflammatory bowel disease in Malta between 1993 and 2005: a retrospective study. Inflamm Bowel Dis. 2008;14:550-553.

22. Loftus EV, Jr. Clinical epidemiology of inflammatory bowel disease: Incidence, prevalence, and environmental influences. Gastroenterology. 2004;126:1504-1517.

23. Russel MG. Changes in the incidence of inflammatory bowel disease: what does it mean? Eur J Intern Med. 2000;11:191-196.

24. Wolters FL, Russel MG, Sijbrandij J, Schouten $\amalg$, Odes S, Riis L, Munkholm P, Bodini P, O'Morain C, Mouzas IA, Tsianos E, Vermeire S, Monteiro E, Limonard C, Vatn M, Fornaciari G, Pereira S, Moum B, Stockbrugger RW. Crohn's disease: increased mortality 10 years after diagnosis in a Europe-wide population based cohort. Gut. 2006;55:510-518.

25. Canavan C, Abrams KR, Hawthorne B, Mayberry JF. Long-term prognosis in Crohn's disease: An epidemiological study of patients diagnosed more than 20 years ago in Cardiff. Aliment Pharmacol Ther. 2007;25:59-65.

26. Jess T, Riis L, Vind I, Winther KV, Borg S, Binder V, Langholz E, Thomsen OO, Munkholm P. Changes in clinical characteristics, course, and prognosis of inflammatory bowel disease during the last 5 decades: a population-based study from Copenhagen, Denmark. Inflamm Bowel Dis. 2007;13:481-489.

27. Gyde S, Prior P, Dew MJ, Saunders V, Waterhouse JA, Allan RN. Mortality in ulcerative colitis. Gastroenterology. 1982;83:36-43.

28. Brostrom O, Monsen U, Nordenwall B, Sorstad J, Hellers G. Prognosis and mortality of ulcerative colitis in Stockholm County, 1955-1979. Scand J Gastroenterol. 1987;22:907-913.

29. Persson PG, Bernell O, Leijonmarck CE, Farahmand BY, Hellers G, Ahlbom A. Survival and cause-specific mortality in inflammatory bowel disease: a population-based cohort study. Gastroenterology. 1996;110:1339-1345.

30. Card T, Hubbard R, Logan RF. Mortality in inflammatory bowel disease: a population-based cohort study. Gastroenterology. 2003;125:1583-1590.

31. Jess T. Prognosis of inflammatory bowel disease across time and countries. An epidemiological study of population-based patient cohorts. Dan Med Bull. 2008;55:103-120.

32. Jess T, Gamborg M, Munkholm P, Sorensen TI. Overall and cause-specific mortality in ulcerative colitis: meta-analysis of population-based inception cohort studies. Am J Gastroenterol. 2007;102:609-617.

33. Hoie O, Schouten L, Wolters FL, Solberg IC, Riis L, Mouzas IA, Politi P, Odes S, Langholz E, Vatn M, Stockbrugger RW, Moum B. Ulcerative colitis: no rise in mortality in a European-wide population based cohort 10 years after diagnosis. Gut. 2007;56:497-503.

34. Sonnenberg A. Time trends of mortality from Crohn's disease and ulcerative colitis. Int J Epidemiol. 2007;36:890-899.

35. Wolters FL, Russel MG, Stockbrugger RW. Systematic review: has disease outcome in Crohn's disease changed during the last four decades? Aliment Pharmacol Ther. 2004;20:483-496.

36. Haug K, Schrumpf E, Barstad S, Fluge G, Halvorsen JF. Epidemiology of ulcerative colitis in western Norway. Scand J Gastroenterol. 1988;23:517-522.

37. Kildebo S, Nordgaard K, Aronsen O, Breckan R, Burhol PG, Jorde R. The incidence of ulcerative colitis in Northern Norway from 1983 to 1986. The Northern Norwegian Gastroenterology Society. Scand J Gastroenterol. 1990;25:890-896.

38. Kildebo S, Breckan R, Nordgaard K, Burhol PG, Jorde R. The incidence of Crohn's disease in northern Norway from 1983 to 1986. Northern Norway Gastroenterology Society. Scand J Gastroenterol. 1989;24:1265-1270.

39. Moum B, Vatn MH, Ekbom A, Aadland E, Fausa O, Lygren I, Sauar J, Schulz T, Stray N. Incidence of ulcerative colitis and indeterminate colitis in four counties of southeastern Norway, 1990-93. A prospective population-based study. The Inflammatory Bowel South-Eastern Norway (IBSEN) Study Group of Gastroenterologists. Scand J Gastroenterol. 1996;31:362-366. 
40. Moum B, Vatn MH, Ekbom A, Aadland E, Fausa O, Lygren I, Stray N, Sauar J, Schulz T. Incidence of Crohn's disease in four counties in southeastern Norway, 1990-93. A prospective population-based study. The Inflammatory Bowel South-Eastern Norway (IBSEN) Study Group of Gastroenterologists. Scand J Gastroenterol. 1996;31:355-361.

41. Ekbom A, Helmick C, Zack M, Adami HO. The epidemiology of inflammatory bowel disease: a large, population-based study in Sweden. Gastroenterology. 1991;100:350-358.

42. Nordenvall B, Brostrom O, Berglund M, Monsen U, Nordenstrom J, Sorstad J, Hellers G. Incidence of ulcerative colitis in Stockholm County 1955-1979. Scand J Gastroenterol. 1985;20:783-790.

43. Binder V, Both $\mathrm{H}$, Hansen PK, Hendriksen C, Kreiner S, Torp-Pedersen K. Incidence and prevalence of ulcerative colitis and Crohn's disease in the County of Copenhagen, 1962 to 1978. Gastroenterology. 1982;83:563-568.

44. Langholz E, Munkholm P, Nielsen $\mathrm{OH}$, Kreiner S, Binder V. Incidence and prevalence of ulcerative colitis in Copenhagen county from 1962 to 1987. Scand J Gastroenterol. 1991;26:1247-1256.

45. Munkholm P, Langholz E, Nielsen $\mathrm{OH}$, Kreiner S, Binder V. Incidence and prevalence of Crohn's disease in the county of Copenhagen, 1962-87: a sixfold increase in incidence. Scand J Gastroenterol. 1992;27:609-614.

46. Morris T, Rhodes J. Incidence of ulcerative colitis in the Cardiff region 1968-1977. Gut. 1984;25:846848.

47. Rose JD, Roberts GM, Williams G, Mayberry JF, Rhodes J. Cardiff Crohn's disease jubilee: the incidence over 50 years. Gut. 1988;29:346-351.

48. Srivastava ED, Mayberry JF, Morris TJ, Smith PM, Williams GT, Roberts GM, Newcombe RG, Rhodes J. Incidence of ulcerative colitis in Cardiff over 20 years: 1968-87. Gut. 1992;33: 256-258.

49. Thomas GA, Millar Jones D, Rhodes J, Roberts GM, Williams GT, Mayberry JF. Incidence of Crohn's disease in Cardiff over 60 years: 1986-1990 an update. European journal of gastroenterology and hepatology. 1995;7:401-405.

50. Shivananda S, Pena AS, Nap M, Weterman IT, Mayberry JF, Ruitenberg EJ, Hoedemaeker PJ. Epidemiology of Crohn's disease in Regio Leiden, The Netherlands. A population study from 1979 to 1983. Gastroenterology. 1987;93:966-974.

51. Shivananda S, Hordijk ML, Pena AS, Mayberry JF. Inflammatory bowel disease: one condition or two? Digestion. 1987;38:187-192.

52. Russel MG, Dorant E, Volovics A, Brummer RJ, Pop P, Muris JW, Bos LP, Limonard CB, Stockbrugger RW. High incidence of inflammatory bowel disease in The Netherlands: results of a prospective study. The South Limburg IBD Study Group. Dis Colon Rectum. 1998;41: 33-40.

53. Dirks E, Forster S, Thom M, Quebe-Fehling E, Goebell H. [Prospective study of the incidence and prevalence of ulcerative colitis in a large urban population in Germany (western Ruhr area)]. Z Gastroenterol. 1994;32:332-337.

54. Goebell H, Dirks E, Forster S. A prospective analysis of the incidence and prevalence of inflammatory bowel disease in an urban population in Germany. Eur J Gastroenterol Hepatol. 1994;6:1039-1045.

55. Timmer A, Breuer-Katschinski B, Goebell H. Time trends in the incidence and disease location of Crohn's disease 1980-1995: a prospective analysis in an urban population in Germany. Inflamm Bowel Dis. 1999;5:79-84.

56. Ott C, Obermeier F, Thieler S, Kemptner D, Bauer A, Scholmerich J, Rogler G, Timmer A. The incidence of inflammatory bowel disease in a rural region of Southern Germany: a prospective population-based study. Eur J Gastroenterol Hepatol. 2008;20:917-923.

57. Gower Rousseau C, Salomez JL, Dupas JL, Marti R, Nuttens MC, Votte A, Lemahieu M, Lemaire B, Colombel JF, Cortot A. Incidence of inflammatory bowel disease in northern France (1988-1990). Gut. 1994;35:1433-1438.

58. Abakar-Mahamat A, Filippi J, Pradier C, Dozol A, Hebuterne X. Incidence of inflammatory bowel disease in Corsica from 2002 to 2003. Gastroenterol Clin Biol. 2007;31:1098-1103.

59. Lakatos L, Mester G, Erdelyi Z, Balogh M, Szipocs I, Kamaras G, Lakatos PL. [Epidemiology of inflammatory bowel diseases in Veszprem county of Western Hungary between 1977 and 2001]. Orv Hetil. 2003;144:1819-1827. 
60. Gheorghe C, Pascu O, Gheorghe L, lacob R, Dumitru E, Tantau M, Vadan R, Goldis A, Balan G, lacob S, Dobru D, Saftoiu A. Epidemiology of inflammatory bowel disease in adults who refer to gastroenterology care in Romania: a multicentre study. Eur J Gastroenterol Hepatol. 2004;16:11531159.

61. Vucelic B, Korac B, Sentic M, Milicic D, Hadzic N, Juresa V, Bozikov J, Rotkvic I, Buljevac M, Kovacevic I, et al. Ulcerative colitis in Zagreb, Yugoslavia: incidence and prevalence 1980-1989. Int J Epidemiol. 1991;20:1043-1047.

62. Vucelic B, Korac B, Sentic M, Milicic D, Hadzic N, Juresa V, Bozikov J, Rotkvic I, Buljevac M, Kovacevic I, et al. Epidemiology of Crohn's disease in Zagreb, Yugoslavia: a ten-year prospective study. Int J Epidemiol. 1991;20:216-220.

63. Ranzi T, Bodini P, Zambelli A, Politi P, Lupinacci G, Campanini MC, Dal Lago AL, Lisciandrano D, Bianchi PA. Epidemiological aspects of inflammatory bowel disease in a north Italian population: a 4-year prospective study. Eur J Gastroenterol Hepatol. 1996;8:657-661.

64. Trallori G, d'Albasio G, Palli D, Bardazzi G, Cipriani F, Frittelli G, Russo A, Vannozzi G, Morettini A. Epidemiology of inflammatory bowel disease over a 10-year period in Florence (1978-1987). Ital J Gastroenterol. 1991;23:559-563.

65. Cottone M, Cipolla C, Orlando A, Oliva L, Aiala R, Puleo A. Epidemiology of Crohn's disease in Sicily: a hospital incidence study from 1987 to 1989. "The Sicilian Study Group of Inflammatory Bowel Disease". Eur J Epidemiol. 1991;7:636-640.

66. Pajares JM, Gisbert JP. Epidemiology of inflammatory bowel disease in Spain. A systematic review. Rev Esp Enferm Dig. 2001;93:9-20.

67. Saro Gismera C, Riestra Menendez S, Milla Crespo A, Sanchez Fernandez R, Lacort Fernandez M, Arguelles Fernandez G, Chovac Z, Florido Mancheno JI, Anton Magarzo JL, Altadill Arregui A, Vizoso F, Pineda Garcia E, Fernandez de Ocariz Archs E, Albert Colomer J, Garcia Perez J, Lopez Rivas L, Lombrana JL. [Incidence and prevalence of inflammatory bowel disease. Asturian study in 5 areas (EIICEA). Spain]. An Med Interna. 2003;20:3-9.

68. Manousos ON, Giannadaki E, Mouzas IA, Tzardi M, Koutroubakis I, Skordilis P, Vassilakis S, Kouroumalis $\mathrm{E}$, Vlachonikolis IG. Ulcerative colitis is as common in Crete as in northern Europe: a 5-year prospective study. Eur J Gastroenterol Hepatol. 1996;8:893-898.

69. Manousos ON, Koutroubakis I, Potamianos S, Roussomoustakaki M, Gourtsoyiannis N, Vlachonikolis IG. A prospective epidemiologic study of Crohn's disease in Heraklion, Crete. Incidence over a 5-year period. Scand J Gastroenterol. 1996;31:599-603.

70. Prior P, Gyde S, Cooke WT, Waterhouse JA, Allan RN. Mortality in Crohn's disease. Gastroenterology. 1981;80:307-312.

71. Mayberry JF, Newcombe RG, Rhodes J. Mortality in Crohn's disease. Q J Med. 1980;49: 63-68.

72. Eason RJ, Lee SP, Tasman-Jones C. Inflammatory bowel disease in Auckland, New Zealand. Aust N Z J Med. 1982;12:125-131.

73. Weterman IT, Biemond I, Pena AS. Mortality and causes of death in Crohn's disease. Review of 50 years' experience in Leiden University Hospital. Gut. 1990;31:1387-1390.

74. Ekbom A, Helmick CG, Zack M, Holmberg L, Adami HO. Survival and causes of death in patients with inflammatory bowel disease: a population-based study. Gastroenterology. 1992;103:954-960.

75. Probert CS, Jayanthi V, Wicks AC, Mayberry JF. Mortality from Crohn's disease in Leicestershire, 1972 1989: an epidemiological community based study. Gut. 1992;33: 1226-1228.

76. Probert CS, Jayanthi V, Wicks AC, Mayberry JF. Mortality in patients with ulcerative colitis in Leicestershire, 1972-1989. An epidemiological study. Dig Dis Sci. 1993;38:538-541.

77. Stewenius J, Adnerhill I, Anderson H, Ekelund GR, Floren CH, Fork FT, Janzon L, Lindstrom C, Ogren M. Incidence of colorectal cancer and all cause mortality in non-selected patients with ulcerative colitis and indeterminate colitis in Malmo, Sweden. Int J Colorectal Dis. 1995;10:117-122.

78. Cottone M, Magliocco A, Rosselli M, Pinzone F, Oliva L, Orlando A, Aiala MR, Cipolla C, Pagliaro L. Mortality in patients with Crohn's disease. Scand J Gastroenterol. 1996;31: 372-375.

79. Davoli M, Prantera C, Berto E, Scribano ML, D'Ippoliti D. Mortality among patients with ulcerative colitis: Rome 1970-1989. Eur J Epidemiol. 1997;13:189-194.

80. Loftus EV, Jr., Silverstein MD, Sandborn WJ, Tremaine WJ, Harmsen WS, Zinsmeister AR. Crohn's disease in Olmsted County, Minnesota, 1940-1993: incidence, prevalence, and survival. Gastroenterology. 1998;114:1161-1168. 
81. Palli D, Trallori G, Saieva C, Tarantino O, Edili E, D'Albasio G, Pacini F, Masala G. General and cancer specific mortality of a population based cohort of patients with inflammatory bowel disease: the Florence Study. Gut. 1998;42:175-179.

82. Ishibashi N, Hirota Y, Ikeda M, Hirohata T. Ulcerative colitis and colorectal cancer: a follow-up study in Fukuoka, Japan. Int J Epidemiol. 1999;28:609-613.

83. Loftus EV, Jr., Silverstein MD, Sandborn WJ, Tremaine WJ, Harmsen WS, Zinsmeister AR. Ulcerative colitis in Olmsted County, Minnesota, 1940-1993: incidence, prevalence, and survival. Gut. 2000;46:336-343.

84. Jess T, Winther KV, Munkholm P, Langholz E, Binder V. Mortality and causes of death in Crohn's disease: follow-up of a population-based cohort in Copenhagen County, Denmark. Gastroenterology. 2002;122:1808-1814.

85. Viscido A, Bagnardi V, Sturniolo GC, Annese V, Frieri G, D'Arienzo A, Papi C, Riegler G, Corrao G, Caprilli R. Survival and causes of death in Italian patients with ulcerative colitis. A GISC nationwide study. Dig Liver Dis. 2001;33:686-692.

86. Farrokhyar F, Swarbrick ET, Grace RH, Hellier MD, Gent AE, Irvine EJ. Low mortality in ulcerative colitis and Crohn's disease in three regional centers in England. Am J Gastroenterol. 2001;96:501-507.

87. Winther KV, Jess T, Langholz E, Munkholm P, Binder V. Survival and cause-specific mortality in ulcerative colitis: follow-up of a population-based cohort in Copenhagen County. Gastroenterology. 2003;125:1576-1582.

88. Masala G, Bagnoli S, Ceroti M, Saieva C, Trallori G, Zanna I, D'Albasio G, Palli D. Divergent patterns of total and cancer mortality in ulcerative colitis and Crohn's disease patients: the Florence IBD study 1978-2001. Gut. 2004;53:1309-1313.

89. Jacobson B, Puho E, Fallingborg J. Mortality in ulcerative colitis in the North Jutland County. A population based 26 years follow-up study [abstract]. Gut. 2005;54(supll VII).

90. Jess T, Loftus Jr EV, Harmsen WS, Zinsmeister AR, Tremaine WJ, Melton LJ, Munkholm P, Sandborn WJ. Survival and cause-specific mortality in patients with inflammatory bowel disease: a long-term outcome study in Olmsted County, Minnesota, 1940-2004. Gut. 2006.

91. Moum B, Ekbom A, Vatn MH, Aadland E, Sauar J, Lygren I, Schulz T, Stray N, Fausa O. Clinical course during the 1st year after diagnosis in ulcerative colitis and Crohn's disease. Results of a large, prospective population-based study in southeastern Norway, 1990-93. Scand J Gastroenterol. 1997;32:1005-1012.

92. Veloso FT, Ferreira JT, Barros L, Almeida S. Clinical outcome of Crohn's disease: analysis according to the vienna classification and clinical activity. Inflamm Bowel Dis. 2001;7:306-313.

93. Lakatos PL, Szalay F, Tulassay Z, Molnar T, Kovacs A, Gasztonyi B, Papp J, Lakatos L. Clinical presentation of Crohn's disease. association between familial disease, smoking, disease phenotype, extraintestinal manifestations and need for surgery. Hepatogastroenterology. 2005;52:817-822.

94. Baert F, Caprilli R, Angelucci E. Medical therapy for Crohn's disease: top-down or step-up? Dig Dis. 2007;25:260-266.

95. Swain MG. Fatigue in chronic disease. Clin Sci (Lond). 2000;99:1-8.

96. Thombs BD, Bassel M, McGuire L, Smith MT, Hudson M, Haythornthwaite JA. A systematic comparison of fatigue levels in systemic sclerosis with general population, cancer and rheumatic disease samples. Rheumatology (Oxford). 2008;47:1559-1563.

97. Pittion-Vouyovitch S, Debouverie M, Guillemin F, Vandenberghe N, Anxionnat R, Vespignani H. Fatigue in multiple sclerosis is related to disability, depression and quality of life. J Neurol Sci. 2006;243:39-45.

98. Dagnelie PC, Pijls-Johannesma MC, Lambin P, Beijer S, De Ruysscher D, Kempen GI. Impact of fatigue on overall quality of life in lung and breast cancer patients selected for high-dose radiotherapy. Ann Oncol. 2007;18:940-944.

99. Beijer S, Kempen GI, Pijls-Johannesma MC, de Graeff A, Dagnelie PC. Determinants of overall quality of life in preterminal cancer patients. Int J Cancer. 2008;123:232-235.

100. Minderhoud IM, Oldenburg B, van Dam PS, van Berge Henegouwen GP. High prevalence of fatigue in quiescent inflammatory bowel disease is not related to adrenocortical insufficiency. Am J Gastroenterol. 2003;98:1088-1093.

101. Gasche C, Lomer MC, Cavill I, Weiss G. Iron, anaemia, and inflammatory bowel diseases. Gut. 2004;53:1190-1197. 
102. Kalaitzakis E, Carlsson E, Josefsson A, Bosaeus I. Quality of life in short-bowel syndrome: impact of fatigue and gastrointestinal symptoms. Scand J Gastroenterol. 2008;43:1057-1065.

103. Carlsson E, Bosaeus I, Nordgren S. Quality of life and concerns in patients with short bowel syndrome. Clin Nutr. 2003;22:445-452.

104. Hauser W, Dietz N, Steder-Neukamm U, Janke KH, Stallmach A. Biopsychosocial determinants of health-related quality of life after ileal pouch anal anastomosis for ulcerative colitis. Inflamm Bowel Dis. 2004;10:399-407.

105. Bernklev T, Jahnsen J, Lygren I, Henriksen M, Vatn M, Moum B. Health-related quality of life in patients with inflammatory bowel disease measured with the short form-36: psychometric assessments and a comparison with general population norms. Inflamm Bowel Dis. 2005; 11:909-918.

106. Casellas F, Lopez-Vivancos J, Casado A, Malagelada JR. Factors affecting health related quality of life of patients with inflammatory bowel disease. Qual Life Res. 2002;11:775-781.

107. Saibeni S, Cortinovis I, Beretta L, Tatarella M, Ferraris L, Rondonotti E, Corbellini A, Bortoli A, Colombo E, Alvisi C, Imperiali G, de Franchis R. Gender and disease activity influence health-related quality of life in inflammatory bowel diseases. Hepatogastroenterology. 2005;52: 509-515.

108. Janke KH, Raible A, Bauer M, Clemens P, Meisner C, Hauser W, Steder-Neukamm U, Henrich G, Herschbach P, Gregor M, Klump B. Questions on life satisfaction (FLZM) in inflammatory bowel disease. Int J Colorectal Dis. 2004;19:343-353.

109. Casellas F, Arenas JI, Baudet JS, Fabregas S, Garcia N, Gelabert J, Medina C, Ochotorena I, Papo M, Rodrigo L, Malagelada JR. Impairment of health-related quality of life in patients with inflammatory bowel disease: a Spanish multicenter study. Inflamm Bowel Dis. 2005;11: 488-496.

110. Bernklev T, Jahnsen J, Schulz T, Sauar J, Lygren I, Henriksen M, Stray N, Kjellevold O, Aadland E, Vatn $M$, Moum B. Course of disease, drug treatment and health-related quality of life in patients with inflammatory bowel disease 5 years after initial diagnosis. Eur J Gastroenterol Hepatol. 2005;17: 1037-1045.

111. Bernklev T, Jahnsen J, Aadland E, Sauar J, Schulz T, Lygren I, Henriksen M, Stray N, Kjellevold O, Vatn $M$, Moum B. Health-related quality of life in patients with inflammatory bowel disease five years after the initial diagnosis. Scand J Gastroenterol. 2004;39:365-373.

112. Hjortswang H, Jarnerot G, Curman B, Sandberg-Gertzen H, Tysk C, Blomberg B, Almer S, Strom M. The influence of demographic and disease-related factors on health-related quality of life in patients with ulcerative colitis. Eur J Gastroenterol Hepatol. 2003;15:1011-1020.

113. Simren M, Axelsson J, Gillberg R, Abrahamsson H, Svedlund J, Bjornsson ES. Quality of life in inflammatory bowel disease in remission: the impact of IBS-like symptoms and associated psychological factors. Am J Gastroenterol. 2002;97:389-396.

114. Lix LM, Graff LA, Walker JR, Clara I, Rawsthorne P, Rogala L, Miller N, Ediger J, Pretorius T, Bernstein $\mathrm{CN}$. Longitudinal study of quality of life and psychological functioning for active, fluctuating, and inactive disease patterns in inflammatory bowel disease. Inflamm Bowel Dis. 2008;14:1575-1584.

115. Russel M. Data management of the South Limburg Inflammatory Bowel Disease Registry 'IBD South Limburg'. Thesis Incidence, risk factors and quality of life in IBD. 1997;ISBN 90-9010684-7:49-57.

116. http://statline.cbs.nl/StatWeb/start.asp?lp=Search/Search.

117. Lennard Jones JE. Classification of inflammatory bowel disease. Scand J Gastroenterol. 1989;s170:2-6.

118. Gasche C, Scholmerich J, Brynskov J, D'Haens G, Hanauer SB, Irvine EJ, Jewell DP, Rachmilewitz D, Sachar DB, Sandborn WJ, Sutherland LR. A simple classification of Crohn's disease: report of the Working Party for the World Congresses of Gastroenterology, Vienna 1998. Inflamm Bowel Dis. 2000;6:8-15.

119. Hoie O, Wolters F, Riis L, Aamodt G, Solberg C, Bernklev T, Odes S, Mouzas IA, Beltrami M, Langholz E, Stockbrugger R, Vatn M, Moum B. Ulcerative colitis: patient characteristics may predict 10-yr disease recurrence in a European-wide population-based cohort. Am J Gastroenterol. 2007;102:1692-1701.

120. Harvey RF, Bradshaw JM. A simple index of Crohn's-disease activity. Lancet. 1980;1:514.

121. Sandler RS, Jordan MC, Kupper LL. Development of a Crohn's index for survey research. J Clin Epidemiol. 1988;41:451-458.

122. Lichtiger S, Present DH, Kornbluth A, Gelernt I, Bauer J, Galler G, Michelassi F, Hanauer S. Cyclosporine in severe ulcerative colitis refractory to steroid therapy. N Engl J Med. 1994;330:1841-1845.

123. Smets EM, Garssen B, Bonke B, De Haes JC. The Multidimensional Fatigue Inventory (MFI) psychometric qualities of an instrument to assess fatigue. J Psychosom Res. 1995;39:315-325. 
124. Smets EM, Garssen B, Cull A, de Haes JC. Application of the multidimensional fatigue inventory (MFI20) in cancer patients receiving radiotherapy. Br J Cancer. 1996;73:241-245.

125. Guyatt G, Mitchell A, Irvine EJ, Singer J, Williams N, Goodacre R, Tompkins C. A new measure of health status for clinical trials in inflammatory bowel disease. Gastroenterology. 1989;96:804-810.

126. Russel MG, Pastoor CJ, Brandon S, Rijken J, Engels LG, van der Heijde DM, Stockbrugger RW. Validation of the Dutch translation of the Inflammatory Bowel Disease Questionnaire (IBDQ): a health-related quality of life questionnaire in inflammatory bowel disease. Digestion. 1997;58:282-288.

127. Ware JE, Jr., Sherbourne CD. The MOS 36-item short-form health survey (SF-36). I. Conceptual framework and item selection. Med Care. 1992;30:473-483.

128. McHorney CA, Ware JE, Jr., Lu JF, Sherbourne CD. The MOS 36-item Short-Form Health Survey (SF-36): III. Tests of data quality, scaling assumptions, and reliability across diverse patient groups. Med Care. 1994;32:40-66.

129. van Tulder MW, Aaronson NK, Bruning PF. The quality of life of long-term survivors of Hodgkin's disease. Ann Oncol. 1994;5:153-158.

130. Zigmond AS, Snaith RP. The hospital anxiety and depression scale. Acta Psychiatr Scand. 1983;67:361370.

131. Spinhoven P, Ormel J, Sloekers PP, Kempen GI, Speckens AE, Van Hemert AM. A validation study of the Hospital Anxiety and Depression Scale (HADS) in different groups of Dutch subjects. Psychol Med. 1997;27:363-370.

132. Bjelland I, Dahl AA, Haug TT, Neckelmann D. The validity of the Hospital Anxiety and Depression Scale. An updated literature review. J Psychosom Res. 2002;52:69-77. 


\section{.}




\section{Part I}

Course of disease in IBD 



\section{Chapter 2}

\section{Inflammatory bowel disease in South Limburg (the}

Netherlands) 1991-2002: Incidence, diagnostic delay, and seasonal variations in onset of symptoms. Results from a population based study, the IBD South Limburg cohort

Mariëlle JL Romberg-Camps, Martine AM Hesselink-van de Kruijs, Leo J Schouten, Pieter C Dagnelie, Charles B Limonard, Arnold DM Kester, Laurens P Bos, Jelle Goedhard, Wim HA Hameeteman, Frank L Wolters, Maurice GVM Russel, Reinhold W Stockbrügger 


\section{Abstract}

\section{Background and Aims}

Increasing incidence in Inflammatory Bowel Disease (IBD) has been suggested. Recent data on population based incidence rates within Europe are however scarce. Primary aim was to investigate prospectively the incidence of IBD within a well-defined geographical and administrative area of the Netherlands, the South Limburg IBD registry. Secondary aims were to study the duration of symptoms before diagnosis (lag time) and seasonal influences on the incidence of IBD.

\section{Methods}

The incidence was examined using standardized registration of all newly diagnosed IBD patients, between 11-1991 and 1-1-2003. Medical records were reviewed to verify the diagnosis. At inclusion, diagnostic lag time was registered in months.

\section{Results}

Age standardized incidence rates per 100.000 person-years ( $p-y)$ were: Crohn's Disease, male 4.84, female 7.58; Ulcerative Colitis, male 8.51, female 6.92; and Indeterminate Colitis, male 1.05, female 0.93. Incidence rates did not significantly changes over time in either Crohn's Disease, Ulcerative Colitis or Indeterminate Colitis. Lag time was 5 (0-360) months in Crohn's Disease, 3.0 (0-480) months in Ulcerative Colitis and 3.0 (0180) months in Indeterminate Colitis. Lag time was not significantly different between the periods 19911993 and 2000-2002, and no statistical differences in the onset of symptoms per calendar month or season were found.

\section{Conclusions}

Our results, from the South Limburg region (the Netherlands), show no significant change in incidence rates of IBD. The incidence found is relatively high compared to other European countries. Lag time did not change during the study period, and seasonal influence of incidence rates could not be confirmed. 


\section{Introduction}

Crohn's Disease (CD), Ulcerative Colitis (UC) and Indeterminate Colitis (IC) are chronic inflammatory disorders of the gastrointestinal tract. UC and IC affect the colon, whereas $C D$ can involve any part of the gastrointestinal tract from the oral cavity to the anus. A patient is classified as having IC if, after careful investigation, the differential diagnosis between $C D$ and $U C$ remains uncertain.

Recent publications show that the incidence of Inflammatory Bowel Diseases (IBD) is still increasing in the adult population in Spain $^{1}$, Greece $^{2}$, Croatia $^{3}$ and Denmark. ${ }^{4}$ Also higher rates of IBD are seen in northern, industrialized countries ${ }^{5}$, however differences seem to get smaller. ${ }^{1,3,6,7}$

During recent years, diagnostic options in the field of IBD have significantly improved. This could possibly influence incidence rates by discovering sub-clinical disease and also the duration of time from first complaints until the diagnosis, i.e. the diagnostic lag time. Possibly also patients and doctors awareness with regard to IBD plays a role in earlier diagnosis. ${ }^{4}$

Although the cause of Inflammatory Bowel Diseases is still not elucidated, genetic and environmental factors are thought to play an important role in the aetiology. ${ }^{8,9}$ Data increasingly implicate that there is a dysfunctional mucosal immune response to bacteria in the pathogenesis of IBD, especially in the case of $\mathrm{CD} .^{10,11}$ Chronic inflammatory response is possibly triggered by infections with bacterial or viral pathogens and/or due to a defective mucosal barrier. The search for causative or modulating risk factors in the environmental field is ongoing, some of them possibly connected with public and personal hygienic circumstances. ${ }^{12,13}$ The risk of infections might be subjected to climate, changes of biorhythm or other environmental events, secondarily influencing IBD onset. This could potentially result in seasonal variation of incidence rates. However, until now, published data on seasonal variation of incidence rates show conflicting results. ${ }^{14-17}$

Primary aim of the present study was to evaluate the incidence of IBD in a regional Dutch population (South Limburg), that has been followed continuously over a prolonged period of time, and to compare these data with the available literature. Secondary aims were to study the diagnostic lag time and the role of seasonality in the onset of disease in this uniformly defined population based inception cohort of IBD patients.

\section{Materials and Methods}

\section{Population and design}

In 1991, a population based IBD Registry was established through collaboration between the Department of Gastroenterology and Hepatology of the University 
Hospital Maastricht and the MEMIC (Centre for Data and Information Management, Maastricht University). Primary objective of the registry was to prospectively study the incidence of IBD and to investigate risk factors within a well-defined geographical and administrative area of the Netherlands, namely South Limburg (IBD-SL). Previous protocols were designed to study the development of clinical features and quality of life in IBD in a medium time prospect. ${ }^{18}$ In the present analysis, incidence rates, prediagnostic duration of symptoms and seasonality are evaluated.

South Limburg is located in the South-East of the Netherlands, bordering Germany to the East and Belgium to the South and West; South Limburg's northern border with the rest of the Netherlands is very narrow. The region had an average population of 645,000 between 1991 and 2003, and migration in and out of the area is known to be low. ${ }^{19}$ Population data for the region of South Limburg, regarding to age and sex, for the years 1991-2002 was obtained from the Central Statistics' Office in the Netherlands (CBS). ${ }^{19}$

All three hospitals in South Limburg, i.e. the University Hospital in Maastricht, the General District Hospitals of Heerlen (Atrium Medical Centre, with associated hospitals Kerkrade and Brunssum) and Sittard (Maasland Hospital) participated in this study. Apart from general practitioner (GP) practices, there are no other hospitals or outpatient clinics in this area. With regard to possible treatment of IBD patients by GPs, completeness of case ascertainment was previously assessed and found to be high. ${ }^{20}$ Inclusion of IBD patients was, after exclusion of infections and other recognized causes of bowel inflammation, based on endoscopic and/or radiological evidence, supported by mucosal biopsies and/or examination of surgical specimens. For case definition of $C D$, the criteria of Lennard-Jones were applied. ${ }^{21}$ Ulcerative colitis was defined as continuous mucosal inflammation without granulomata, affecting the rectum and/or some or all of the colon in continuity with the rectum. Using the strict criteria mentioned above, patient recruitment for all diagnosed patients (hospitalized and outpatients) was performed by gastroenterologists, physicians, surgeons and paediatricians working in the IBD-SL area. ${ }^{20}$ At inclusion, duration of symptoms before diagnosis (lag time) was registered in months. If disease criteria were not completely met, patients could temporarily be classified as having "possible UC" or "possible CD". In the present study, all newly diagnosed patients (i.e. with no prior history on IBD), registered between January $1^{\text {st }}, 1991$ and January $1^{\text {st }}, 2003$, were included. The patients were followed from inclusion until data collection for the present analysis, from July $1^{\text {st }}, 2005$, until January $1^{\text {st }}, 2006$, or to a prior date in case of death or loss to follow-up (LTFU). At data collection, inclusion criteria were once again verified for all patients. The enrolment diagnosis was used for data analysis except for patients with a change of diagnosis within one month after enrolment; in these cases, the corrected diagnosis were used for analysis $(\mathrm{N}=40)$.

The Ethical Committees of all participating centres approved the protocol, and written informed consent was obtained from all patients. If patients were below 18 years of age, parents or a legal representative signed for informed consent. 


\section{Statistical analysis}

Calculations were performed using the definite registered diagnosis according to the above criteria. Annual incidence rates were calculated based upon the number of patients diagnosed as numerator and the average number of inhabitants in each calendar year as denominator, for both genders, and in 10-year age strata. To adjust for changes in the age distribution of the population, age incidence rates were standardized using the European Standard Population, indicated as European Age Standardized Rate (EASR). ${ }^{22}$

The Estimated Annual Percentage Change (EAPC) was calculated by fitting a regression line to the natural logarithm of the rates using calendar year as a regressor variable, i.e. $y=m x+b$ where $y=\ln$ (rate) and $x=$ calendar year. Then the EAPC equals $100 *\left(e^{m}\right.$ -1). Testing the hypothesis that the EAPC is equal to zero is equivalent to testing the hypothesis that the slope of the line in the above equation is equal to zero. The latter hypothesis was tested using a t-test, with a number of degrees of freedom equal to the number of calendar years minus two. The standard error of mean was obtained from the fit of the regression line. ${ }^{23,24}$ This calculation assumed that the rates increased/ decreased at a constant rate over the entire period.

With regard to lag time, the median time with range was calculated and proportions of patients with different lag time intervals were statistically tested using chi square analysis. The onset of symptoms for CD, UC and IC was calculated by subtracting lag time (months) from the date of diagnosis, the overall variation per month and season per diagnosis was subsequently analyzed using chi square analysis. Seasons were defined as Winter (December - February), Spring (March - May), Summer (June August), Autumn (September - November). Data analyses were performed using the Statistical Package for the Social Sciences (SPSS 15.0 for Windows; SPSS Inc., Chicago, IL). P-values less than 0.05 were considered statistically significant.

\section{Results}

\section{Patient population}

Between January 1st, 1991 and January 1st, 2003, 1264 newly diagnosed patient were included in the IBD-SL registry. After reviewing medical records, ten patients were excluded who had no IBD (haemorrhoids: 1, diverticular disease: 1, ischemic colitis: 1 , infectious gastro-enteritis: 1 , irritable bowel syndrome: 3 and unknown diagnoses with no report of earlier IBD: 3 ).

Of the 1254 remaining patients, 67 patients were excluded because medical records were unavailable and diagnosis could not be confirmed, leaving 1187 patients included. There was no significant difference in age, sex or diagnosis between included and excluded patients. Distribution of diagnoses for the included patients was 476 for CD, 630 for UC and 81 for IC. The sex distribution in CD was 187 males and 289 
females. For UC there were 350 males and 280 females, and for IC 43 males and 38 females. Mean age (range) was 34 (5-79) years for CD, 42 (8-84) years for UC, and 42 (13-77) years for IC.

In CD, $53 \%$ smoked at diagnosis compared to $20 \%$ for UC and $30 \%$ for IC $(p<0.0001)$. The percentage of patients having stopped smoking before diagnosis was $16 \%$ for $C D$, $44 \%$ for UC and $34 \%$ for IC $(p<0.0001)$. Mean time from cessation of smoking to diagnosis was not significantly different between the diagnostic groups. Thirty-one percent, $36 \%$ and $36 \%$ for CD, UC and IC had never smoked, respectively.

\section{Incidence}

In Table 2.1 data on crude and age standardized incidence rates per 100.000 personyears ( $p-y)$ over time are shown according to diagnosis and gender. Mean - EASR corrected - incidence values, per diagnosis were: for $C D$, male 4.84, female 7.58; for UC, male 8.51, female 6.92; and for IC, male 1.05, female 0.93 per 100.000 p-y. Overall incidence rates were for CD 6.2, UC 7.7 and IC 1.0 per 100.000 p-y.

Figure 2.1 shows the standardized incidence rates for male and female patients over time (1991-2002) for CD, UC and IC in the IBD-SL region, based on the three years' moving average. The EAPC [95\% Confidence Interval] during 1991-2002 was for CD male; $-3.4 \%$ [-10.3\%,4.1\%], CD female; $-0.6 \%$ [-6.4\%,5.5\%], UC male; $-5.3 \%$ [$10.6 \%, 0.2 \%]$, UC female; $-4.6 \%$ [-10.4\%,1.6\%], IC male; $-11 \%[-24.9 \%, 5.4 \%]$ and IC female; $-1.4 \%$ [-16.8\%,17.0\%]. None of these values was statistically significant.

In Figure 2.2, age-specific incidence rates (per 100.000 person-years) in 1991-2002 are shown for CD, UC and IC for male and female patients. In CD, incidence peaked at 20 to 29 years of age, being markedly higher in females ( 21.9 per $100.000 \mathrm{p}-\mathrm{y}$ ) than in males (11.6 per 100.000 p-y). In UC, peak incidence at young age was similar in males and females. However, the peak incidence for males was observed a decade later (30-39 years of age), with a second peak in incidence at 60-69 years of age. The incidence of IC was low, being only 1.0 per 100.000 p-y in male and 0.9 per $100.000 p$-y in female patients. 
Table 2.1 Crude and Standardized (EASR) Incidence Rates (per 100.000 person-years) 1991-2002.

\begin{tabular}{|c|c|c|c|c|c|c|c|c|c|c|c|c|c|}
\hline & 1991 & 1992 & 1993 & 1994 & 1995 & 1996 & 1997 & 1998 & 1999 & 2000 & 2001 & 2002 & $\begin{array}{c}1991- \\
2002 \\
\end{array}$ \\
\hline \multicolumn{14}{|l|}{$C D$} \\
\hline \multicolumn{14}{|l|}{ Male } \\
\hline crude & 6.66 & 9.48 & 4.73 & 4.08 & 3.44 & 5.31 & 2.81 & 4.38 & 3.44 & 5.33 & 4.40 & 4.78 & 4.90 \\
\hline standardized & 6.09 & 8.95 & 4.51 & 4.16 & 3.52 & 5.17 & 3.12 & 4.23 & 3.32 & 5.69 & 4.03 & 5.43 & 4.84 \\
\hline \multicolumn{14}{|l|}{ Female } \\
\hline crude & 5.54 & 8.89 & 9.48 & 9.76 & 7.91 & 5.77 & 8.20 & 4.25 & 7.28 & 7.29 & 7.61 & 6.17 & 7.35 \\
\hline standardized & 5.61 & 8.38 & 9.63 & 9.43 & 7.67 & 5.47 & 8.95 & 4.54 & 7.70 & 7.91 & 8.94 & 6.34 & 7.58 \\
\hline \multicolumn{14}{|l|}{ UC } \\
\hline \multicolumn{14}{|l|}{ Male } \\
\hline crude & 9.83 & 14.22 & 10.08 & 9.42 & 9.70 & 10.00 & 11.25 & 8.75 & 6.26 & 7.83 & 6.91 & 5.73 & 9.17 \\
\hline standardized & 8.89 & 13.27 & 9.44 & 9.15 & 8.74 & 9.20 & 10.71 & 8.17 & 5.94 & 7.12 & 6.71 & 5.11 & 8.51 \\
\hline \multicolumn{14}{|l|}{ Female } \\
\hline crude & 6.77 & 7.67 & 11.62 & 7.62 & 7.91 & 7.29 & 7.89 & 7.59 & 6.07 & 5.16 & 5.78 & 4.01 & 7.12 \\
\hline standardized & 6.49 & 7.04 & 11.49 & 7.10 & 7.52 & 7.40 & 7.35 & 7.46 & 6.10 & 5.32 & 5.71 & 3.61 & 6.92 \\
\hline \multicolumn{14}{|l|}{ IC } \\
\hline \multicolumn{14}{|l|}{ Male } \\
\hline crude & 1.90 & 2.21 & 1.58 & 1.26 & 0.63 & 1.25 & 0.62 & 1.25 & 0.31 & 1.25 & 0.63 & 0.64 & 1.13 \\
\hline standardized & 1.83 & 2.00 & 1.52 & 1.10 & 0.56 & 1.12 & 0.64 & 1.09 & 0.36 & 1.05 & 0.52 & 0.55 & 1.05 \\
\hline \multicolumn{14}{|l|}{ Female } \\
\hline crude & 1.23 & 0.61 & 0.61 & 1.52 & 0.91 & 1.52 & 0.61 & 1.21 & 0.91 & 0.61 & 1.52 & 0.31 & 0.97 \\
\hline standardized & 1.09 & 0.68 & 0.57 & 1.45 & 0.86 & 1.38 & 0.60 & 1.16 & 0.85 & 0.67 & 1.49 & 0.29 & 0.93 \\
\hline
\end{tabular}

$C D=$ Crohn's Disease, UC= Ulcerative Colitis, IC= Indeterminate Colitis, EASR= European Age Standardized Rate

\section{Lag time}

In 1122 out of 1187 patients (95\%), patient reported data with regard to duration of symptoms before diagnosis (lag time) were available. Patients with and without information on lag time, did not significantly differ with regard to gender, diagnosis and overall mortality.

In the total study population, the median lag time was $3(0-480)$ months.

The median lag time by diagnosis was five months (0-360) in CD, $3.0(0-480)$ in UC and $3.0(0-180)$ in IC. 


\section{Crohn}

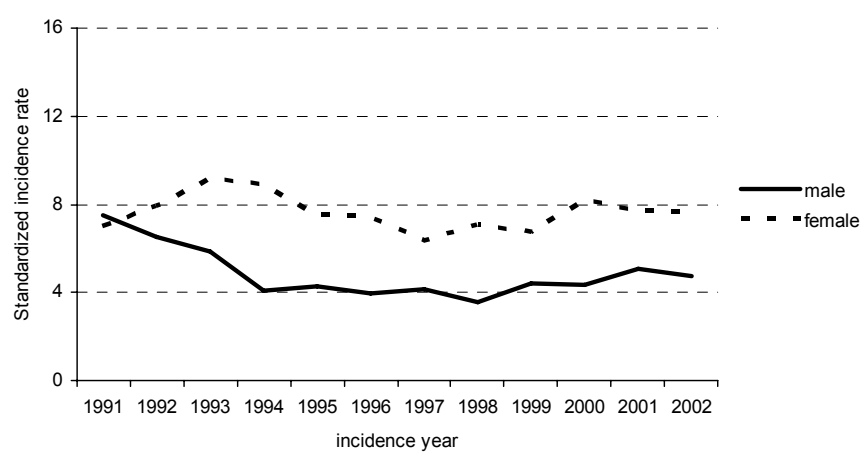

\section{Ulcerative Colitis}

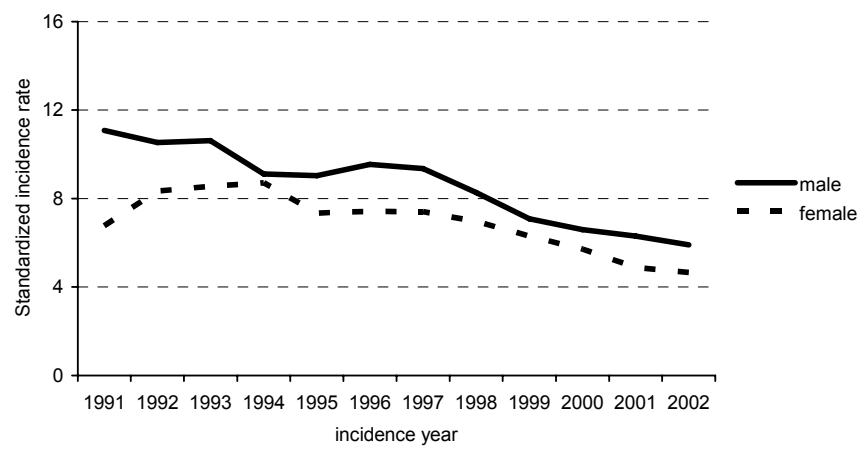

Indeterminate Colitis

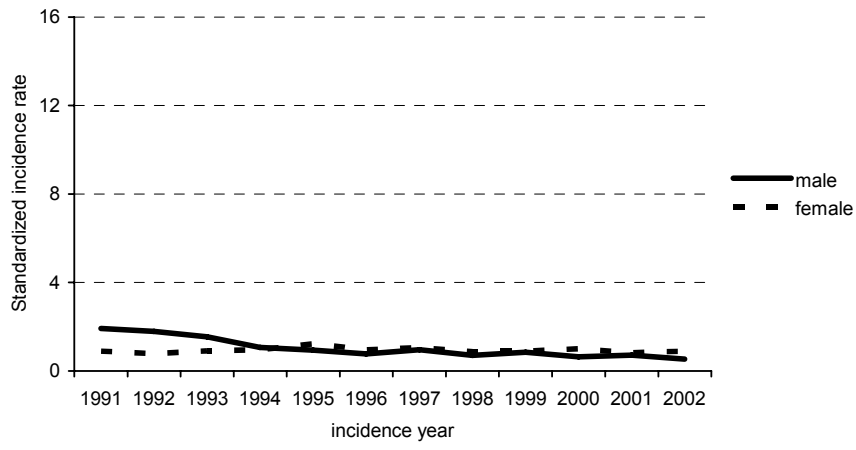

Figure 2.1 Standardized incidence rates per 100.000 person-years, 1991-2002, based on the 3-years moving average. 
M. Crohn

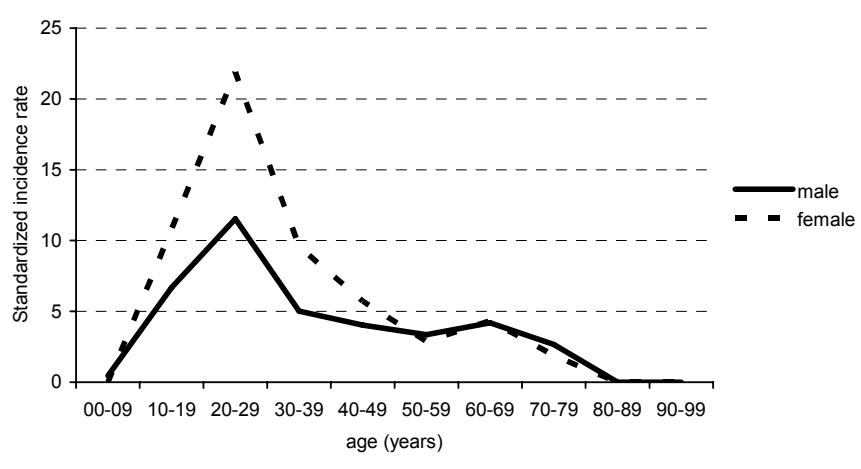

Ulcerative Colitis

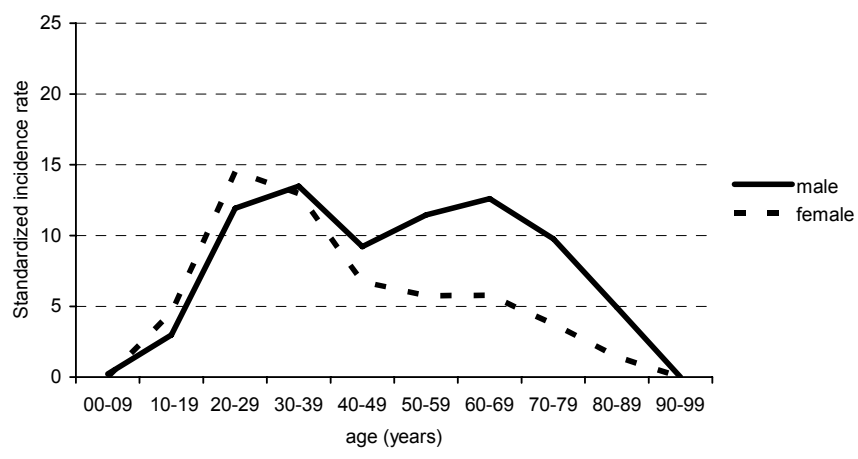

Indeterminate Colitis

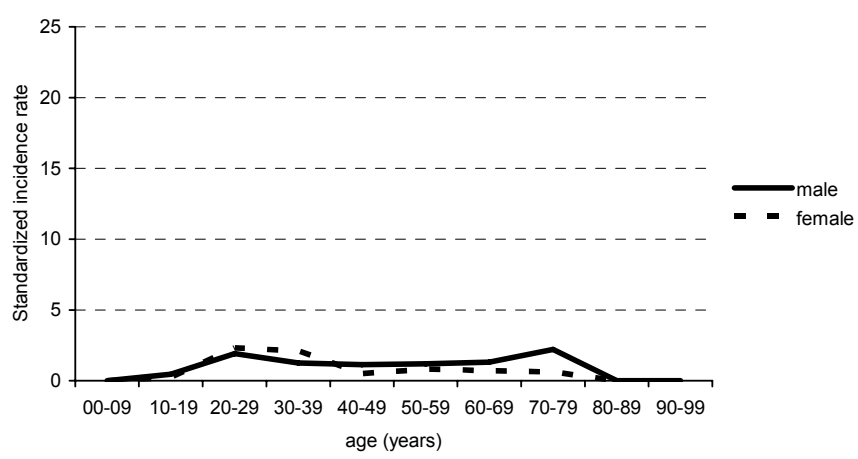

Figure 2.2 Age-specific standardized incidence rates per 100.000 person-years 1991-2002. 
In Table 2.2 the distribution of lag time is shown. The percentage of all patients reporting complaints less than one year before diagnosis was $83 \%$, for less than two years this was $91 \%$.

In order to investigate a possible change in lag time patients diagnosed in the 3-year period from 1991 to 1993 ( $\mathrm{N}=338$ ) were compared with patients diagnosed in the 3year period from 2000 to $2002(\mathrm{~N}=236)$. The percentages of patients having complaints for more than one year, more than two years, or even longer were not statistically different between the two time periods.

Table 2.2 Lag time: percentage of patients having complaints before diagnosis in different time periods.

\begin{tabular}{|c|c|c|c|c|c|c|}
\hline Duration of Complaints & $\begin{array}{c}C D \\
(N=448)\end{array}$ & $(\mathrm{N}=600)$ & $(\mathrm{N}=74)$ & $\begin{array}{c}\text { Year of } \\
\text { Diagnosis } \\
1991-1993 \\
(\mathrm{~N}=338) \\
\end{array}$ & $\begin{array}{c}\text { Year of } \\
\text { Diagnosis } \\
2000-2002 \\
(\mathrm{~N}=236)\end{array}$ & Overall \\
\hline Less than one year & $77 \%$ & $88 \%$ & $89 \%$ & $86 \%$ & $81 \%$ & $83 \%$ \\
\hline Between one and two years & $11 \%$ & $6 \%$ & $9 \%$ & $7 \%$ & $9 \%$ & $8 \%$ \\
\hline Between two and five years & $6 \%$ & $4 \%$ & $0 \%$ & $3 \%$ & $5 \%$ & $5 \%$ \\
\hline Between five and ten years & $5 \%$ & $2 \%$ & $1 \%$ & $3 \%$ & $3 \%$ & $3 \%$ \\
\hline More than ten years & $1 \%$ & $0 \%$ & $1 \%$ & $1 \%$ & $2 \%$ & $1 \%$ \\
\hline
\end{tabular}

$\mathrm{CD}=$ Crohn's Disease, $\mathrm{UC}=$ Ulcerative Colitis, $\mathrm{IC}=$ Indeterminate Colitis

\section{Seasonal variation}

The distribution of onset of symptoms according to calendar month is shown in Figure 2.3. No statistically significant difference was found by month either in the entire IBD cohort, or in CD, UC and IC. Neither was there a significant difference when the onset of symptoms was analyzed by season.

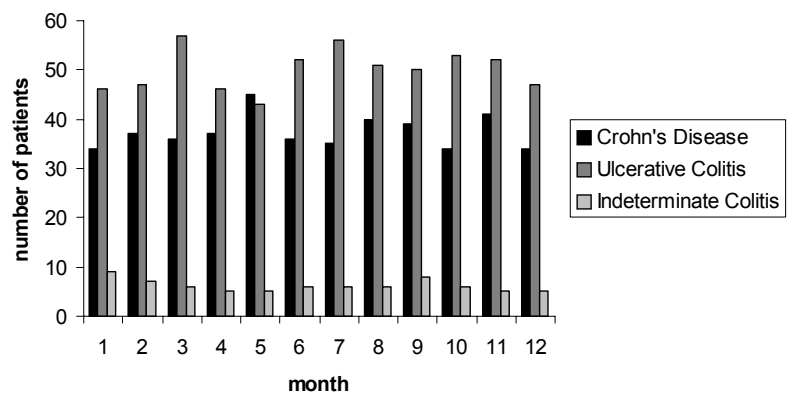

Figure 2.3 Overall variation per month in onset of symptoms for $C D, U C$ and IC $(N=1122)$. 


\section{Discussion}

\section{Incidence}

The present population based study in the IBD-SL region shows no significant increase in the total incidence of CD, UC and IC together. However, although not significant, a trend to a decline of the incidence of UC could be observed. Nevertheless, incidence rates in South Limburg are relatively high compared to reports from the central part of the Netherlands ten years earlier by Shivananda and co-workers, who used similar inclusion criteria. ${ }^{25,26}$ No recent incidence figures from other regions of the Netherlands are available.

Age and sex distribution are similar to those reported by Russel et al. in $1998^{20}$ and comparable to other studies. ${ }^{4,27-31}$ A peak incidence for $C D$ in earlier age and higher incidence rates in females than males were found. In UC, incidence peaks between twenty and forty years of age, with a second peak for men at more advanced age, that possibly reflects an exposure to extrinsic risk factors as previously suggested. ${ }^{32-34}$

An overview of published European incidence rates is given in Table 2.3. 1-7,20,25-33,35-58 $^{-3}$ A recent study from Germany also found a stable incidence of $C D$ and $U C{ }^{47}$ However, our incidence results are in contrast to data from Sweden ${ }^{30,39}$, Denmark ${ }^{4,5,29,32,40}$ and the United Kingdom ${ }^{42-44}$ which all indicate an increasing IBD incidence. Recent publications from Copenhagen found an increasing incidence of CD rather than of UC for the time period 2003-2005. ${ }^{4}$ And although IBD incidence rates are still very low in Greece, an increasing incidence of CD was also found there. ${ }^{2}$ Moreover, the overview in Table 2.3 shows generally higher incidence rates in the North than in the South of Europe, earlier described in a large European cohort study (EC-IBD). ${ }^{5}$ More recent studies from Croatia $^{3}$, Malta ${ }^{7}$ and Spain $^{1}$ show however incidence rates comparable to those in Northern Europe. The reported increase of IBD incidence over the last decades in different European countries supports the idea that environmental factors play an important role in the aetiology and pathogenesis of IBD. At inclusion, the influence of smoking as an extrinsic influencing factor was confirmed in our data, in CD smoking might be seen as an etiologic factor whereas in UC significantly more patients stopped smoking before the start of there complaints. ${ }^{59-61}$ A change to westernized lifestyle $^{62}$ and improved hygienic circumstances ${ }^{12,13}$ have also been implicated. Other factors with impact on incidence rates are the improvement of diagnostic facilities and a better access to health care facilities. The stable incidence rates in the South Limburg cohort would suggest that such factors have been levelling out in the past 15 years in this area. 
Table 2.3 Incidence rates of CD, UC and IC per 100.000 inhabitants and year in Europe from the North to the South European countries.

\begin{tabular}{|c|c|c|c|c|c|c|}
\hline $\begin{array}{l}\text { Publication } \\
\text { year }\end{array}$ & $\begin{array}{l}\text { Time } \\
\text { period }\end{array}$ & Country area & $\begin{array}{l}\text { First Author, } \\
\text { reference }\end{array}$ & $C D$ & UC & IC \\
\hline 1988 & 1983-1984 & Norway western & Haug $^{35}$ & & 14.8 & \\
\hline 1990 & 1983-1986 & Norway northern & Kildebo $^{36,37}$ & 5.8 & 12.8 & \\
\hline 1996 & 1990-1993 & Norway Oslo & Moum 33,38 & 5.8 & 13.6 & \\
\hline 1991 & $1965-1983$ & Sweden Uppsala & Ekbom $^{30}$ & 6.6 & 11.5 & \\
\hline 1985 & 1955-1979 & Sweden Stockholm & Nordenvall $^{39}$ & & $1.7 / 4.3$ & \\
\hline 1982 & $1962-1978$ & $\begin{array}{l}\text { Denmark } \\
\text { Copenhagen }\end{array}$ & Binder $^{40}$ & 2.7 & 8.1 & \\
\hline 1991 & $1962-1987$ & $\begin{array}{l}\text { Denmark } \\
\text { Copenhagen }\end{array}$ & $\begin{array}{l}\text { Langholz } \\
\text { Munkholm }^{29}\end{array}$ & 4.1 & 9.2 & \\
\hline 1996 & 1991-1993 & $\begin{array}{l}\text { Denmark } \\
\text { Copenhagen }\end{array}$ & Shivananda ${ }^{5}$ & M/F 5.4/9.3 & $\mathrm{M} / \mathrm{F} 8.4 / 11.2$ & \\
\hline 2006 & 2003-2005 & $\begin{array}{l}\text { Denmark } \\
\text { Copenhagen }\end{array}$ & Vind $^{4}$ & $M / F 8.6 / 9.1$ & $\mathrm{M} / \mathrm{F} 13.4 / 13.3$ & M/F 1.1/1.4 \\
\hline 1996 & 1991-1993 & Ireland Dublin ${ }^{\mathrm{a}}$ & Shivananda ${ }^{5}$ & $\mathrm{M} / \mathrm{F} 4.5 / 5.9$ & M/F 18.6/11.6 & \\
\hline 1984 & $1968-1977$ & $\begin{array}{l}\text { UK South } \\
\text { Glamorgan }\end{array}$ & Morris $^{41}$ & & 7.2 & \\
\hline 1988 & $1935-1954$ & UK Cardiff & Rose $^{42}$ & 0.2 & & \\
\hline 1992 & 1968-1987 & UK Cardiff & Srivastava $^{43}$ & & 6.4 & \\
\hline 1995 & $1986-1990$ & $\begin{array}{l}\text { UK Cardiff } \\
\text { The Netherlands }\end{array}$ & Thomas $^{44}$ & 5.9 & & \\
\hline 1987 & $1979-1983$ & Leiden & Shivananda ${ }^{25,26}$ & $\mathrm{M} / \mathrm{F} 3.8 / 4.0$ & 6.8 & \\
\hline $\begin{array}{l}1998 \\
\text { present }\end{array}$ & 1990-1994 & South Limburg & Russel $^{20}$ & 6.9 & 10.0 & \\
\hline study & 1991-2003 & South Limburg & Romberg-Camps & $\mathrm{M} / \mathrm{F} 4.8 / 7.6$ & $\mathrm{M} / \mathrm{F} 8.5 / 7.0$ & M/F 1.1/0.9 \\
\hline 1994 & $1980-1984$ & Germany Ruhr area & Dirks $^{45}$ & & 2.9 & \\
\hline 1994 & $1980-1984$ & Germany Ruhr area & Goebell $^{28}$ & 4.0 & & \\
\hline 1999 & 1980-1995 & Germany $^{a}$ & Timmer $^{46}$ & & 5.0 & \\
\hline 2008 & 2004-2006 & Germany $^{a}$ & $\mathrm{Ott}^{47}$ & 6.6 & 3.9 & \\
\hline 1994 & $1988-1990$ & France Northern ${ }^{\mathrm{b}}$ & Gower Rousseau $^{27}$ & 3.2 & 4.9 & \\
\hline 2007 & $2002-2003$ & France Corsica & Abakar-Mahamat ${ }^{48}$ & 4.1 & 9.5 & \\
\hline 2003 & $1997-2001$ & Hungary Western & Lakatos $^{49}$ & 4.7 & 11.0 & 0.7 \\
\hline 2004 & $2002-2003$ & Romania & Gheorghe $^{31}$ & 0.5 & 1.0 & \\
\hline 1991 & 1980-1989 & Yugoslavia Zagreb & Vucelic $^{50,51}$ & 0.7 & 1.5 & \\
\hline 2006 & $2000-2004$ & $\begin{array}{l}\text { Croatia, } \\
\text { Primorsko-goranska }\end{array}$ & Sincic $^{3}$ & 7.0 & 4.3 & \\
\hline 1996 & 1990-1993 & Italy Northern & Ranzi $^{52}$ & 3.4 & 7.0 & \\
\hline 1991 & 1978-1992 & Italy Florence & Trallori $^{53}$ & 1.5 & 4.0 & \\
\hline 1991 & 1987-1989 & Sicily & Cottone $e^{54}$ & 2.7 & & \\
\hline 2001 & $\begin{array}{l}\text { Review } \\
\text { article }\end{array}$ & Spain & Pajares $^{55}$ & 1.9 & 3.8 & \\
\hline 2003 & 1954-1997 & Spain & Saro Gismera ${ }^{56}$ & 2.0 & 2.8 & 1.1 \\
\hline 2004 & $2000-2002$ & Spain Northern $^{a}$ & Rodrigo $^{6}$ & 7.5 & 9.1 & \\
\hline 2008 & 2001-2003 & Spain Navarre $^{a}$ & Arin Letamendia ${ }^{1}$ & 5.9 & 9.6 & 0.6 \\
\hline 2008 & $1993-2005$ & Malta $^{a}$ & Cachia $^{7}$ & $\mathrm{M} / \mathrm{F} 1 / 1.6$ & $M / F 8.2 / 7.6$ & \\
\hline 1996 & 1990-1994 & Greece Crete $^{a}$ & Manousos ${ }^{57,58}$ & 3.0 & 8.9 & \\
\hline 2007 & $1983-2005$ & Greece North-Western & Economou $^{2}$ & 0.9 & 2.7 & \\
\hline
\end{tabular}

${ }^{\text {a }}$ Standardized incidence rates are presented using European Age Standardized Population (EASP) correction,

${ }^{\mathrm{b}}$ Standardized incidence rates using the World Standardized Population for age correction, $\mathrm{M}=$ male, $\mathrm{F}=$ Female 
Incidence rates of diseases depend mainly on the completeness of case collection in a well-defined geographic or political area as well as on the accuracy of information about the background population. In this study, continuously updated background figures were provided by the Statistics Netherlands. ${ }^{19}$ Completeness of case collection can also be assumed high, due to the small number of hospitals involved and the common practice in the Netherlands that patients with IBD are almost exclusively treated by medical specialists associated with the regional hospitals. One could argue that completeness of case ascertainment in our study could have been further improved by involving General Practitioners (GPs). For logistic reasons, the circa 300 GPs working in the IBD-SL region were not individually involved in the study but received recurrent requests to check whether their IBD patients had been registered in the cohort. In this context there is a risk that patients with mild disease, e.g. UC proctitis, could have been missed. However, in the present study, follow-up duration of patients with proctitis was not significantly shorter than that of left-sided or pancolitis (data not shown). In addition, 240 of the registered UC patients (38\%) had at diagnosis proctitis as disease location, resulting in a mean incidence of 3.1 per 100.000 inhabitants a year (1991-2001). This incidence is even higher than the one found by Russel et al. 1991 to $1994^{20}$ supporting the assumption that few patients were missed for inclusion. The incidence of proctitis at diagnosis reported from other countries differs widely, ranging from $18 \%$ even up to $60 \%$. ${ }^{4,16,27,31-33,48,63,64}$

An important potential cause of differences in crude incidence rates between different studies is variation in age distribution of the populations assessed. Therefore, age standardization has to be applied when studying time trends, as age distributions can change over time. Also for incidence comparison between countries standardisation is necessary. We found one study using incidence correction with the use of the World Standardized Population for age correction. ${ }^{27}$ Some others did use EASR correction ${ }^{1-3,5-}$ $7,46,57$ however, this is in the minority of European IBD incidence studies.

\section{Lag time and seasonal influence}

Median duration of symptoms before diagnosis was five months in CD, 3.0 in UC and 3.0 in IC. Overall, $83 \%$ of patients were diagnosed within one year after the start of their complaints. Despite the fact that health care organisation and diagnostic tools had improved over time, we found no significant difference in lag time during the total study period.

A recent study from Corsica ${ }^{48}$ shows comparable results on lag time. However, shorter time periods are reported from Italy ${ }^{14}$ and longer median intervals were reported from Denmark. ${ }^{4}$ The percentage of patients having symptoms for less than one year before diagnosis reported was around $70 \%$ in two studies ${ }^{20,63}$, and $80 \%$ for patients diagnosed within two years in one. ${ }^{14}$ In the present study diagnosis was made earlier as suggested by the high proportion of patients having complaints shorter than one or two years. Reason could be the easy access to health care, and the granted basic insurance for 
every inhabitant in the Netherlands. In older studies, lag time during ongoing inclusion over a prolonged period of time is reported as stable in $U C^{39}$, decreasing in $C D^{4,29,63}$ and decreasing in UC. ${ }^{63}$

Seasonal influences on the temporal incidence of IBD could not be confirmed. IBD patients generally present with quite a long history of symptoms before diagnosis, making it difficult to retrospectively determine when symptoms began. As infections and/or a dysfunctional mucosal immune response to bacteria could play an important role in the pathogenesis of IBD (especially in the case of $C D^{10,11}$ ), the frequent onset of symptoms in spring and summer in $C D$ reported from Italy ${ }^{14}$ is interesting. However, no conclusive evidence for one specific microbial agent is available. A cyclic pattern with regard to specific infections is commonly observed. ${ }^{65}$ Such pattern has been described by some authors for $U C^{15,17}$ and denied by others for both $C D^{15}$ and $U C^{14,16}$

Although this study is population based in a well-defined geographical area and patient inclusion was prospective, recall bias on the timing of onset of symptoms is still a confounding factor. Investigating seasonality of disease onset is also difficult for other reasons: extrinsic pathogenic factors can act in the most different ways, as the time between environmental influences and the reaction of the patient can be highly variable (for example acute reaction to a triggering infection or slow alteration of the patients immune system by repeated exposition). Conditions useful and/or necessary for the study of seasonality in IBD have recently been discussed ${ }^{66}$ but will also be difficult to be fulfilled in future research.

In conclusion, our results show a relatively high incidence of IBD in the South Limburg region without significant change of incidence rates during the 11 years' study period. If any, the incidence of UC tended to decline during the investigated period. No seasonal influence was found, and despite the introduction of new diagnostic techniques, diagnostic lag time did not change. The stable incidence rates could mean, that the extrinsic influences which have modified the epidemiology of IBD in recent years (decline of UC and increase of $C D$ ) have slowed down to a near steady state in the study area. This may be different in other geographic and social environments. Therefore, continued studies with prospective and comparable registrations of IBD in an (inter-)national context will be extremely important for the understanding of factors contributing to onset and development of these disorders, but may also be helpful for well planned distribution of health care resources and - not in the least for the invention of new therapeutic principles. 


\section{References}

1. Arin Letamendia A, Borda Celaya F, Burusco Paternain MJ, Prieto Martinez C, Martinez Echeverria A, Elizalde Apestegui I, Laiglesia Izquierdo M, Macias Mendizabal E, Tamburri Moso P, Sanchez Valverde F. [High incidence rates of inflammatory bowel disease in Navarra (Spain). Results of a prospective, population-based study]. Gastroenterol Hepatol. 2008;31:111-116.

2. Economou M, Filis G, Tsianou Z, Alamanos J, Kogevinas A, Masalas K, Petrou A, Tsianos EV. Crohn's disease incidence evolution in North-western Greece is not associated with alteration of NOD2/CARD15 variants. World J Gastroenterol. 2007;13:5116-5120.

3. Sincic BM, Vucelic B, Persic M, Brncic N, Erzen DJ, Radakovic B, Micovic V, Stimac D. Incidence of inflammatory bowel disease in Primorsko-goranska County, Croatia, 2000-2004: A prospective population-based study. Scand J Gastroenterol. 2006;41:437-444.

4. Vind I, Riis L, Jess T, Knudsen E, Pedersen N, Elkjaer M, Bak Andersen I, Wewer V, Norregaard P, Moesgaard F, Bendtsen F, Munkholm P. Increasing incidences of inflammatory bowel disease and decreasing surgery rates in Copenhagen City and County, 2003-2005: a population-based study from the Danish Crohn colitis database. Am J Gastroenterol. 2006;101:1274-1282.

5. Shivananda S, Lennard Jones J, Logan R, Fear N, Price A, Carpenter L, van Blankenstein M. Incidence of inflammatory bowel disease across Europe: is there a difference between north and south? Results of the European Collaborative Study on Inflammatory Bowel Disease (EC-IBD). Gut. 1996;39:690-697.

6. Rodrigo L, Riestra S, Nino P, Cadahia V, Tojo R, Fuentes D, Moreno M, Gonzalez Ballina E, Fernandez E. A population-based study on the incidence of inflammatory bowel disease in Oviedo (Northern Spain). Rev Esp Enferm Dig. 2004;96:296-305.

7. Cachia E, Calleja N, Aakeroy R, Degaetano J, Vassallo M. Incidence of inflammatory bowel disease in Malta between 1993 and 2005: a retrospective study. Inflamm Bowel Dis. 2008;14:550-553.

8. Kucharzik T, Maaser C, Lugering A, Kagnoff M, Mayer L, Targan S, Domschke W. Recent understanding of IBD pathogenesis: implications for future therapies. Inflamm Bowel Dis. 2006;12:1068-1083.

9. Feeney MA, Murphy F, Clegg AJ, Trebble TM, Sharer NM, Snook JA. A case-control study of childhood environmental risk factors for the development of inflammatory bowel disease. Eur J Gastroenterol Hepatol. 2002;14:529-534.

10. Hanauer SB. Inflammatory bowel disease: epidemiology, pathogenesis, and therapeutic opportunities. Inflamm Bowel Dis. 2006;12 Suppl 1:S3-9.

11. Shiobara N, Suzuki Y, Aoki H, Gotoh A, Fujii Y, Hamada Y, Suzuki S, Fukui N, Kurane I, Itoh T, Suzuki R. Bacterial superantigens and $T$ cell receptor beta-chain-bearing $T$ cells in the immunopathogenesis of ulcerative colitis. Clin Exp Immunol. 2007;150:13-21.

12. Koloski NA, Bret L, Radford-Smith G. Hygiene hypothesis in inflammatory bowel disease: a critical review of the literature. World J Gastroenterol. 2008;14:165-173.

13. Amre DK, Lambrette P, Law L, Krupoves A, Chotard V, Costea F, Grimard G, Israel D, Mack D, Seidman EG. Investigating the hygiene hypothesis as a risk factor in pediatric onset Crohn's disease: a casecontrol study. Am J Gastroenterol. 2006;101:1005-1011.

14. Aratari A, Papi C, Galletti B, Angelucci E, Viscido A, D'Ovidio V, Ciaco A, Abdullahi M, Caprilli R. Seasonal variations in onset of symptoms in Crohn's disease. Dig Liver Dis. 2006;38: 319-323.

15. Moum B, Aadland E, Ekbom A, Vatn MH. Seasonal variations in the onset of ulcerative colitis. Gut. 1996;38:376-378.

16. Evans JG, Acheson ED. An epidemiological study of ulcerative colitis and regional enteritis in the Oxford area. Gut. 1965;6:311-324.

17. Cave D, Freedman L. Seasonal variations in the clinical presentation of Crohn's disease and ulcerative colitis. Int J Epidemiol. 1975:317-320.

18. Russel M. Data management of the South Limburg Inflammatory Bowel Disease Registry 'IBD South Limburg'. Thesis Incidence, risk factors and quality of life in IBD, Russel, M. 1997: 49-57.

19. http://statline.cbs.nl/StatWeb/start.asp?lp=Search/Search.

20. Russel MG, Dorant E, Volovics A, Brummer RJ, Pop P, Muris JW, Bos LP, Limonard CB, Stockbrugger RW. High incidence of inflammatory bowel disease in The Netherlands: results of a prospective study. The South Limburg IBD Study Group. Dis Colon Rectum. 1998;41: 33-40. 
21. Lennard Jones JE. Classification of inflammatory bowel disease. Scandinavian journal of gastroenterology. Supplement. 1989;170:2-6; discussion 16-19.

22. Waterhouse J, Muir C, Correa P, Powel J. Cancer Incidence in Five Continents, Volume III. Lyon: IARC scientific Publications, International Agency for Research on Cancer. 1976.

23. Hayden RW. A Review of Applied Regression Anlaysis and Other Multivariable Methods. J Biopharm Stat. 2008;18:797-798.

24. Kleinbaum DG, Kupper LL, Muller KE. Applied regression analysis and other multivariable methods. 1988.

25. Shivananda S, Pena AS, Nap M, Weterman IT, Mayberry JF, Ruitenberg EJ, Hoedemaeker PJ. Epidemiology of Crohn's disease in Regio Leiden, The Netherlands. A population study from 1979 to 1983. Gastroenterology. 1987;93:966-974.

26. Shivananda S, Hordijk ML, Pena AS, Mayberry JF. Inflammatory bowel disease: one condition or two? Digestion. 1987;38:187-192.

27. Gower Rousseau C, Salomez JL, Dupas JL, Marti R, Nuttens MC, Votte A, Lemahieu M, Lemaire B, Colombel JF, Cortot A. Incidence of inflammatory bowel disease in northern France (1988-1990). Gut. 1994;35:1433-1438.

28. Goebell H, Dirks E, Forster S. A prospective analysis of the incidence and prevalence of inflammatory bowel disease in an urban population in Germany. Eur J Gastroenterol Hepatol. 1994;6:1039-1045.

29. Munkholm P, Langholz E, Nielsen $\mathrm{OH}$, Kreiner S, Binder V. Incidence and prevalence of Crohn's disease in the county of Copenhagen, 1962-87: a sixfold increase in incidence. Scand J Gastroenterol. 1992;27:609-614.

30. Ekbom A, Helmick C, Zack M, Adami HO. The epidemiology of inflammatory bowel disease: a large, population-based study in Sweden. Gastroenterology. 1991;100:350-358.

31. Gheorghe C, Pascu O, Gheorghe L, lacob R, Dumitru E, Tantau M, Vadan R, Goldis A, Balan G, lacob S, Dobru D, Saftoiu A. Epidemiology of inflammatory bowel disease in adults who refer to gastroenterology care in Romania: a multicentre study. Eur J Gastroenterol Hepatol. 2004;16:11531159.

32. Langholz E, Munkholm P, Nielsen $\mathrm{OH}$, Kreiner S, Binder V. Incidence and prevalence of ulcerative colitis in Copenhagen county from 1962 to 1987. Scand J Gastroenterol. 1991;26:1247-1256.

33. Moum B, Vatn MH, Ekbom A, Aadland E, Fausa O, Lygren I, Sauar J, Schulz T, Stray N. Incidence of ulcerative colitis and indeterminate colitis in four counties of southeastern Norway, 1990-93. A prospective population-based study. The Inflammatory Bowel South-Eastern Norway (IBSEN) Study Group of Gastroenterologists. Scand J Gastroenterol. 1996;31:362-366.

34. Tysk C, Jarnerot G. Ulcerative proctocolitis in Orebro, Sweden. A retrospective epidemiologic study, 1963-1987. Scand J Gastroenterol. 1992;27:945-950.

35. Haug K, Schrumpf E, Barstad S, Fluge G, Halvorsen JF. Epidemiology of ulcerative colitis in western Norway. Scand J Gastroenterol. 1988;23:517-522.

36. Kildebo S, Nordgaard K, Aronsen O, Breckan R, Burhol PG, Jorde R. The incidence of ulcerative colitis in Northern Norway from 1983 to 1986. The Northern Norwegian Gastroenterology Society. Scand J Gastroenterol. 1990;25:890-896.

37. Kildebo S, Breckan R, Nordgaard K, Burhol PG, Jorde R. The incidence of Crohn's disease in northern Norway from 1983 to 1986. Northern Norway Gastroenterology Society. Scand J Gastroenterol. 1989;24:1265-1270.

38. Moum B, Vatn MH, Ekbom A, Aadland E, Fausa O, Lygren I, Stray N, Sauar J, Schulz T. Incidence of Crohn's disease in four counties in southeastern Norway, 1990-93. A prospective population-based study. The Inflammatory Bowel South-Eastern Norway (IBSEN) Study Group of Gastroenterologists. Scand J Gastroenterol. 1996;31:355-361.

39. Nordenvall B, Brostrom O, Berglund M, Monsen U, Nordenstrom J, Sorstad J, Hellers G. Incidence of ulcerative colitis in Stockholm County 1955-1979. Scand J Gastroenterol. 1985;20:783-790.

40. Binder V, Both H, Hansen PK, Hendriksen C, Kreiner S, Torp-Pedersen K. Incidence and prevalence of ulcerative colitis and Crohn's disease in the County of Copenhagen, 1962 to 1978. Gastroenterology. 1982;83:563-568.

41. Morris T, Rhodes J. Incidence of ulcerative colitis in the Cardiff region 1968-1977. Gut. 1984;25:846848 . 
42. Rose JD, Roberts GM, Williams G, Mayberry JF, Rhodes J. Cardiff Crohn's disease jubilee: the incidence over 50 years. Gut. 1988;29:346-351.

43. Srivastava ED, Mayberry JF, Morris TJ, Smith PM, Williams GT, Roberts GM, Newcombe RG, Rhodes J. Incidence of ulcerative colitis in Cardiff over 20 years: 1968-87. Gut. 1992;33: 256-258.

44. Thomas GA, Millar Jones D, Rhodes J, Roberts GM, Williams GT, Mayberry JF. Incidence of Crohn's disease in Cardiff over 60 years: 1986-1990 an update. European journal of gastroenterology and hepatology. 1995;7:401-405.

45. Dirks E, Forster S, Thom M, Quebe-Fehling E, Goebell H. [Prospective study of the incidence and prevalence of ulcerative colitis in a large urban population in Germany (western Ruhr area)]. Z Gastroenterol. 1994;32:332-337.

46. Timmer A, Breuer-Katschinski B, Goebell H. Time trends in the incidence and disease location of Crohn's disease 1980-1995: a prospective analysis in an urban population in Germany. Inflamm Bowel Dis. 1999;5:79-84.

47. Ott C, Obermeier F, Thieler S, Kemptner D, Bauer A, Scholmerich J, Rogler G, Timmer A. The incidence of inflammatory bowel disease in a rural region of Southern Germany: a prospective population-based study. Eur J Gastroenterol Hepatol. 2008;20:917-923.

48. Abakar-Mahamat A, Filippi J, Pradier C, Dozol A, Hebuterne X. Incidence of inflammatory bowel disease in Corsica from 2002 to 2003. Gastroenterol Clin Biol. 2007;31:1098-1103.

49. Lakatos L, Mester G, Erdelyi Z, Balogh M, Szipocs I, Kamaras G, Lakatos PL. [Epidemiology of inflammatory bowel diseases in Veszprem county of Western Hungary between 1977 and 2001]. Orv Hetil. 2003;144:1819-1827.

50. Vucelic B, Korac B, Sentic M, Milicic D, Hadzic N, Juresa V, Bozikov J, Rotkvic I, Buljevac M, Kovacevic I, et al. Ulcerative colitis in Zagreb, Yugoslavia: incidence and prevalence 1980-1989. Int J Epidemiol. 1991;20:1043-1047.

51. Vucelic B, Korac B, Sentic M, Milicic D, Hadzic N, Juresa V, Bozikov J, Rotkvic I, Buljevac M, Kovacevic I, et al. Epidemiology of Crohn's disease in Zagreb, Yugoslavia: a ten-year prospective study. Int J Epidemiol. 1991;20:216-220.

52. Ranzi T, Bodini P, Zambelli A, Politi P, Lupinacci G, Campanini MC, Dal Lago AL, Lisciandrano D, Bianchi PA. Epidemiological aspects of inflammatory bowel disease in a north Italian population: a 4-year prospective study. Eur J Gastroenterol Hepatol. 1996;8:657-661.

53. Trallori G, d'Albasio G, Palli D, Bardazzi G, Cipriani F, Frittelli G, Russo A, Vannozzi G, Morettini A. Epidemiology of inflammatory bowel disease over a 10-year period in Florence (1978-1987). Ital J Gastroenterol. 1991;23:559-563.

54. Cottone M, Cipolla C, Orlando A, Oliva L, Aiala R, Puleo A. Epidemiology of Crohn's disease in Sicily: a hospital incidence study from 1987 to 1989. "The Sicilian Study Group of Inflammatory Bowel Disease". Eur J Epidemiol. 1991;7:636-640.

55. Pajares JM, Gisbert JP. Epidemiology of inflammatory bowel disease in Spain. A systematic review. Rev Esp Enferm Dig. 2001;93:9-20.

56. Saro Gismera C, Riestra Menendez S, Milla Crespo A, Sanchez Fernandez R, Lacort Fernandez M, Arguelles Fernandez G, Chovac Z, Florido Mancheno JI, Anton Magarzo JL, Altadill Arregui A, Vizoso F, Pineda Garcia E, Fernandez de Ocariz Archs E, Albert Colomer J, Garcia Perez J, Lopez Rivas L, Lombrana JL. [Incidence and prevalence of inflammatory bowel disease. Asturian study in 5 areas (EIICEA). Spain]. An Med Interna. 2003;20:3-9.

57. Manousos ON, Giannadaki E, Mouzas IA, Tzardi M, Koutroubakis I, Skordilis P, Vassilakis S, Kouroumalis $\mathrm{E}$, Vlachonikolis IG. Ulcerative colitis is as common in Crete as in northern Europe: a 5-year prospective study. Eur J Gastroenterol Hepatol. 1996;8:893-898.

58. Manousos ON, Koutroubakis I, Potamianos S, Roussomoustakaki M, Gourtsoyiannis N, Vlachonikolis IG. A prospective epidemiologic study of Crohn's disease in Heraklion, Crete. Incidence over a 5-year period. Scand J Gastroenterol. 1996;31:599-603.

59. Russel MG, Volovics A, Schoon EJ, van Wijlick EH, Logan RF, Shivananda S, Stockbrugger RW. Inflammatory bowel disease: is there any relation between smoking status and disease presentation? European Collaborative IBD Study Group. Inflamm Bowel Dis. 1998;4:182-186.

60. Tuvlin JA, Raza SS, Bracamonte S, Julian C, Hanauer SB, Nicolae DL, King AC, Cho JH. Smoking and inflammatory bowel disease: trends in familial and sporadic cohorts. Inflamm Bowel Dis. 2007;13:573579. 
61. Lakatos PL, Szamosi T, Lakatos L. Smoking in inflammatory bowel diseases: good, bad or ugly? World J Gastroenterol. 2007;13:6134-6139.

62. Russel MG, Engels LG, Muris JW, Limonard CB, Volovics A, Brummer RJ, Stockbrugger RW. Modern life' in the epidemiology of inflammatory bowel disease: a case-control study with special emphasis on nutritional factors. Eur J Gastroenterol Hepatol. 1998;10:243-249.

63. Berner J, Kiaer T. Ulcerative colitis and Crohn's disease on the Faroe Islands 1964-83. A retrospective epidemiological survey. Scand J Gastroenterol. 1986;21:188-192.

64. Ekbom A, Helmick C, Zack M, Adami HO. Ulcerative proctitis in central Sweden 1965-1983. A population-based epidemiological study. Dig Dis Sci. 1991;36:97-102.

65. Dowell SF. Seasonal variation in host susceptibility and cycles of certain infectious diseases. Emerg Infect Dis. 2001;7:369-374.

66. Stockbrugger RW. Seasonality in IBD: Do we really know about it? Dig Liver Dis. 2006;38: 323-325. 


\section{Chapter 3}

\section{Mortality in inflammatory bowel disease in the}

Netherlands 1991-2002. Results of a population based study, the IBD South Limburg cohort

Mariëlle JL Romberg-Camps, Edith Kuiper, Leo J Schouten, Arnold DM Kester, Martine AM Hesselink-van de Kruijs, Charles B Limonard, Laurens P Bos, Jelle Goedhard, Wim HA Hameeteman, Frank L Wolters, Maurice GVM Russel, Reinhold W Stockbrügger, Pieter C Dagnelie Inflamm Bowel Dis. 2009; epub ahead of print 


\section{Abstract}

\section{Background}

To evaluate overall and disease-specific mortality in a population based IBD cohort in the Netherlands, as well as risk factors for mortality.

\section{Methods}

IBD patients diagnosed between January 1st, 1991 and January 1st, 2003 were included. Standardized Mortality Ratios (SMRs) were calculated overall and with regard to causes of death, gender, as well as age, phenotype, smoking status at diagnosis, and medication use.

\section{Results}

At the censoring date, 72 out of 1187 patients had died (21 CD, 47 UC and 4 IC patients). SMR (95\% CI) was 1.1 (0.7-1.6) for CD, and 0.9 (0.7-1.2) for UC and 0.7 (0.2-1.7) for IC. Disease-specific mortality risk was significantly increased for gastrointestinal (GI) causes of death both in CD (SMR 7.5, 95\% Cl: 2.8-16.4) and UC (SMR 3.4, 95\% Cl: 1.4-7.0); in CD patients, especially in patients $<40$ years of age at diagnosis. For UC, an increased SMR was noted in female patients, as well as in patients $<19$ years and $>80$ years at diagnosis. In contrast, UC patients had a decreased mortality risk from cancer (SMR 0.5, 95\% Cl; 0.2-0.9).

\section{Conclusions}

In this population based IBD study, overall mortality in CD, UC and IC was comparable to the background population. The increased mortality risk for gastro-intestinal causes may reflect a complicated disease course, with especially young and elderly patients at diagnosis needing intensive follow-up. 


\section{Introduction}

Inflammatory bowel disease (IBD) includes three disorders: Crohn's Disease (CD), Ulcerative Colitis (UC), and Indeterminate Colitis (IC). A patient is classified as having IC if, after careful investigation, the differential diagnosis between $C D$ and $U C$ remains uncertain. Even though a recent meta-analysis showed a decline in overall IBD mortality over time ${ }^{1}$, other authors reported stable $C D$ mortality rates ${ }^{2,3}$ in concordance with a review covering the last four decades. ${ }^{4}$ Thus, the debate whether IBD carries an increased mortality risk is still ongoing. Results from the European Collaborative-IBD study group showed an increased mortality risk for CD mainly due to gastro-intestinal causes, suggesting that mortality might be a surrogate marker for disease severity and phenotype at diagnosis. ${ }^{5}$ Other studies showed similar findings in CD patients. ${ }^{3,6}$ In UC, in contrast to older reports ${ }^{7-10}$ recent studies reported no increased mortality risk. ${ }^{2,11,12}$

Because of the heterogeneity of IBD, specification of high-risk patients based on initial disease characteristics would be valuable, especially if obtained from an unselected patient population with uniform diagnostic criteria.

The aim of the present study was to evaluate overall and disease-specific mortality in a population based regional Dutch cohort of IBD patients (South Limburg), which has been followed continuously since 1991. In addition, possible risk factors for mortality were investigated.

\section{Materials and Methods}

\section{Population and design}

In 1991, a population based IBD Registry was established in collaboration between the Department of Gastroenterology/Hepatology and the MEMIC (Centre for Data and Information Management, University of Maastricht). The primary objective of the registry was to prospectively study the incidence of IBD and risk factors for disease severity and outcome within a well-defined area of the Netherlands, namely South Limburg (IBD-SL). Previous studies had dealt with the development of clinical features and quality of life in IBD in a medium time prospect. ${ }^{13}$ In the present analysis, the influence of phenotype at diagnosis and other potential risk factors for mortality (smoking status at diagnosis and medication use) were evaluated.

South Limburg is located in the South-East of the Netherlands between Germany and Belgium; its northern border with the rest of the Netherlands is narrow. The region had an average population of 645.000 between 1991 and 2003, and the migration rate in and out of the area is low. ${ }^{14}$ Population data for the region of South Limburg, regarding age, sex and mortality were obtained from Statistics Netherlands. ${ }^{14}$

All three hospitals in South Limburg, i.e. University Hospital Maastricht and the General District Hospitals of Heerlen and Sittard participated in this study. Apart from 
general practitioners (GPs), there are no other in- or outpatient clinics treating patients with IBD in this area. Treatment of IBD patients by GPs has previously been assessed. ${ }^{15}$ Inclusion of IBD patients was based on endoscopic and/or radiological evidence, supported by mucosal biopsies and/or examination of a surgical specimen. For case definition of $C D$, the criteria of Lennard-Jones were applied. ${ }^{16}$ Ulcerative colitis was defined as continuous mucosal inflammation without granulomata, affecting the rectum and/or some or all of the colon in continuity with the rectum. Patient recruitment for all diagnosed patients (hospitalized and outpatients) was performed by gastroenterologists, internists, surgeons and paediatricians working in the IBD-SL area. ${ }^{15}$ In the present study, all newly diagnosed patients (i.e. without prior history of IBD), registered between January $1^{\text {st }}, 1991$, and January $1^{\text {st }}, 2003$, were included. For the purpose of this investigation, patients were characterized according to the Vienna classification at diagnosis. ${ }^{17}$ In UC, disease activity proximal to the splenic flexure was classified as "extensive colitis", colonic inflammation distal to the splenic flexure as "distal colitis", and disease limited to the rectum $15 \mathrm{~cm}$ above the linea dentata as "proctitis". In IC patients, the extent of disease was classified as in UC. At inclusion, patients filled out a questionnaire containing information on smoking habits before and at the moment of diagnosis. Smoking status was classified in three categories: "smoker at diagnosis"; "stopped smoking before diagnosis"; "never smoked before diagnosis".

Patients were followed from inclusion until the start of data collection for the present analysis, i.e. January $1^{\text {st }}, 2006$, or until a prior date in case of death or loss to follow-up (LTFU). To verify whether LTFU patients had actually died, we performed several search methods. At first we selected the LTFU patients as those who had not visited the outpatient clinic after June 1st, 2005, and had not returned a mailed questionnaire. Of the remaining LTFU patients we looked in our hospital databases if after January $1^{\text {st }}, 2006$ any other registered investigation took place (e.g. blood tests or visit outpatient clinic). If thereafter a patients was still lost to follow-up, the general practitioner was contacted, and finally a central Dutch inhabitants registry (Central Bureau for Genealogy) was contacted.

Dates of death were registered and causes of death were recorded according to the single level Clinical Classical Software (CCS). ${ }^{18}$ In the CCS, ICD-10 codes are broken down into a smaller number of clinically meaningful categories, thus creating broad diagnostic groups which are more useful for descriptive statistics than ICD-10 codes. The CCS aggregates illnesses and conditions into 259 mutually exclusive categories, most of which are clinically homogeneous.

Additionally, in all hospitals, both the original written medical records and the electronic patient files were reviewed by physicians, specialized nurses or trained senior students with regard to diagnosis, phenotype at diagnosis and medication use. Death circumstances were collected and judged individually by three gastroenterologists to categorize the cause of death as either "not IBD related", "possibly IBD related", "probably IBD related" or "certainly IBD related". In case of 
inconsistency of judgment, the individual case was discussed until definite categorization.

Medication use was registered per three months' periods and defined as positive when taken at any time point within that period. All collected data were instantly and uniformly registered in an Access database. The most commonly used drugs for IBD were chosen for analysis and reported as cumulative percentage of medication ever used during follow-up. Medication use was analyzed for sulfazalazine, mesalazine (5ASA) (systemic use), corticosteroids (topical and/or systemic use of prednisone, prednisolon, beclomethason or budesonide), and "other" immune modulating medication (azathioprine, 6-mercaptopurine, thioguanine, cyclosporine and methotrexate). The group of "other" immune modulating medication will be referred to as "immuno-suppressives" throughout this paper.

\section{Statistical analysis}

Calculations were performed using the final registered diagnosis according to the mentioned criteria. Patient characteristics per diagnosis are reported with regard to sex, age at diagnosis, phenotype at diagnosis, smoking status at diagnosis, and medication use during follow-up of the patients alive at the censoring date and of the deceased patient. Differences between these groups were appraised using Pearson chi-square tests.

Standardized Mortality Ratios (SMRs) were calculated by dividing observed mortality by expected mortality rates using age- (ten-year age groups), gender- and period(1991-95, 1996-2000 and 2001-05) specific mortality rates from the Statistics Netherlands mortality database. ${ }^{14} 95 \%$ Confidence intervals $(95 \% \mathrm{Cl})$ were calculated by means of the Byar's approximation.

Using Cox proportional hazards regression models, we obtained hazard ratios (HR) for overall mortality with confidence intervals for the potential determinants: age, gender, and smoking status at diagnosis.

Analyses were performed separately for CD and UC. In IC the number of deceased patients was too low to perform multivariate statistical analysis. The proportional hazards assumption was tested by inspection of the log-log curves of the survival rate. $^{19}$ Data analyses were performed using the Statistical Package for the Social Sciences (SPSS 15.0 for Windows; SPSS Inc., Chicago, IL) and Stata 8.2. ${ }^{20}$

$\mathrm{P}$-values less than 0.05 were considered statistically significant.

\section{Ethical considerations}

The Ethical Committees of all participating centres approved the protocol, and written informed consent was obtained from all patients. If patients were below 18 years of age, parents or a legal representative signed for informed consent. 


\section{Results}

\section{Patient population}

Between January $1^{\text {st }}, 1991$ and January $1^{\text {st }}, 2003,1264$ newly diagnosed IBD patients were included in the IBD-SL registry. After reviewing medical records, ten patients were excluded as they had no IBD (haemorrhoids: 1 , diverticular disease: 1 , ischemic colitis: 1 , infectious gastro-enteritis: 1 , irritable bowel syndrome: 3 , and unknown diagnoses with no report of earlier IBD: 3 ).

Of the 1254 remaining patients, 67 patients were excluded because medical records were unavailable, leaving 1187 patients for data analysis. Data on disease location at diagnosis were missing in $27 \mathrm{CD}, 34 \mathrm{UC}$ and 12 IC patients; these patients were included for further overall mortality analysis as follow-up data were available. Mean age at diagnosis, sex distribution and IBD diagnosis (CD, UC and IC) were not significantly different between in- en excluded patients (data not shown). As is shown in Table 3.1, the study population ( $N=1187$ ) comprised 476 patients with $C D, 630$ with UC and 81 with IC. The sex distribution was 187 male and 289 female in CD, 350 male and 280 female in UC, and 43 male and 38 female in IC. Mean age (SD) at diagnosis was 33.5 (15.4) years for CD, 42.0 (16.1) years for UC, and 42.3 (17.1) years for IC.

At the censoring date, 21 out of 476 CD patients, 47 out of 630 UC patients and 4 out of 81 IC patients had died, without significant difference of proportions between the $C D$, UC and IC patients ( $p=0.14)$.

Median (range) follow-up time for patients alive at the censoring date was 7.8 (0.2-15.4) years in CD, $7.0(0.1-15.0)$ years in UC and $7.6(0.1-14.6)$ years in IC. In the deceased patients, median follow-up time (range) from diagnosis until death was 5.6 (0.4-10.1) years for CD, 6.8 (1.4-14.0) years for UC and 4.9 (3.9-6.8) years for IC.

Table 3.1 also shows patient characteristics by diagnostic group with regard to gender, age at diagnosis, phenotype at diagnosis and smoking habits of patients being alive ("survivors") and patients deceased before the censoring date of January $1^{\text {st }}, 2006$. Overall and for CD and UC separately, survivors were significantly younger at diagnosis than those who deceased $(p<0.005)$. In $C D$, significantly more patients had died in patients $>40$ years of age at diagnosis $(p<0.005)$. Disease location, disease behaviour at diagnosis and smoking status were not significantly different between deceased CD patients and survivors. Cumulative medication use of steroids and immunosuppressives was significantly less frequent in deceased CD patients $(p<0.05)$ than in survivors (data not shown). 
Table 3.1 Patients characteristics per diagnosis in patients alive at censoring date (January $1^{\text {st }}, 2006$; "survivors") and deceased patients.

\begin{tabular}{|c|c|c|c|}
\hline & Survivors & Died & Total \\
\hline CD & $\mathrm{N}=455$ & $\mathrm{~N}=21$ & $\mathrm{~N}=476$ \\
\hline Sex male/female & 179 / 276 & $8 / 13$ & $187 / 289$ \\
\hline Age at diagnosis, mean (SD) & $32.4(14.2)^{a}$ & $58.5(19.4)$ & $33.5(15.4)$ \\
\hline \multicolumn{4}{|l|}{ Phenotype at diagnosis (\%) } \\
\hline \multicolumn{4}{|l|}{ Age } \\
\hline$<40$ years & $336(74)^{\mathrm{a}}$ & $4(19)$ & $340(71)$ \\
\hline$\geq 40$ years & $119(26)$ & $17(81)$ & $136(29)$ \\
\hline \multicolumn{4}{|l|}{ Disease location } \\
\hline Terminal ileum & $143(31)$ & $4(20)$ & $147(31)$ \\
\hline Colon & $120(26)$ & $8(38)$ & $128(27)$ \\
\hline Ileo-coloni̦ic & $144(32)$ & $5(24)$ & $149(31)$ \\
\hline Upper GI & $23(5)$ & $2(10)$ & $25(5)$ \\
\hline Unknown & $25(5)$ & $2(10)$ & $27(6)$ \\
\hline \multicolumn{4}{|l|}{ Disease behaviour } \\
\hline Inflammatory & $346(76)$ & $15(70)$ & $361(76)$ \\
\hline Stricturing & $63(14)$ & $3(15)$ & $66(14)$ \\
\hline Penetrating & $34(7)$ & $2(10)$ & $36(7)$ \\
\hline Stricturing and penetrating & $12(3)$ & $1(5)$ & $13(3)$ \\
\hline \multicolumn{4}{|l|}{ Smoking status at diagnosis } \\
\hline Never smoked before diagnosis & $129(28)$ & $1(5)$ & $130(27)$ \\
\hline Stopped smoking before diagnosis & $62(14)$ & $4(19)$ & $66(14)$ \\
\hline Smoker at diagnosis & $217(48)$ & $9(43)$ & $226(48)$ \\
\hline Missing & $47(10)$ & $7(33)$ & $54(11)$ \\
\hline UC & $\mathrm{N}=583$ & $N=47$ & $\mathrm{~N}=630$ \\
\hline Sex male/female & $317 / 266$ & 33 / 14 & $350 / 280$ \\
\hline Age at diagnosis, mean (SD) & $39.8(15.0)^{\mathrm{a}}$ & $62.3(14.5)$ & $42.0(16.1)$ \\
\hline \multicolumn{4}{|l|}{ Phenotype at diagnosis: $\mathrm{N}(\%)$} \\
\hline Proctitis & $226(39)$ & $14(30)$ & $240(38)$ \\
\hline Distal colitis & $254(43)$ & $19(41)$ & $273(43)$ \\
\hline Extensive colitis & $80(14)$ & $3(76)$ & $83(13)$ \\
\hline Unknown & $23(4)$ & $11(23)^{\mathrm{a}}$ & $34(5)$ \\
\hline \multicolumn{4}{|l|}{ Smoking status at diagnosis: $\mathrm{N}(\%)$} \\
\hline Never smoked before diagnosis & $195(33)$ & 9 (19) & $204(32)$ \\
\hline Stopped smoking before diagnosis & 227 (39) & $27(57)$ & $254(40)$ \\
\hline Smoker at diagnosis & $107(18)$ & $5(11)$ & $112(18)$ \\
\hline Missing & $53(9)$ & $7(14)$ & $60(10)$ \\
\hline
\end{tabular}

${ }^{a}$ p-value $<0.005$

In UC, $70 \%$ of the deceased patients were male compared to $54 \%$ of survivors $(p<0.05)$. UC patients with unknown phenotype at diagnosis had a significantly higher mortality risk in relation to all other phenotypes $(p<0.005)$.

In UC, smoking status was not significantly different between deceased patients and survivors. Cumulative medication of 5-ASA was significantly less in deceased patients $(p<0.005)$ (data not shown). 


\section{Overall mortality, and mortality by gender and phenotype}

In Table 3.2, male, female and total mortality according to age and disease phenotype at diagnosis are shown for CD and UC. In CD, 21 patients had died compared to an expected death number of 19.6, giving a SMR of 1.1 (95\% Cl: 0.7-1.6). Mortality risk in CD was not significantly related with gender or phenotype at diagnosis, although a nearly significant increased mortality risk in female patients was observed, SMR 1.8 (95\% Cl: 0.9-3.0). In UC, 47 deaths were observed, whereas 51.3 were expected, yielding an SMR of 0.9 (95\% Cl: 0.7-1.2). SMR was unrelated with age and gender in UC, except for the phenotype "unknown disease location at diagnosis" (SMR 2.5; 95\% $\mathrm{Cl}$ : 1.3-4.5). In IC, with 4 deaths and 6.2 expected, SMR was 0.7 (95\% Cl: 0.2-1.7) without significant association with gender, age or phenotype at diagnosis, as the number of included IC patient was so small they did not reach any statistical significance in further analysis and will not be reported throughout the rest of the paper.

\section{Cause-specific mortality}

Table 3.3 shows cause specific mortality rates for CD, UC and IC patients. In all deceased patients the cause of death could be established.

In $\mathrm{CD}$, mortality risk was significantly increased for gastrointestinal (GI) causes (CCS, ICD-10:138-155) (SMR 7.5, 95\% Cl: 2.8-16.4). Within the category of GI-related deaths, SMR was increased to a similar extent for most categories (gender, disease location at diagnosis and disease behaviour), but found to be especially elevated in CD patients $<40$ years of age at diagnosis (SMR 34.4, 95\% Cl: 6.9-100.5). For cardiovascular causes of death (CCS, ICD-10: 099-118), the SMR was 1.2 (95\% Cl: 0.5-2.3), but colonic disease location was found to have an increased cardiovascular mortality risk (SMR 3.5, 95\% Cl: 1.1-8.2). In UC patients, cause specific mortality was also significantly increased for gastrointestinal causes (SMR 3.4, 95\% Cl: 1.4-7.0), mainly in female UC patients (SMR 8.6, 95\% Cl: 2.8-20.0) and in patients <19 years of age at diagnosis (SMR 537.3, 95\% Cl: 7.0-2989.6) and $>80$ years at diagnosis (SMR 25.0, 95\% Cl: 5.0-73.0). Mortality risk from cancer (CCS, ICD-10: 011-044) was significantly decreased in UC patients (SMR $0.5,95 \% \mathrm{Cl}: 0.2-0.9)$, especially in patients with proctitis at diagnosis (SMR $0.1,95 \% \mathrm{Cl}$ : 0.0-0.8).

In IC, due to small numbers, cause-specific mortality was neither significantly increased nor decreased in the separate disease categories. 


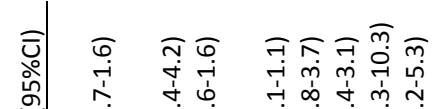

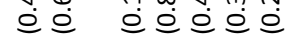

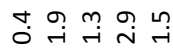

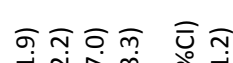

華

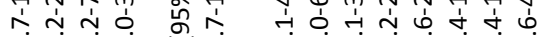

응ㅇ

의

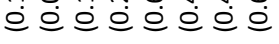

$\stackrel{\sim}{\sim} \stackrel{\infty}{\circ} \stackrel{0}{i} \stackrel{0}{0}$

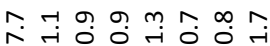

mָ

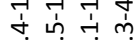

이언

$\stackrel{\infty}{\infty} \stackrel{\infty}{0} \stackrel{0}{0} \stackrel{n}{0} \stackrel{n}{\sim}$

गु

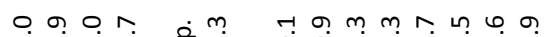

เก เก 0 .

mुm

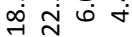

ฮ্ণ

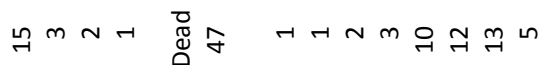

곽 $m$

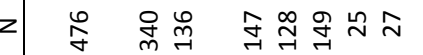

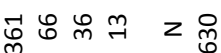

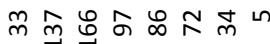

옹 $\stackrel{m}{\sim} \infty$

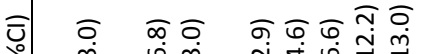

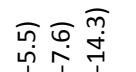

তু

के

岁

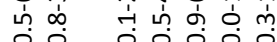

응

으으으응

마

孚

कุ

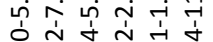

응ㅇㅇㅇㅇㅇ

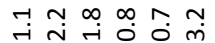

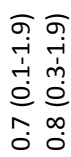

$\frac{0}{\pi} \frac{\dot{\theta}}{\stackrel{\leftarrow}{*}} \quad m$

$\ln \infty \infty \ln ^{\infty}$

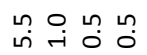

这 $\stackrel{m}{m}$

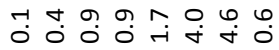

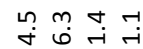

$\stackrel{m}{\square} \quad m$

$n \rightarrow \ln r$

$a \sim n$

뮴

o ornmmm

$m$ ก $\circ 6$

$z$

$\stackrel{\infty}{\stackrel{ }{N}}$

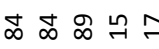

$\stackrel{n}{N} \stackrel{\infty}{\sim}+z \infty$

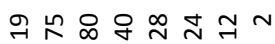

ิㅗㅇํำ

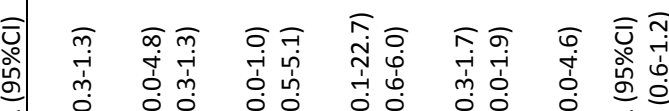

कุ बำ

ते

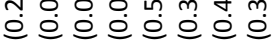

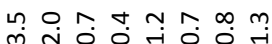

ชธ

응ㅇㅇ

舟茴

mo

감

$\stackrel{\infty}{0} \stackrel{m}{0}$

$\sum_{i}^{\infty}$ o.

m N

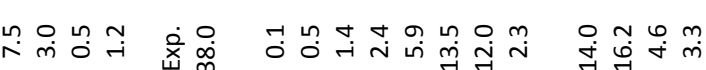

๑ோ

$040-4$

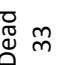

$4 \rightarrow-4 \operatorname{rag} m$

$\exists \rightarrow \operatorname{m} n$

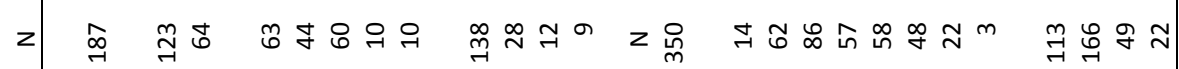
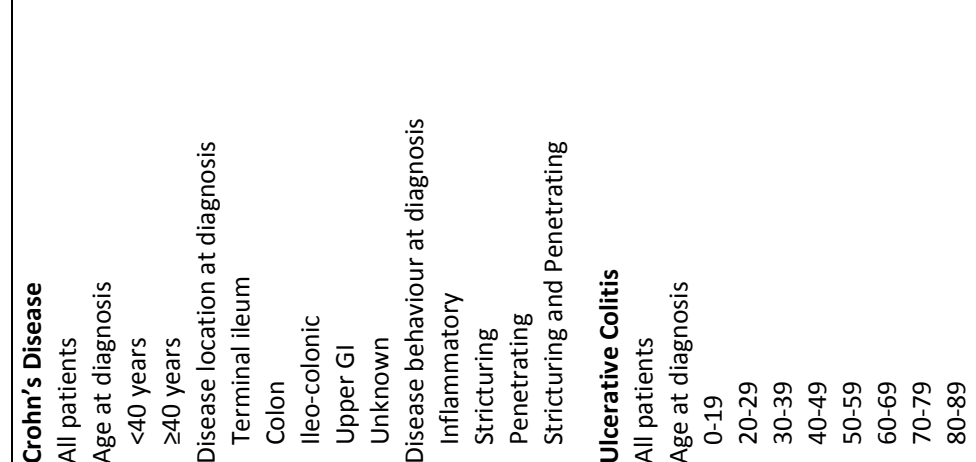


\section{IBD-related mortality}

In Tables 3.4a and 3.4b, IBD- and not IBD-related causes of death per diagnosis are given for individual patients. Overall, the median time from diagnosis to death for IBD related deaths was 3.4 (range 0.4-10.9) years, compared to 6.8 (1.4-13.9) years in patients who died from causes unrelated to IBD. Per diagnosis, the median time from diagnosis to death for IBD-related deaths was 2.0 (range 0.4-6.3) years for CD, 3.5 (2.210.9) years for UC and 5.8 years (only one patient who died due to an IBD-related cause) for IC. For patients who died due to causes unrelated to IBD, median survival times were 6.1 (range 3.9-10.1), 6.5 (1.4-13.9) and 4.0 (3.9-6.8) years, respectively.

For IBD-related deaths, out of a total of 21 deceased patients (Table 3.3), six deaths (29\%) were CD-related. Details of these patients are shown in Table 3.4a. Of these six deaths, two were certainly and four possibly related to IBD. In all these cases, death was due to a gastrointestinal cause. For UC, out of 47 deaths (Table 3.3), eight were IBD-related (17\%). Five UC-related deaths in the UC group had a gastrointestinal cause. In two, this was judged to be certainly UC-related. Table 3.4b summarizes all IBDunrelated causes of death. Overall, 12 out of 54 patients died due to cancer, none of which was colonic. Only one of these patients had ever used immune-suppressive medication.

\section{Risk factors for mortality}

To define independent contributions of age, gender, and smoking status at diagnosis to mortality risk, multivariate analyses per diagnosis group were performed for $C D$ and UC; for IC, patient numbers were to small for multivariate analyses.

In CD patients, age $>40$ years at diagnosis was associated with a significantly increased hazard ratio ( $\mathrm{HR} 8.5,95 \% \mathrm{Cl}: 2.2-32.4$ ). Gender did not significantly influence mortality risk (1.48 [95\%-Cl: 0.4-4.2]). Smoking in CD did not influence mortality risk.

For UC, as in $\mathrm{CD}$, older age at diagnosis was associated with a significantly increased mortality risk (HR 9.4, 95\% Cl: 3.2-27.3). Gender was unrelated to mortality (HR 0.8, 95\% Cl: 0.4-1.6). Smoking at diagnosis was not significantly related with mortality risk (smokers at diagnosis: HR 0.6, 95\% Cl: 0.2-1.7; former smokers: $\mathrm{HR} 1.0,95 \% \mathrm{Cl}: 0.4-2.2$, with never-smokers as reference. 
56 $\mid$ Chapter 3

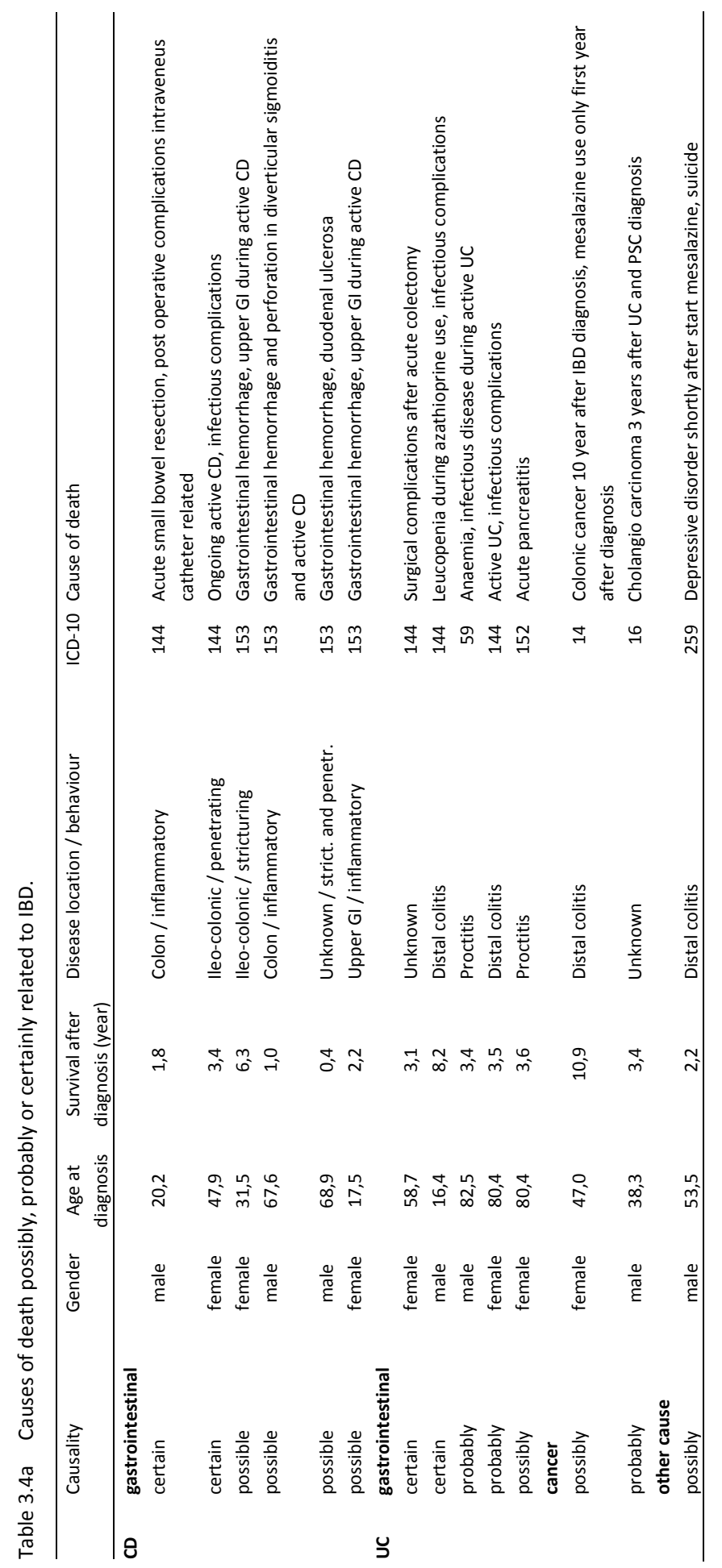




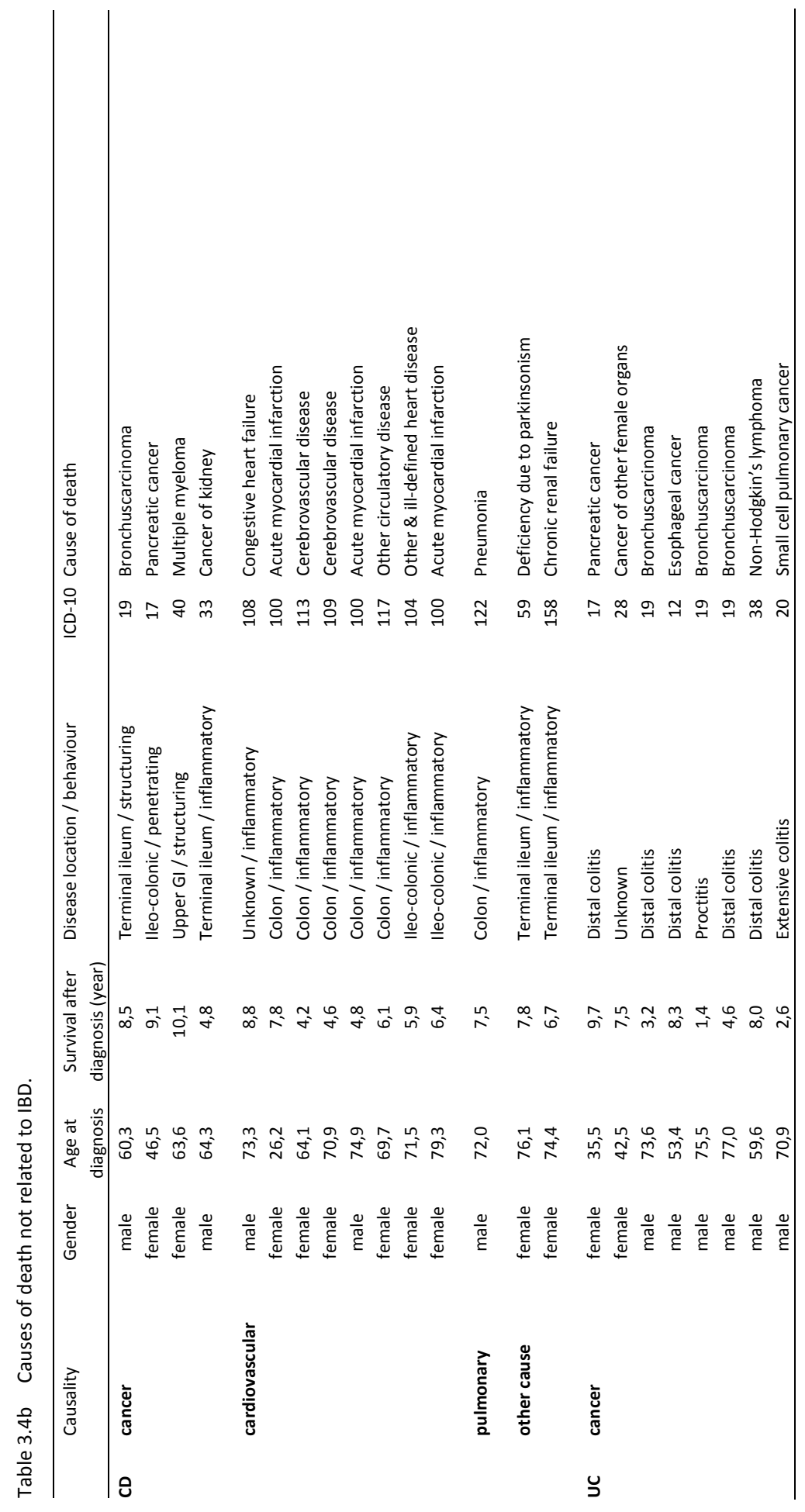


58 $\mid$ Chapter 3

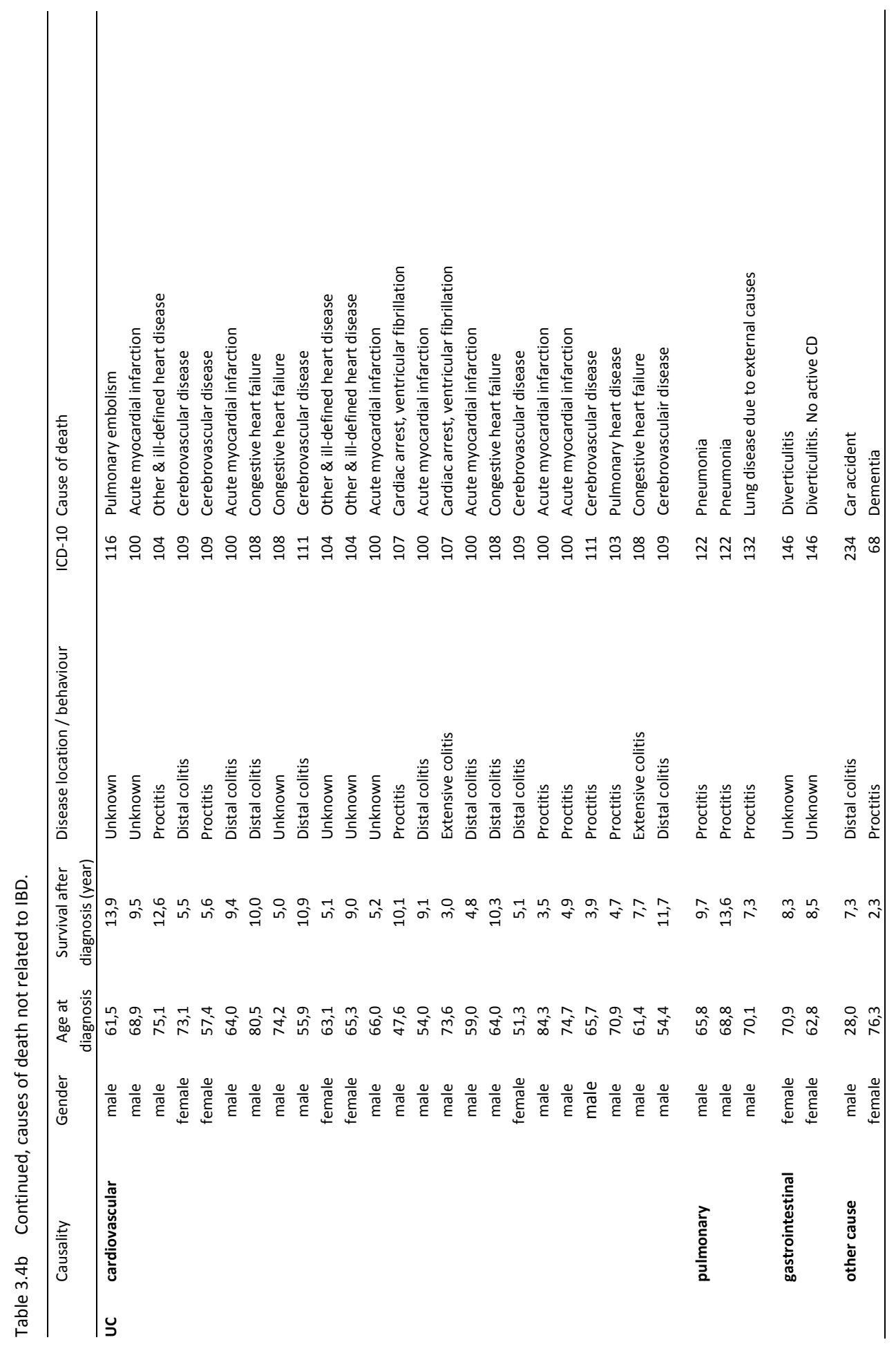




\section{Discussion}

The present population based study in the IBD South Limburg cohort, the Netherlands, showed similar overall mortality rates in CD, UC and IC patients when compared with the background population. However, disease-specific mortality risk was significantly increased for gastrointestinal (GI) causes of death both in CD and UC.

The numerous studies reporting on IBD mortality often differ in terms of patient selection, patient inception, follow-up rates and duration. A literature overview of mortality data with regard to $C D$ and $U C$ is presented in Table 3.5. In a review on time trends of mortality in CD and UC during the last 5 decades, an increased mortality in CD was reported until the mid 1970s with a subsequent decrease. ${ }^{1}$ In UC initially, in the 1950s, a six-fold higher mortality risk was found, subsequently decreasing over the observation time of five decades. ${ }^{1}$ In a recent review by Wolters et al. ${ }^{4}$ on disease outcome in $C D$, SMRs were significantly increased in most of the presented population based studies. The authors emphasized the difficulty of comparing different study populations, as for example referral centres reported higher mortality rates ${ }^{4}$ and longer follow-up showed an increase in the SMR found over time. ${ }^{21,22}$ For UC, a metaanalysis performed by Jess and co-authors in $2007^{11}$ showed a mortality risk comparable to the background population although there were specific subgroups which did have an increased risk (first year after diagnosis, extensive colitis). ${ }^{11}$

In the present study, we found that CD as well as UC related deaths occurred relatively early after diagnosis and were mostly due to severe attacks of inflammation and/or postoperative complications. This finding confirms earlier reports in literature. ${ }^{7-9,11,22-31}$ However, in $C D$, increased mortality has also been reported incidentally after follow-up periods as long as ten years ${ }^{5}$, thirteen years ${ }^{26}$ and even longer. ${ }^{22}$

The $C D$ mortality rates we found were comparable to the background population which is consistent with several other reports. ${ }^{29,30,32,33}$, even though most studies on CD mortality showed an overall increased SMR. ${ }^{3,5,6,10,22,34,35}$ Comparable to CD, in UC, mortality rates were also comparable to the background population, as was observed in most studies on UC mortality. ${ }^{6,12,24,30,33,36-43}$ Only a few reported a decreased ${ }^{23,34}$ or increased mortality in UC patients. ${ }^{7-10,25}$

\section{Gender / Age}

In our study, both male and female CD patients had a significantly increased mortality from gastrointestinal causes, without a difference by gender, as was also reported previously. ${ }^{5,33}$ In UC, gender was not significantly associated with higher mortality, however, early reports in UC have shown conflicting results. $8,12,24,34$

The increased mortality risk from gastrointestinal causes for $C D$ patients $<40$ years of age at diagnosis was confirmed ${ }^{3,5,22,26-28}$, although also above 50 years at diagnosis an increased risk ${ }^{3,5,22,26,44}$ was reported as there was one study that showed no effect of age at onset on mortality. ${ }^{33}$ As young age at diagnosis appears to be an independent 
risk factor for disease recurrence ${ }^{45-47}$, the high mortality risk of young CD patients could be due to a more severe disease course. In old patients, the increased risk for mortality may be due to co-morbidity and/or effects of disease- and therapy-related complications.

The SMR on age for UC patients who died from gastrointestinal disease was significant increased in a binominal manner (patients $<19$ years and $>80$ years old) whereas others reported an excess mortality only in UC patients of older age at diagnosis. ${ }^{12,24,30}$ Thus, young and elderly UC-patients may need more intensive follow-up during the disease course.

\section{Phenotype}

The increased mortality from gastrointestinal causes in CD patients in our study was found for all different disease locations as well as disease behaviour categories, some HRs might not have been significant due to small numbers. An increased risk for gastrointestinal mortality associated with disease location and behaviour has been described previously ${ }^{5,29-31}$, however, in three CD cohorts no differences were found. ${ }^{9,22,25}$ These inconsistent reports could be due to patient selection at inclusion or due to differences in phenotypic classification.

In UC patients, only "unknown" disease location at diagnosis (overall and in female patients) was found to have an increased SMR, which could be a result of misclassification if patients were too ill for extensive diagnostic evaluation at first presentation. In earlier reports, the extent of disease in UC was associated with excess mortality in many ${ }^{8,9,11,24,25,30}$, but not all studies. ${ }^{12}$

\section{Other risk factors}

Even though the use of immunosuppressive and corticosteroid treatment in our study was higher in deceased CD patients relative to survivors, numbers were too small for statistical appraisal or for multivariate analysis. It remains questionable whether medication use is a risk factor for mortality, as differences in drug treatments could also merely reflect differences in disease severity and follow-up time. Notably, none of the deceased patients (IBD- and non-IBD related deaths) of this study had received infliximab treatment during the disease course. This is not remarkable as infliximab was introduced during the study period in 1997. After 2000 we observed that infliximab was started increasingly earlier after diagnosis. Independently of follow-up duration, in $2005,7.8 \%$ of patients with the diagnosis of $C D(N=476)$ were under treatment with infliximab. Of the patients who were started $(N=77)$, eleven received only one gift. In those who received continuous infusions in ten patients side effects were registered and in twelve patients there was a failure in therapy results. Further future observations will be very important to observe the influence of infliximab on mortality in IBD. In UC patients we found no relation between medication use and mortality, confirming one earlier report. ${ }^{12}$ 
CD patients with colonic disease location at diagnosis had increased mortality risk for cardiovascular causes. Although the observed difference in smoking habits between CD and UC patients might provide an explanation, the lack of a comparable non-IBD control group prohibits any conclusion in this respect. Smoking has previously been described as an independent risk factor in CD-mortality ${ }^{10}$, fuelling hope that ongoing anti-smoking campaigns will influence mortality in CD in a favourable way. In UC, the SMR for cardiovascular mortality was comparable to the background population, a finding consistent with a recent meta-analysis. ${ }^{48}$ Others reported a decreased SMR due to cardio-vascular disease in $\mathrm{UC}^{23,25,33,34}$ and suggested a relation with the low prevalence of cigarette smoking among these patients.

In the present study the previously reported increased mortality from colon carcinoma in $C D$ and $U C^{32-34,49,50}$ could not be confirmed. The median follow up period of 7 years in our study may have been too short to observe this effect, as colorectal cancer is known to have a long latency period. ${ }^{9,25,38,50-52}$ Other risk factors for the development of colon carcinoma in IBD reported in literature were treatment in referral centres ${ }^{53-55}$, and the presence of extensive colitis. ${ }^{56}$ In general, results on colon cancer mortality over time in CD patients are conflicting. ${ }^{21,51,57,58}$ In UC, a decreasing risk for colon carcinoma in has also been reported. ${ }^{24,59,60}$ As chronic medication with 5-ASA is considered protective, the incidence of colon carcinoma in both UC and CD may further decline over time. ${ }^{61-63}$ In the present cohort, the cumulative use of 5-ASA and the percentage of patients that used 5-ASA during follow-up was very high in CD patients, nearly equalling the frequency of its use by UC patients. ${ }^{64}$

With regard to lung cancer, excess mortality was reported for $C D$ in earlier reports $^{34,50,51,65}$ but could not be confirmed in this cohort, possibly due to relatively short follow-up.

In the cancer-related mortality category, male UC patients and patients having proctitis as disease location at diagnosis had a decreased SMR. A low mortality in UC due to lung cancer, as reported in literature, might be due to less aggressive smoking habits. ${ }^{11,23,34,57}$ In contrast, however, in the literature Chronic Obstructive Lung Disease (COPD) mortality was reported to be increased in UC patients ${ }^{9,11,12,24,25,38,66}$, a finding that could be compatible with some common pathophysiological pathway in UC and COPD that is not yet recognized.

Other factors described in literature influencing the SMR in UC such as hepato-biliary disease $^{9}$, pulmonary embolism ${ }^{11,24,67}$ and suicide ${ }^{24}$ could not be confirmed in the present study.

\section{Strengths and limitations of the present study}

Strengths of the present study are the population based, prospective design of an uniformly diagnosed inception cohort of IBD patients in a well characterized geographical area. Population based findings concerning the relation between 
phenotypic features at diagnosis and subsequent mortality risk in IBD are scarce, but may help in identifying specific subgroups with an increased mortality risk.

Our study has some limitations. Most data concerning mortality and causes of death were collected retrospectively, however, all causes of death could be identified. Furthermore, patient classification by disease location and behaviour at diagnosis could have been influenced by inter-observer differences, but, as classification was done by a limited number of persons using uniform definitions, this risk was minimized. Furthermore, due to small numbers in different disease categories, our study lacks power to achieve significance for some of the reported associations, which may still become clinically relevant with longer follow-up time.

Finally, due to the relatively short median follow-up period, we are likely to have found relatively low numbers of late causes of IBD-related mortality, e.g. gastrointestinal cancer or long term complications of current pharmacological treatment. Continued follow-up in the future may yield more information in this respect.

\section{Conclusion}

This population based IBD study shows overall mortality rates for CD, UC and IC which are comparable to the background population. This is an important observation, as at least in CD an increased SMR has been reported in the majority of other studies. The favourable outcome of the present study might be due to uniform regional treatment strategies in South Limburg as well as to the opportunity to offer specialized IBD care in geographically close high-volume centres. As recently reported by Nguyen et al., this could lead to reduced mortality in $\mathrm{CD}^{68}$ We found a significant increase in diseasespecific risk of death due to gastro-intestinal causes in both $C D$ and UC, probably reflecting complicated disease course. Based on these findings, we suggest that some IBD sub-groups may need intensive follow-up in order to achieve a further decrease of the mortality risk, especially newly diagnosed IBD patients the first year after diagnosis, as well as IBD patients very young or elderly at diagnosis. So far diseasespecific mortality rates from cancer were found to be low both in CD and UC, however follow-up duration might yet be too short for cancer development. ${ }^{69,70}$ Our results stress the importance of continued population based research in IBD with lengthy follow-up periods in order to gain more and highly powered information on mortality risk over time after diagnosis. 


\section{References}

1. Sonnenberg A. Time trends of mortality from Crohn's disease and ulcerative colitis. Int J Epidemiol. 2007;36:890-899.

2. Jess T. Prognosis of inflammatory bowel disease across time and countries. An epidemiological study of population-based patient cohorts. Dan Med Bull. 2008;55:103-120.

3. Canavan C, Abrams KR, Hawthorne B, Mayberry JF. Long-term prognosis in Crohn's disease: An epidemiological study of patients diagnosed more than 20 years ago in Cardiff. Aliment Pharmacol Ther. 2007;25:59-65.

4. Wolters FL, Russel MG, Stockbrugger RW. Systematic review: has disease outcome in Crohn's disease changed during the last four decades? Aliment Pharmacol Ther. 2004;20:483-496.

5. Wolters FL, Russel MG, Sijbrandij J, Schouten L, Odes S, Riis L, Munkholm P, Bodini P, O'Morain C, Mouzas IA, Tsianos E, Vermeire S, Monteiro E, Limonard C, Vatn M, Fornaciari G, Pereira S, Moum B, Stockbrugger RW. Crohn's disease: increased mortality 10 years after diagnosis in a Europe-wide population based cohort. Gut. 2006;55:510-518.

6. Jess T, Riis L, Vind I, Winther KV, Borg S, Binder V, Langholz E, Thomsen OO, Munkholm P. Changes in clinical characteristics, course, and prognosis of inflammatory bowel disease during the last 5 decades: a population-based study from Copenhagen, Denmark. Inflamm Bowel Dis. 2007;13:481-489.

7. Gyde S, Prior P, Dew MJ, Saunders V, Waterhouse JA, Allan RN. Mortality in ulcerative colitis. Gastroenterology. 1982;83:36-43.

8. Brostrom O, Monsen U, Nordenwall B, Sorstad J, Hellers G. Prognosis and mortality of ulcerative colitis in Stockholm County, 1955-1979. Scand J Gastroenterol. 1987;22:907-913.

9. Persson PG, Bernell O, Leijonmarck CE, Farahmand BY, Hellers G, Ahlbom A. Survival and cause-specific mortality in inflammatory bowel disease: a population-based cohort study. Gastroenterology. 1996; 110:1339-1345.

10. Card T, Hubbard R, Logan RF. Mortality in inflammatory bowel disease: a population-based cohort study. Gastroenterology. 2003;125:1583-1590.

11. Jess T, Gamborg M, Munkholm P, Sorensen TI. Overall and cause-specific mortality in ulcerative colitis: meta-analysis of population-based inception cohort studies. Am J Gastroenterol. 2007;102:609-617.

12. Hoie O, Schouten L, Wolters FL, Solberg IC, Riis L, Mouzas IA, Politi P, Odes S, Langholz E, Vatn M, Stockbrugger RW, Moum B. Ulcerative colitis: no rise in mortality in a European-wide population based cohort 10 years after diagnosis. Gut. 2007;56:497-503.

13. Russel M. Data management of the South Limburg Inflammatory Bowel Disease Registry 'IBD South Limburg'. Thesis Incidence, risk factors and quality of life in IBD, Russel, M. 1997:49-57.

14. http://statline.cbs.nl/StatWeb/start.asp?lp=Search/Search.

15. Russel MG, Dorant E, Volovics A, Brummer RJ, Pop P, Muris JW, Bos LP, Limonard CB, Stockbrugger RW. High incidence of inflammatory bowel disease in The Netherlands: results of a prospective study. The South Limburg IBD Study Group. Dis Colon Rectum. 1998;41: 33-40.

16. Lennard Jones JE. Classification of inflammatory bowel disease. Scandinavian journal of gastroenterology. Supplement. 1989;170:2-6; discussion 16-19.

17. Gasche C, Scholmerich J, Brynskov J, D'Haens G, Hanauer SB, Irvine EJ, Jewell DP, Rachmilewitz D, Sachar DB, Sandborn WJ, Sutherland LR. A simple classification of Crohn's disease: report of the Working Party for the World Congresses of Gastroenterology, Vienna 1998. Inflamm Bowel Dis. 2000;6:8-15.

18. Clinical Classification Sofware for ICD-10 Data: 2003 Software and User's Guide.: Agency for Healthcare Research and Quality R, MD.

19. Grambsch PM, Therneau TM. Proportional hazards test and diagnostics based on weighted residuals. Biometrica. 1994;81:515-526.

20. Statacorp. Stata Statistical Software: Release 8.2. Stata corperation: College Station, TX, 2005.

21. Munkholm P, Langholz E, Davidsen $M$, Binder V. Intestinal cancer risk and mortality in patients with Crohn's disease. Gastroenterology. 1993;105:1716-1723.

22. Jess T, Winther KV, Munkholm P, Langholz E, Binder V. Mortality and causes of death in Crohn's disease: follow-up of a population-based cohort in Copenhagen County, Denmark. Gastroenterology. 2002;122:1808-1814. 
23. Palli D, Trallori G, Saieva C, Tarantino O, Edili E, D'Albasio G, Pacini F, Masala G. General and cancer specific mortality of a population based cohort of patients with inflammatory bowel disease: the Florence Study. Gut. 1998;42:175-179.

24. Winther KV, Jess T, Langholz E, Munkholm P, Binder V. Survival and cause-specific mortality in ulcerative colitis: follow-up of a population-based cohort in Copenhagen County. Gastroenterology. 2003;125:1576-1582.

25. Ekbom A, Helmick CG, Zack M, Holmberg L, Adami HO. Survival and causes of death in patients with inflammatory bowel disease: a population-based study. Gastroenterology. 1992; 103:954-960.

26. Mayberry JF, Newcombe RG, Rhodes J. Mortality in Crohn's disease. Q J Med. 1980;49: 63-68.

27. Prior P, Gyde S, Cooke WT, Waterhouse JA, Allan RN. Mortality in Crohn's disease. Gastroenterology. 1981;80:307-312.

28. Weterman IT, Biemond I, Pena AS. Mortality and causes of death in Crohn's disease. Review of 50 years' experience in Leiden University Hospital. Gut. 1990;31:1387-1390.

29. Probert CS, Jayanthi V, Wicks AC, Mayberry JF. Mortality from Crohn's disease in Leicestershire, 19721989: an epidemiological community based study. Gut. 1992;33: 1226-1228.

30. Farrokhyar F, Swarbrick ET, Grace RH, Hellier MD, Gent AE, Irvine EJ. Low mortality in ulcerative colitis and Crohn's disease in three regional centers in England. Am J Gastroenterol. 2001;96:501-507.

31. Cottone M, Rosselli M, Casa A. Smoking, azathioprine, and clinical course in Crohn's disease. Gastroenterology. 1996;111:1161-1162.

32. Cottone M, Magliocco A, Rosselli M, Pinzone F, Oliva L, Orlando A, Aiala MR, Cipolla C, Pagliaro L. Mortality in patients with Crohn's disease. Scand J Gastroenterol. 1996;31: 372-375.

33. Jess T, Loftus EV, Jr., Harmsen WS, Zinsmeister AR, Tremaine WJ, Melton LJ, 3rd, Munkholm P, Sandborn WJ. Survival and cause specific mortality in patients with inflammatory bowel disease: a long term outcome study in Olmsted County, Minnesota, 1940-2004. Gut. 2006;55:1248-1254.

34. Masala G, Bagnoli S, Ceroti M, Saieva C, Trallori G, Zanna I, D'Albasio G, Palli D. Divergent patterns of total and cancer mortality in ulcerative colitis and Crohn's disease patients: the Florence IBD study 1978-2001. Gut. 2004;53:1309-1313.

35. Canavan C, Abrams KR, Mayberry JF. Meta-analysis: mortality in Crohn's disease. Aliment Pharmacol Ther. 2007; 25:861-870.

36. Eason RJ, Lee SP, Tasman-Jones C. Inflammatory bowel disease in Auckland, New Zealand. Aust N Z J Med. 1982;12:125-131.

37. Probert CS, Jayanthi V, Wicks AC, Mayberry JF. Mortality in patients with ulcerative colitis in Leicestershire, 1972-1989. An epidemiological study. Dig Dis Sci. 1993;38:538-541.

38. Stewenius J, Adnerhill I, Anderson H, Ekelund GR, Floren CH, Fork FT, Janzon L, Lindstrom C, Ogren M. Incidence of colorectal cancer and all cause mortality in non-selected patients with ulcerative colitis and indeterminate colitis in Malmo, Sweden. Int J Colorectal Dis. 1995;10:117-122.

39. Davoli M, Prantera C, Berto E, Scribano ML, D'Ippoliti D. Mortality among patients with ulcerative colitis: Rome 1970-1989. Eur J Epidemiol. 1997;13:189-194.

40. Ishibashi $\mathrm{N}$, Hirota $\mathrm{Y}$, Ikeda M, Hirohata T. Ulcerative colitis and colorectal cancer: a follow-up study in Fukuoka, Japan. Int J Epidemiol. 1999;28:609-613.

41. Loftus EV, Jr., Silverstein MD, Sandborn WJ, Tremaine WJ, Harmsen WS, Zinsmeister AR. Ulcerative colitis in Olmsted County, Minnesota, 1940-1993: incidence, prevalence, and survival. Gut. 2000;46: 336-343.

42. Viscido A, Bagnardi V, Sturniolo GC, Annese V, Frieri G, D'Arienzo A, Papi C, Riegler G, Corrao G, Caprilli R. Survival and causes of death in Italian patients with ulcerative colitis. A GISC nationwide study. Dig Liver Dis. 2001;33:686-692.

43. Jacobson B, Puho E, Fallingborg J. Mortality in ulcerative colitis in the North Jutland County. A population based 26 years follow-up study [abstract]. Gut. 2005;54(supII VII).

44. Loftus EV, Jr., Silverstein MD, Sandborn WJ, Tremaine WJ, Harmsen WS, Zinsmeister AR. Crohn's disease in Olmsted County, Minnesota, 1940-1993: incidence, prevalence, and survival. Gastroenterology. 1998;114:1161-1168.

45. Veloso FT, Ferreira JT, Barros L, Almeida S. Clinical outcome of Crohn's disease: analysis according to the vienna classification and clinical activity. Inflamm Bowel Dis. 2001;7:306-313. 
46. Wolters FL, Russel MG, Sijbrandij J, Ambergen T, Odes S, Riis L, Langholz E, Politi P, Qasim A, Koutroubakis I, Tsianos E, Vermeire S, Freitas J, van Zeijl G, Hoie O, Bernklev T, Beltrami M, Rodriguez D, Stockbrugger RW, Moum B. Phenotype at diagnosis predicts recurrence rates in Crohn's disease. Gut. 2006;55:1124-1130.

47. D'Haens G, Rutgeerts P. Postoperative recurrence of Crohn's disease: pathophysiology and prevention. Inflamm Bowel Dis. 1999;5:295-303.

48. Dorn SD, Sandler RS. Inflammatory bowel disease is not a risk factor for cardiovascular disease mortality: results from a systematic review and meta-analysis. Am J Gastroenterol. 2007;102:662-667.

49. Ekbom A, Helmick C, Zack M, Adami HO. Increased risk of large-bowel cancer in Crohn's disease with colonic involvement. Lancet. 1990;336:357-359.

50. Bernstein CN, Blanchard JF, Kliewer E, Wajda A. Cancer risk in patients with inflammatory bowel disease: a population-based study. Cancer. 2001;91:854-862.

51. Mellemkjaer L, Johansen C, Gridley G, Linet MS, Kjaer SK, Olsen JH. Crohn's disease and cancer risk (Denmark). Cancer causes and control CCC. 2000;11:145-150.

52. Karlen P, Lofberg R, Brostrom O, Leijonmarck CE, Hellers G, Persson PG. Increased risk of cancer in ulcerative colitis: a population-based cohort study. Am J Gastroenterol. 1999;94:1047-1052.

53. Prior P, Gyde S, Allan RN. Mortality in ulcerative colitis: methods of analysis. Gastroenterology. 1982; 83:524-525.

54. Gyde SN, Prior P, Allan RN, Stevens A, Jewell DP, Truelove SC, Lofberg R, Brostrom O, Hellers G. Colorectal cancer in ulcerative colitis: a cohort study of primary referrals from three centres. Gut. 1988;29:206-217.

55. Kvist N, Jacobsen O, Kvist HK, Norgaard P, Ockelmann HH, Schou G, Jarnum S. Malignancy in ulcerative colitis. Scand J Gastroenterol. 1989;24:497-506.

56. Gillen CD, Walmsley RS, Prior P, Andrews HA, Allan RN. Ulcerative colitis and Crohn's disease: a comparison of the colorectal cancer risk in extensive colitis. Gut. 1994;35: 1590-1592.

57. Palli D, Trallori G, Bagnoli S, Saieva C, Tarantino O, Ceroti M, d'Albasio G, Pacini F, Amorosi A, Masala G. Hodgkin's disease risk is increased in patients with ulcerative colitis. Gastroenterology. 2000; 119:647-653.

58. Thomas GA, Rhodes J, Green JT. Inflammatory bowel disease and smoking--a review. Am J Gastroenterol. 1998;93:144-149.

59. Langholz E, Munkholm P, Davidsen M, Binder V. Colorectal cancer risk and mortality in patients with ulcerative colitis. Gastroenterology. 1992;103:1444-1451.

60. Palli D, Trallori G, Masala G, Saieva C, Bardazzi G, Milla M, Bonanomi A, Cimoli F, D'Albasio G, Pacini F, Amorosi A. General and Cancer Specific Mortality in the Follow-up of a Cohort of IBD Patients in Florence. In: United European Gastroenterology Week; 1997; Birmingham; 1997.

61. Ryan BM, Russel MG, Langholz E, Stockbrugger RW. Aminosalicylates and colorectal cancer in IBD: a not-so bitter pill to swallow. Am J Gastroenterol. 2003;98:1682-1687.

62. Cheng Y, Desreumaux P. 5-aminosalicylic acid is an attractive candidate agent for chemoprevention of colon cancer in patients with inflammatory bowel disease. World J Gastroenterol. 2005;11:309-314.

63. Munkholm P. Review article: the incidence and prevalence of colorectal cancer in inflammatory bowel disease. Aliment Pharmacol Ther. 2003;18 Suppl 2:1-5.

64. Romberg-Camps MJ, Dagnelie PC, Kester AD, Hesselink-van de Kruijs MA, Cilissen M, Engels LG, Van Deursen C, Hameeteman WH, Wolters FL, Russel MG, Stockbrugger RW. Influence of phenotype at diagnosis and of other potential prognostic factors on the course of inflammatory bowel disease. Am J Gastroenterol. 2009;104:371-383.

65. Persson PG, Karlen P, Bernell O, Leijonmarck CE, Brostrom O, Ahlbom A, Hellers G. Crohn's disease and cancer: a population-based cohort study. Gastroenterology. 1994;107:1675-1679.

66. Stewenius J, Adnerhill I, Ekelund GR, Floren CH, Fork FT, Janzon L, Lindstrom C, Ogren M. Risk of relapse in new cases of ulcerative colitis and indeterminate colitis. Dis Colon Rectum. 1996;39:1019-1025.

67. Koutroubakis IE. Role of thrombotic vascular risk factors in inflammatory bowel disease. Dig Dis. 2000;18:161-167.

68. Nguyen GC, Steinhart AH. Nationwide patterns of hospitalizations to centers with high volume of admissions for inflammatory bowel disease and their impact on mortality. Inflamm Bowel Dis. 2008;14:1688-1694. 
69. Russel MG, Ryan BM, Dagnelie PC, de Rooij M, Sijbrandij J, Feleus A, Hesselink M, Muris JW, Stockbrugger R. Insurance problems among inflammatory bowel disease patients: results of a Dutch population based study. Gut. 2003;52:358-362.

70. Travis SP. Review article: insurance risks for patients with ulcerative colitis or Crohn's disease. Aliment Pharmacol Ther. 1997;11:51-59.

71. Jess T, Loftus Jr EV, Harmsen WS, Zinsmeister AR, Tremaine WJ, Melton LJ, Munkholm P, Sandborn WJ. Survival and cause-specific mortality in patients with inflammatory bowel disease: a long-term outcome study in Olmsted County, Minnesota, 1940-2004. Gut. 2006. 


\section{Chapter 4}

\section{Influence of phenotype at diagnosis and of other potential prognostic factors on the course of inflammatory bowel disease. A medium- to long-term} follow-up study of the IBD South Limburg cohort

Mariëlle JL Romberg-Camps, Pieter C Dagnelie, Arnold DM Kester, Martine AM Hesselink-van de Kruijs, Mia Cilissen, Leopold GJB Engels, Cees van Deursen, Wim HA Hameeteman, Frank L Wolters, Maurice GVM Russel, Reinhold W Stockbrügger. 


\section{Abstract}

\section{Background}

Disease course in Inflammatory Bowel Disease (IBD) is variable and difficult to predict. To optimize prognosis it is of interest to identify phenotypic characteristics at disease onset and other prognostic factors that predict disease course. The aim of this study was to evaluate such factors in a population based IBD group.

\section{Methods}

IBD patients diagnosed between January $1^{\text {st }}, 1991$ and January $1^{\text {st }}, 2003$ were included. A follow-up questionnaire was developed and medical records were reviewed. Patients were classified according to phenotype at diagnosis and risk factors were registered. Disease severity, cumulative medication use, and "surgical" and "non-surgical" recurrence rates were calculated as outcome parameters.

\section{Results}

476 Crohn's Disease (CD), 630 Ulcerative Colitis (UC) and 81 Indeterminate Colitis (IC) patients were diagnosed. In CD (mean follow-up 7.6 years), 50\% had undergone resective surgery. In UC (mean follow-up seven years), colectomy rate was $8.3 \%$. First year, cumulative recurrence rates per 100 patient-years for $C D$, UC and IC were 53, 44 and $42 \%$, respectively. In CD, small bowel location and stricturing disease were negative prognostic factors for surgery, as was young age. Overall recurrence rate was increased by young age and current smoking. In UC, extensive colitis increased surgical risk. In UC, older age at diagnosis initially increased recurrence risk but subsequently was protective.

\section{Conclusions}

This population based IBD study showed high recurrence rates in the first year. In CD, small bowel location, stricturing disease and young age were predictive for disease recurrence. In UC, extensive colitis and older age at diagnosis were negative prognostic predictors. 


\section{Introduction}

Inflammatory bowel disease (IBD) comprises three disorders: Crohn's Disease (CD), Ulcerative Colitis (UC) and Indeterminate Colitis (IC). UC and IC affect the colon, whereas $C D$ can involve any part of the gastrointestinal tract from the oral cavity to the anus. The exact cause of IBD is unknown, but both genetic and environmental factors play a significant role in the aetiology and pathogenesis. ${ }^{1}$ In Europe, the incidence of CD is three to eight new cases per 100,000 persons a year and three to fourteen per 100,000 a year for UC. ${ }^{2,3}$ Age distribution for CD shows peak incidences at ages of 15-25, especially in female patients, whereas in UC male incidence is still high in older age groups. ${ }^{4,5}$ Indeterminate colitis is found in up to $10 \%$ of IBD patients. ${ }^{6}$ IBD has important socio-economic consequences. Apart from health care costs resulting from medication and hospitalization, IBD afflicts young adults in their economically productive years and can lead to long-term productivity loss or even inability to work. $^{7-9}$

The disease course in IBD is highly variable ${ }^{10,11}$ and seems to be difficult to predict on the basis of information acquired at the moment of diagnosis. ${ }^{12-17}$ However, for clinical purposes it would be useful to categorize patients at the onset of disease into low or high risk groups. In that way, specific therapeutic and preventive strategies might be chosen earlier in the disease course, and patients could be informed more precisely about their prognosis. Even more because recent data suggest that treating severe IBD "top-down" might change natural history of the disease. ${ }^{18}$

The aim of the present study was to evaluate the course of IBD with regard to different phenotypes at first presentation in an unselected regional population followed over a prolonged time period, taking relevant demographic and environmental factors into account.

\section{Materials and methods}

\section{Population and design}

In 1991, a population based IBD Registry was established through collaboration between the Department of Gastroenteroly and Hepatology of the University Hospital Maastricht and the MEMIC (Center for Data and Information Management, University of Maastricht). The primary objective of the registry was to prospectively study the incidence of IBD and to investigate risk factors within a stable population in a substantial and well-defined geographical and administrative area, namely South Limburg. The protocol was also designed to study the development of clinical features and quality of life in IBD in a medium time prospect. ${ }^{19}$ This study deals primarily with clinical outcome and conditioning factors.

South Limburg is located in the southeast of the Netherlands, bordering Germany to the east and Belgium to the south and west; South Limburg's northern border with the 
rest of the Netherlands is very narrow. The region had a population of about 645,000 between 1991 and 2003, and mobility into and out of the area is known to be low. ${ }^{20}$

All three hospitals in South Limburg, i.e. the University Hospital in Maastricht, the General District Hospitals of Heerlen (Atrium Medical Center, with associated hospitals Kerkrade and Brunssum) and Sittard (Maasland Hospital) participated in the study. Apart from general practitioner (GP) practices there are no other hospitals or outpatient clinics in this area. With regard to possible treatment of IBD patients by GPs, completeness of hospital case ascertainment was verified by Russel et al. and found to be very high. ${ }^{3}$

Inclusion of IBD patients was, after exclusion of infections and other recognized causes of bowel inflammation, based on clinical presentation, endoscopic and/or radiological evidence, supported by mucosal biopsy and/or examination of a surgical specimen. For case definition of $C D$ the criteria of Lennard-Jones were applied. ${ }^{21}$ UC was defined as continuous mucosal inflammation without granulomata, affecting the rectum and/or some or all of the colon in continuity with the rectum. The term "Indeterminate Colitis" was used for cases of IBD in which, after careful investigation, the differential diagnosis between $C D$ and UC remained uncertain. Using the strict criteria mentioned above, patient recruitment for all diagnosed patients (hospitalized and outpatients) was performed by gastroenterologists, physicians, surgeons and paediatricians working in the IBD South Limburg (IBD-SL) area. ${ }^{3}$ If criteria were not completely met, patients could be (temporarily) classified having "possible UC" or "possible CD". The Ethical Committees of all participating centres approved the protocol, and written informed consent was obtained from all patients. If patients were below 18 years of age, parents or a legal representative signed for informed consent. In the present study, all newly diagnosed patients (i.e. with no prior history on IBD), registered between January $1^{\text {st }}, 1991$ and January $1^{\text {st }}, 2003$ were included. These patients were followed from inclusion until data collection for the present study, which took place between July $1^{\text {st }}, 2005$ and January $1^{\text {st }}, 2006$, or until a prior date in case of death or loss to follow-up (LTFU). During data collection for the present study, inclusion criteria were verified for all patients. The enrolment diagnosis was used for data analysis except for patients with a change of diagnosis within one month $(N=40)$ after enrolment; in their case, the corrected diagnosis was used for analysis.

\section{Data collection}

A follow-up patient questionnaire was developed containing items on demographic features, current medication use, appendectomy, smoking and family history of IBD. Additionally, in all hospitals, the original written medical records as well as electronic patient files were reviewed by physicians, specialized nurses or trained senior students. These charts were reviewed with regard to diagnosis, recurrent disease (surgical or non-surgical), admissions, medication, extra-intestinal disease and appendectomy. Medication use was registered as positive per three months' period if 
used at any moment in such time period. All collected data were instantly and uniformly registered in an Access database. With regard to smoking, questionnaire results at inclusion were available for all patients and used for further analysis.

\section{Definitions}

For the purpose of this investigation, patients were characterized according to the Vienna classification at diagnosis. ${ }^{22}$ Definitions for "location" and "recurrence" were used according to earlier publications of the European Collaborative study group on Inflammatory Bowel Disease (EC-IBD). ${ }^{16,23}$ In UC, disease activity proximal to the splenic flexure was classified as "extensive colitis", colonic inflammation distal to the splenic flexure as "distal colitis", and disease limited to the rectum $15 \mathrm{~cm}$ above the linea dentata as "proctitis". In IC patients, the extent of disease was classified as in UC for further analyses.

Recurrences were dated on the follow-up time scale and recorded as "surgical" or "non-surgical". A "surgical recurrence" was defined as an episode of increased disease activity requiring surgical intervention, either with or without medication change. A "non-surgical recurrence" was defined as an episode of increased disease activity requiring an increased dose of current medication or the addition of new medication, but no surgery. Surgical recurrences were further sub-classified into being either "resective" (part of the bowel was resected) or any "other type" of surgery (including abscess drainages, fistula operations, etc.). "all type recurrences" was defined as the sum of "surgical" plus "non-surgical" recurrences.

At diagnosis, smoking status had been divided in three categories; "smoker at diagnosis"; "stopped smoking before diagnosis"; "never smoked before diagnosis". A "current smoker" is defined as a patient that continued smoking during the disease course.

\section{Statistical analysis}

Data concerning age and time periods were summarized as median and range (minmax) or as means and standard deviations (SD), as appropriate. Differences between patient groups were appraised using t-tests, ANOVA or nonparametric (MannWhitney, Kruskal-Wallis) tests. Exclusion and Lost To Follow-Up (LTFU) rates were compared using chi-square tests.

The number of relapses was calculated as the total number of relapses per time period at risk, which was defined from time of diagnosis until July $1^{\text {st }}, 2005$, death, last consultation, or colectomy. Recurrence rates within the first, third, fifth or seventh year were calculated in those patients with respective length of follow-up. Recurrence rates within the first three years after diagnosis were compared for early (1991-1993) and late periods (1998-2000) of inception, using a Poisson model with robust variance estimation. Cumulative first, second and third recurrence rates were calculated with adjustment for LTFU using Kaplan-Meier estimates. Finally, we analyzed the first three 
"all type recurrences" using a multiple-event Cox regression model, assuming separate baseline hazards for the three events and accounting for within-patient dependence by robustly calculated variances.

We obtained hazard ratios (HR) with confidence intervals for a number of potentially explanatory variables: age, gender, phenotype, smoking and appendectomy. With regard to educational level and family history (acquired from the questionnaire) analysis was performed only for patients with available results on these items ( $N=707)$. All analyses were done separately per diagnostic subgroup (CD, UC, IC). Determinants that were positive in less than 10 patients (appendectomy, positive family history of IBD and extra-intestinal manifestations) were not included in the Cox regression analysis, and variables that were missing for a substantial part of the data were omitted from the model when not significant. The validity of the model was checked using the proportional hazards test. ${ }^{24}$ In case of a significant test indication of model violation, we added an interaction term for the offending variable and follow-up time to the model. This allows the hazard ratio to be varying over time; an independent variable could, for instance, be a risk factor at and shortly after diagnosis but be protective during later follow-up. P-values $<5 \%$ were considered significant. All analyses were performed using Stata $8.2 .^{25}$

\section{Results}

\section{Patient population}

Between January $1^{\text {st }}, 1991$ and January $1^{\text {st }}, 2003,1264$ newly diagnosed patients were included in the IBD-SL registry. After reviewing medical records 10 patients who had no IBD (one with haemorrhoids, one with diverticular disease, one with ischemic colitis, one with infectious gastro-enteritis, three with irritable bowel syndrome and three with unknown diagnoses with no report of earlier (BD) were excluded.

Of the 1254 remaining patients, 67 patients were excluded because medical records were unavailable, leaving 1187 patients. Incomplete data on disease location at diagnosis were found in another $27 \mathrm{CD}, 34 \mathrm{UC}$ and 12 IC patients. These patients were included for further analysis because follow-up data were available. There was no significant difference for age, sex and diagnosis between included and excluded patients. Of the 1187 included patients, 68 patients had deceased and 31 patients could not be traced. From the remaining 1088 patients 707 questionnaires were received (response 65\%). There was no difference in response rates with regard to IBD diagnosis, age at diagnosis and phenotype at diagnosis. For gender, however, there were more female patients returning the questionnaire ( $p$-value $<0.0001)$.

To verify whether LTFU was due to decease of patients we contacted the general practitioners of 55 (20\%), randomly selected patients out of the 275 who had not returned the questionnaire and had not visited the outpatient clinic after June $1^{\text {st }}$, 
2005. None of these 55 patients had died during the follow-up, and 51 of them (94\%) had consulted their general practitioner within the last six months before the review period.

\section{Change in diagnosis}

In 50 out of 1187 patients, the diagnosis was changed after the initial diagnosis had been established. Mean time (SD) before change of diagnosis of these 50 patients was 3.9 years (4.0). Change of diagnosis for patients having $C D$ as initial diagnosis was rare (three out of 476 patients $(0.6 \%)$, two into UC and one into IC. For UC this was 21 out of 630 patients (3.3\%) and for IC 26 out of 81 patients (32.1\%). Change in diagnosis for patients with initial UC was mainly to CD (16 out of 21 patients, $76.2 \%$ ), with initial IC the change to CD and UC was almost equally divided (to CD 15/26 patients [57.7\%] and to UC $11 / 26$ patients [42.3\%]).

\section{Phenotype at diagnosis, age and sex distribution}

Table 4.1 shows, data on age, sex, length of follow-up and LTFU stratified according to phenotype at diagnosis.

In $C D$, mean age at diagnosis was 34 years and $71 \%$ of patients had been diagnosed before the age of 40 . Age distribution did not differ significantly between phenotype at diagnosis. Sixty-one percent of patients having CD were female. In $76 \%$ of CD patients, disease behaviour was inflammatory. Upper gastro-intestinal disease location was found in $5 \%$ of the CD patients. Disease location was: terminal ileum in $31 \%$, colonic in $27 \%$ and ileo-colonic in $31 \%$ of CD patients and in $6 \%$ found to be unknown.

In UC and IC, mean age at diagnosis was 42 years for both diseases. Age distribution in UC and IC at diagnosis was not significantly different between the phenotypic subgroups. In UC, $56 \%$ were male, in IC this was $53 \%$. Thirteen percent of UC patients and $27 \%$ of IC patients had an extensive colitis as presenting phenotype at diagnosis. The prevalence of perianal fistula within the first 6 months after diagnosis for CD, UC and IC was $4.8 \%, 0.3 \%$ and $1.2 \%$, respectively. Cumulative prevalence at final follow-up was $10.3 \%$ in CD, $1.8 \%$ in UC and $1.2 \%$ in IC. 


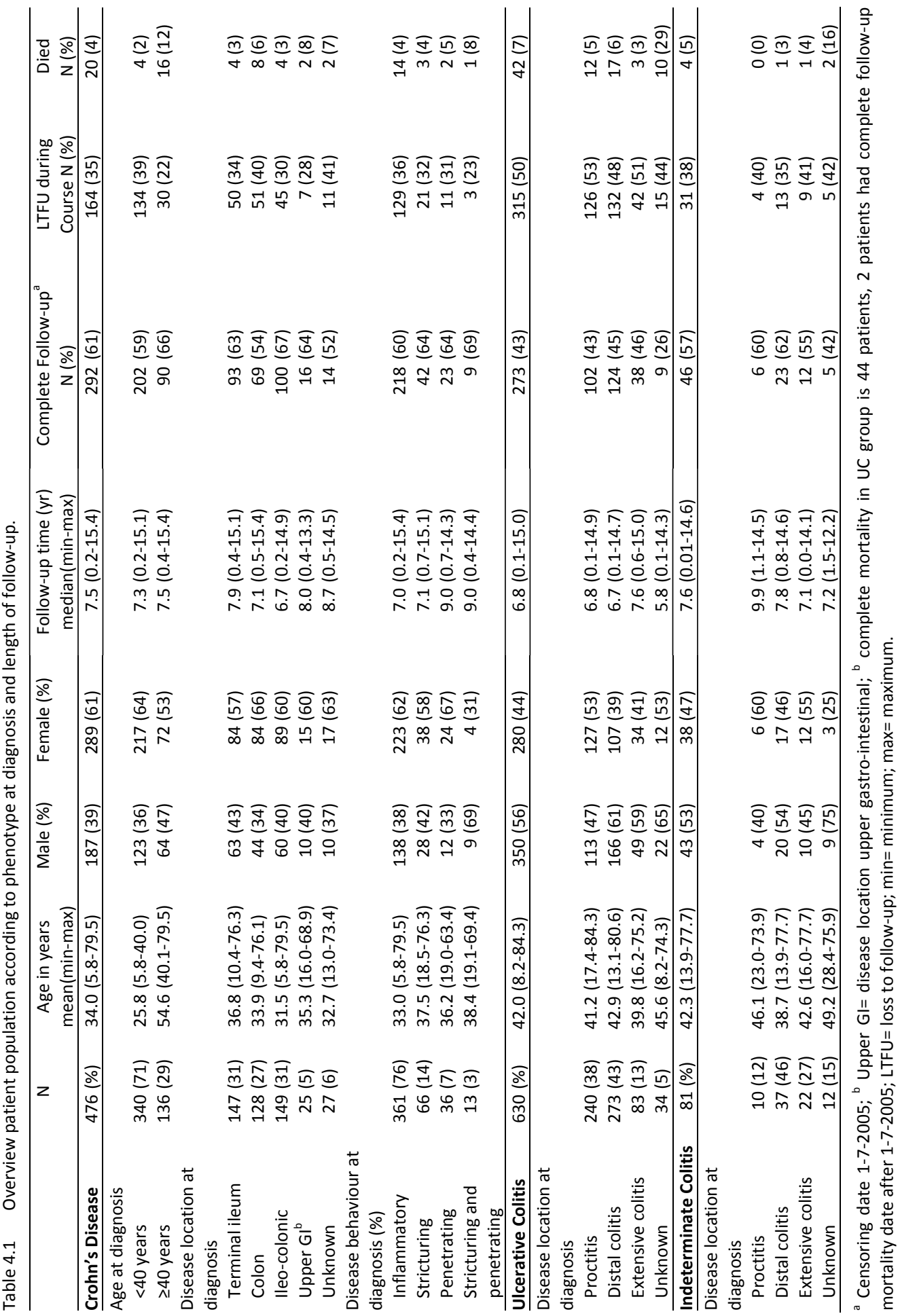




\section{Length of follow-up}

Median follow-up time of all 1,187 IBD patients was 7.1 years (range 0.01-15.4 years) with a significant difference between the three diagnostic groups CD, UC and IC $(p<0.001)$, mainly due to a shorter follow-up time for UC compared to CD $(p<0.001)$, median follow-up time for CD, UC and IC being 7.5 (range 0.2-15.4), 6.8 (range 0.115.0) and 7.6 (range 0.01-14.6) years, respectively. Age, gender and phenotype at diagnosis were unrelated to follow-up time in either diagnostic group. The proportion of patients who had died during the follow-up period, was $4 \%, 7 \%$ and $5 \%$ for CD, UC and IC, respectively.

\section{Recurrence rates}

Of 1187 patients, $10 \%$ did not have any type of recurrence after diagnosis over the total follow-up period, with no difference between the diagnostic groups.

Table 4.2 shows the disease recurrence rate over time for each diagnostic group. In the first year after diagnosis, the incidence was 53 for CD, 44 for UC and 42 for IC per 100 patient-years. Thereafter, the recurrence rate was approximately 30 per 100 patientyears for all diagnostic groups. There was no significant difference in recurrence rate in the first two follow-up years between patients diagnosed in the period of 1991-1993 $(\mathrm{N}=363)$ and that of 2000-2002 $(\mathrm{N}=245)$. There was no trend to change in recurrence rates over the entire period from 1991 to 2002 for either CD, UC or IC.

In Figure 4.1, cumulative recurrence rates over time are shown for "all type recurrences", "surgical recurrences" and "resective surgical recurrence".

Of the $476 \mathrm{CD}$ patients, $9.5 \%(\mathrm{~N}=45)$ were operated on at the time of diagnosis. In these, the type of surgery was mainly resective: ileo-coecal $(\mathrm{N}=33)$, terminal ileum $(N=4)$, other small bowel $(N=1)$, segmental large bowel $(N=3)$, with few other types of surgery ( $\mathrm{N}=4$ : fistulectomy and abscess drainage). Over the total follow-up period, using Kaplan-Meier estimates, $50 \%$ of CD patients had undergone resective surgery. Of these resections, $21 \%, 29 \%, 35 \%$ and $38 \%$ had been performed within 1, 3, 5 and 7 years after diagnosis, respectively.

In the 630 UC patients, acute operation (subtotal colectomy) at the moment of diagnosis was rare, $0.6 \%(\mathrm{~N}=4)$. The total percentage of "resective surgery" using Kaplan-Meier estimates in UC was $11 \%$. Over the total follow-up period, total colectomy rate in UC patients was $8,3 \%(\mathrm{~N}=52)$. Of these, 17 patients had proctitis, 18 distal colitis and 16 extensive colitis and in one patient disease location at diagnosis was unknown, 3\%, 6\%, and 7\% having been performed within 1, 3 and 5 years after diagnosis, respectively. 
Table 4.2 Mean incidence recurrence per 100 patient-years for CD, UC and IC.

\begin{tabular}{lcccccc}
\hline $\begin{array}{l}\text { Years after } \\
\text { diagnosis }\end{array}$ & \multicolumn{2}{c}{\begin{tabular}{c} 
Ulcerative Colitis \\
Incidence per 100 \\
\cline { 2 - 6 }
\end{tabular}} & $\mathrm{N}-\mathrm{N}$ & $\begin{array}{c}\text { Indeterminate colitis } \\
\text { Incidence per } 100 \\
\text { p-y }\end{array}$ & $\mathrm{N}$ & $\begin{array}{c}\text { Incidence per } 100 \\
\text { p-y }\end{array}$ \\
\hline 1 & 466 & 53 & 588 & 44 & 77 & 42 \\
2 & 457 & 39 & 552 & 33 & 73 & 32 \\
3 & 435 & 32 & 511 & 31 & 71 & 28 \\
4 & 389 & 35 & 446 & 29 & 61 & 39 \\
5 & 337 & 33 & 402 & 27 & 55 & 38 \\
6 & 289 & 28 & 353 & 26 & 48 & 36 \\
7 & 249 & 28 & 303 & 24 & 45 & 40 \\
8 & 216 & 27 & 264 & 29 & 37 & 27 \\
9 & 185 & 25 & 204 & 27 & 34 & 20 \\
10 & 148 & 28 & 165 & 31 & 25 & 34 \\
11 & 122 & 33 & 121 & 27 & 20 & 41 \\
12 & 82 & 33 & 85 & 29 & 16 & 11 \\
\hline
\end{tabular}

$\mathrm{N}=$ number of patients, $\mathrm{CD}=$ Crohn's disease, $\mathrm{UC}=$ Ulcerative Colitis, $\mathrm{IC}=$ Indeterminate Colitis, $\mathrm{p}-\mathrm{y}=$ patient years

\section{Medication use}

Table 4.3 shows medication use at different time points after diagnosis (1-11 years). Overall, the use of mesalazine (5-ASA) decreased during the years after diagnosis. The use of steroids in CD was relatively stable over time. In UC a trend of decreasing steroid use was seen however this was not significant. As the percentage of patients using immune suppressive medication was small, the different categories were summarized for further analysis. Immune suppressive medications registered were; azathioprine, 6-mercaptopurine, thioguanine, cyclosporine and methotrexate. The use of immunosuppressive drugs showed an increasing trend in time, mainly for CD. Medication at one year after diagnosis was compared between IBD patients diagnosed in the periods 1991-1993 and 2001-2003, respectively. In CD, the frequency of using steroid and immunosuppressive medication had increased in patients diagnosed between 2001-2003 compared to 1991-1993 ( $p<0.05$ ). In UC, the use of corticosteroids did not significantly differ between the two time periods $(p=0.051)$, however, the use of immunosuppressive medication was higher in patients diagnosed between 2001 and $2003(p<0.005)$. 

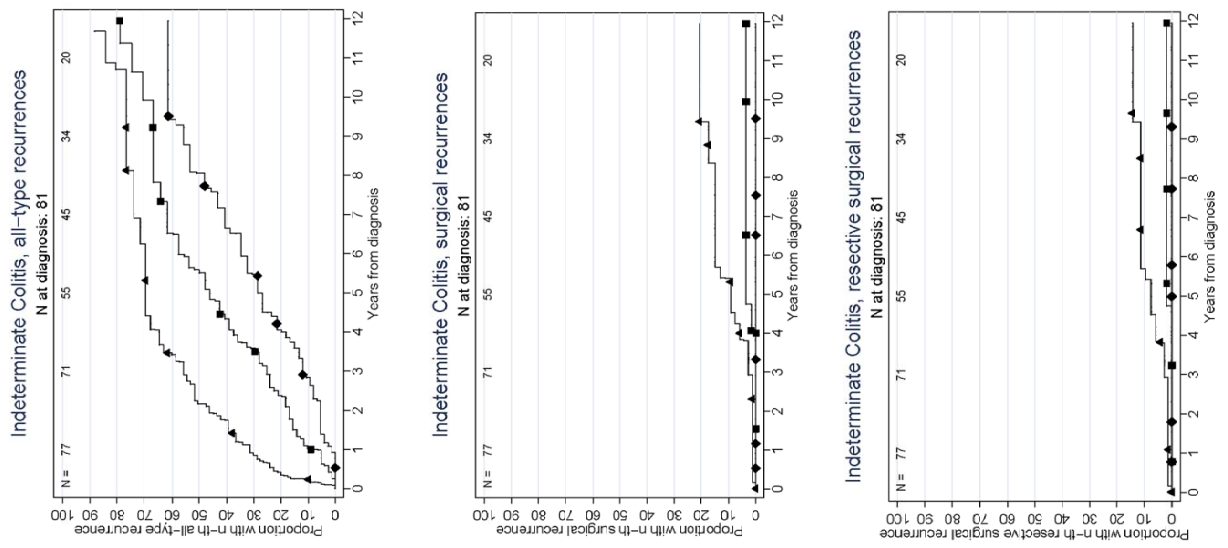

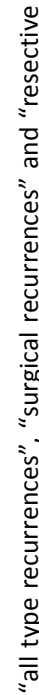
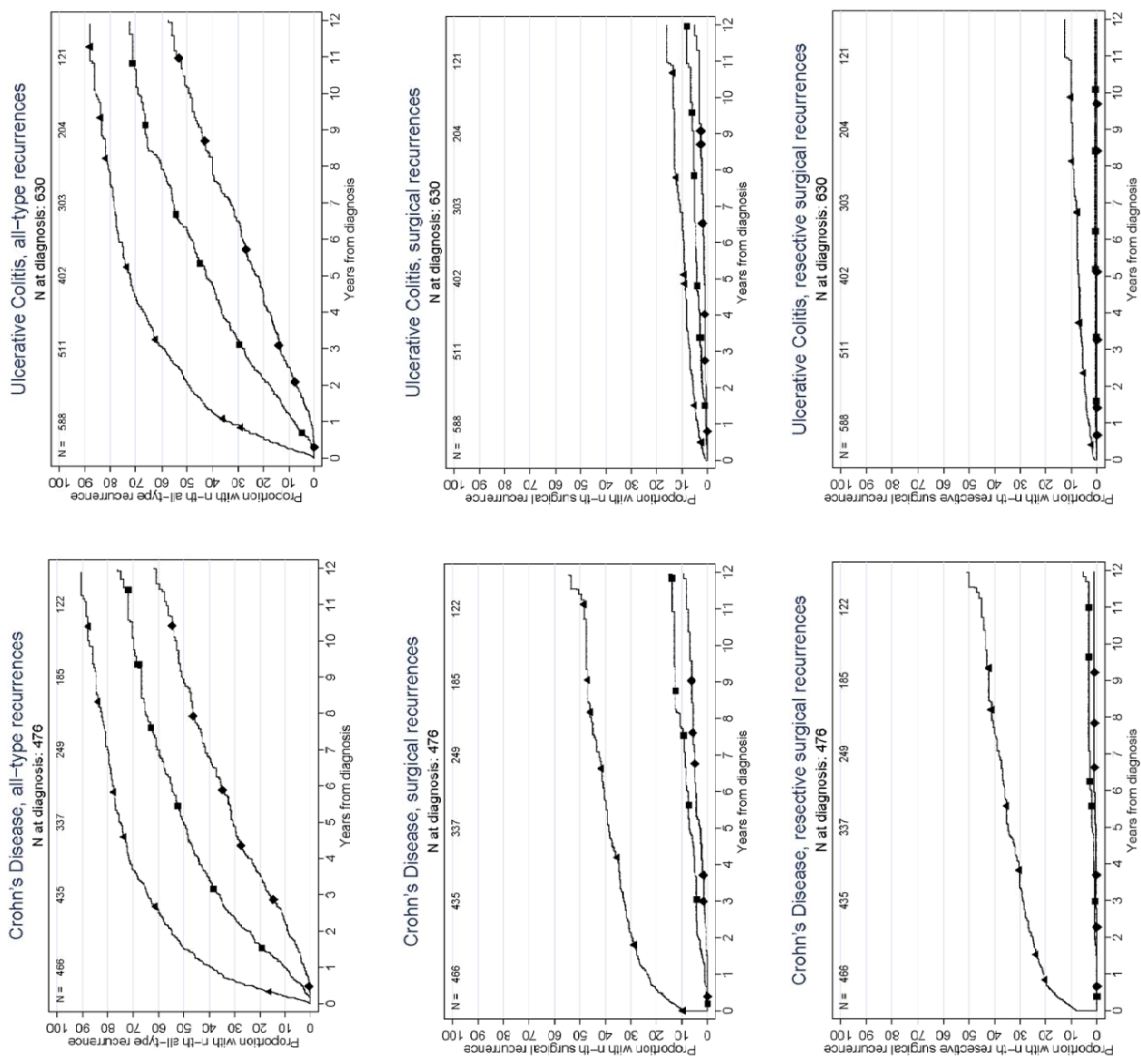
Table 4.3 Prevalence of Medication (\% of patients) at different time points.

\begin{tabular}{lcccccc}
\hline Crohn's disease & $\mathrm{t}=1$ year & $\mathrm{t}=3$ years & $\mathrm{t}=5$ years & $\mathrm{t}=7$ years & $\mathrm{t}=9$ years & $\mathrm{t}=11$ years \\
& $\mathrm{N}=466$ & $\mathrm{~N}=435$ & $\mathrm{~N}=337$ & $\mathrm{~N}=249$ & $\mathrm{~N}=185$ & $\mathrm{~N}=122$ \\
\hline No medication & 19.7 & 26.2 & 32.6 & 34.5 & 31.9 & 37.7 \\
Sulfazalazine & 4.3 & 3.2 & 3.9 & 4.4 & 3.8 & 4.1 \\
5-asa & 68.2 & 63.0 & 57.9 & 59.0 & 60.0 & 54.1 \\
Steroids & 33.5 & 28.3 & 22.8 & 24.5 & 22.2 & 30.3 \\
Immunosuppressive & 12.0 & 20.7 & 23.4 & 20.5 & 23.2 & 29.5 \\
Infliximab & 1.5 & 2.8 & 1.2 & 2.8 & 4.9 & 5.7 \\
\hline Ulcerative Colitis & $\mathrm{t}=1$ year & $\mathrm{t}=3$ years & $\mathrm{t}=5$ years & $\mathrm{t}=7$ years & $\mathrm{t}=9$ years & $\mathrm{t}=11$ years \\
& $\mathrm{N}=588$ & $\mathrm{~N}=511$ & $\mathrm{~N}=402$ & $\mathrm{~N}=303$ & $\mathrm{~N}=204$ & $\mathrm{~N}=121$ \\
\hline No medication & 26.4 & 32.7 & 32.3 & 36.0 & 39.2 & 38.8 \\
Sulfazalazine & 5.4 & 6.1 & 6.0 & 6.6 & 8.3 & 4.1 \\
5-asa & 73.3 & 67.9 & 64.7 & 61.7 & 61.8 & 59.5 \\
Steroids & 19.9 & 16.4 & 17.9 & 16.2 & 16.7 & 11.6 \\
Immunosuppressive & 5.4 & 8.0 & 11.7 & 13.2 & 12.3 & 11.6 \\
\hline Indeterminate Colitis & $\mathrm{t}=1$ year & $\mathrm{t}=3$ years & $\mathrm{t}=5$ years & $\mathrm{t}=7$ years & $\mathrm{t}=9$ years & $\mathrm{t}=11$ years \\
& $\mathrm{N}=77$ & $\mathrm{~N}=71$ & $\mathrm{~N}=55$ & $\mathrm{~N}=45$ & $\mathrm{~N}=34$ & $\mathrm{~N}=20$ \\
\hline No medication & 27.3 & 26.8 & 32.7 & 22.2 & 29.4 & 35.0 \\
Sulfazalazine & 6.5 & 5.6 & 9.1 & 6.7 & 5.9 & 10.0 \\
5-asa & 67.5 & 66.2 & 63.6 & 64.4 & 58.8 & 40.0 \\
Steroids & 19.5 & 18.3 & 16.4 & 17.8 & 17.6 & 30.0 \\
Immunosuppressive & 9.1 & 12.7 & 20.0 & 35.6 & 35.6 & 30.0 \\
\hline
\end{tabular}

\section{Infliximab}

After 1997, 6.5\% of 1187 patients $(\mathrm{N}=77)$ had been treated with infliximab. Out of these 77 patients, diagnosis at inclusion was CD in 62 patients, UC in 10 patients and IC in five patients. Eight $C D$ patients treated with infliximab had small bowel disease, whereas location in the large bowel and combined location in small and large bowel was equally divided in the remaining patients. In eight patients (five with initial UC and three with initial IC), diagnosis had been changed prior to infliximab treatment, in all cases to $C D$. The absolute number of patients treated with infliximab had increased gradually during the years from one patient in 1998 to 39 patients in 2005. Independently of follow-up duration, in $2005,7.8 \%$ of patients with the diagnosis of CD $(\mathrm{N}=476)$ were under treatment with infliximab. In Table 4.3 prevalence of infliximab use for $C D$ is shown according to length of follow-up time. As infliximab was introduced during the study period, we observed a higher prevalence in the third year after diagnosis, indicating that in patients diagnosed after 2000, infliximab was started increasingly earlier after diagnosis. In patients with longer follow-up periods, the frequency of starting infliximab increased with time of follow-up.

\section{Disease severity parameters}

In Table 4.4, disease severity parameters are shown according to phenotype at diagnosis in CD, UC and IC patients. 
Table 4.4 Disease severity parameters during the disease course according to phenotype at diagnosis.

\begin{tabular}{|c|c|c|c|c|c|}
\hline & \multicolumn{4}{|c|}{ Cumulative \% in the course of disease } & \multirow[b]{2}{*}{$\begin{array}{c}\text { Recurrence per } 100 \\
p-y \\
\text { mean (SD) }\end{array}$} \\
\hline & $\mathrm{N}$ & $\begin{array}{c}\text { \% Operated } \\
\text { (resective) }\end{array}$ & $\begin{array}{c}\% \text { Steroid } \\
\text { use }\end{array}$ & $\begin{array}{l}\text { \% Immuno- } \\
\text { suppressive }\end{array}$ & \\
\hline \multicolumn{6}{|l|}{ Crohn's Disease } \\
\hline Overall & 476 & $43 \%$ & $73 \%$ & $44 \%$ & $41(98)$ \\
\hline \multicolumn{6}{|l|}{ Age at diagnosis } \\
\hline$<40$ years & 340 & $44 \%$ & $76 \%$ & $47 \%$ & $46(113)$ \\
\hline$\geq 40$ years & 136 & $43 \%$ & $65 \%^{a}$ & $36 \%^{a}$ & $29(35)^{b}$ \\
\hline \multicolumn{6}{|l|}{ Disease location at diagnosis } \\
\hline Terminal ileum & 147 & $59 \%^{c}$ & $67 \%$ & $31 \%^{\mathrm{g}}$ & $33(37)^{\mathrm{h}}$ \\
\hline Colon & 128 & $23 \%$ & $73 \%$ & $49 \%$ & $39(36)$ \\
\hline Ileo-colonic & 149 & $49 \%^{d}$ & $76 \%$ & $52 \%$ & $51(164)$ \\
\hline Upper GI & 25 & $52 \%{ }^{e}$ & $96 \%^{f}$ & $60 \%$ & $51(57)$ \\
\hline Unknown & 27 & $15 \%$ & $59 \%$ & $33 \%$ & $34(60)$ \\
\hline \multicolumn{6}{|l|}{ Disease behaviour at diagnosis } \\
\hline Inflammatory & 361 & $35 \%$ & $74 \%$ & $46 \%$ & 43 (109) \\
\hline Stricturing & 66 & $76 \%$ & $73 \%$ & $35 \%$ & $37(45)$ \\
\hline Penetrating & 36 & $56 \%$ & $61 \%$ & $44 \%$ & $35(52)$ \\
\hline Stricturing and penetrating & 13 & $85 \%^{j}$ & $69 \%$ & $38 \%$ & $39(69)$ \\
\hline \multicolumn{6}{|l|}{ Ulcerative Colitis } \\
\hline Overall & 630 & $11 \%$ & $57 \%$ & $20 \%$ & 35 (49) \\
\hline \multicolumn{6}{|l|}{ Disease location at diagnosis } \\
\hline Proctitis & 240 & $10 \%$ & $52 \%$ & $17 \%$ & $39(59)$ \\
\hline Distal colitis & 273 & $9 \%$ & $59 \%$ & $23 \%$ & $35(41)$ \\
\hline Extensive colitis & 83 & $20 \%^{k}$ & $73 \%$ & $24 \%$ & $31(44)$ \\
\hline Unknown & 34 & $3 \%$ & $47 \%$ & $9 \%$ & $19(27)$ \\
\hline \multicolumn{6}{|l|}{ Indeterminate Colitis } \\
\hline Overall & 81 & $14 \%$ & $62 \%$ & $36 \%$ & $34(42)$ \\
\hline \multicolumn{6}{|l|}{ Disease location at diagnosis } \\
\hline Proctitis & 10 & $30 \%$ & $80 \%$ & $40 \%$ & $62(82)$ \\
\hline Distal colitis & 37 & $16 \%$ & $59 \%$ & $38 \%$ & $35(32)$ \\
\hline Extensive colitis & 22 & $5 \%$ & $68 \%$ & $45 \%$ & $26(33)$ \\
\hline Unknown & 12 & $8 \%$ & $42 \%$ & $8 \%$ & $23(23)$ \\
\hline
\end{tabular}

${ }^{a} p<0.05,{ }^{b} p<0.0005,{ }^{c} p<0.0001$ terminal ileum versus colonic location, ${ }^{d} p<0.0001$ ileocolonic versus colonic location, e $p<0.05$ upper $\mathrm{Gl}$ versus colonic location, ${ }^{\mathrm{f}} \mathrm{p}<0.05$ upper $\mathrm{Gl}$ versus terminal ileum, colon, ileocolonic and unknown, ${ }^{\mathrm{g}} \mathrm{p}<0.05$ terminal ileum versus colonic and ileo-colonic location, ${ }^{\mathrm{h}} \mathrm{p}<0.05$ terminal ileum versus colonic location, ${ }^{i} p<0.0001$ inflammatory versus stricturing, ${ }^{j} p<0.001$ inflammatory versus stricturing and penetrating, ${ }^{k} p<0.05$ pancolitis versus left sided colitis, ${ }^{l} p<0.05$ extensive colitis versus proctitis and unknown.

For $\mathrm{CD}$, the use of steroids and immunosuppressive medication was significantly higher in the group $<40$ years of age at diagnosis $(p<0.05)$, and the frequency of recurrences per 100 patient-years was significantly higher in the group of $<40$ years of age at diagnosis $(p<0.0005)$. With regard to disease location in $C D$, patients having upper $G I$ location used significantly more steroids compared to all other locations $(p<0.05)$. Also the use of immunosuppressive medication was significantly lower in patients having 
small bowel location compared to colonic and ileo-colonic location $(p<0.05)$. Disease behaviour at diagnosis in $C D$ was not related to the use of steroids and immunosuppressive medication in $C D$. The percentage of operations in $C D$ was higher in patients having small bowel $(p<0.0001)$ and upper GI location $(p<0.05)$ than in those with colonic disease alone and was also increased in those with stricturing or combined stricturing and penetrating disease $(p<0.001)$. Disease behaviour in $C D$ did not influence the number of recurrences per 100 patient-years but small bowel location had significant less recurrences per 100 patient-years in relation to colon location $(p<0.05)$.

In UC, the use of steroids was significantly higher in patients having extensive colitis at presentation in comparison to patients having proctitis or unknown disease location $(p<0.05)$. The use of immunosuppressive medication was not different in the various phenotypic groups at diagnosis. For patients having extensive colitis, the number of operations was significantly higher than in the total group $(p<0.05)$.

For IC, the number of patients per disease location at diagnosis was small and showed no significant differences for either the need for surgery, steroid use, immunosuppressive use or number of recurrences per 100 patient-years.

\section{Prognostic factors for disease course}

Table 4.5 shows hazard ratio results with regard to prognostic factors for disease course off CD, UC and IC. Data were analyzed for the first three "all type recurrences".

\section{Age, gender disease location and disease behaviour}

In $\mathrm{CD}$, age at diagnosis had a HR per periods of 10 years of 0.89 (95\%-Cl: $0.84-0.95)$, implicating that the average risk of "all type recurrences" decreased by $11 \%$ every ten years during follow-up. Disease location did not significantly influence "all type recurrence" rates in $\mathrm{CD}$, however, the HR of colon location showed a trend to increase during follow-up. Gender and disease behaviour according to the Vienna classification did not provide additional significant differences.

In UC, the proportional hazards test for "all type recurrences" was significant for age. When an interaction term of follow-up time and age at diagnosis was added, the initial HR was 1.08 (95\%-Cl: 1.01-1.16) per 10 years with a significant decrease of this ratio over time of follow-up, resulting in a HR of 1.00 at 2.4 years follow-up and an HR of 0.77 (95\%-Cl: $0.68-0.88)$ per 10-year periods of age at 10 years of follow-up. Furthermore, the HR of extensive colitis for "all type recurrences" in UC was 0.78 (95\%$\mathrm{Cl}$ : 0.63-0.96) relative to proctitis (HR 1.00) or distal colitis (HR 1.00, 95\%-Cl: 0.87-1.16). Gender was not found to be prognostic in the disease course. 
Table 4.5 Multiple event Cox regression analysis on first three "all type recurrences".

\begin{tabular}{|c|c|c|c|}
\hline & Hazard ratio & 95\%-Confidence Interval & p-value \\
\hline \multicolumn{4}{|l|}{ Crohn's Disease } \\
\hline \multicolumn{4}{|l|}{ Age } \\
\hline$<40$ years at diagnosis ${ }^{a}$ & 0.89 & $0.84-0.95$ & 0.003 \\
\hline Gender & 0.99 & $0.85-1.15$ & n.s. \\
\hline \multicolumn{4}{|l|}{ Disease location $^{\mathrm{b}}$} \\
\hline Colon & 1.05 & $0.84-1.31$ & n.s. \\
\hline Ileo-colonic & 0.99 & $0.80-1.22$ & n.s. \\
\hline Upper GI & 0.81 & $0.55-1.19$ & n.s. \\
\hline \multicolumn{4}{|l|}{ Smoking } \\
\hline Current smoking & 1.25 & $1.06-1.48$ & 0.007 \\
\hline Stopped smoking before diagnosis & 1.13 & $0.88-1.45$ & n.s. \\
\hline Appendectomy before diagnosis & 1.12 & $0.83-1.52$ & n.s. \\
\hline Family history of IBD & 0.94 & $0.74-1.19$ & n.s. \\
\hline Educational level & 0.99 & $0.93-1.05$ & n.s. \\
\hline \multicolumn{4}{|l|}{ Ulcerative Colitis $^{c}$} \\
\hline \multicolumn{4}{|l|}{ Age } \\
\hline Age at diagnosis ${ }^{d}$ & 1.08 & $1.01-1.16$ & 0.02 \\
\hline Age after 10 years of follow up & 0.77 & $0.68-0.88$ & 0.000 \\
\hline Gender & 1.11 & $0.96-1.27$ & n.s. \\
\hline \multicolumn{4}{|l|}{ Disease location $^{\mathrm{e}}$} \\
\hline Distal colitis & 1.00 & $0.87-1.16$ & n.s. \\
\hline Extensive colitis & 0.78 & $0.63-0.96$ & 0.02 \\
\hline \multicolumn{4}{|l|}{ Smoking } \\
\hline Current smoking & 0.99 & $0.83-1.19$ & n.s. \\
\hline Stopped smoking before diagnosis & 0.96 & $0.81-1.13$ & n.s. \\
\hline Family history of IBD & 1.14 & $0.93-1.39$ & n.s. \\
\hline Educational level & 1.00 & $0.95-1.05$ & n.s. \\
\hline \multicolumn{4}{|l|}{ Indeterminate Colitis $^{f}$} \\
\hline Age & 0.99 & $0.98-1.00$ & n.s. \\
\hline Gender & 1.10 & $0.72-1.67$ & n.s. \\
\hline \multicolumn{4}{|l|}{ Disease location ${ }^{\mathrm{g}}$} \\
\hline Distal colitis & 0.59 & $0.33-1.06$ & n.s. \\
\hline Extensive colitis & 0.66 & $0.35-1.25$ & n.s. \\
\hline \multicolumn{4}{|l|}{ Smoking } \\
\hline Current smoking & 0.96 & $0.60-1.54$ & n.s. \\
\hline Stopped smoking before diagnosis & 0.96 & $0.59-1.57$ & n.s. \\
\hline Educational level & 1.04 & $0.90-1.21$ & n.s. \\
\hline
\end{tabular}

${ }^{a}$ per 10 years follow-up period, ${ }^{b}$ terminal ileum location having assumed HR of $1,{ }^{c}$ appendectomy before diagnosis, numbers to small for analysis, ${ }^{d}$ per 10 years follow-up period, ${ }^{e}$ with proctitis having assumed $\mathrm{HR}$ of $1,{ }^{f}$ number of patients to small for further analysis with regard to appendectomy before diagnosis and family history of IBD, ${ }^{\mathrm{g}}$ with proctitis having assumed HR of 1.

In IC patients, the initial model contained age, gender and location as variables. Smoking behaviour and educational level were added. None of these were significant predictors of disease course, nor was there any indication of non-proportionality of the hazards. 


\section{Smoking}

In CD, $53 \%$ smoked at diagnosis compared to $20 \%$ for UC and $30 \%$ for IC $(p<0.0001)$. The percentage of patients having stopped smoking before diagnosis was $16 \%$ for $C D$, $44 \%$ for UC and $34 \%$ for IC $(p<0.0001)$. Mean time from cessation of smoking to diagnosis was not significantly different between the diagnostic groups. For CD, UC and IC (31\%, 36\% and 36\% respectively) had never smoked. When we calculated Hazard Ratios (HRs) with regard to the first three recurrences in CD, "current smoking" had a HR of 1.25 (95\%-Cl: 1.06-1.48) for "all type recurrences". In UC smoking habits after diagnosis did not significantly influence the "all type recurrences" rate.

\section{Appendectomy}

Before diagnosis, appendectomy had been performed in 34 CD, 6 UC and 2 IC patients. As numbers were small we found no significant influence of appendectomy before diagnosis on disease course in CD, UC and IC patient. After UC diagnosis, 61 out of 630 patients underwent an appendectomy, however there was no significant influence on the further disease course in UC.

\section{Family history and extra-intestinal manifestations}

From questionnaire results $(\mathrm{N}=707)$ a positive family history for IBD (at least one first degree relative diseased) was found in 39 CD, 49 UC and 5 IC patients. For second degree family members, this was 17,13 and 3, respectively, for $C D, U C$ and IC. Even when combining frequencies from the first and second degree family members with IBD the number was too small to show significant influence on the disease course.

The life-time incidence of extra-intestinal manifestations was highest in CD, 15\% (71 out of 576 patients). For UC and IC this was 7\% (47 out of 630 patients) and $9 \%$ (7 out of 81 patients), respectively. Before the IBD diagnosis there were $10 \mathrm{CD}$, five UC and one IC patient(s) having extra-intestinal disease. This number was too small for further analysis.

\section{Educational level}

Educational level, as retrieved from questionnaire data in 707 patients, did not show any significant influence on the disease course for "all type recurrences" in CD, UC and IC.

\section{Discussion}

This population based study aimed to evaluate disease course in IBD patients in the context of internationally recognized phenotypes at first presentation. Our results indicate that in CD patients, young age at diagnosis and terminal ileum location are the 
most prominent predictors of disease recurrence. Small bowel location gave a significantly increased risk for surgery, as did stricturing and combined stricturing and penetrating disease.

In UC, higher age at diagnosis showed an increased risk for "all type recurrences" in the first year, whereas after 2.4 or more years of follow-up, older age at diagnosis was protective. Also, in UC, extensive colitis at diagnosis was related to increased risk for colectomy.

In general, in this cohort, disease course was relatively benign as over a mean followup period of 7 years, $10 \%$ of patients experienced no recurrence and around $40 \%$ of the patients did not use any medication. In the diagnostic subgroups CD, UC, and IC, recurrence incidence was highest in the first year and subsequently stabilized at 30 recurrences per 100 patient-years.

\section{Crohn's disease}

In the present cohort study, ten percent of CD patients were still relapse free after 12 years of follow-up, consistent with previous reports, in which recurrence-free disease course was found in $14 \%$ and $10 \%$ at five and ten years follow-up respectively. ${ }^{14,16}$ In a study from Copenhagen, $22 \%$ of patients had no relapse after a mean follow-up duration of 8.5 years. ${ }^{10}$

Nearly $10 \%$ of the $C D$ patients had needed resective surgery at the moment of diagnosis. Earlier reports provided figures between 4.5 and $16 \%{ }^{12,14,16}$ Out of all patients with resective surgery, $21 \%$ were operated on during the first year. This is lower than mentioned in previous reports ${ }^{10,14,26,27}$, but higher than in the recent European cohort study. ${ }^{16}$ Cumulative first resective surgery rate in CD after 7 and 12 years was $38 \%$ and $50 \%$, respectively.

After 12 years of follow-up, re-operation rate was around $10 \%$ for all types of surgical intervention and $2 \%$ for resective surgery, this being lower than mentioned in previous reports. ${ }^{10,16,26,27}$ This low re-operation rate percentage might be due to local treatment habits with a low tendency for surgery, or due to the fact that this population based cohort contains a more "benign" spectrum of IBD patients.

In $C D$, the correlation between disease phenotype at diagnosis and post-surgical recurrence has been reported in several referral-centre based studies, indicating penetrating disease as a risk factor. ${ }^{28,29}$ Other reported phenotypic risk factors in $C D$ for post-surgical disease recurrence were young age at diagnosis ${ }^{13,16,29}$, male gender $^{28,30}$ female gender ${ }^{31}$, upper gastro-intestinal disease location ${ }^{16}$, small bowel involvement $^{11,13}$, perforating disease ${ }^{12,13,28-30,32-35}$ and perianal disease ${ }^{31}$. In a recent European study ${ }^{16}$, patients from the North of Europe had a higher risk for surgery, with colonic disease location at diagnosis as well as non-smoking during the disease course were found to be protective.

In general, in the present study, CD patients with disease location in the terminal ileum, ileo-colonic and upper gastrointestinal as well as patients with stricturing and 
combined stricturing-penetrating behaviour had a relatively higher surgery risk than other presentations.

With regard to immune-suppressive and steroid medication we found influence of phenotype on the need for these medications in CD. Patients under 40 years of age used immune-suppressive medication and steroid more often and this group of CD patients experienced significantly more recurrences, most probably reflecting a worse disease course. As the use of immunomodulatory maintenance treatment reduces, both overall general and postoperative disease recurrence rates ${ }^{33,36-39}$ the observed correlation is probably causal. In an earlier published Dutch study ${ }^{12}$, the use of immune-suppressive medication was very high (56\% at any time point in the course of disease), however, the percentage of patients with structuring and penetrating disease in the concerned patient population was much higher than in our study population, possibly due to the fact that patients were not included in a population based manner. In $C D$, we found an overall decreasing risk for disease recurrence with increasing age after diagnosis, but it seems that the HR for patients with colon location increased with follow-up time, which might be due to the restrictions on existing surgical options. However, one might expect that the use of immunosuppressive medication would have been significantly higher as it plays an important role in controlling disease activity. Regarding extrinsic factors, the number of CD patients smoking at the moment of diagnosis was high and the HR for current smoking at diagnosis was 1.25 , a result confirming earlier reports. ${ }^{40}$ Hopefully, ongoing anti-smoking campaigns in many European countries will influence incidence rates and disease course of $C D$ in a favourable way.

\section{Ulcerative Colitis}

In the present study, $12 \%$ of UC patients were still relapse-free after 12 years of followup, which is low in compared to $20 \%$ observed by Henriksen ${ }^{15}$ after five years of follow-up and $22 \%$ reported by Hoie ${ }^{23}$ after ten years of follow-up. The follow-up duration and the high colectomy rate in the past in northern countries is most likely one of the explanations as Langholz et al. from Denmark found it to be $10 \%$ at 25 years follow-up. ${ }^{41}$

Total colectomy rate after five years was approximately $7 \%$ with a gradual increase to $13 \%$ at 12 years follow-up. This is comparable with recent published data with five and 10 years follow-up. ${ }^{15}$ The 10 -years cumulative colectomy rate in patients having extended disease at diagnosis in an unselected European cohort was $8.7 \%$ (10.4\% in the northern and $3.9 \%$ in the southern participating centres) and the cumulative colectomy risk was $20 \%{ }^{42}$, which was significantly higher than in patients with less extended disease at diagnosis. Also in an earlier publication a long-term colectomy rate of $20 \%$ in UC has been reported. ${ }^{43-45}$ 
In this study, total relapse rate at 10 years after diagnosis in UC was $85 \%$. Previously reported observations were comparable, with relapse rates between $67 \%$ and $97 \% .^{23,41,46-48}$

In the Cox proportional hazard regression model with regard to "all type recurrences", there was a significant protective effect of the disease extent (i.e. extensive colitis, as compared to left sided colitis) on recurrence rate. This finding was in contrast with data reported by Hoie et al. ${ }^{42}$ who found no significant influence of disease extent in UC. The high surgery rate in "extensive colitis" patients, might have given a selection bias leaving patients with a relative "benign" disease course for further analysis, as patients were censured with regard to recurrent disease after colectomy. This could also have influenced our study results. The protective risk for "all type recurrence" in "extensive colitis" that we found, could not be explained by gender, age or differences in medication use influencing final results.

Other previously described risk factors for recurrence are female gender and young age. ${ }^{11,15}$ The binominal influence of age on recurrence rates found in the present study was also previously reported; Hoie and coworkers reported a decreasing risk with increasing age at diagnosis ${ }^{11,23,49}$, whereas others reported the opposite. ${ }^{50,51} \mathrm{We}$ presume that possibly the vulnerability in older patients diagnosed with UC is higher. However, with time evolving, there might develop a more benign disease course, as older patient could be more willing to follow the doctor's advice, i.e. medication use, follow-up visits. The value of introducing age as a subgroup in the phenotypic classification of UC was discussed in the Montreal classification working party report. ${ }^{52}$ With regard to our results it could be of future importance to re-evaluate this statement.

A protective effect of smoking on disease recurrence in UC could not be confirmed in this study. However, at the time of diagnosis, there was a remarkable difference in smoking habits between CD and UC patients, possibly influencing disease incidence and phenotype development before and at the time of diagnosis. We found no differences in medication use in relation to the extent of disease at diagnosis in the entire UC group. Throughout the observation time, the percentage of 5-ASA use decreased ( 73 to $60 \%$ ). This could be a reflection of the increasing use of immunosuppressants. In the future it is imaginable that the increasing evidence of the cancer preventive effect of mesalazine could invert the observed negative trend.

\section{Indeterminate Colitis}

The number of patients with IC in this study was too small for calculations regarding prognostic factors. Nevertheless, the descriptions of the follow-up results of these patients remains of interest, since patient data on IC are most often not included in population based IBD studies. 
Studies of population based, prospectively and uniformly diagnosed regional inception cohorts are of great importance, as they can provide clues about intrinsic and extrinsic risk factors and possibly illustrate differences in disease outcome with respect to the combined effect of "natural course" and therapeutic interventions. However, definitions of outcome based on treatment parameters such as surgery and/or medication change, as they were used in this study still carry the disadvantage that stereotype treatment habits rarely exist, even in limited geographic areas. Therefore, in an epidemiological situation, the effects of natural disease course and of treatment will always remain difficult to discern scientifically.

The design of this study might have other limitations. First of all there is a risk of misdiagnosis at inclusion. Using the strict inclusion criteria, diagnosis was verified with regard to original reports (for example endoscopic reports, pathology and radiology reports). In $4 \%(\mathrm{~N}=50)$ of patients diagnosis changed during follow-up. If misdiagnosis at enrolment would have been an important issue one might expect that this percentage would have been higher. In spite of continuous thorough registration in all study sites, there are still missing patients. For example those patients treated by a general practitioner for mild disease, or those lost due to incompleteness of recording by specialists. Further bias can be due to loss to follow up during the course of disease. We found a significantly shorter follow-up time for UC than for CD, but there was no influence of gender, age and phenotype on this duration. As it is considered common practice in the Netherlands to keep IBD patients under specialized control at least once a year, the low percentage of patients still in follow-up (50-60\%) may have been due a generally benign disease course. The response percentage on the mailed questionnaire was $65 \%$ with significantly more women returning the questionnaire. This percentage can be seen as considerable: in the European follow-up study described by Wolters et $a l^{53}$, response numbers are discussed. A threshold of $60 \%$ was needed to be included into further analysis. This was reached in CD for 10 out of 13 and in UC in 9 out of 13 countries. In the present study, the Vienna classification had to be done retrospectively in a substantial number of patients. This might have caused bias. To reduce this risk, we used uniform definitions for classifying patients in the study area at diagnosis and for reporting in the medical charts. Modifications of the Vienna classification have been proposed. Amendments proposed were the use of perianal disease as a modifier in the behaviour category and co-classification of upper gastrointestinal involvement (L4) together with location categories L1-L3, and an early age of onset category. ${ }^{54}$ We chose not to apply this new classification in order to be able to compare our results with previously published reports. However, half of all perianal fistula in $C D$ were already present within the first six months after diagnosis. This confirms that adding perianal disease as a modifier in the behaviour category is important in future research. Regarding the definition of recurrence, significant upgrade of medication and/or operation was used as criterium. Due to inter-physician variability in treatment choice bias could develop. The amount of recurrences could be underestimated, especially for change in medication. We used medical records to 
register recurrent disease. However, in some centres involved in this study physicians might have instructed their patients to start or increase medication without prior consultation in case of mildly increased disease activity.

In conclusion, this Dutch population based study of IBD confirmed that there are identifiable phenotypic, demographic and environmental risk factors at the onset of disease with respect to further outcome, when expressed as medical and surgical recurrence rates. In CD, small bowel location, stricturing disease, young age and smoking were predictive for disease recurrence. In UC, extensive colitis was a negative prognostic predictor with regard to surgical. Older age at diagnosis in UC initially increased recurrence risk, but subsequently was protective. Recognizing these factors will help to identify patients who could profit from early intervention in order to prevent a negative disease course. Continued follow-up of this inception cohort will in the ongoing observation period offer the opportunity to analyze the effect of early treatment with immune suppressive and biological medication. Also, as genotypic characteristics might explain part of the differences in phenotypic presentation and disease development, knowledge about those factors has to be added in future models that are aimed at establishing reliable risk factor profiles for the disease course in individual patients. 


\section{References}

1. Sartor RB. Pathogenesis and immune mechanisms of chronic inflammatory bowel diseases. Am J Gastroenterol. 1997;92:5S-11S.

2. Shivananda S, Lennard Jones J, Logan R, Fear N, Price A, Carpenter L, van Blankenstein M. Incidence of inflammatory bowel disease across Europe: is there a difference between north and south? Results of the European Collaborative Study on Inflammatory Bowel Disease (EC-IBD). Gut. 1996;39:690-697.

3. Russel MG, Dorant E, Volovics A, Brummer RJ, Pop P, Muris JW, Bos LP, Limonard CB, Stockbrugger RW. High incidence of inflammatory bowel disease in The Netherlands: results of a prospective study. The South Limburg IBD Study Group. Dis Colon Rectum. 1998;41: 33-40.

4. Russel MG. Changes in the incidence of inflammatory bowel disease: what does it mean? Eur J Intern Med. 2000;11:191-196.

5. Loftus EV, Jr. Clinical epidemiology of inflammatory bowel disease: Incidence, prevalence, and environmental influences. Gastroenterology. 2004;126:1504-1517.

6. Joossens S, Reinisch W, Vermeire S, Sendid B, Poulain D, Peeters M, Geboes K, Bossuyt X, Vandewalle $P$, Oberhuber $G$, Vogelsang $H$, Rutgeerts $P$, Colombel JF. The value of serologic markers in indeterminate colitis: a prospective follow-up study. Gastroenterology. 2002;122:1242-1247.

7. Boonen A, Dagnelie PC, Feleus A, Hesselink MA, Muris JW, Stockbrugger RW, Russel MG. The impact of inflammatory bowel disease on labor force participation: results of a population sampled case-control study. Inflamm Bowel Dis. 2002;8:382-389.

8. Stark R, Konig HH, Leidl R. Costs of inflammatory bowel disease in Germany. Pharmacoeconomics. 2006;24:797-814.

9. Bassi A, Dodd S, Williamson P, Bodger K. Cost of illness of inflammatory bowel disease in the UK: a single centre retrospective study. Gut. 2004;53:1471-1478.

10. Munkholm P, Langholz E, Davidsen M, Binder V. Disease activity courses in a regional cohort of Crohn's disease patients. Scand J Gastroenterol. 1995;30:699-706.

11. Moum B, Ekbom A, Vatn MH, Aadland E, Sauar J, Lygren I, Schulz T, Stray N, Fausa O. Clinical course during the 1st year after diagnosis in ulcerative colitis and Crohn's disease. Results of a large, prospective population-based study in southeastern Norway, 1990-93. Scand J Gastroenterol. 1997;32:1005-1012.

12. Oostenbrug LE, van Dullemen HM, te Meerman GJ, Jansen PL, Kleibeuker JH. Clinical outcome of Crohn's disease according to the Vienna classification: disease location is a useful predictor of disease course. Eur J Gastroenterol Hepatol. 2006;18:255-261.

13. Veloso FT, Ferreira JT, Barros L, Almeida S. Clinical outcome of Crohn's disease: analysis according to the vienna classification and clinical activity. Inflamm Bowel Dis. 2001;7:306-313.

14. Henriksen M, Jahnsen J, Lygren I, Aadland E, Schulz T, Vatn MH, Moum B. Clinical course in Crohn's disease: results of a five-year population-based follow-up study (the IBSEN study). Scand J Gastroenterol. 2007;42:602-610.

15. Henriksen M, Jahnsen J, Lygren I, Sauar J, Kjellevold O, Schulz T, Vatn MH, Moum B. Ulcerative colitis and clinical course: results of a 5-year population-based follow-up study (the IBSEN study). Inflamm Bowel Dis. 2006;12:543-550.

16. Wolters FL, Russel MG, Sijbrandij J, Ambergen T, Odes S, Riis L, Langholz E, Politi P, Qasim A, Koutroubakis I, Tsianos E, Vermeire S, Freitas J, van Zeijl G, Hoie O, Bernklev T, Beltrami M, Rodriguez D, Stockbrugger RW, Moum B. Phenotype at diagnosis predicts recurrence rates in Crohn's disease. Gut. 2006;55:1124-1130.

17. Lakatos PL, Szalay F, Tulassay Z, Molnar T, Kovacs A, Gasztonyi B, Papp J, Lakatos L. Clinical presentation of Crohn's disease. association between familial disease, smoking, disease phenotype, extraintestinal manifestations and need for surgery. Hepatogastroenterology. 2005;52:817-822.

18. Baert F, Caprilli R, Angelucci E. Medical therapy for Crohn's disease: top-down or step-up? Dig Dis. 2007;25:260-266.

19. Russel M. Data management of the South Limburg Inflammatory Bowel Disease Registry 'IBD South Limburg'. Thesis Incidence, risk factors and quality of life in IBD, Russel, M. 1997: 49-57.

20. Aloi M, Cucchiara S. Extradigestive manifestations of IBD in pediatrics. Eur Rev Med Pharmacol Sci. 2009;13 Suppl 1:23-32. 
21. Lennard Jones JE. Classification of inflammatory bowel disease. Scandinavian journal of gastroenterology. Supplement. 1989;170:2-6; discussion 16-19.

22. Gasche C, Scholmerich J, Brynskov J, D'Haens G, Hanauer SB, Irvine EJ, Jewell DP, Rachmilewitz D, Sachar DB, Sandborn WJ, Sutherland LR. A simple classification of Crohn's disease: report of the Working Party for the World Congresses of Gastroenterology, Vienna 1998. Inflamm Bowel Dis. 2000;6:8-15.

23. Hoie O, Wolters F, Riis L, Aamodt G, Solberg C, Bernklev T, Odes S, Mouzas IA, Beltrami M, Langholz E, Stockbrugger R, Vatn M, Moum B. Ulcerative colitis: patient characteristics may predict 10-yr disease recurrence in a European-wide population-based cohort. Am J Gastroenterol. 2007;102:1692-1701.

24. Grambsch PM, Therneau TM. Proportional hazards test and diagnostics based on weighted residuals. Biometrica. 1994;81:515-526.

25. Statacorp. Stata Statistical Software: Release 8.2. Stata corperation: College Station, TX, 2005.

26. Shivananda S, Hordijk ML, Pena AS, Mayberry JF. Crohn's disease: risk of recurrence and reoperation in a defined population. Gut. 1989;30:990-995.

27. Agrez MV, Valente RM, Pierce W, Melton LJ, 3rd, van Heerden JA, Beart RW, Jr. Surgical history of Crohn's disease in a well-defined population. Mayo Clinic proceedings. 1982;57: 747-752.

28. Nemetz A, Molnar T, Zagoni T, Kovacs A, Tulassay Z, Nagy F, Salvador Pena A. Phenotypes defined by the "Vienna Classification" in 100 Hungarian patients with Crohn's disease. Rev Esp Enferm Dig. 2003;95:533-538, 527-533.

29. D'Haens G, Rutgeerts P. Postoperative recurrence of Crohn's disease: pathophysiology and prevention. Inflamm Bowel Dis. 1999;5:295-303.

30. Hofer B, Bottger T, Hernandez-Richter T, Seifert JK, Junginger T. The impact of clinical types of disease manifestation on the risk of early postoperative recurrence in Crohn's disease. Hepatogastroenterology. 2001;48:152-155.

31. Bernell O, Lapidus A, Hellers G. Risk factors for surgery and postoperative recurrence in Crohn's disease. Annals of surgery. 2000;231:38-45.

32. Greenstein AJ, Lachman P, Sachar DB, Springhorn J, Heimann T, Janowitz HD, Aufses AH, Jr. Perforating and non-perforating indications for repeated operations in Crohn's disease: evidence for two clinical forms. Gut. 1988;29:588-592.

33. Sugita A, Fukushima T, Yamazaki Y, Harada H, Goh K, Koganei K, Tsuchiya S. [Postoperative recurrence form of Crohn's disease: comparison between perforating and non perforating types]. Nippon Geka Gakkai Zasshi. 1993;94:114-118.

34. Aeberhard P, Berchtold W, Riedtmann HJ, Stadelmann G. Surgical recurrence of perforating and nonperforating Crohn's disease. A study of 101 surgically treated Patients. Dis Colon Rectum. 1996;39:80-87.

35. Hamon JF, Carbonnel F, Beaugerie L, Sezeur A, Gallot D, Malafosse M, Parc R, Gendre JP, Cosnes J. [Comparison of long-term course of perforating and non-perforating Crohn disease]. Gastroenterol Clin Biol. 1998;22:601-606.

36. Rutgeerts PJ. Conventional treatment of Crohn's disease: objectives and outcomes. Inflamm Bowel Dis. 2001;7 Suppl 1:S2-8.

37. Hanauer SB, Present DH. The state of the art in the management of inflammatory bowel disease. Rev Gastroenterol Disord. 2003;3:81-92.

38. Bianchi Porro G, Cassinotti A, Ferrara E, Maconi G, Ardizzone S. Review article: the management of steroid dependency in ulcerative colitis. Aliment Pharmacol Ther. 2007;26:779-794.

39. Feagan BG. Maintenance therapy for inflammatory bowel disease. Am J Gastroenterol. 2003;98:S6S17.

40. Lakatos PL, Szamosi T, Lakatos L. Smoking in inflammatory bowel diseases: good, bad or ugly? World J Gastroenterol. 2007;13:6134-6139.

41. Langholz E, Munkholm P, Davidsen M, Binder V. Course of ulcerative colitis: analysis of changes in disease activity over years. Gastroenterology. 1994;107:3-11.

42. Hoie O, Wolters FL, Riis L, Bernklev T, Aamodt G, Clofent J, Tsianos E, Beltrami M, Odes S, Munkholm P, Vatn M, Stockbrugger RW, Moum B. Low colectomy rates in ulcerative colitis in an unselected European cohort followed for 10 years. Gastroenterology. 2007;132:507-515.

43. Langholz E, Munkholm P, Davidsen M, Binder V. Colorectal cancer risk and mortality in patients with ulcerative colitis. Gastroenterology. 1992;103:1444-1451. 
44. Farmer RG, Easley KA, Rankin GB. Clinical patterns, natural history, and progression of ulcerative colitis. A long-term follow-up of 1116 patients. Digestive diseases and sciences. 1993;38:1137-1146.

45. Leijonmarck CE, Persson PG, Hellers G. Factors affecting colectomy rate in ulcerative colitis: an epidemiologic study. Gut. 1990;31:329-333.

46. Edwards FC, Truelove SC. The Course and Prognosis of Ulcerative Colitis. Gut. 1963;4: 299-315.

47. Hendriksen C, Kreiner S, Binder V. Long term prognosis in ulcerative colitis--based on results from a regional patient group from the county of Copenhagen. Gut. 1985;26:158-163.

48. Stewenius J, Adnerhill I, Ekelund GR, Floren CH, Fork FT, Janzon L, Lindstrom C, Ogren M. Risk of relapse in new cases of ulcerative colitis and indeterminate colitis. Dis Colon Rectum. 1996;39:10191025.

49. Bitton A, Peppercorn MA, Antonioli DA, Niles JL, Shah S, Bousvaros A, Ransil B, Wild G, Cohen A, Edwardes MD, Stevens AC. Clinical, biological, and histologic parameters as predictors of relapse in ulcerative colitis. Gastroenterology. 2001;120:13-20.

50. Sinclair TS, Brunt PW, Mowat NA. Nonspecific proctocolitis in northeastern Scotland: a community study. Gastroenterology. 1983;85:1-11.

51. Hiwatashi N, Yamazaki H, Kimura M, Morimoto T, Watanabe H, Toyota T. Clinical course and long-term prognosis of Japanese patients with ulcerative colitis. Gastroenterol Jpn. 1991;26:312-318.

52. Satsangi J, Silverberg MS, Vermeire S, Colombel JF. The Montreal classification of inflammatory bowel disease: controversies, consensus, and implications. Gut. 2006;55: 749-753.

53. Wolters FL, van Zeijl G, Sijbrandij J, Wessels F, O'Morain C, Limonard C, Russel MG, Stockbrugger RW. Internet-based data inclusion in a population-based European collaborative follow-up study of inflammatory bowel disease patients: description of methods used and analysis of factors influencing response rates. World J Gastroenterol. 2005;11:7152-7158.

54. Silverberg MS, Satsangi J, Ahmad T, Arnott ID, Bernstein CN, Brant SR, Caprilli R, Colombel JF, Gasche C, Geboes K, Jewell DP, Karban A, Loftus Jr EV, Pena AS, Riddell RH, Sachar DB, Schreiber S, Steinhart AH, Targan SR, Vermeire S, Warren BF. Toward an integrated clinical, molecular and serological classification of inflammatory bowel disease: Report of a Working Party of the 2005 Montreal World Congress of Gastroenterology. Can J Gastroenterol. 2005;19 Suppl A:5-36. 


\section{Part II}

Fatigue and Health Related Quality of Life in IBD 



\section{Chapter 5}

\section{Fatigue and Health Related Quality of Life in}

Inflammatory Bowel Disease. Results from a population

based study in the Netherlands; the IBD South Limburg cohort

Mariëlle JL Romberg-Camps, Yvonne Bol, Pieter C Dagnelie,

Martine AM Hesselink-van de Kruijs, Arnold DM Kester, Leopold GJB Engels, Cees van Deursen, Wim HA Hameeteman, Marieke Pierik, Frank L Wolters, Maurice GVM Russel, Reinhold W Stockbrügger.

Inflamm Bowel Dis. 2010; epub ahaed of print 


\section{Abstract}

\section{Objective}

The importance of fatigue in chronic disease has been increasingly recognized, however, little is known about fatigue in Inflammatory Bowel Disease (IBD). The aim of the present study was to investigate the prevalence and severity of fatigue and the impact on Health Related Quality of Life (HRQoL) in patients included in a population based IBD cohort in the Netherlands.

\section{Design}

IBD patients, diagnosed between January $1^{\text {st }}, 1991$, and January $1^{\text {st }}, 2003$, were followed up for a median of 7.1 years. They completed a questionnaire, which included a disease activity score, the Multidimensional Fatigue Inventory (MFI-20), the Inflammatory Bowel Disease Questionnaire (IBDQ) and the Short Form health survey (SF-36). Haemoglobin levels were recorded.

\section{Results}

Data were available in 304 Crohn's Disease [CD], 368 Ulcerative Colitis [UC] and 35 Indeterminate Colitis [IC] patients. During quiescent disease, the prevalence of fatigue was nearly $40 \%$. MFI-20 and HRQoL scores were significantly worse in IBD patients having active disease. In a multivariate analysis, disease activity was positively related with the level of fatigue in both CD and UC. In UC, anaemia influenced the general fatigue score independently of disease activity. Disease activity as well as fatigue were independently associated with an impaired IBDQ.

\section{Conclusions}

In IBD, even in remission, fatigue is an important feature. Both in CD and in UC, fatigue determined HRQoL independently of disease activity or anaemia. This implies that in IBD patients physicians need to be aware of fatigue in order to better understand its impact and to improve the HRQoL. 


\section{Introduction}

The importance of fatigue and its negative impact on patients' Health Related Quality of Life (HRQoL) has been increasingly recognized and studied in several chronic diseases $^{1-3}$ and cancer. ${ }^{4,5}$ Persistent fatigue from chronic illness involves ongoing exhaustion that is disproportionate to exertion and not alleviated by rest. ${ }^{1}$ Fatigue is often the most debilitating part of the disease. ${ }^{1,5}$

Little is known about fatigue in inflammatory bowel disease (IBD). In an earlier report the prevalence of fatigue in IBD was found to be over $40 \%$, and was independent of disease activity; this was however studied in a small group of patients $(\mathrm{N}=80)$ being treated in a referral hospital. ${ }^{6}$

The first aim our study was to investigate the prevalence and severity of fatigue in patients with IBD in an unselected regional population. The influence of age, gender, length of follow-up, IBD sub-diagnosis, disease activity, anaemia and current medication on fatigue was assessed. Secondly, we investigated whether fatigue is an independent determinant of the HRQoL in IBD

\section{Methods}

\section{Population and design}

In 1991 a population-based Inflammatory Bowel Disease Registry was established in collaboration between the Departments of Gastroenteroly/Hepatology and the MEMIC (Centre for Data and Information Management, University of Maastricht). The primary objective of the registry was to prospectively study the incidence of IBD and risk factors for disease severity and outcome within a well-defined area of the Netherlands, namely South-Limburg (IBD-SL). ${ }^{7-9}$

South Limburg is located in the South-East of the Netherlands between Germany and Belgium; its northern border with the rest of the Netherlands is narrow. The region had a population of about 645,000 between 1991 and 2003, and migration rate in and out of the area is low. ${ }^{10}$

All three hospitals in South Limburg, i.e. University Hospital in Maastricht and the General district hospitals of Heerlen and Sittard participated in the study. Apart from general practitioners (GPs), there are no other in- or outpatient clinics treating IBD patients in this area. With regard to possible treatment of IBD patients by GPs alone, completeness of hospital case ascertainment was verified by Russel et al. and found to be high. ${ }^{11}$ The completeness of the registry was checked by comparing registered cases in the IBD-SL registry and those IBD cases registered in a local Registration Network of General practioners (RNH), covering part of the IBD-SL region, during the first three years of inclusion (January $1^{\text {st }}, 1991$ until January $\left.1^{\text {st }}, 1994\right)$. Thirty-nine new cases of IBD were diagnosed and registered in the RNH registry. Of those 39 patients, 18 were unknown in the IBD-SL registration. After verification of the exact data of diagnosis and 
diagnostic criteria, twelve patients could be excluded. The remaining 6 patients, 5 with UC ( 3 of these with proctitis) and one with IC. Four of the six patients were known to specialists in the study area but had not yet been reported. ${ }^{11}$

Inclusion of IBD patients was based on endoscopic and/or radiological evidence, supported by mucosal biopsy and/or examination of a surgical specimen. For case definition of Crohn's Disease (CD), the criteria of Lennard-Jones were applied. ${ }^{12}$ Ulcerative colitis (UC) was defined as continuous mucosal inflammation without granulomata, affecting the rectum and/or some or all of the colon in continuity with the rectum. The term IBD unclassified (IBDU) was used for cases of IBD in which, after careful investigation, the differential diagnosis between $C D$ and $U C$ remained uncertain. $^{13}$ Patient recruitment for all diagnosed patients (hospitalized and outpatients) was performed by gastroenterologists, internists, surgeons and paediatricians. ${ }^{11}$ In the present study, all newly diagnosed patients (i.e. without prior history of $(\mathrm{BD})$, registered between January $1^{\text {st }}, 1991$, and January $1^{\text {st }}, 2003$, were included. These patients were followed from inclusion until data collection for the present study, which took place between July $1^{\text {st }}, 2005$, and January $1^{\text {st }}, 2006$, or until a prior date in case of death or loss to follow-up (LTFU). During data collection for the present study, inclusion criteria were re-verified for all patients.

\section{Definitions and medical record data collection}

In the hospitals, medical records were reviewed. Collected data were instantly and uniformly registered in an Access database.

Medical charts were reviewed with regard to diagnosis. In 50 out of 1187 patients, the IBD sub-diagnosis had been changed after that the initial diagnosis had been established. ${ }^{9}$ For the current analysis the last established diagnosis was used for further analysis.

Patients were characterized according to the Vienna classification at diagnosis. ${ }^{14}$ Definitions for "location" were used according to earlier publications of the European Collaborative study group on Inflammatory Bowel Disease (EC-IBD). ${ }^{15,16}$ In IBDU patients, the extent of disease was classified as in UC for further analyses.

All available laboratory data between June $1^{\text {st }}, 2005$ and January $1^{\text {st }}, 2006$ with regard to the haemoglobin level were registered. Patients were classified as having anaemia using a cutoff value, male: $8.5 \mathrm{mmol} / \mathrm{l}$ and female: $7.5 \mathrm{mmol} / \mathrm{l}$. Haemoglobin data were classified as; "no anaemia"; "anaemia" or "not determined".

\section{Questionnaire}

In June 2005, questionnaires were sent to the included patients. When no response was received within six weeks a reminding letter was sent to the respective patients. When again no response was received, a further letter, together with a duplicate of the questionnaire, was sent (October 2005). Final date for acceptance of 
questionnaires was January $1^{\text {st }}, 2006$. The composite questionnaire included items on the following:

\section{Medication use}

Current use of medication was noted and subsequently categorized in: no medication use, category 1 ; mesalazine (5-ASA), category 2; corticosteroids (topical and/or systemic use of prednisone, prednisolon, beclomethason or budesonide), category 3 ; "other" immune modulating medication (azathioprine, 6-mercaptopurine, thioguanine, cyclosporine and methotrexate), category 4 , and infliximab, category 5 . The group of "other" immune modulating medication will be referred to as "immunosuppressives" throughout this paper. If patients were using medication from more than one category we evaluated them applying the highest scoring category.

\section{Disease activity}

In $\mathrm{CD}$, the Harvey Bradshaw Index $(\mathrm{HBI})^{17}$ was used for further analysis. As patients were not examined physically the item of "abdominal mass" was scored as zero (no mass and no abdominal pain on palpation). To evaluate the accuracy of the HBI, a subgroup of patients also scored disease activity using a validated diary developed by Sandler et al. ${ }^{18}$ to establish disease activity in $\mathrm{CD}$. The correlation between this diary and $\mathrm{HBI}$ was high $(\mathrm{r}=0.80)$. A HBI under five indicated no disease activity.

In UC, the Colitis Activity Index (CAI)(19) was used. As in the CD patients, no physical examination took place. The item regarding "abdominal pain on palpation" was set to be zero ("no abdominal pain"). A CAI under ten indicated no disease activity. For IBDU, as the inflammation per definition is located in the colon the CAI was used in further analysis.

\section{Fatigue}

To measure fatigue, the validated Dutch Multidimensional Fatigue Inventory (MFI-20) was used. This is a 20-item instrument designed to measure five fatigue dimensions: general fatigue, physical fatigue, reduced activity, reduced motivation and mental fatigue. ${ }^{20,21}$ Each dimension contains four questions, resulting in a score range from 4-20. A higher score indicates more fatigue.

\section{Health related quality of life}

The Inflammatory Bowel Disease Questionnaire (IBDQ) and the Short Form health survey (SF-36) were used to measure HRQoL. The IBDQ is a 32 item disease specific $\mathrm{HRQ}$ oL questionnaire, including four health dimensions: bowel symptoms; systemic symptoms; emotional well-being and social functioning. Responses are graded on a 7point Likert scale in which " 1 " represents a very severe problem and "7" represents no problem at al. ${ }^{22,23}$ Consequently, a higher score indicates a better quality of life. 
The SF-36 includes multi-item scales measuring eight general health concepts: physical functioning; role of limitations due to physical health problems; bodily pain; general health perception; vitality; social function; role limitations due to personal or emotional problems and mental health. ${ }^{24,25}$ Translation to Dutch was carried out as part of a International Quality of Life assessment project. ${ }^{26}$ From the SF-36, a "physical health" and a "mental health" summary score were computed. ${ }^{24,25}$

\section{Anxiety and depression}

Anxiety and depression were measured with the Hospital Anxiety and Depression Scale (HADS). The HADS is a self-assessment scale which is a reliable and valid screening instrument for anxiety and depression in the setting of a hospital medical outpatient clinic, consisting of 7 items on anxiety (HADS-A) and 7 items on depression (HADS-D) (scores per item ranging from 0 to 3$)^{27,28}$ On either subscale, a score above eight indicates the presence of anxiety or depression. ${ }^{29}$

\section{Statistical analysis}

Patient characteristics per diagnosis are reported with regard to: gender; age at diagnosis; age at the moment of questionnaire; length of follow-up; phenotype at diagnosis; disease activity; anaemia; current medication use. Differences between these groups were appraised using Pearson chi-square tests.

Up to one missing item of each questionnaire was replaced by the median of the items of the respective subscale in the concerned patient. If more than one item per questionnaire was missing the concerned questionnaire was excluded from further analysis. To calculate the prevalence of fatigue two different cut off values were used. In the healthy population, using a comparable age group as was found in our study group, a mean general fatigue score of 10 was reported. ${ }^{30}$ To calculate the prevalence of fatigue compared to this healthy population we defined fatigue as a general fatigue score above ten. Secondly, in a Dutch IBD patient sample ${ }^{6}$ and in the general population $^{30}$, the prevalence of fatigue was reported using the upper $95^{\text {th }}$ percentile of the healthy controls and the general population as a cut of value, being a score above fourteen. ${ }^{30,6}$

Using multiple regression analysis, we evaluated first possible determinants of fatigue, including diagnosis; gender; age; length of follow-up, current medication use; disease activity and anaemia. Subsequently a multiple regression analysis was performed for the same determinants and additionally fatigue with HRQoL as outcome parameter. Analyses were performed separately for CD and UC. In IBDU, the number of patients was too low to perform meaningful multiple regression analysis.

Data analyses were performed using Stata 8.2. ${ }^{31}$ P-values less than 0.05 were considered statistically significant. 


\section{Ethical considerations}

The Ethical Committees of all participating centres approved of the protocol, and written informed consent was obtained from all patients at inclusion in the IBD-SL registry for future analysis and publication of data. In the few patients below 18 years of age their parents or a legal representative signed for informed consent.

\section{Results}

\section{Patient population}

Between January $1^{\text {st }}, 1991$, and January $1^{\text {st }}, 2003,1254$ newly diagnosed IBD patients were included in the IBD-SL registry. Of these, 67 patients were excluded because medical records were unavailable, leaving 1187 patients for data analysis. Mean age at diagnosis, sex distribution and IBD diagnosis (CD, UC and IBDU) were not significantly different between in- and excluded patients (data not shown). Data on disease location at diagnosis were missing in $27 \mathrm{CD}, 34 \mathrm{UC}$ and 12 IBDU patients; these patients were included for further analysis as questionnaire data were available. The study population at inclusion ( $\mathrm{N}=1187$ ) comprised 476 patients with $\mathrm{CD}, 630$ with $\mathrm{UC}$ and 81 with IBDU. The sex distribution was (male / female) 187 / 289 in CD, 350 / 280 in UC, and 43 / 38 in IBDU. Median age (range, minimum-maximum) at diagnosis was 29.0 (5.8-79.5) years for CD, 38.0 (8.2-84.3) years for UC, and 36.0 (13.9-77.7) years for IBDU. At the censoring date (January $1^{\text {st }}, 2006$ ), 21 out of 476 CD patients, 47 out of 630 UC patients and 4 out of 81 IBDU patients had died, without significant difference of proportions between the CD, UC and IBDU patients $(p=0.14)$. Median (range, minimum-maximum) follow-up time for patients alive at the censoring date was 7.8 $(0.2-15.4)$ years in CD, $7.0(0.1-15.0)$ years in UC and $7.6(0.1-14.6)$ years in IBDU.

Of the 1187 (male 580 / female 607) included patients, after subtraction of 72 deceased patients (male 44 / female 28) and 31 patients that could not be traced (male 16 / female 15), 1084 patients remained; from these, 707 questionnaires were received (male 315 / female 392, response 65\%). There was no difference in response rates with regard to IBD diagnosis, age at diagnosis, age at moment of questionnaire, phenotype at diagnosis and length of follow-up. Response rate was significantly higher in female than in male patients $(70 \%$ versus $61 \%, p<0.0001)$.

In Table 5.1, demographic and clinical characteristics of the study population ( $N=707)$ are presented. There were significantly more female patients in de CD patient group. The age at diagnosis was significant lower for CD patients compared to UC and IBDU patients, as was their age at the moment of questionnaire. Median length of follow-up in CD patients was slightly, but significantly, longer than the one found in UC and IBDU patients. Disease location in CD was terminal ileum in $32 \%$, colonic in $26 \%$, ileo-colonic in $32 \%$, upper gastro-intestinal in $4 \%$, and unknown in $6 \%$ of patients. In $C D$, disease behaviour was inflammatoir in most patients (74\%), stricturing disease was found in 
$14 \%$ of CD patients, penetrating in $9 \%$, and a combination of stricturing and penetrating in $3 \%$. In UC patients, disease location was proctitis in $38 \%$, distal colitis in $44 \%$, extensive colitis in $14 \%$ and unknown in $4 \%$. For IBDU, this was $11 \%, 44 \%, 28 \%$ and $17 \%$, respectively.

In $C D$ the percentage of patients having active disease at the moment of questionnaire was significantly higher than in UC and IBDU ( $p<0.0005)$. With regard to medication, significantly more $C D$ patients used corticosteroids, immunosuppressives and infliximab, whereas more UC patients were currently using 5-ASA.

Table 5.1 Demographic and clinical characteristics of the study population.

\begin{tabular}{lccc}
\hline & CD & UC & IBDU \\
\hline Number of patients, N (\%) & $304(43)$ & $368(52)$ & $35(5)$ \\
Male, N (\%) & $104(34)$ & $189(51)$ & $22(63)$ \\
Female, N (\%) & $200(66)$ & $179(49)$ & $13(37)$ \\
Age at diagnosis in years, median (min-max) & $31(11-76)^{\mathrm{a}}$ & $39(13-75)$ & $41(16-78)$ \\
Age at moment of questionnaire, median (range) & $40(21-89)^{\mathrm{a}}$ & $48(19-85)$ & $51(28-82)$ \\
Length of follow-up in years, median (range) & $8.1(0.7-15.4)$ & $7.6(0.1-14.8)$ & $7.5(0.9-15.0)$ \\
Disease activity & & & \\
Active & $143(47)^{\mathrm{a}}$ & $16(4)$ & $0(0)$ \\
Quiescent & $161(53)^{\mathrm{a}}$ & $352(96)$ & $35(100)$ \\
Anaemia & & & $21(60)$ \\
No, N (\%) & $213(70)$ & $208(57)$ & $3(9)$ \\
Yes, N (\%) & $35(12)^{a}$ & $27(7)$ & $11(31)$ \\
Not determined, N (\%) & $56(18)^{*}$ & $133(36)$ & $11(31)$ \\
Current medication use, N (\%)** & & & $11(31)$ \\
1 No medication use & $66(22)^{\mathrm{a}}$ & $112(30)$ & $4(12)$ \\
2 5-ASA & $86(28)^{\mathrm{b}}$ & $170(46)$ & $8(23)$ \\
3 Corticosteroids & $37(12)^{\mathrm{a}}$ & $33(9)$ & $1(3)$ \\
4 Immunosuppressives & $63(21)^{\mathrm{a}}$ & $50(14)$ & $3(1)$ \\
5 Infliximab & $52(17)^{\mathrm{a}}$ & &
\end{tabular}

Values for CD compared to UC and IBDU: a p<0.0005, b p<0.005, * between June 1st, 2005 and January 1st, $2006, * *$ patients using medication from more than one category were registered with the highest ranging category, $\min =$ minimum, $\max =$ maximum

\section{Fatigue, HRQoL, HADS-Anxiety and HADS-Depression}

In Table 5.2, mean MFI-20, IBDQ, SF-36, HADS-A and HADS-D scores per diagnosis are presented. Data are presented overall and according to disease activity and presence of anaemia. Overall scores of the MFI-20 dimensions "general fatigue" and "physical fatigue" were significantly worse in CD compared to UC and IBDU $(p<0.0005)$. All IBDQ dimensions and the computed physical health dimension of the SF-36 score was also significantly worse in CD patients $(p<0.005)$. Of the SF-36 the dimensions: physical functioning; role of limitations due to physical health problems; bodily pain; general health perception; vitality and social function were significantly worse in CD compared to UC (data not shown). In CD, all MFI-20 dimensions scored significantly worse in patients with active disease. For UC, this was similar for general fatigue; physical fatigue and reduced activity but not for reduced motivation and mental fatigue. 
Mean MFI-20, IBDQ and SF-36 scores per diagnosis.

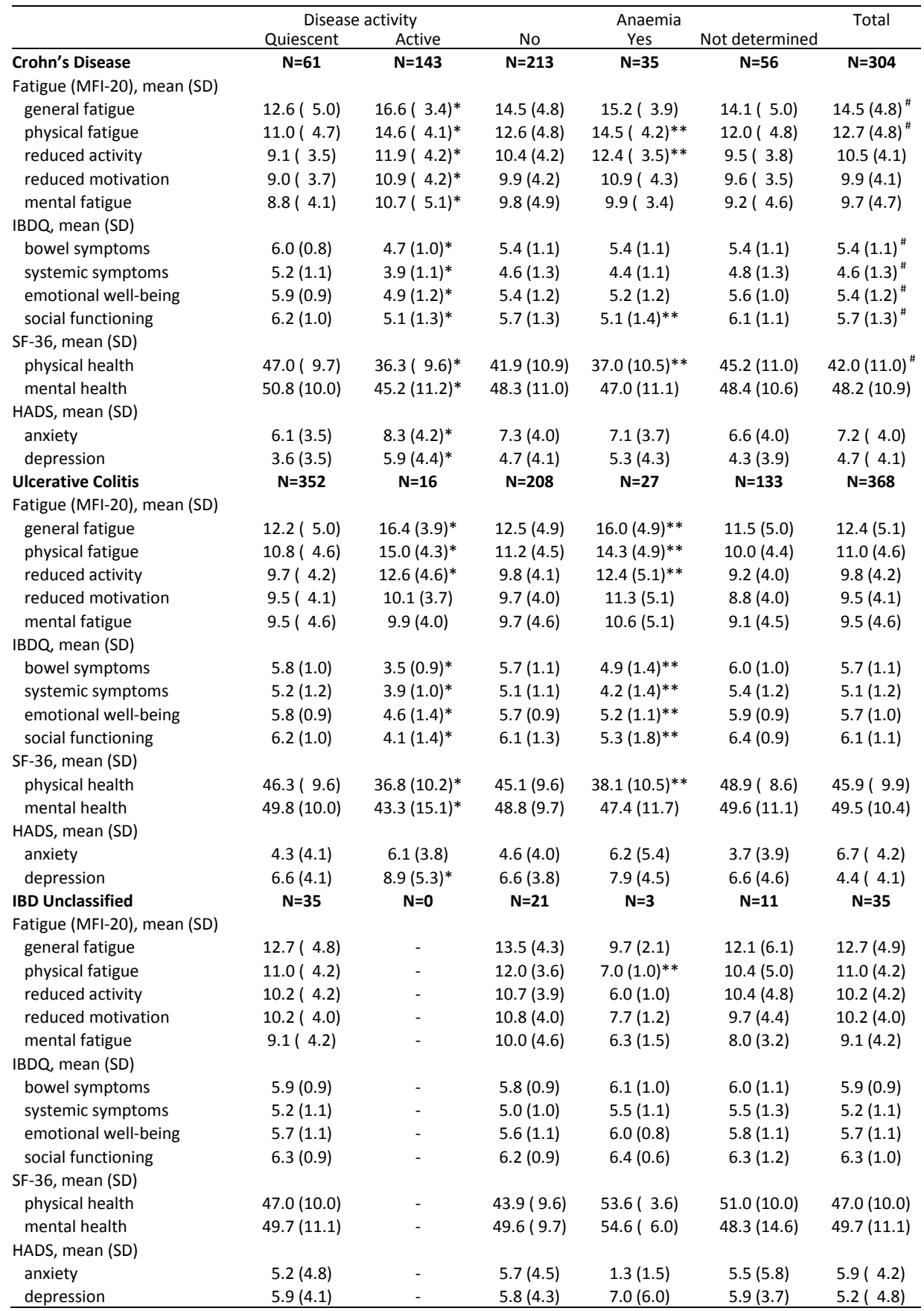

$\mathrm{CAI}=$ Colitis Activity Index, $\mathrm{HBI}=$ Harvey Bradshaw Index, IBDQ=Inflammatory Bowel Disease Questionnaire (a lower score is worse), MFI=Multidimensional Fatigue Inventory (a higher score is worse), SD=standard deviation, SF-36=Short Form health survey (a lower score is worse), * active versus quiescent disease $\mathrm{p}<0.005, * *$ presence of anaemia versus no anaemia $\mathrm{p}<0.05,{ }^{\#}$ CD versus UC and IBDU $\mathrm{p}<0.005$ 
Scores of all dimensions of the IBDQ and SF-36 were significantly worse in both CD and UC patients with active disease compared to those with quiescent state. There were no IBDU patients having active disease. In CD as well as in UC patients with anaemia, the MFI-20 was significantly worse for physical fatigue and reduced activity than in patients without anaemia. In anaemic UC patients, scores were also significantly worse on the dimension general fatigue $(p<0.0005)$, in anaemic IBDU patients, only physical fatigue scored significantly worse $(p<0.05)$. In $C D$, anaemia was also associated with a significantly worse score on the IBDQ dimension social functioning $(p<0.05)$ and the SF-36 dimensions; role of limitations due to physical health problems, bodily pain (data not shown) and physical health $(\mathrm{p}<0.05)$. In anaemic UC patients, all IBDQ dimensions scored significantly worse than in non-anaemic, as were the SF-36 dimensions physical functioning; role of limitations due to physical health problems; bodily pain; general health perception; vitality; social function (data not shown) and the computed dimension physical health $(\mathrm{p}<0.005)$. In anaemic IBDU patients, IBDQ and SF-36 dimensions were not significantly different from non-anaemic, probably due to the small number of patients.

In CD patients, active disease resulted in significantly worse HADS-A and HADS-D scores $(p<0.0005)$. In UC, this was only found for HADS-D $(p<0.05)$. Neither HADS-A nor HADS-D were significantly different in anaemic patients compared to non-anaemic patients in all disease categories.

\section{Prevalence and determinants of fatigue}

\section{Prevalence}

In Table 5.3 the percentage of patients is presented having a general fatigue score above ten and fourteen, respectively, in order to illustrate the prevalence of fatigue. A general fatigue score above 10 was found in $66.5 \%$ of CD, $62.9 \%$ of UC and $62.8 \%$ of IBDU patients during quiescent disease. A score over 14 was found in $38 \%$ of CD, 36\% of UC and $40 \%$ of IBDU patients having quiescent disease.

\section{Multiple regression analysis of risk factors for fatigue}

In Table 5.4, regression coefficients using the sub-score "general fatigue" are presented for $C D$ and $U C$. In $C D$, patients using medication were significantly more tired than patients using no medication. In $C D$, corticosteroids and immunosuppressives, were independently associated with a higher "general fatigue" score. Active disease in $C D$ was significantly related with a worse general fatigue score. Gender, age, length of follow-up, anaemia and the use of infliximab did not determine the level of fatigue in $C D$.

In UC, disease activity and anaemia were independent determinants of general fatigue, both resulting in a worse score. Moreover, in UC, female gender was associated with 
higher fatigue scores resulting in a worse score. Age, length of follow-up and medication use were unrelated with the level of fatigue in UC.

Table 5.3 Prevalence of the MFI-20 sub-score "general fatigue"*

\begin{tabular}{|c|c|c|c|c|c|c|}
\hline & \multicolumn{2}{|c|}{ Disease activity } & \multicolumn{3}{|c|}{ Anaemia } & \multirow[t]{2}{*}{ Total } \\
\hline & Quiescent & Active & No & Yes & $\begin{array}{c}\text { Not } \\
\text { determined }\end{array}$ & \\
\hline Crohn's Disease & $\mathrm{N}=161$ & $\mathrm{~N}=143$ & $\mathrm{~N}=\mathbf{2 1 3}$ & $\mathrm{N}=35$ & $N=56$ & $\mathrm{~N}=304$ \\
\hline \multicolumn{7}{|l|}{ Fatigue (MFI) number (\%) } \\
\hline general fatigue score $>10$ & 66.5 & 94.4 & 79.1 & 82.7 & 80.4 & 79.7 \\
\hline general fatigue score>14 & 38.0 & 76.9 & 57.1 & 62.9 & 50.0 & 56.5 \\
\hline Ulcerative Colitis & $N=352$ & $\mathrm{~N}=16$ & $\mathrm{~N}=\mathbf{2 0 8}$ & $\mathrm{N}=\mathbf{2 7}$ & $\mathrm{N}=133$ & $\mathrm{~N}=368$ \\
\hline \multicolumn{7}{|l|}{ Fatigue (MFI) number (\%) } \\
\hline general fatigue score $>10$ & 62.9 & 87.5 & 65.5 & 81.5 & 57.6 & 63.9 \\
\hline general fatigue score $>14$ & 36.3 & 68.8 & 36.9 & 70.4 & 31.8 & 37.7 \\
\hline IBD Unclassified & $\mathrm{N}=35$ & $\mathrm{~N}=\mathbf{0}$ & $\mathbf{N}=\mathbf{2 1}$ & $\mathrm{N}=3$ & $\mathrm{~N}=11$ & $\mathrm{~N}=35$ \\
\hline \multicolumn{7}{|l|}{ Fatigue (MFI) number (\%) } \\
\hline general fatigue score $>10$ & 62.8 & - & 71.4 & 33.3 & 54.6 & 62.9 \\
\hline general fatigue score $>14$ & 40.0 & - & 38.1 & 0.0 & 54.6 & 40.0 \\
\hline
\end{tabular}

* score >10: cut off value healthy population taken into account mean age of the present study population; score $>14$ : cut off value upper $95^{\text {th }}$ percentile of the general population. ${ }^{6,30}$

Table 5.4 Determinants of fatigue in a multivariate analysis using the sub-score "general fatigue", a positive score indicates more fatigue (95\%-confidence interval).

\begin{tabular}{lll}
\hline & Crohn's Disease & Ulcerative Colitis \\
\hline Female gender & n.s. & $1.19(0.24-2.15)^{\mathrm{b}}$ \\
Age & n.s. & n.s. \\
Current medication use* & & \\
$\quad$ Medication use (overall) & $2.37(0.51-4.21)^{\mathrm{a}}$ & n.s. \\
3 Corticosteroids & $1.99(0.21-3.76)^{\mathrm{b}}$ & n.s. \\
4 Immunosuppressives & $1.84(0.26-3.43)^{\mathrm{b}}$ & n.s. \\
Disease activity & $0.44(0.32-0.56)^{\mathrm{a}}$ & $0.71(0.54-0.88)^{\mathrm{a}}$ \\
Anaemia & n.s. & $2.45(0.66-4.25)^{\mathrm{b}}$ \\
\hline
\end{tabular}

${ }^{a} p<0.0005,{ }^{b} p<0.05$, n.s. $=$ not significant, $*$ patients using medication from more than one category were registered within the highest scoring category.

\section{Determinants of the HRQoL}

In both $C D$ and $U C$, gender, age at diagnosis and at the time of the study, length of follow-up, no medication use and use of 5-ASA were all unrelated with HRQoL outcome. In Table 5.5, regression coefficients are presented for CD and UC.

In $C D$ the general fatigue score influenced the HRQoL independent of disease activity with a higher general fatigue score and more disease activity resulting in a worse HRQoL. In this patient group, also anaemia was associated with an impaired HRQoL in the SF-36 physical health score as did the use of infliximab; corticosteroid use in CD was related to a worse IBDQ score. 
In UC, as in CD, general fatigue score negatively determined the HRQoL independent of disease activity. Unlike CD, in UC anaemia did not significantly influence the HRQoL in either of the scores. Furthermore, in UC the use of immunosuppressives was negatively associated with the physical score of the SF-36.

Table 5.5 Determinants of HRQoL in a multivariate analysis, a negative score indicates a lower HRQoL (95\%-confidence interval).

\begin{tabular}{|c|c|c|c|}
\hline Crohn's Disease & SF-36 physical & SF-36 mental & IBDQ total \\
\hline \multicolumn{4}{|l|}{ Current medication use* } \\
\hline 3 Corticosteroids & n.s. & n.s. & $-1.47(-2.69,-0.26)^{b}$ \\
\hline 4 Immunosuppressives & n.s. & n.s. & n.s. \\
\hline 5 Infliximab & $-3.58(-6.75,-0.41)^{b}$ & n.s. & n.s. \\
\hline MFI-20 general fatigue & $-1.06(-1.29,-0.84)^{a}$ & $-0.94(-1.20,-0.67)^{a}$ & $-0.38(-0.46,-0.30)^{a}$ \\
\hline Disease activity & $-0.67(-0.92,-0.41)^{a}$ & $-0.36(-0.65,-0.06)^{b}$ & $-0.43(-0.52,-0.34)^{a}$ \\
\hline Anaemia & $-3.51(-6.59,-0.45)^{b}$ & n.s. & n.s. \\
\hline Ulcerative Colitis & SF-36 physical & SF-36 mental & IBDQ total \\
\hline \multicolumn{4}{|l|}{ Current medication use* } \\
\hline 3 Corticosteroids & n.s. & n.s. & n.s. \\
\hline 4 Immunosuppressives & $-3.24(-5.77,-0.70)^{b}$ & n.s. & n.s. \\
\hline 5 Infliximab & n.s. & n.s. & n.s. \\
\hline MFI-20 general fatigue & $-0.99(-1.16,-0.83)^{a}$ & $-1.11(-1.33,-0.90)^{a}$ & $-0.39(-0.44,-0.33)^{a}$ \\
\hline Disease activity & $-0.78(-1.07,-0.49)^{a}$ & n.s. & $-0.57(-0.67,-0.47)^{a}$ \\
\hline Anaemia & n.s. & n.s. & n.s. \\
\hline
\end{tabular}

${ }^{a} p<0.0005,{ }^{b} p<0.05$, n.s. = not significant, * patients using medication from more than one category were registered within the highest scoring category.

\section{Discussion}

The present population-based study in the Dutch IBD-South Limburg cohort showed a very high prevalence of fatigue in IBD patients, resulting in a lowered HRQoL. CD patients suffered significantly more than UC patients. In UC, disease activity and anaemia were independent contributors to the level of fatigue, whereas in CD fatigue was mainly influenced by disease activity; however, also in patients with quiescent disease the prevalence of fatigue was nearly $40 \%$.

The prevalence of fatigue in IBD reported in literature greatly depends on the definition of fatigue, the type of questionnaire(s) used and the sensitivity levels applied. In the general population, the prevalence of fatigue reported in literature is between 6 and $8.5 \%$. $^{32-34}$

The mean general fatigue sub-score of the MFI- 20 measured in the general population and healthy controls varies between 6 and $11^{30,6,35}$ and was shown to increase with older age. ${ }^{30}$ When the prevalence of fatigue in the present patient cohort is defined as the $95^{\text {th }}$ percentile of the general fatigue subscale of the general population ${ }^{30}$, taking into account the age distribution of our study population, a cut off level of 14 would seem to be appropriate. A similar definition was also used by Minderhoud et al. ${ }^{6}$ who, 
using healthy controls as a reference, reported a fatigue prevalence of $41 \%$ in IBD. The prevalence in the present study was slightly lower, possibly due to the fact that Minderhoud et al. $^{6}$ had a selected hospital-based study population. The mean general fatigue level we found in patients having quiescent disease and no anaemia was around 12.5. This is comparable to values found in rheumatic disease ${ }^{36,37}$, systemic sclerosis $^{3}$, Sjogren's syndrome ${ }^{38}$, chronic liver disease ${ }^{39}$ and cancer. ${ }^{40-42}$

Despite the high prevalence of fatigue in IBD, this symptom remains poorly understood. As we confirmed in our study, in anaemic IBD patients fatigue was more frequently found than in patients without anaemia. ${ }^{43}$ Basal cortisol and cytokine levels were unrelated to the level of fatigue. ${ }^{6,44}$ Worse fatigue scores were reported in patients with short bowel syndrome ${ }^{45,46}$ and in patients with ileal-anal pouch anastomosis for $\mathrm{UC}^{47}$, but a possible influence of the disease course itself is difficult to exclude in these patients. No significant difference in fatigue scores was found in patients with Primary Sclerosing Cholangitis PSC and IBD relative to those with IBD alone. ${ }^{48}$ Promising results were reported in a recent study on fatigue in patients receiving Adalimumab maintenance treatment. During follow-up (until week 56) fatigue scores showed a sustained improvement. ${ }^{49}$ As no other studies on fatigue in IBD are available with regard to fatigue scores before and after treatment, it is still difficult to speculate if the found improvement in fatigue scores is disease activity related or if "biologicals" also could have an positive effect on the cause of fatigue which is still not completely elucidated. We found that depression scores were higher with active disease in both CD and UC patients, whereas anxiety symptoms were increased with active disease in $C D$ patients only. Earlier reports showed a higher degree of depression in CD than in UC patients ${ }^{50,51}$, but after correction for gender and severity of disease ${ }^{52}$, no significant difference remained between $C D$ and UC. There are a few studies that found depression to be an independent risk factor for fatigue in IBD and in the combination of IBD and PSC. ${ }^{48,53}$ In most studies, IBD severity was not associated with depressive symptoms ${ }^{54}$ or a firm diagnosis of depression ${ }^{55-58}$, however, it is difficult to measure the influence of depression as such, since invalidating fatigue symptoms could be a cause of depressive symptoms as well. Even more, it was found that psychological factors such as a depressive mood - associated with anxiety and impaired quality of life - are capable to negatively influence the disease course of IBD. ${ }^{51,59}$

There are numerous reports showing that the HRQoL in IBD patients is impaired compared to the general population. ${ }^{60-65} \mathrm{CD}$ patients might even suffer more than UC patients. ${ }^{50}$ We found fatigue to be an independent contributor to the impaired HRQoL in IBD, as was reported by few others. ${ }^{6,43,49}$ Also, the contributing factor most frequently reported in literature - active disease - was confirmed in the present study. ${ }^{49,52,61,63-76}$ Other factors described in literature which unfavourable affect HRQoL in IBD were female gender ${ }^{50,62,64,68}$, corticosteroid $^{64,77,78}$ or immunosuppressive drug use $^{78}$, hospitalization ${ }^{64}$, short bowel syndrome ${ }^{45,46}$, extra-intestinal manifesta- 
tions $^{47,62,74,78}$, IBS-like symptoms ${ }^{60,79}$, and impaired coping behaviour. ${ }^{80-83}$ Factors positively influencing $\mathrm{HRQOL}$ in $C D$ were use of immunosuppressives (after one year follow-up) ${ }^{64}$, post-surgery situation ${ }^{50,84,85}$, adalimumab maintenance treatment (at week 56$)^{49}$ and having a partner ${ }^{65}$ or social support of any kind after a surgical intervention. $^{82}$ As most factors influencing fatigue and HRQOL are directly or indirectly related to active disease the most interesting question remains, why the prevalence of fatigue is that high during quiescent disease. Possibly the answer must be found in a longitudinal analysis as it might be true that the sum of disease related "events" together with an individual physiological, immunological and/or neurophysiologic susceptibility lead to higher fatigue scores.

A considerable strength of the present study is the population-based prospective design, as findings concerning fatigue and HRQoL are so far not reported in this type of cohort. The present results clearly indicate the influence of fatigue on the HRQoL in $\mathrm{IBD}$, in the quiescent as well as in the active state.

The study has some limitations. Questionnaire response rates were $65 \%$, with more female than male patients responding. This may have influenced the results as - in UC female gender was a significant unfavourable determinant for fatigue as well as the HRQoL in IBD. ${ }^{50,62,64,68}$ However, with regard to IBD diagnosis, age at diagnosis, age at moment of questionnaire, phenotype at diagnosis and length of follow-up, there was no significant difference between the responders en non-responders. Therefore bias as a result of a more severe disease course in the responders group seems unlikely.

Secondly, the omission of physical data from the disease activity scores could not be avoided from practical reasons. However, Sandler et al assessed the accuracy of the CD activity score in a subgroup of patients comparing with a validated diary ${ }^{18}$; the correlation between both was high ( $r=0.80)$.

Thirdly, we had no actual haemoglobin results available in a minority of patients, as the indication for blood tests was made by the managing physicians. As fatigue and HRQoL scores in the patients with no haemoglobin level determined were comparable with those of patients having quiescent disease we assume that these patients were in remission.

In conclusion, we have shown that fatigue is a very important contributor to the $H R Q o L$ in IBD, also independently of disease activity and degree of anaemia. This implies that in patients with CD or UC, a high awareness of this symptom or state is required to achieve a better understanding of its impact on the patients and to find means of improving the HRQoL. Future longitudinal, psychological and biological research is necessary to gain more insight into the concept of fatigue in chronic recurrent inflammation such as IBD hoping that early detection and adequate intervention will lead to a better HRQoL. 


\section{References}

1. Swain MG Fatigue in chronic disease. Clin Sci (Lond) 2000;99:1-8.

2. Pittion-Vouyovitch S, Debouverie M, Guillemin F, Vandenberghe N, Anxionnat R, Vespignani H. Fatigue in multiple sclerosis is related to disability, depression and quality of life. J Neurol Sci. 2006;243:39-45.

3. Thombs BD, Bassel M, McGuire L, Smith MT, Hudson M, Haythornthwaite JA. A systematic comparison of fatigue levels in systemic sclerosis with general population, cancer and rheumatic disease samples. Rheumatology (Oxford). 2008;47:1559-1563.

4. B Beijer S, Kempen GI, Pijls-Johannesma MC, de Graeff A, Dagnelie PC. Determinants of overall quality of life in preterminal cancer patients. Int J Cancer. 2008;123:232-235.

5. Dagnelie PC, Pijls-Johannesma MC, Lambin P, Beijer S, De Ruysscher D, Kempen GI. Impact of fatigue on overall quality of life in lung and breast cancer patients selected for high-dose radiotherapy. Ann Oncol. 2007;18:940-944.

6. Minderhoud IM, Oldenburg B, van Dam PS, van Berge Henegouwen GP. High prevalence of fatigue in quiescent inflammatory bowel disease is not related to adrenocortical insufficiency. Am J Gastroenterol. 2003;98:1088-1093.

7. Russel M Data management of the South Limburg Inflammatory Bowel Disease Registry 'IBD South Limburg'. Thesis Incidence, risk factors and quality of life in IBD 1997;ISBN 90-9010684-7:49-57.

8. Romberg-camps MJ, Hesselink-van de Kruijs MA, Schouten L, Dagnelie PC, Limonard C, Kester AD, Bos LP, Goedhard J, Hameeteman WH, Wolters FL, Russel MG, Stockbrugger RW. Inflammatory bowel disease in South Limburg (the Netherlands) 1991-2002: Incidence, diagnostic delay, and seasonal variations in onset of symptoms. Results of a population based study, the IBD-South Limburg cohort. JCC. 2009;3:115-124.

9. Romberg-Camps MJ, Dagnelie PC, Kester AD, Hesselink-van de Kruijs MA, Cilissen M, Engels LG, Van Deursen C, Hameeteman WH, Wolters FL, Russel MG, Stockbrugger RW. Influence of phenotype at diagnosis and of other potential prognostic factors on the course of inflammatory bowel disease. Am J Gastroenterol. 2009;104:371-383.

10. http://statline.cbs.nl/StatWeb/start.asp?!p=Search/Search.

11. Russel MG, Dorant E, Volovics A, Brummer RJ, Pop P, Muris JW, Bos LP, Limonard CB, Stockbrugger RW. High incidence of inflammatory bowel disease in The Netherlands: results of a prospective study. The South Limburg IBD Study Group. Dis Colon Rectum. 1998;41: 33-40.

12. Lennard Jones JE Classification of inflammatory bowel disease. Scand J Gastroenterol 1989;s170:2-6.

13. Geboes K, Colombel JF, Greenstein A, Jewell DP, Sandborn WJ, Vatn MH, Warren B, Riddell RH. Indeterminate colitis: a review of the concept--what's in a name? Inflamm Bowel Dis. 2008;14: 850-857.

14. Gasche C, Scholmerich J, Brynskov J, D'Haens G, Hanauer SB, Irvine EJ, Jewell DP, Rachmilewitz D, Sachar DB, Sandborn WJ, Sutherland LR. A simple classification of Crohn's disease: report of the Working Party for the World Congresses of Gastroenterology, Vienna 1998. Inflamm Bowel Dis. 2000;6:8-15.

15. Hoie O, Wolters F, Riis L, Aamodt G, Solberg C, Bernklev T, Odes S, Mouzas IA, Beltrami M, Langholz E, Stockbrugger R, Vatn M, Moum B. Ulcerative colitis: patient characteristics may predict 10-yr disease recurrence in a European-wide population-based cohort. Am J Gastroenterol. 2007;102:1692-1701.

16. Wolters FL, Russel MG, Sijbrandij J, Ambergen T, Odes S, Riis L, Langholz E, Politi P, Qasim A, Koutroubakis I, Tsianos E, Vermeire S, Freitas J, van Zeijl G, Hoie O, Bernklev T, Beltrami M, Rodriguez D, Stockbrugger RW, Moum B. Phenotype at diagnosis predicts recurrence rates in Crohn's disease. Gut. 2006;55:1124-1130.

17. Harvey RFBradshaw JM A simple index of Crohn's-disease activity. Lancet 1980;1:514.

18. Sandler RS, Jordan MCKupper LL Development of a Crohn's index for survey research. J Clin Epidemiol 1988;41:451-8.

19. Lichtiger S, Present DH, Kornbluth A, Gelernt I, Bauer J, Galler G, Michelassi F, Hanauer S. Cyclosporine in severe ulcerative colitis refractory to steroid therapy. N Engl J Med. 1994;330:1841-1845.

20. Smets EM, Garssen B, Cull A, de Haes JC. Application of the multidimensional fatigue inventory (MFI$20)$ in cancer patients receiving radiotherapy. Br J Cancer. 1996;73:241-245. 
21. Smets EM, Garssen B, Bonke B, De Haes JC. The Multidimensional Fatigue Inventory (MFI) psychometric qualities of an instrument to assess fatigue. J Psychosom Res. 1995;39: 315-325.

22. Russel MG, Pastoor CJ, Brandon S, Rijken J, Engels LG, van der Heijde DM, Stockbrugger RW. Validation of the Dutch translation of the Inflammatory Bowel Disease Questionnaire (IBDQ): a health-related quality of life questionnaire in inflammatory bowel disease. Digestion. 1997;58:282-288.

23. Guyatt G, Mitchell A, Irvine EJ, Singer J, Williams N, Goodacre R, Tompkins C. A new measure of health status for clinical trials in inflammatory bowel disease. Gastroenterology. 1989;96:804-810.

24. McHorney CA, Ware JE, Jr., Lu JF, Sherbourne CD. The MOS 36-item Short-Form Health Survey (SF-36): III. Tests of data quality, scaling assumptions, and reliability across diverse patient groups. Med Care. 1994;32:40-66.

25. Ware JE, Jr.Sherbourne CD The MOS 36-item short-form health survey (SF-36). I. Conceptual framework and item selection. Med Care 1992;30:473-83.

26. van Tulder MW, Aaronson NKBruning PF The quality of life of long-term survivors of Hodgkin's disease. Ann Oncol 1994;5:153-8.

27. Spinhoven P, Ormel J, Sloekers PP, Kempen GI, Speckens AE, Van Hemert AM. A validation study of the Hospital Anxiety and Depression Scale (HADS) in different groups of Dutch subjects. Psychol Med. 1997;27:363-370.

28. Zigmond ASSnaith RP The hospital anxiety and depression scale. Acta Psychiatr Scand 1983;67:361-70.

29. Bjelland I, Dahl AA, Haug TT, Neckelmann D. The validity of the Hospital Anxiety and Depression Scale. An updated literature review. J Psychosom Res. 2002;52:69-77.

30. Schwarz R, Krauss OHinz A Fatigue in the general population. Onkologie 2003;26:140-4.

31. Statacorp. Stata Statistical Software: Release 8.2. Stata corperation: College Station, TX, 2005

32. Lawrie SM, Manders DN, Geddes JR, Pelosi AJ. A population-based incidence study of chronic fatigue. Psychol Med. 1997;27:343-353.

33. Walker EA, Katon WJJemelka RP Psychiatric disorders and medical care utilization among people in the general population who report fatigue. J Gen Intern Med 1993;8:436-40.

34. Bates DW, Schmitt W, Buchwald D, Ware NC, Lee J, Thoyer E, Kornish RJ, Komaroff AL. Prevalence of fatigue and chronic fatigue syndrome in a primary care practice. Arch Intern Med. 1993;153: 2759-2765.

35. Watt T, Groenvold M, Bjorner JB, Noerholm V, Rasmussen NA, Bech P. Fatigue in the Danish general population. Influence of sociodemographic factors and disease. J Epidemiol Community Health. 2000;54:827-833.

36. van Tubergen A, Coenen J, Landewe R, Spoorenberg A, Chorus A, Boonen A, van der Linden S, van der Heijde D. Assessment of fatigue in patients with ankylosing spondylitis: a psychometric analysis. Arthritis Rheum. 2002;47:8-16.

37. Rupp I, Boshuizen HC, Jacobi CE, Dinant HJ, van den Bos GA. Impact of fatigue on health-related quality of life in rheumatoid arthritis. Arthritis Rheum. 2004;51:578-585.

38. Barendregt PJ, Visser MR, Smets EM, Tulen JH, van den Meiracker AH, Boomsma F, Markusse HM. Fatigue in primary Sjogren's syndrome. Ann Rheum Dis. 1998;57:291-295.

39. Unal G, de Boer JB, Borsboom GJ, Brouwer JT, Essink-Bot M, de Man RA. A psychometric comparison of health-related quality of life measures in chronic liver disease. J Clin Epidemiol. 2001;54:587-596.

40. Hagelin CL, Wengstrom Y, Runesdotter S, Furst CJ. The psychometric properties of the Swedish Multidimensional Fatigue Inventory MFI-20 in four different populations. Acta Oncol. 2007;46:97-104.

41. Visser MRSmets EM Fatigue, depression and quality of life in cancer patients: how are they related? Support Care Cancer 1998;6:101-8.

42. Holzner B, Kemmler G, Greil R, Kopp M, Zeimet A, Raderer M, Hejna M, Zochbauer S, Krajnik G, Huber $\mathrm{H}$, Fleischhacker WW, Sperner-Unterweger B. The impact of hemoglobin levels on fatigue and quality of life in cancer patients. Ann Oncol. 2002;13:965-973.

43. Gasche C, Lomer MC, Cavill I, Weiss G. Iron, anaemia, and inflammatory bowel diseases. Gut. 2004;53:1190-1197.

44. Minderhoud IM, Samsom MOldenburg B Crohn's disease, fatigue, and infliximab: is there a role for cytokines in the pathogenesis of fatigue? World J Gastroenterol 2007;13:2089-93.

45. Carlsson E, Bosaeus INordgren S Quality of life and concerns in patients with short bowel syndrome. Clin Nutr 2003;22:445-52. 
46. Kalaitzakis E, Carlsson E, Josefsson A, Bosaeus I. Quality of life in short-bowel syndrome: impact of fatigue and gastrointestinal symptoms. Scand J Gastroenterol. 2008;43:1057-1065.

47. Hauser W, Dietz N, Steder-Neukamm U, Janke KH, Stallmach A. Biopsychosocial determinants of health-related quality of life after ileal pouch anal anastomosis for ulcerative colitis. Inflamm Bowel Dis. 2004;10:399-407.

48. Bjornsson $\mathrm{E}$, Simren $\mathrm{M}$, Olsson $\mathrm{R}$, Chapman RW. Fatigue in patients with primary sclerosing cholangitis. Scand J Gastroenterol. 2004;39:961-968.

49. Loftus EV, Feagan BG, Colombel JF, Rubin DT, Wu EQ, Yu AP, Pollack PF, Chao J, Mulani P. Effects of adalimumab maintenance therapy on health-related quality of life of patients with Crohn's disease: patient-reported outcomes of the CHARM trial. Am J Gastroenterol 2008;103:3132-3141.

50. Nordin K, Pahlman L, Larsson K, Sundberg-Hjelm M, Loof L. Health-related quality of life and psychological distress in a population-based sample of Swedish patients with inflammatory bowel disease. Scand J Gastroenterol. 2002;37:450-457.

51. Kurina LM, Goldacre MJ, Yeates D, Gill LE. Depression and anxiety in people with inflammatory bowel disease. J Epidemiol Community Health. 2001;55:716-720.

52. Guthrie E, Jackson J, Shaffer J, Thompson D, Tomenson B, Creed F. Psychological disorder and severity of inflammatory bowel disease predict health-related quality of life in ulcerative colitis and Crohn's disease. Am J Gastroenterol. 2002;97:1994-1999.

53. McKegney FP, Gordon ROLevine SM A psychosomatic comparison of patients with ulcerative colitis and Crohn's disease. Psychosom Med 1970;32:153-66.

54. Ondersma SJ, Lumley MA, Corlis ME, Tojek TM, Tolia V. Adolescents with inflammatory bowel disease: the roles of negative affectivity and hostility in subjective versus objective health. J Pediatr Psychol. 1997;22:723-738.

55. Helzer JE, Chammas S, Norland CC, Stillings WA, Alpers DH. A study of the association between Crohn's disease and psychiatric illness. Gastroenterology. 1984;86:324-330.

56. Tarter RE, Switala J, Carra J, Edwards KL, Van Thiel DH. Inflammatory bowel disease: psychiatric status of patients before and after disease onset. Int J Psychiatry Med. 1987; 17:173-181.

57. Walker EA, Gelfand MD, Gelfand AN, Creed F, Katon WJ. The relationship of current psychiatric disorder to functional disability and distress in patients with inflammatory bowel disease. Gen Hosp Psychiatry. 1996;18:220-229.

58. Engstrom ILindquist BL Inflammatory bowel disease in children and adolescents: a somatic and psychiatric investigation. Acta Paediatr Scand 1991;80:640-7.

59. Mittermaier C, Dejaco C, Waldhoer T, Oefferlbauer-Ernst A, Miehsler W, Beier M, Tillinger W, Gangl A, Moser G. Impact of depressive mood on relapse in patients with inflammatory bowel disease: a prospective 18-month follow-up study. Psychosom Med. 2004;66:79-84.

60. Simren M, Axelsson J, Gillberg R, Abrahamsson H, Svedlund J, Bjornsson ES. Quality of life in inflammatory bowel disease in remission: the impact of IBS-like symptoms and associated psychological factors. Am J Gastroenterol. 2002;97:389-396.

61. Petrak F, Hardt J, Clement T, Borner N, Egle UT, Hoffmann SO. Impaired health-related quality of life in inflammatory bowel diseases: psychosocial impact and coping styles in a national German sample. Scand J Gastroenterol. 2001;36:375-382.

62. Bernklev T, Jahnsen J, Aadland E, Sauar J, Schulz T, Lygren I, Henriksen M, Stray N, Kjellevold O, Vatn $M$, Moum B. Health-related quality of life in patients with inflammatory bowel disease five years after the initial diagnosis. Scand J Gastroenterol. 2004;39:365-373.

63. Janke KH, Raible A, Bauer M, Clemens P, Meisner C, Hauser W, Steder-Neukamm U, Henrich G, Herschbach P, Gregor M, Klump B. Questions on life satisfaction (FLZM) in inflammatory bowel disease. Int J Colorectal Dis. 2004;19:343-353.

64. Blondel-Kucharski F, Chircop C, Marquis P, Cortot A, Baron F, Gendre JP, Colombel JF. Health-related quality of life in Crohn's disease: a prospective longitudinal study in 231 patients. Am J Gastroenterol. 2001;96:2915-2920.

65. Bernklev T, Jahnsen J, Lygren I, Henriksen M, Vatn M, Moum B. Health-related quality of life in patients with inflammatory bowel disease measured with the short form-36: psychometric assessments and a comparison with general population norms. Inflamm Bowel Dis. 2005;11:909-918.

66. Han SW, McColl E, Barton JR, James P, Steen IN, Welfare MR. Predictors of quality of life in ulcerative colitis: the importance of symptoms and illness representations. Inflamm Bowel Dis. 2005;11:24-34. 
67. Pizzi LT, Weston CM, Goldfarb NI, Moretti D, Cobb N, Howell JB, Infantolino A, Dimarino AJ, Cohen S. Impact of chronic conditions on quality of life in patients with inflammatory bowel disease. Inflamm Bowel Dis. 2006;12:47-52.

68. Casellas F, Lopez-Vivancos J, Badia X, Vilaseca J, Malagelada JR. Influence of inflammatory bowel disease on different dimensions of quality of life. Eur J Gastroenterol Hepatol. 2001;13:567-572.

69. Sewitch MJ, Abrahamowicz M, Bitton A, Daly D, Wild GE, Cohen A, Katz S, Szego PL, Dobkin PL. Psychological distress, social support, and disease activity in patients with inflammatory bowel disease. Am J Gastroenterol. 2001;96:1470-1479.

70. Casellas F, Arenas JI, Baudet JS, Fabregas S, Garcia N, Gelabert J, Medina C, Ochotorena I, Papo M, Rodrigo L, Malagelada JR. Impairment of health-related quality of life in patients with inflammatory bowel disease: a Spanish multicenter study. Inflamm Bowel Dis. 2005;11: 488-496.

71. Walker EA, Gelfand AN, Gelfand MD, Katon WJ. Psychiatric diagnoses, sexual and physical victimization, and disability in patients with irritable bowel syndrome or inflammatory bowel disease. Psychol Med. 1995;25:1259-1267.

72. Casellas F, Lopez-Vivancos J, Casado A, Malagelada JR. Factors affecting health related quality of life of patients with inflammatory bowel disease. Qual Life Res. 2002;11:775-781.

73. Porcelli $\mathrm{P}$, Leoci CGuerra $\vee \mathrm{A}$ prospective study of the relationship between disease activity and psychologic distress in patients with inflammatory bowel disease. Scand J Gastroenterol 1996;31: 792-796.

74. Hjortswang H, Jarnerot G, Curman B, Sandberg-Gertzen H, Tysk C, Blomberg B, Almer S, Strom M. The influence of demographic and disease-related factors on health-related quality of life in patients with ulcerative colitis. Eur J Gastroenterol Hepatol. 2003;15:1011-1020.

75. Graff LA, Walker JR, Lix L, Clara I, Rawsthorne P, Rogala L, Miller N, Jakul L, McPhail C, Ediger J, Bernstein $\mathrm{CN}$. The relationship of inflammatory bowel disease type and activity to psychological functioning and quality of life. Clin Gastroenterol Hepatol. 2006;4:1491-1501.

76. Saibeni S, Cortinovis I, Beretta L, Tatarella M, Ferraris L, Rondonotti E, Corbellini A, Bortoli A, Colombo E, Alvisi C, Imperiali G, de Franchis R. Gender and disease activity influence health-related quality of life in inflammatory bowel diseases. Hepatogastroenterology. 2005;52: 509-515.

77. Faubion WA, Jr., Loftus EV, Jr., Harmsen WS, Zinsmeister AR, Sandborn WJ. The natural history of corticosteroid therapy for inflammatory bowel disease: a population-based study. Gastroenterology. 2001;121:255-260.

78. Bernklev T, Jahnsen J, Schulz T, Sauar J, Lygren I, Henriksen M, Stray N, Kjellevold O, Aadland E, Vatn M, Moum B. Course of disease, drug treatment and health-related quality of life in patients with inflammatory bowel disease 5 years after initial diagnosis. Eur J Gastroenterol Hepatol. 2005;17: 1037-1045.

79. Minderhoud IM, Oldenburg B, Wismeijer JA, van Berge Henegouwen GP, Smout AJ. IBS-like symptoms in patients with inflammatory bowel disease in remission; relationships with quality of life and coping behavior. Dig Dis Sci. 2004;49:469-474.

80. Tanaka MKazuma K Ulcerative colitis: factors affecting difficulties of life and psychological well being of patients in remission. J Clin Nurs 2005;14:65-73.

81. Smolen DMTopp R Coping methods of patients with inflammatory bowel disease and prediction of perceived health, functional status, and well-being. Gastroenterol Nurs 1998;21:112-8.

82. Moskovitz DN, Maunder RG, Cohen Z, McLeod RS, MacRae H. Coping behavior and social support contribute independently to quality of life after surgery for inflammatory bowel disease. Dis Colon Rectum. 2000;43:517-521.

83. van der Zaag-Loonen HJ, Grootenhuis MA, Last BF, Derkx HH. Coping strategies and quality of life of adolescents with inflammatory bowel disease. Qual Life Res. 2004;13:1011-1019.

84. Thirlby RC, Sobrino MARandall JB The long-term benefit of surgery on health-related quality of life in patients with inflammatory bowel disease. Arch Surg 2001;136:521-7.

85. Thirlby RC, Land JC, Fenster LF, Lonborg R. Effect of surgery on health-related quality of life in patients with inflammatory bowel disease: a prospective study. Arch Surg. 1998;133: 826-832. 


\section{Chapter 6}

\section{The influence of disease course on fatigue and health related quality of life in inflammatory bowel disease}

Results from the population based IBD South Limburg cohort

Mariëlle JL Romberg-Camps, Yvonne Bol, Martine AM Hesselink-van de Kruijs, Arnold DM Kester, Laurens P Bos, Cees van Deursen, Wim HA Hameeteman, Marieke Pierik, Frank L Wolters, Maurice GVM Russel, Reinhold W Stockbrügger, Pieter C Dagnelie 


\section{Abstract}

\section{Background and aims}

The importance of fatigue and its negative impact on patients' Health Related Quality of Life (HRQoL) has been increasingly recognized. Little is known about fatigue in Inflammatory Bowel Disease (IBD). The aim of the present study was to evaluate determinants of fatigue and HRQoL from diagnosis onwards during the disease course in an unselected regional cohort of IBD patients.

\section{Methods}

IBD patients diagnosed between January 1st, 1991, and January 1st, 2003, were included and followed until data collection, July 1st, 2005, to January 1st, 2006. Medical records were reviewed (diagnosis, medication, recurrences). Haemoglobin levels were recorded. Patients completed a disease activity questionnaire, the Multidimensional Fatigue Inventory 20, the Inflammatory Bowel Disease Questionnaire and the Short Form Health Survey 36.

\section{Results}

Data were available of 304 Crohn's Disease (CD) and 368 Ulcerative Colitis (UC) patients. In CD and UC, a severe disease course as reported by patients and assessed from objective findings, was associated with a higher degree of fatigue and lower HRQoL. Other determinants were female gender in UC, and corticosteroid and immunosuppressive use in both CD and UC. In the multivariate analysis, infliximab use in CD resulted in low fatigue and better HRQoL scores.

\section{Conclusions}

In CD and UC, a more severe disease course is associated with more fatigue and an impaired HRQoL, suggesting that IBD has a continuous impact on patients' perceived and objective disease course even when they have little or no symptoms. 


\section{Introduction}

Inflammatory Bowel Disease (IBD) is a group of inflammatory conditions of the intestine. The major types of IBD are Crohn's Disease (CD) and Ulcerative Colitis (UC). The main difference between $C D$ and $U C$ is the location and nature of the inflammatory changes. Whereas $C D$ can involve any part of the gastrointestinal tract from the oral cavity to the anus, UC is restricted to the colon. The exact cause of IBD is unknown, but both genetic and environmental factors are thought to play a significant role in its aetiology and pathogenesis. ${ }^{1-3}$ In Europe, the incidence of $C D$ is three to eight new cases per 100,000 persons per year and three to fourteen per 100,000 per year for UC. ${ }^{4,5}$ Age standardized incidence rates (1991-2002) per 100,000 person-years ( $\left.p-y\right)$ in the Netherlands, South-Limburg were for CD: male 4.84, female 7.58 and for UC:

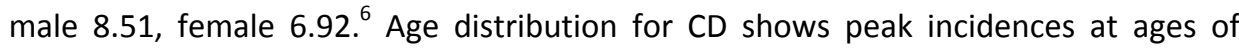
$15-25$, especially in female patients, whereas in UC male incidence is still high in older age groups. $^{6-8}$

IBD not only has a compromising effect on physical functioning, it has also a major impact on patients' mental and social functioning. In the last decade several studies indicate that Health Related Quality of Life (HRQoL) in IBD is negatively influenced by disease activity. ${ }^{9-13}$ However, other variables such as extra-intestinal manifestations ${ }^{14-16}$, Irritable Bowel (IBS) like symptoms ${ }^{17}$, anaemia ${ }^{18}$, short bowel syndrome, ileo anal pouch ${ }^{19,20}$ and higher age ${ }^{9}$ also result in a reduced HRQoL. For the course of disease and its effect on the HRQoL in IBD, treatment with systemic corticosteroid or immunosuppressive drugs, a relapsing disease course and extra-intestinal manifestations were reported as negative determinants of HRQoL. ${ }^{14,21}$

The importance of fatigue and its negative impact on patients' Health Related Quality of Life (HRQoL) has been increasingly recognized and studied in several chronic diseases $^{22-24}$ and cancer. ${ }^{25,26}$ Persistent fatigue from chronic illness involves ongoing exhaustion that is disproportionate to exertion and not alleviated by rest. ${ }^{22}$ Fatigue is often experienced by patients as the most debilitating part of the disease. ${ }^{22,25}$ Little is known about fatigue and its impact on the HRQoL in IBD. Higher levels of fatigue were reported in IBD patients having active disease ${ }^{27}$ and anaemic IBD patients ${ }^{18}$, a finding we recently confirmed. ${ }^{28,29}$ Moreover, within our IBD cohort, the presence of fatigue had a strong negative impact on the patients' HRQoL. ${ }^{29,30}$ But how to explain the high prevalence of fatigue in IBD patients without disease activity ${ }^{27-29}$, an observation similarly found for other chronic relapsing diseases such as multiple sclerosis ${ }^{24,31}$ and rheumatoid arthritis. ${ }^{32}$

The aim of the present study was therefore, to identify determinants of fatigue and HRQoL occurring from diagnosis onwards during the disease course, in unselected patients with IBD from a well-defined regional population. 


\section{Methods}

\section{Population and design}

In 1991 a population-based Inflammatory Bowel Disease Registry was established in collaboration between the Departments of Gastroenteroly/Hepatology and the MEMIC (Centre for Data and Information Management, University of Maastricht). The primary objective of the registry was to prospectively study the incidence of IBD and risk factors for disease severity and outcome within a well-defined area of the Netherlands, namely South-Limburg (IBD-SL). ${ }^{33}$

South Limburg is located in the South-East of the Netherlands between Germany and Belgium; its northern border with the rest of the Netherlands is narrow. The region had a population of about 645,000 between 1991 and 2003, and migration rate in and out of the area is low. ${ }^{34}$

All three hospitals in South Limburg, i.e. Maastricht University Medical Center in Maastricht and the General district hospitals of Heerlen and Sittard participated in the study. Apart from general practitioners (GPs), there are no other in- or outpatient clinics treating patients with IBD in this area. With regard to possible treatment of IBD patients by GPs, completeness of hospital case ascertainment was verified by Russel et al. ${ }^{5}$ and found to be very high.

Inclusion of IBD patients was based on endoscopic and/or radiological evidence, supported by mucosal biopsy and/or examination of a surgical specimen. For case definition of $C D$, the criteria of Lennard-Jones were applied. ${ }^{35}$ UC was defined as continuous mucosal inflammation without granulomata, affecting the rectum and/or some or all of the colon in continuity with the rectum. The term IBD unclassified (IDBU) was used for cases of IBD in which, after careful investigation, the differential diagnosis between $C D$ and UC remained uncertain. ${ }^{36}$

Patient recruitment was performed by gastroenterologists, internists, surgeons and paediatricians working in the IBD-SL area ${ }^{5}$. In the present study, all newly diagnosed patients (i.e. without prior history of IBD), registered between January $1^{\text {st }}, 1991$, and January $1^{\text {st }}, 2003$, were included. These patients were followed from inclusion until data collection for the present study, which took place from July $1^{\text {st }}, 2005$, to January $1^{\text {st }}, 2006$, or until a prior date in case of death or loss to follow-up (LTFU). During data collection for the present study, inclusion criteria were re-verified for all patients.

The Ethical Committees of all participating centres approved of the protocol, and written informed consent was obtained from all patients at inclusion in the IBD-SL registry for future analysis and publication of data. In patients $<18$ years of age their parents or a legal representative signed for informed consent.

\section{Medical record data collection and definitions}

In all hospitals, the original written medical records as well as electronic patient files were reviewed. All collected data were instantly and uniformly registered in an Access 
database. The charts were reviewed with regard to diagnosis, disease recurrences and medication use. In 50 out of 1187 patients, the diagnosis had been changed after the initial diagnosis had been established. ${ }^{37}$ For the current analysis, the last established diagnosis was used for further analysis. Medication use was registered as positive for a three months' period if used at any moment during that time period. The most commonly used drugs for IBD were selected for analysis and reported as the percentage of patients that ever used the drug during follow-up. Medication registered was mesalazine (5-ASA) (systemic use), corticosteroids (topical and/or systemic use of prednisone, prednisolone, beclomethason or budesonide), "other immune modulating medication" (azathioprine, 6-mercaptopurine, thioguanine, cyclosporine and methotrexate) and infliximab. The group of "other immune modulating medication" will be referred to as "immunosuppressives" throughout this paper.

Patients were characterized according to the Vienna classification at diagnosis. ${ }^{38}$ For the purpose of this investigation, patients included before publication of the Vienna classification (year 2000) were retrospectively classified. Definitions for "location" and "recurrence" were used according to an earlier publication of the European Collaborative study group on Inflammatory Bowel Disease (EC-IBD). ${ }^{39,40}$. In UC disease activity limited to the rectum (up to $15 \mathrm{~cm}$ above the linea dentata) was classified as "proctitis", colonic inflammation distal to the splenic flexure as "distal colitis" and disease activity proximal to the splenic flexure was classified as "extensive colitis". Recurrences were dated on the follow-up time scale and recorded as "surgical" or "non-surgical". A "surgical recurrence" was defined as an episode of increased disease activity requiring surgical intervention, either with or without medication change. A "non-surgical recurrence" was defined as an episode of increased disease activity requiring an increased dose of current medication or the addition of new medication, but no surgery. Surgical recurrences were further sub-classified into being either "resective" (part of the bowel was resected) or any "other type" of surgery (including abscess drainages, fistula operations, stoma and pouch procedures etc.). In UC surgical recurrence in the majority were patients diagnosed with inflammation who subsequently during disease course needed a colectomy. "All type recurrences" were defined as the sum of "surgical" plus "non-surgical" recurrences.

All available laboratory data between June $1^{\text {st }}, 2005$, and January $1^{\text {st }}, 2006$, with regard to the haemoglobin level were registered. Patients were classified as having anaemia using a cut off value, male: $8.5 \mathrm{mmol} / \mathrm{l}$ and female: $7.5 \mathrm{mmol} / \mathrm{l}$.

Throughout this study, where applicable, medical record data will be referred to as "objective disease course".

\section{Questionnaire}

In June 2005, questionnaires were sent to the included patients. When no response was received within six weeks a reminding letter was sent to the respective patients. When again no response was received a new reminding letter, together with a 
duplicate of the questionnaire, was sent (October 2005). Final date for inclusion of questionnaires was January $1^{\text {st }}, 2006$.

The composite questionnaire included items on:

\section{Disease activity}

In $\mathrm{CD}$, the Harvey Bradshaw Index $(\mathrm{HBI})^{41}$ was used for analysis of disease activity. As patients were not examined physically the item of "abdominal mass" was scored as zero (no mass and no abdominal pain on palpation). To evaluate the accuracy of the $\mathrm{HBI}$, a subgroup of patients also scored disease activity using a validated diary developed by Sandler et al. ${ }^{42}$ to establish disease activity in CD. The correlation between this diary and $\mathrm{HBI}$ was high $(\mathrm{r}=0.80)$. $\mathrm{A} \mathrm{HBI}$ equal or more than five indicated presence of disease activity. In UC, the Colitis Activity Index (CAI) ${ }^{43}$ was used. As in the CD patients, no physical examination took place. The item regarding "abdominal pain on palpation" was set to be zero ("no abdominal pain"). A CAl equal of more than ten indicated disease activity. Active disease at the moment of questionnaire was noted as a recurrence.

\section{Disease course}

In the questionnaire patients were asked to overall rate their disease course as; "inactive since the IBD diagnosis" ("inactive"), "in most years since the diagnosis no disease activity" ("most years no activity"), "in most years since the diagnosis disease activity, but not in every year" ("most years activity"), and "disease activity in every year since the IBD diagnosis" ("every year activity"). Throughout the report we will refer to this question as "subjective disease course".

\section{Fatigue}

To measure fatigue, the validated Dutch Multidimensional Fatigue Inventory (MFI-20) was used. This is a 20-item instrument designed to measure five fatigue dimensions: general fatigue; physical fatigue; reduced activity; reduced motivation; mental fatigue $^{44,45}$. Each dimension contains four items with a five point response format, resulting in a cumulative score range from 4-20 per dimension. A higher score indicates a higher degree of fatigue.

\section{Health related quality of life}

The Inflammatory Bowel Disease Questionnaire (IBDQ) and the Short Form health survey (SF-36) were used to measure HRQoL. The IBDQ is a 32 item disease specific $\mathrm{HRQ}$ oL questionnaire, including four health dimensions: bowel symptoms (10 items); systemic symptoms (5 items); emotional well-being (12 items); social functioning (5 items $)^{46,47}$. Responses are graded on a 7-point Likert scale in which " 1 " represents a very severe problem and " 7 " represents no problem at all. In each dimension the mean 
value is calculated. Consequently, a higher score indicates a better quality of life. From the mean IBDQ sub-scores a total IBDQ score was computed per patient and used in the multivariate analysis.

The SF-36 includes multi-item scales measuring eight general health concepts: physical functioning (10 items); role of limitations due to physical health problems (4 items); bodily pain ( 2 items); general health perception ( 5 items); vitality ( 4 items); social function ( 2 items); role limitations due to personal or emotional problems ( 3 items); mental health (5 items) ${ }^{48,49}$. One question covers change in health status over the past year. This question is not counted in scoring in the eight dimensions. Translation of this questionnaire into Dutch was carried out as part of an International Quality of Life assessment project. ${ }^{50}$ From the SF-36, individual "physical health" and "mental health" summary scores were computed using a norm-based scoring. ${ }^{48,49}$ The "physical health" summary score is calculated using the dimensions, physical functioning, role of limitations due to physical health problems, bodily pain and general health perception. For calculating the "mental health" summary score social function, role limitations due to personal or emotional problems and mental health is used. This calculation results in a score in which 50 (standard deviation 10) is the norm based score found in the USA population, a finding comparable to results of the average Dutch population. ${ }^{48}$ For example a higher score indicates a better quality of life compared to the average USA population.

\section{Statistical analysis}

Calculations were performed on the basis of the last established IBD diagnosis, according to the mentioned criteria. Differences in diagnostic groups were appraised using Pearson chi-square tests. If one of the items of a subscale was missing, it was replaced by the median of the remaining items of that subscale in the concerned patient. If more than one item per questionnaire was missing, the concerned questionnaire was excluded from further analysis.

Using multiple regression analysis, we first evaluated possible determinants of fatigue, including: diagnosis; gender; age; phenotype at diagnosis, disease course (questionnaire), recurrences; medication use. For HRQoL as outcome, a multiple regression analysis was performed including the same determinants and additionally the presence of fatigue. Analyses were performed separately for $C D$ and $U C$.

To see whether primarily patients with current disease activity and/or anaemia caused the found relations, all analyses on fatigue and HRQoL outcome were repeated without these patient categories.

Data analyses were performed using Stata $8.2 .^{51}$ P-values less than 0.05 were considered statistically significant. 


\section{Results}

\section{Patient population}

Between January $1^{\text {st }}, 1991$, and January $1^{\text {st }}, 2003,1254$ newly diagnosed IBD patients were included in the IBD-SL registry. Of the 1254 remaining patients, 67 patients were excluded because medical records were unavailable. In 81 patients, IBDU was diagnosed at inclusion, these were excluded from the analysis, as numbers would have been to small for meaningful analysis, leaving 1106 patients for data analysis. Data on disease location at diagnosis were missing in 27 CD and 34 UC patients; these patients were included for further analysis if questionnaire data were available. Mean age at diagnosis, gender and IBD diagnosis (CD and UC) were not significantly different between in- and excluded patients (data not shown). The study population at inclusion $(\mathrm{N}=1106)$ comprised 476 patients with $\mathrm{CD}$ and 630 with UC. The sex distribution was 187 male, 289 female in CD and 350 male, 280 female in UC. Median age (range) at diagnosis was 29.0 (5.8-79.5) years for CD and 38.0 (8.2-84.3) years for UC. At the censoring date (January $\left.1^{\text {st }}, 2006\right), 21$ out of 476 CD patients and 47 out of 630 UC patients had died, without significant difference of proportions between the $C D$ and UC ( $p=0.14)$.

Median (range) follow-up time for patients alive at the censoring date was 7.8 (0.2-15.4) years in CD and $7.0(0.1-15.0)$ years in UC.

Of the 1106 included patients, 68 had deceased and 31 could not be traced. Of the remaining 1007 patients, 672 questionnaires were received (response rate 67\%). There was no difference in response rates with regard to IBD diagnosis, age at diagnosis, age at moment of questionnaire, phenotype at diagnosis and length of follow-up. Within the entire IBD patient group there were more female than male patients returning the questionnaire $(p<0.0001)$.

In Table 6.1, demographic and clinical characteristics of the study population ( $N=672$ ) are presented. There were significantly more female patients in the CD patient group. The age at diagnosis was significantly lower for CD patients compared to UC patients, as was their age when they filled out our questionnaire. Follow-up time in CD patients was slightly, but significantly, longer than in UC. Disease location in CD was: terminal ileum in $31 \%$, colonic in $29 \%$, ileo-colonic in $30 \%$, upper gastro-intestinal in $4 \%$, and unknown in $6 \%$ of patients. In CD, disease behaviour was inflammatory in most patients (75\%), stricturing disease was found in $14 \%$ of CD patients, penetrating in $8 \%$, and a combination of stricturing and penetrating in 3\%. In UC patients, disease location was proctitis in $38 \%$, distal colitis in $44 \%$, extensive colitis in $14 \%$ and unknown in $4 \%$ (data not shown). In CD, when compared to UC, significantly more patients had active disease and/or anaemia during data collection. Subjective disease course in CD patients was significantly worse compared to UC. Also cumulative recurrence percentages and number of recurrences per 100 patient-years $(p-y)$ were significantly higher in $C D$ patients especially with regard to surgical recurrences. 
During their disease course, a significantly higher proportion of CD than of UC patients used corticosteroids, immunosuppressives and infliximab, whereas relatively more UC patients used 5-ASA.

Table 6.1 Demographic and clinical characteristics.

\begin{tabular}{|c|c|c|}
\hline & CD & UC \\
\hline Number of patients, $\mathrm{N}(\%)^{* *}$ & $304(43)$ & $368(52)$ \\
\hline Male, N (\%) & $104(34)^{*}$ & $189(51)$ \\
\hline Female, N (\%) & $200(66)^{*}$ & $179(49)$ \\
\hline Age at diagnosis in years, mean (SD) & $34.5(14.3)^{*}$ & $41.2(14.4)$ \\
\hline Age at moment of questionnaire, mean (SD) & $42.8(14.6)^{*}$ & $49.9(14.5)$ \\
\hline Length of follow-up in years, mean (SD) & $8.3(3.7)$ & $7.5(4.0)$ \\
\hline Currently active disease and/or anaemia, N (\%) & $162(53)^{*}$ & $40(11)$ \\
\hline Activity disease, $\mathrm{N}(\%)$ & $143(47)^{*}$ & $16(4)$ \\
\hline Anaemia, N (\%) & $35(12)$ & $27(7)$ \\
\hline \multicolumn{3}{|l|}{ Subjective disease course, N (\%) } \\
\hline "inactive" & $28(9)$ & $42(11)$ \\
\hline "most years no activity" & $117(39)^{*}$ & $174(47)$ \\
\hline "most years activity" & $63(21)^{*}$ & $44(12)$ \\
\hline “every year activity” & $86(28)$ & $98(27)$ \\
\hline Missing & $10(3)$ & $10(3)$ \\
\hline \multicolumn{3}{|l|}{ Cumulative recurrence (\%) } \\
\hline All type recurrences & $89.1 \% *$ & $78.3 \%$ \\
\hline Surgical recurrences & $44.7 \% *$ & $9.5 \%$ \\
\hline Resective surgical recurrences & $39.8 \% *$ & $7.3 \%$ \\
\hline \multicolumn{3}{|l|}{ Recurrence per $100 p-y$, mean (SD) } \\
\hline All type recurrences & $44.7(43.9)^{*}$ & $37.2(50.6)$ \\
\hline Surgical recurrences & $12.8(26.8)^{*}$ & $6.8(41.1)$ \\
\hline Resective surgical recurrences & $7.0(13.8)^{*}$ & $2.5(17.0)$ \\
\hline \multicolumn{3}{|l|}{ Cumulative medication use (\%) } \\
\hline $5-A S A$ & $269(89)^{*}$ & $342(93)$ \\
\hline Corticosteroids & $226(74)^{*}$ & $212(58)$ \\
\hline Immunosuppressives & $135(44)^{*}$ & $78(21)$ \\
\hline Infliximab & $52(17)^{*}$ & $3(1)$ \\
\hline Never medication use & $17(6)$ & $15(4)$ \\
\hline
\end{tabular}

* significantly different between CD and UC ( $\mathrm{p}<0.05),{ }^{* *}$ last established diagnosis

\section{Fatigue scores}

In Table 6.2 $2_{L}$ mean MFI-20 scores are presented per diagnosis. In CD, as well as in UC, female patients scored significantly worse on the "general fatigue" sub-score (CD; female 15.0, male 13.6, UC; female 13.3, male 11.5). In other sub-scores, gender did not significantly determine outcome. Fatigue scores for the different phenotypes at diagnosis were not significantly different in $C D$ and in UC. 
Table 6.2 Mean MFI-20 scores (SD) per diagnosis.

\begin{tabular}{|c|c|c|c|c|c|c|}
\hline \multicolumn{2}{|l|}{ Crohn's Disease $(N=304)$} & $\begin{array}{l}\text { General } \\
\text { fatigue }\end{array}$ & $\begin{array}{l}\text { Physical } \\
\text { fatigue }\end{array}$ & $\begin{array}{l}\text { Reduced } \\
\text { activity }\end{array}$ & $\begin{array}{c}\text { Reduced } \\
\text { motivation }\end{array}$ & $\begin{array}{l}\text { Mental } \\
\text { score }\end{array}$ \\
\hline \multicolumn{7}{|l|}{ Subjective disease course } \\
\hline \multicolumn{2}{|l|}{ "inactive" ref } & $11.4(5.6)$ & $10.1(5.3)$ & $8.5(4.2)$ & $9.4(4.2)$ & $9.3(4.6)$ \\
\hline \multicolumn{2}{|l|}{ "most years no activity" } & $13.1(4.8)^{\mathrm{a}}$ & $10.9(4.4)$ & $9.1(3.7)$ & $8.9(3.6)$ & $8.6(4.3)$ \\
\hline \multicolumn{2}{|l|}{ "most years activity" } & $15.6(4.4)^{\mathrm{a}}$ & $13.9(4.5)^{\mathrm{a}}$ & $11.2(3.9)^{\mathrm{a}}$ & $10.1(4.2)^{\mathrm{a}}$ & $9.8(5.1)$ \\
\hline \multicolumn{2}{|l|}{ "every year activity" } & $16.6(3.6)^{\mathrm{a}}$ & $15.2(3.7)^{\mathrm{a}}$ & $12.2(4.1)^{\mathrm{a}}$ & $11.4(4.1)^{\mathrm{a}}$ & $11.6(4.5)^{\mathrm{a}}$ \\
\hline \multicolumn{7}{|l|}{ Cumulative recurrence } \\
\hline \multirow[t]{2}{*}{ All type recurrences } & no ${ }^{\text {ref }}$ & $12.6(4.5)$ & $10.9(4.4)$ & $9.7(3.3)$ & $8.3(3.1)$ & $7.9(3.6)$ \\
\hline & yes & $14.7(4.7)^{\mathrm{c}}$ & $12.9(4.8)^{\mathrm{c}}$ & $10.5(4.2)$ & $10.1(4.1)^{\mathrm{c}}$ & $9.9(4.8)^{\mathrm{c}}$ \\
\hline \multicolumn{7}{|l|}{ Recurrence per 100 p-y } \\
\hline \multicolumn{7}{|l|}{ All type recurrences } \\
\hline \multicolumn{2}{|l|}{$\leq 20$ per 100 p-y ${ }^{\text {ref }}$} & $12.8(4.7)$ & $11.1(4.5)$ & $9.5(3.8)$ & $9.1(4.0)$ & $8.6(4.0)$ \\
\hline \multicolumn{2}{|l|}{$>20-\leq 30$ per $100 p-y$} & $13.7(5.4)^{\mathrm{a}}$ & $11.8(4.9)$ & 9.7 (3.9) & $9.3(4.0)$ & $8.8(4.8)$ \\
\hline \multicolumn{2}{|l|}{$>30$ per 100 p-y } & $15.5(4.3)^{\mathrm{a}}$ & $13.7(4.7)^{\mathrm{a}}$ & $11.1(4.2)^{b}$ & $10.5(4.1)^{\mathrm{c}}$ & $10.5(4.8)^{b}$ \\
\hline \multicolumn{7}{|l|}{ Surgical recurrences } \\
\hline \multicolumn{2}{|l|}{$\leq 20$ per 100 p-y ${ }^{\text {ref }}$} & $14.3(4.7)$ & $12.5(4.6)$ & $10.1(3.9)$ & $9.6(3.8)$ & $9.4(4.5)$ \\
\hline \multicolumn{2}{|l|}{$>20-\leq 30$ per 100 p-y } & $14.6(5.2)$ & $13.4(5.2)$ & $11.4(4.5)$ & $10.6(4.9)$ & $10.3(4.3)$ \\
\hline \multicolumn{2}{|l|}{$>30$ per 100 p-y } & $15.4(4.8)$ & $13.8(5.3)$ & $11.8(4.8)^{\mathrm{c}}$ & $11.3(4.6)$ & $11.6(5.5)^{\mathrm{c}}$ \\
\hline \multicolumn{7}{|l|}{ Medication use } \\
\hline \multirow[t]{2}{*}{ Corticosteroids } & no ${ }^{\text {ref }}$ & $13.4(5.0)$ & $11.6(4.5)$ & $9.8(4.0)$ & $9.6(3.8)$ & $9.2(4.7)$ \\
\hline & yes & $14.9(4.6)^{c}$ & $13.1(4.8)^{\mathrm{c}}$ & $10.7(4.1)$ & $10.1(4.2)$ & $9.9(4.7)$ \\
\hline \multirow[t]{2}{*}{ Immunosuppressives } & no ${ }^{\text {ref }}$ & $13.6(4.8)$ & $11.7(4.6)$ & $9.8(4.0)$ & $9.5(3.9)$ & $9.3(4.7)$ \\
\hline & yes & $15.6(4.4)^{\mathrm{a}}$ & $14.0(4.7)^{\mathrm{a}}$ & $11.2(4.1)^{b}$ & $10.5(4.2)^{\mathrm{c}}$ & $10.2(4.6)$ \\
\hline \multirow[t]{2}{*}{ Infliximab } & no ${ }^{\text {ref }}$ & $14.2(4.9)$ & $12.3(4.8)$ & $10.1(4.1)$ & $9.9(4.1)$ & $9.5(4.6)$ \\
\hline & yes & $16.3(3.8)$ & $14.8(4.0)^{\mathrm{b}}$ & $11.9(4.1)^{\mathrm{b}}$ & $10.3(3.7)$ & $10.5(5.0)$ \\
\hline Ulcerative Colitis $(\mathrm{N}=368$ & & & & & & \\
\hline Subjective disease cours & & & & & & \\
\hline "inactive" ref & & $9.2(4.4)$ & $8.4(4.0)$ & $8.1(4.0)$ & $8.0(3.5)$ & $8.5(3.4)$ \\
\hline "most years no activity & & $11.4(4.5)^{\mathrm{a}}$ & $10.1(4.0)^{\mathrm{a}}$ & $9.2(3.6)^{a}$ & $8.9(3.8)^{a}$ & $8.7(4.2)^{a}$ \\
\hline "most years activity" & & $14.1(4.3)^{\mathrm{a}}$ & $12.0(4.2)^{\mathrm{a}}$ & $10.3(4.0)^{\mathrm{a}}$ & $10.1(4.0)^{\mathrm{a}}$ & $11.1(5.1)^{\mathrm{a}}$ \\
\hline "every year activity" & & $15.0(5.1)^{\mathrm{a}}$ & $13.4(4.8)^{\mathrm{a}}$ & $11.5(4.8)^{\mathrm{a}}$ & $11.0(4.5)^{\mathrm{a}}$ & $10.7(5.0)^{\mathrm{a}}$ \\
\hline Cumulative recurrence & & & & & & \\
\hline All type recurrences & no ${ }^{\text {ref }}$ & $11.4(4.8)$ & $10.0(4.2)$ & $9.0(3.7)$ & $8.9(3.9)$ & $9.3(4.5)$ \\
\hline & yes & $12.7(5.1)^{\mathrm{c}}$ & $11.3(4.7)^{\mathrm{c}}$ & $10.1(4.3)$ & $9.7(4.2)$ & $9.6(4.6)$ \\
\hline Surgical recurrences & no ${ }^{\text {ref }}$ & $12.3(5.0)$ & $10.8(4.6)$ & $9.6(4.2)^{f}$ & $9.5(4.1)$ & $9.5(4.5)$ \\
\hline & yes & $13.6(5.5)$ & $12.6(4.9)^{\mathrm{c}}$ & $11.5(4.2)^{c}$ & $9.9(4.6)$ & $10.0(5.3)$ \\
\hline Recurrence per $100 p-y$ & & & & & & \\
\hline All type recurrences & & & & & & \\
\hline$\leq 20$ per 100 p-y ${ }^{\text {ref }}$ & & $11.5(4.8)$ & $10.1(4.5)$ & 9.1 (3.9) & $9.0(4.0)$ & $9.3(4.6)$ \\
\hline$>20 \leq 30$ per 100 p-y & & $12.9(5.2)$ & $11.3(4.5)$ & $10.1(4.0)$ & $9.6(3.9)$ & $9.2(4.2)$ \\
\hline$>30$ per 100 p-y & & $13.1(5.1)^{\mathrm{c}}$ & $11.7(4.7)$ & $10.4(4.5)^{c}$ & $9.9(4.3)$ & $9.9(4.7)$ \\
\hline Surgical recurrences & & & & & & \\
\hline$\leq 20$ per 100 p-y ${ }^{\text {ref }}$ & & $12.3(5.0)$ & $10.9(4.6)$ & $9.7(4.2)$ & $9.4(4.1)$ & $9.5(4.6)$ \\
\hline$>20 \leq 30$ per 100 p-y & & $13.6(6.8)$ & $14.0(6.6)$ & $13.9(5.0)^{\mathrm{c}}$ & $11.3(6.0)$ & $11.6(5.8)$ \\
\hline >30 per 100 p-y & & $14.3(5.1)$ & $12.8(4.6)$ & $11.1(3.8)$ & $9.9(4.7)$ & $9.2(5.3)$ \\
\hline Medication use & & & & & & \\
\hline Corticosteroids & no ${ }^{\text {ref }}$ & $11.5(5.0)$ & $10.2(4.3)$ & $9.3(3.7)$ & $9.1(4.0)$ & $9.0(4.2)$ \\
\hline & yes & $13.1(5.0)^{b}$ & $11.6(4.8)^{b}$ & $10.2(4.6)^{c}$ & $9.8(4.2)$ & $9.9(4.8)$ \\
\hline Immunosuppressives & no & $12.0(5.1)$ & $10.6(4.6)$ & $9.5(4.1)$ & $9.2(4.1)$ & $9.2(4.5)$ \\
\hline & yes & $14.0(4.5)^{b}$ & $12.5(4.4)^{b}$ & $11.1(4.4)^{b}$ & $10.8(4.2)^{\mathrm{b}}$ & $10.7(4.9)^{c}$ \\
\hline
\end{tabular}

${ }^{\text {ref }}$ reference value, significantly different from reference value; ${ }^{a} p<0.0005,{ }^{b} p<0.005,{ }^{c} p<0.05$ 
Relative to $C D$ patients with an inactive subjective disease course, all other disease course categories in $C D$ scored significantly worse on the subcategories "general fatigue", "physical fatigue", "reduced activity" and "reduced motivation". For the subscore "mental fatigue" this was only significant in CD patients having disease activity "every year". In UC, compared to the reference group "inactive", significantly worse fatigue scores were found for all categories.

CD patients ever having had any recurrence ("all type") during disease course as also patients with over 30 "all type" recurrences per 100 p-y had significantly higher fatigue scores in most sub-categories compared to no recurrence or under 20 recurrences per $100 \mathrm{p}-\mathrm{y}$.

In CD, patients with over 30 surgical recurrences per 100 p-y scored significantly worse on the sub-scores "reduced activity" and "mental score".

In UC, "physical fatigue" and "reduced activity" scores were significantly worse in patients with a surgical recurrence at any time. UC patients having over 30 "all type" recurrences per 100 p-y scored worse on the sub-score "general fatigue" and "reduced activity". In CD as well as UC, use of corticosteroids, immunosuppressive medication and infliximab was associated with a significantly higher (worse) fatigue score. Excluding patients with current disease activity and/or anaemia did not significantly change the above reported statistical results although absolute values of fatigue degrees were lower (results not shown).

\section{Health Related Quality of Life}

\section{$I B D Q$}

In Table 6.3, a summary of IBDQ scores are presented. In CD, gender did not have any effect on IBDQ scores whereas in UC female patients scored significantly worse in the "bowel" and "systemic" symptoms sub-category. In CD, "emotional well being" was significantly lower in patients diagnosed under age of 40 years. Disease location and behaviour did not significantly determine outcome in IBDQ scores in CD and UC.

Using an "inactive" disease course as reference category in CD and UC, "most years activity" and "every year activity" scored significantly worse on all IBDQ subcategories. CD patients ever having had a recurrence ("all type") during disease course had a significantly worse IBDQ on all sub-scores. In UC, this was found for "bowel symptoms", "systemic symptoms" and "social functioning". Similar results for CD and UC patients were found when using the "all type" recurrence per $100 \mathrm{p}$-y definition.

Only patients who had over 30 surgical recurrences per 100 p-y scored worse within the sub-category "social functioning". 
Table 6.3 Mean IBDQ scores (SD) per diagnosis.

\begin{tabular}{|c|c|c|c|c|c|c|}
\hline \multicolumn{2}{|l|}{ Crohn's Disease (N=304) } & $\begin{array}{c}\text { bowel } \\
\text { symptoms }\end{array}$ & $\begin{array}{c}\text { systemic } \\
\text { symptoms }\end{array}$ & $\begin{array}{l}\text { emotional } \\
\text { well-being }\end{array}$ & $\begin{array}{c}\text { social } \\
\text { functioning }\end{array}$ & $\begin{array}{l}\text { IBDQ } \\
\text { total }\end{array}$ \\
\hline \multicolumn{7}{|l|}{ Subjective disease course } \\
\hline "inactive" ref & & $5.9(1.1)$ & $5.2(1.3)$ & $5.8(1.0)$ & $6.2(1.0)$ & $23.1(4.0)$ \\
\hline "most years no activity" & & $5.8(1.0)$ & $5.1(1.2)$ & $5.8(0.9)$ & $6.4(0.7)$ & $23.1(3.2)$ \\
\hline "most years activity" & & $5.2(0.9)^{\mathrm{a}}$ & $4.3(1.3)^{\mathrm{a}}$ & $5.2(1.2)^{\mathrm{a}}$ & $5.4(1.3)^{\mathrm{a}}$ & $20.1(4.1)^{a}$ \\
\hline “every year activity” & & $4.8(1.1)^{\mathrm{a}}$ & $4.0(1.2)^{\mathrm{a}}$ & $4.8(1.2)^{\mathrm{a}}$ & $4.8(1.4)^{\mathrm{a}}$ & $18.4(4.2)^{\mathrm{a}}$ \\
\hline \multicolumn{7}{|l|}{ Cumulative recurrence } \\
\hline \multirow[t]{2}{*}{ All type recurrences } & no ${ }^{\text {ref }}$ & $6.0(0.7)$ & $5.4(1.0)$ & $6.0(0.8)$ & $6.4(0.8)$ & $23.8(2.6)$ \\
\hline & yes & $5.3(1.1)^{a}$ & $4.5(1.3)^{\mathrm{a}}$ & $5.3(1.2)^{b}$ & $5.6(1.3)^{b}$ & $20.8(4.3)^{a}$ \\
\hline \multicolumn{7}{|l|}{ Recurrence per 100 p-y } \\
\hline \multicolumn{7}{|l|}{ All type recurrences } \\
\hline$\leq 20$ per 100 p-y ${ }^{\text {ref }}$ & & $5.9(0.8)$ & $5.3(1.0)$ & $5.9(0.8)$ & $6.3(0.9)$ & $23.4(2.8)$ \\
\hline$>20 \leq 30$ per 100 p-y & & $5.7(1.0)$ & $4.9(1.4)$ & $5.6(1.2)$ & $6.1(1.1)$ & $22.2(4.2)$ \\
\hline$>30$ per 100 p-y & & $5.1(1.1)^{\mathrm{a}}$ & $4.2(1.3)^{\mathrm{a}}$ & $5.1(1.2)^{\mathrm{a}}$ & $5.3(1.3)^{\mathrm{a}}$ & $19.7(4.3)^{\mathrm{a}}$ \\
\hline \multicolumn{7}{|l|}{ Medication use } \\
\hline \multirow[t]{2}{*}{ Corticosteroids } & no ${ }^{\text {ref }}$ & $5.6(0.9)$ & $5.1(1.1)$ & $5.7(1.0)$ & $6.1(1.0)$ & $22.6(3.4)$ \\
\hline & yes & $5.3(1.1)^{c}$ & $4.5(1.3)^{a}$ & $5.3(1.2)^{b}$ & $5.6(1.3)^{b}$ & $20.6(4.4)^{\mathrm{a}}$ \\
\hline \multirow[t]{2}{*}{ Immunosuppressives } & no ${ }^{\text {ref }}$ & $5.5(1.0)$ & $4.9(1.2)$ & $5.6(1.0)$ & $6.0(1.1)$ & $22.1(3.7)$ \\
\hline & yes & $5.2(1.2)^{c}$ & $4.2(1.4)^{\mathrm{a}}$ & $5.1(1.3)^{\mathrm{a}}$ & $5.4(1.4)^{\mathrm{a}}$ & $19.9(4.7)^{\mathrm{a}}$ \\
\hline \multirow[t]{2}{*}{ Infliximab } & no ${ }^{\text {ref }}$ & $5.5(1.0)$ & $4.7(1.3)$ & $5.5(1.2)$ & $5.8(1.2)$ & $21.5(4.1)$ \\
\hline & yes & $5.0(1.3)^{\mathrm{c}}$ & $4.1(1.3)^{b}$ & $5.0(1.2)^{\mathrm{c}}$ & $5.1(1.5)^{a}$ & $19.4(4.6)^{b}$ \\
\hline \multicolumn{7}{|l|}{ Ulcerative Colitis ( $\mathrm{N=368)}$} \\
\hline \multicolumn{7}{|l|}{ Subjective disease course } \\
\hline "inactive" ref & & $6.3(1.1)$ & $5.8(1.3)$ & $6.1(0.9)$ & $6.4(1.3)$ & 24.6 (3.9) \\
\hline "most years no activity & & $6.1(0.7)$ & $5.4(1.0)$ & $6.0(0.7)$ & $6.5(0.7)$ & $24.1(2.5)$ \\
\hline "most years activity" & & $5.2(1.2)^{\mathrm{a}}$ & $4.8(1.2)^{\mathrm{a}}$ & $5.4(1.0)^{\mathrm{a}}$ & $5.8(1.3)^{\mathrm{a}}$ & $21.1(4.1)^{\mathrm{a}}$ \\
\hline "every year activity" & & $4.9(1.2)^{\mathrm{a}}$ & $4.4(1.3)^{\mathrm{a}}$ & $5.2(1.1)^{\mathrm{a}}$ & $5.5(1.3)^{\mathrm{a}}$ & $20.0(4.2)^{\mathrm{a}}$ \\
\hline \multicolumn{7}{|l|}{ Cumulative recurrence } \\
\hline \multirow[t]{2}{*}{ All type recurrences } & no ${ }^{\text {ref }}$ & $6.1(0.9)$ & $5.3(1.2)$ & $5.9(0.9)$ & $6.5(0.8)$ & $23.8(3.5)$ \\
\hline & yes & $5.6(1.1)^{b}$ & $5.0(1.2)^{\mathrm{c}}$ & $5.7(1.0)$ & $6.0(1.2)^{\mathrm{c}}$ & $22.4(3.9)^{b}$ \\
\hline \multicolumn{7}{|l|}{ Recurrence per 100 p-y } \\
\hline \multicolumn{7}{|l|}{ All type recurrences } \\
\hline$\leq 20$ per 100 p-y ${ }^{\text {ref }}$ & & $6.0(0.9)$ & $5.3(1.2)$ & $5.9(0.9)$ & $6.4(1.1)$ & $23.7(3.5)$ \\
\hline$>20 \leq 30$ per 100 p-y & & $5.7(1.0)$ & $5.0(1.0)$ & $5.8(0.7)$ & $6.1(1.1)$ & $22.6(3.3)$ \\
\hline$>30$ per 100 p-y & & $5.5(1.2)^{a}$ & $4.9(1.3)^{c}$ & $5.6(1.0)^{c}$ & $5.9(1.3)^{b}$ & $21.9(4.2)^{\mathrm{a}}$ \\
\hline \multicolumn{7}{|l|}{ Surgical recurrences } \\
\hline$\leq 20$ per 100 p-y ${ }^{\text {ref }}$ & & $5.7(1.1)$ & $5.1(1.2)$ & $5.7(0.9)$ & $6.2(1.1)$ & $22.8(3.8)$ \\
\hline$>20 \leq 30$ per 100 p-y & & $5.5(1.3)$ & $4.5(1.6)$ & $5.4(1.4)$ & $5.0(1.3)$ & $19.4(4.9)$ \\
\hline$>30$ per 100 p-y & & $5.7(0.9)$ & $4.9(1.5)$ & $5.6(1.1)$ & $5.7(1.3)^{\mathrm{c}}$ & $22.0(4.0)$ \\
\hline \multicolumn{7}{|l|}{ Medication use } \\
\hline \multirow[t]{2}{*}{ Corticosteroids } & no ${ }^{\text {ref }}$ & $5.9(1.0)$ & $5.3(1.2)$ & $5.8(0.9)$ & $6.4(0.9)$ & $23.4(3.6)$ \\
\hline & yes & $5.6(1.1)^{c}$ & $5.0(1.2)^{\mathrm{c}}$ & $5.7(1.0)$ & $5.9(1.3)^{\mathrm{a}}$ & $22.2(4.0)^{\mathrm{c}}$ \\
\hline \multirow[t]{2}{*}{ Immunosuppressives } & no ${ }^{\text {ref }}$ & $5.8(1.0)$ & $5.2(1.2)$ & $5.8(0.9)$ & $6.3(1.1)$ & $23.1(3.7)$ \\
\hline & yes & $5.3(1.3)^{b}$ & $4.7(1.2)^{b}$ & $5.5(1.0)^{c}$ & $5.6(1.3)^{\mathrm{a}}$ & $21.1(4.0)^{\mathrm{a}}$ \\
\hline \multirow[t]{2}{*}{ Infliximab } & no ${ }^{\text {ref }}$ & $5.7(1.1)$ & $5.1(1.2)$ & $5.7(1.0)$ & $6.1(1.1)$ & 22.7 (3.9) \\
\hline & yes & $5.6(1.9)$ & $4.5(1.6)$ & $5.6(1.7)$ & $6.2(1.2)$ & $21.9(6.1)$ \\
\hline
\end{tabular}

${ }^{\text {ref }}$ reference value, significantly different from reference value; a $p<0.0005$, b $p<0.005, c p<0.05$ 
In $C D$, the use of corticosteroids, immunosuppressive medication and infliximab during disease course resulted in a significant worse IBDQ score within all sub- categories. For UC, this was equally found for corticosteroids and immunosuppressive use. Excluding patients with current disease activity and/or anaemia did not significantly change the above reported statistical significances, although it resulted in higher IBDQ scores (results not shown).

\section{SF-36}

In CD, mean SF-36 summary scores on physical and mental health were significantly worse in patients over 40 years of age at diagnosis, in patients with subjective disease activity "every year", and in patients who had more than 30 "all type" recurrences per 100 p-y. Moreover, in CD, patients who used corticosteroids, immunosuppressive medication or infliximab during disease course scored significantly worse in the physical but not in to mental health.

In UC, SF-36 summary scores on physical and mental health were significantly worse in patients having subjective disease activity "every year". Female gender, more than 30 "all type" recurrences per 100 p-y, corticosteroid use and immunosuppressive use also resulted in a significantly worse physical health summary score. Again, excluding patients with current disease activity and/or anemia did not significantly change the above reported statistical results although it resulted in higher SF-36 scores (results not shown).

\section{Determinants of fatigue and HRQoL}

\section{Fatigue}

In Table 6.4, independent determinants of fatigue, using the MFI sub-score "general fatigue" are presented. Based on multivariate analysis, in UC, female gender was a negative predictor for "general fatigue". Age at diagnosis, phenotype at diagnosis, medication use, "all type" and "surgical" recurrences did not significantly determine "general fatigue" scores in CD nor in UC. From the questionnaire results, using "inactive" course as reference category, significant determinants for fatigue were CD patients with disease activity in "most years" and "every year". Results in UC were comparable; the category "most years no activity", "most years activity" and "every year activity" scored significantly worse than those having an "inactive" disease course. The determinants of fatigue remained unchanged when excluding patients with current disease activity and/or anaemia, in which also the correlation coefficients did not change statistically significant. 
Table 6.4 Significant determinants of "general fatigue" score (MFI). A positive score indicates more fatigue (95\%-confidence interval).

\begin{tabular}{lcc}
\hline & $\begin{array}{c}\text { Crohn's Disease } \\
\text { RC }(95 \%-C l)\end{array}$ & $\begin{array}{c}\text { Ulcerative Colitis } \\
\text { RC }(95 \%-C l)\end{array}$ \\
\hline $\begin{array}{l}\text { Female gender (male**) } \\
\text { Subjective disease course }\end{array}$ & $0.99(-0.16,2.13)$ & $1.61(0.58,2.63)^{*}$ \\
"inactive" & $0.00^{* *}$ & $0.00^{* *}$ \\
"most years no activity" & $0.79(-1.14,2.72)$ & $2.28(0.63,3.94)^{*}$ \\
"most years activity" & $3.30(1.16,5.43)^{*}$ & $4.73(2.60,6.86)^{*}$ \\
"every year activity" & $3.81(1.69,5.93)^{*}$ & $5.55(3.72,7.37)^{*}$ \\
\hline
\end{tabular}

*significantly different from reference value $(\mathrm{p}<0.05), * *$ reference value, $\mathrm{RC}=$ regression coefficient, $\mathrm{Cl}=$ confidence interval

\section{Health related quality of life}

In Table 6.5, determinants influencing HRQoL are presented with SF-36 summary scores and total IBDQ score as outcome parameter. Gender did not significantly determine HRQoL in CD nor in UC. In UC, higher age at diagnosis was a significant determinant for the SF-36 physical summary score, resulting in a lower score. In CD patients age at diagnosis phenotype at presentation was not found to be a determinant of HRQOL. In UC, patients having "distal colitis" scored significantly better in the SF-36 "mental health summary score" $(6.62,95 \%-\mathrm{Cl}: 1.56,11.68)$ than the other UC phenotypes at diagnosis ("proctitis" and "extensive colitis"). Using "inactive" disease course as reference category, CD as well as UC patients with disease activity in every year scored significantly worse on the SF-36 physical health summary score and IBDQ. The number of surgical recurrences was unrelated to all HRQoL outcome parameters, whereas with regard to the "all type" recurrences in $C D$ results were mainly worse with an increasing number of recurrences on the IBDQ. After adjustment for all "disease course" parameters, fatigue was associated a significantly lower HRQoL in CD and UC for all HRQoL scores.

After excluding patients with current disease activity and/or anaemia, "most years disease activity" also appeared to be a significant negative determinant. For CD as well as UC in the SF-36 "physical health" score, regression coefficients (95\% confidence interval) were respectively $-7.75(95 \%-\mathrm{Cl}:-12.98,-2.53)$ and $-3.98(95 \%-\mathrm{Cl}:-7.46$, $-0.50)$. For the total IBDQ score these were $-1.83(95 \%-\mathrm{Cl}:-3.58,-0.07)$ in $\mathrm{CD}$ and -2.00 (95\%-Cl: $-3.20,-0.80)$ in UC. Outcome on the SF-36 "mental health" sub-score remained unchanged. Moreover in $\mathrm{CD}$, after exclusion of the active and anaemic patients, the use of infliximab during the disease course resulted in a better SF-36 physical $(5.68,95 \%$-Cl: $0.97,10.41)$ and IBDQ total score $(1.65,95 \%-\mathrm{Cl}: 0.06,3.23)$. 
Table 6.5 Significant determinants of HRQoL. A negative score indicates a lower HRQoL.

\begin{tabular}{|c|c|c|c|}
\hline $\begin{array}{l}\text { Crohn's Disease } \\
\text { RC (95\%-CI) }\end{array}$ & SF-36 physical & SF-36 mental & IBDQ total \\
\hline \multicolumn{4}{|l|}{ Subjective disease course } \\
\hline "inactive" & $0.00 * *$ & $0.00 * *$ & $0.00 * *$ \\
\hline "most years no activity" & $1.05(-2.61,4.71)$ & $-0.40(-4.69,3.90)$ & $0.98(-0.36,2.31)$ \\
\hline "most years activity" & $-2.90(-7.02,1.21)$ & $-1.89(-6.72,2.95)$ & $-0.64(-2.15,0.87)$ \\
\hline "every year activity" & $-5.31(-9.44,-1.19)^{*}$ & $-1.28(-6.13,3.56)$ & $-1.76(-3.27,-0.26)^{*}$ \\
\hline \multicolumn{4}{|l|}{ Recurrence per $100 \mathrm{p}-\mathrm{y}$} \\
\hline \multicolumn{4}{|l|}{ All type recurrences } \\
\hline$\leq 20$ per 100 p-y ${ }^{\text {ref }}$ & $0.00 * *$ & $0.00 * *$ & $0.00 * *$ \\
\hline$>20-\leq 30$ per 100 p-y & $2.83(-0.61,6.26)$ & $-5.77(-9.80,-1.74)^{*}$ & $-1.30(-2.55,-0.05)^{*}$ \\
\hline$>30$ per 100 p-y & $0.39(-2.58,3.37)$ & $-3.24(-6.74,0.25)$ & $-1.47(-2.55,-0.38)^{*}$ \\
\hline MFI-20 general fatigue & $-1.18(-1.41,-0.95)^{*}$ & $-1.00(-1.27,-0.73)^{*}$ & $-0.45(-0.53,-0.36)^{*}$ \\
\hline \multicolumn{4}{|l|}{ Ulcerative Colitis } \\
\hline \multicolumn{4}{|l|}{$\mathrm{RC}(95 \%-\mathrm{Cl})$} \\
\hline Age at diagnosis & $-0.15(-0.21,-0.10)^{*}$ & $-0.02(-0.09,0.05)$ & $-0.01(-0.04,0.01)$ \\
\hline \multicolumn{4}{|l|}{ Subjective disease course } \\
\hline "inactive" & $0.00 * *$ & $0.00 * *$ & $0.00 * *$ \\
\hline "most years no activity" & $-0.25(-2.94,2.44)$ & $-0.77(-4.08,2.54)$ & $0.43(-0.56,1.42)$ \\
\hline "most years activity" & $-2.40(-5.85,1.05)$ & $-0.08(-4.33,4.16)$ & $-0.99(-2.26,0.28)$ \\
\hline “every year activity” & $-4.01(-7.05,-0.96)^{*}$ & $0.15(-3.60,3.89)$ & $-1.76(-2.90,-0.63)^{*}$ \\
\hline \multicolumn{4}{|l|}{ Recurrence per $100 p-y$} \\
\hline \multicolumn{4}{|l|}{ All type recurrences } \\
\hline$\leq 20$ per 100 p-y & $0.00 * *$ & $0.00 * *$ & $0.00 * *$ \\
\hline$>20-\leq 30$ per $100 p-y$ & $0.00(-2.34,2.33)$ & $0.20(-2.67,3.07)$ & $-0.37(-1.23,0.48)$ \\
\hline$>30$ per 100 p-y & $0.34(-1.61,2.30)$ & $-1.85(-4.26,0.56)$ & $-0.24(-0.94,0.48)$ \\
\hline MFI-20 general fatigue & $-1.12(-1.29,-0.95)^{*}$ & $-1.16(-1.37,-0.95)^{*}$ & $-0.48(-0.54,-0.42)^{*}$ \\
\hline
\end{tabular}

* significantly different from reference value $(\mathrm{p}<0.05), * *$ reference value, $\mathrm{RC}=$ regression coefficient, $\mathrm{Cl}=$ confidence interval

\section{Discussion}

In the present population-based study in the Dutch IBD-South Limburg cohort, we evaluated the effect of disease course on fatigue and HRQoL. Results showed that, even when patients with current disease activity and/or anaemia were excluded, a more severe disease course independently resulted in worse fatigue scores and lower HRQoL. Especially, the number of "all type" recurrences had a negative impact, whereas surgical interventions alone showed almost no effect on fatigue and HRQoL. Also the use of corticosteroids and immunosuppressives resulted in worse fatigue and HRQoL scores. Regarding the use of infliximab in CD, scores on fatigue and HRQoL were worse in univariate analysis, but became favourable in the multivariate analysis, when patients with current active disease and/or anaemia were excluded, now becoming a significant advantage regarding fatigue and HRQoL. Other determinants of fatigue were female gender in both CD and UC. In UC, older age at diagnosis was an independent negative predictor for HRQoL as was the presence of fatigue in both $C D$ and UC. 
Fatigue has increasingly become recognized as a serious symptom of chronic disease which can significantly impair a person's functioning and have a negative impact on HRQoL. The relationship between fatigue, HRQoL and disease course over time has to our knowledge rarely been studied. Only one recent study in patients receiving adalimumab maintenance treatment (56 weeks follow-up) showed a sustained improvement of fatigue scores, however follow-up is still relatively short. ${ }^{52}$ Although we earlier confirmed that the presence of disease activity and/or anaemia in IBD negatively determined fatigue and HRQoL scores ${ }^{28-30}$, interestingly, fatigue and HRQoL outcome does not completely correlate with current disease status or clinical findings. A finding also reported in other chronic diseases ${ }^{22}$, for example Rheumatoid Arthritis $(\mathrm{RA})^{32}$ and Multiple Sclerosis (MS). ${ }^{31}$

In IBD, a negative association between active disease and/or anaemia, and HRQoL has often been reported. ${ }^{9-13,18,27,53}$. In remission both a HRQoL similar to the general population $^{13,16}$ as an impaired HRQoL have been reported ${ }^{54-56}$. The present study confirmed results found by few others for $\mathrm{CD}^{14,21}$ and $\mathrm{UC}^{14,21,57}$, a more severe disease course, the use of corticosteroids, immunosuppressives and infliximab negatively determined HRQoL scores. The finding, that infliximab treatment has a positive influence on HRQoL appears to indicate a favourable effect of that treatment over time. Increased disease activity and the use of advanced immunosuppressive medication are closely correlated. When patients were followed up with HRQoL measurements before and after medical intervention it has been shown that a patient's HRQoL improves after effective medical treatment and deteriorates again with disease relapse. ${ }^{46,58-64}$ Based on these findings one would have expected that effective treatment should result in a normalization of fatigue and HRQoL scores. For most pharmaceutical interventions the opposite, was found in this study. This divergence might be explained by the fact that the medications concerned - and here especially steroids - produce own adverse effects which were felt stronger than the benefit provided, but also by the fear of patients for known or suspected consequences of those medications.

This study confirmed that female gender was an independent risk factor for fatigue, in conformity with most ${ }^{16,55,65,66}$ but not all earlier reports ${ }^{67,68}$ from the general population and IBD patients. The explanation for increased fatigue in women with IBD might be sought in their multiple social functions (work; home care; child care) and - in earlier age - by fears connected with procreation (less personal attraction; problems with infertility and also pregnancy, child birth and the intensive effort of child raising). From a number of studies on the role of gender in fatigue ${ }^{69-71}$ it appears that women are more likely to report fatigue and more severe degrees of it. Also, women are more likely to seek medical help for their fatigue.

The pathogenesis of fatigue in chronic disease is not well understood. It has been proposed that it may be mainly of central-nervous origin. ${ }^{22,31}$ In this setting it has been 
suggested that the hypothalamic-pituitary-adrenal axis is not functioning appropriately and, moreover, might be associated with depressive disorders and thus fatigue. ${ }^{22,72,73}$ However, within the IBD population this could not be confirmed. ${ }^{27}$ Another possible influencing mechanism might be the role of circulating cytokines as they have often elevated in chronic disease. However, the mechanism whereby elevations in cytokine levels outside the central nervous system may induce alterations in behaviour is unclear, but may involve direct interactions through the blood brain-barrier cells, into the brain. ${ }^{22}$ The presence of fatigue however, could also be secondary as alterations in cytokine levels can induce sleep disorders ${ }^{74}$ a condition which is also highly prevalent in IBD patients even during quiescent disease. ${ }^{75}$ In a Dutch study on cytokine levels in a heterogeneous IBD population (having active and quiescent disease) a possible relation with the presence of fatigue could not be confirmed. ${ }^{76}$ Another neurotransmitter investigated in the aetiology of fatigue, and well known in the pathophysiology of depression, is serotonin. Although a recent review about the role of neuropeptides in IBD was not conclusive, further clarification in the mechanism of action might reveal new IBD treatment options in the future. ${ }^{77}$

Other factors potentially contributing to fatigue and lowered HRQoL in IBD patients, such as psychological symptoms - including anxiety and depression - have been addressed in numerous studies. ${ }^{78-84}$ However, there are also studies in which real or perceived IBD severity were not associated with depressive symptoms ${ }^{85}$ or a confirmed diagnosis of depression. ${ }^{86-89}$ Apart from mood disorders, also psychological distress ${ }^{65,79}$ was found to negatively influence HRQoL. Results regarding the role of personality traits in this context are conflicting. ${ }^{79,90}$ Possibly, early identification of and intervention against depression and anxiety could improve fatigue and HRQoL outcome in patients with both active and inactive disease. For example, active stimulation of coping mechanisms early in the disease course might help to prevent anxiety and cognitive reactivity. ${ }^{91,92}$ A review on psychotherapy in IBD could not confirm any general impact on the course of disease but suggested in some cases positive effects on the patient's psychological state (depression, anxiety, coping). ${ }^{93}$

A strength of the present study is the population-based prospective design and the adequate sample size for analysis. Fatigue and HRQoL have so far only rarely been reported in this type of cohort. We do however acknowledge some limitations: The response rate to our questionnaire was $67 \%$, with more female than male patients responding. Since we adjusted for gender in the multivariate analysis, the unequal response rates have, to our opinion, not influenced final outcome.

It could also be questioned whether the "subjective" disease course as reported by patients is a valid measure of disease activity over time. The strong correlation with objective disease course clearly indicates that this was indeed the case. Furthermore, the presence of current disease could have induced information bias with regard to the "subjective" measurement of fatigue. In this context it is crucial that the negative patient perceptions remained unchanged also after exclusion of patients with current 
disease activity or anaemia. Our results indicate that the subjective question on disease course can be put to patients in clinical practice with high diagnostic value for an important care problem and an indication for potential need of intervention, also with psycho-social measures.

In conclusion, we have shown that a severe disease course is an important contributor to fatigue and low HRQoL in IBD, independent of current disease activity and presence of anaemia. Moreover, fatigue is an independent predictor of low HRQoL. This implies that patients with repeated exacerbations in the past, who have required more intensive drug treatment, are at risk of developing fatigue and a decrease in HRQoL. A probable exception in this is the use of infliximab in CD which ameliorates this outcome. As the presence of fatigue has a major impact on personal functioning and satisfaction, among treating physicians a high awareness of the prevalence and impact of fatigue is warranted. Further research, especially of longitudinal psychological character would be valuable to gain more insight in fatigue and its effect on HRQoL in IBD. This might lead to an IBD management with an integrated "bio-psycho-social" long-term approach, in line with a modern thinking in medicine with regard to chronic debilitating disorders. ${ }^{32,94-99}$ 


\section{References}

1. Sartor RB. Pathogenesis and immune mechanisms of chronic inflammatory bowel diseases. Am J Gastroenterol. 1997;92:5S-11S.

2. Tsianos EV, Katsanos K. Do we really understand what the immunological disturbances in inflammatory bowel disease mean? World J Gastroenterol. 2009;15:521-525.

3. Noomen CG, Hommes DW, Fidder HH. Update on genetics in inflammatory disease. Best Pract Res Clin Gastroenterol. 2009;23:233-243.

4. Shivananda S, Lennard Jones J, Logan R, Fear N, Price A, Carpenter L, van Blankenstein M. Incidence of inflammatory bowel disease across Europe: is there a difference between north and south? Results of the European Collaborative Study on Inflammatory Bowel Disease (EC-IBD). Gut. 1996;39:690-697.

5. Russel MG, Dorant E, Volovics A, Brummer RJ, Pop P, Muris JW, Bos LP, Limonard CB, Stockbrugger RW. High incidence of inflammatory bowel disease in The Netherlands: results of a prospective study. The South Limburg IBD Study Group. Dis Colon Rectum. 1998;41:33-40.

6. Romberg-Camps MJ, Hesselink-van de Kruijs MA, Schouten L, Dagnelie PC, Limonard C, Kester AD, Bos LP, Goedhard J, Hameeteman WH, Wolters FL, Russel MG, Stockbrugger RW. Inflammatory bowel disease in South Limburg (the Netherlands) 1991-2002: Incidence, diagnostic delay, and seasonal variations in onset of symptoms. Results of a population based study, the IBD-South Limburg cohort. JCC. 2009;3:115-124.

7. Loftus EV, Jr. Clinical epidemiology of inflammatory bowel disease: Incidence, prevalence, and environmental influences. Gastroenterology. 2004;126:1504-1517.

8. Russel MG. Changes in the incidence of inflammatory bowel disease: what does it mean? Eur J Intern Med. 2000;11:191-196.

9. Bernklev T, Jahnsen J, Lygren I, Henriksen M, Vatn M, Moum B. Health-related quality of life in patients with inflammatory bowel disease measured with the short form-36: psychometric assessments and a comparison with general population norms. Inflamm Bowel Dis. 2005;11:909-918.

10. Casellas F, Lopez-Vivancos J, Casado A, Malagelada JR. Factors affecting health related quality of life of patients with inflammatory bowel disease. Qual Life Res. 2002;11:775-781.

11. Saibeni S, Cortinovis I, Beretta L, Tatarella M, Ferraris L, Rondonotti E, Corbellini A, Bortoli A, Colombo E, Alvisi C, Imperiali G, de Franchis R. Gender and disease activity influence health-related quality of life in inflammatory bowel diseases. Hepatogastroenterology. 2005;52:509-515.

12. Janke $\mathrm{KH}$, Raible $A$, Bauer $M$, Clemens $P$, Meisner $C$, Hauser W, Steder-Neukamm U, Henrich G, Herschbach P, Gregor M, Klump B. Questions on life satisfaction (FLZM) in inflammatory bowel disease. Int J Colorectal Dis. 2004;19:343-353.

13. Casellas F, Arenas JI, Baudet JS, Fabregas S, Garcia N, Gelabert J, Medina C, Ochotorena I, Papo M, Rodrigo L, Malagelada JR. Impairment of health-related quality of life in patients with inflammatory bowel disease: a Spanish multicenter study. Inflamm Bowel Dis. 2005;11:488-496.

14. Bernklev T, Jahnsen J, Schulz T, Sauar J, Lygren I, Henriksen M, Stray N, Kjellevold O, Aadland E, Vatn $M$, Moum B. Course of disease, drug treatment and health-related quality of life in patients with inflammatory bowel disease 5 years after initial diagnosis. Eur J Gastroenterol Hepatol. 2005;17: 1037-1045.

15. Bernklev T, Jahnsen J, Aadland E, Sauar J, Schulz T, Lygren I, Henriksen M, Stray N, Kjellevold O, Vatn $M$, Moum B. Health-related quality of life in patients with inflammatory bowel disease five years after the initial diagnosis. Scand J Gastroenterol. 2004;39:365-373.

16. Hjortswang H, Jarnerot G, Curman B, Sandberg-Gertzen H, Tysk C, Blomberg B, Almer S, Strom M. The influence of demographic and disease-related factors on health-related quality of life in patients with ulcerative colitis. Eur J Gastroenterol Hepatol. 2003;15:1011-1020.

17. Simren M, Axelsson J, Gillberg R, Abrahamsson H, Svedlund J, Bjornsson ES. Quality of life in inflammatory bowel disease in remission: the impact of IBS-like symptoms and associated psychological factors. Am J Gastroenterol. 2002;97:389-396.

18. Gasche C, Lomer MC, Cavill I, Weiss G. Iron, anaemia, and inflammatory bowel diseases. Gut. 2004;53:1190-1197.

19. Carlsson E, Bosaeus I, Nordgren S. Quality of life and concerns in patients with short bowel syndrome. Clin Nutr. 2003;22:445-452. 
20. Hauser W, Dietz N, Steder-Neukamm U, Janke KH, Stallmach A. Biopsychosocial determinants of health-related quality of life after ileal pouch anal anastomosis for ulcerative colitis. Inflamm Bowel Dis. 2004;10:399-407.

21. Lix LM, Graff LA, Walker JR, Clara I, Rawsthorne P, Rogala L, Miller N, Ediger J, Pretorius T, Bernstein $\mathrm{CN}$. Longitudinal study of quality of life and psychological functioning for active, fluctuating, and inactive disease patterns in inflammatory bowel disease. Inflamm Bowel Dis. 2008;14:1575-1584.

22. Swain MG. Fatigue in chronic disease. Clin Sci (Lond). 2000;99:1-8.

23. Thombs BD, Bassel M, McGuire L, Smith MT, Hudson M, Haythornthwaite JA. A systematic comparison of fatigue levels in systemic sclerosis with general population, cancer and rheumatic disease samples. Rheumatology (Oxford). 2008;47:1559-1563.

24. Pittion-Vouyovitch S, Debouverie M, Guillemin F, Vandenberghe N, Anxionnat R, Vespignani H. Fatigue in multiple sclerosis is related to disability, depression and quality of life. J Neurol Sci. 2006;243:39-45.

25. Dagnelie PC, Pijls-Johannesma MC, Lambin P, Beijer S, De Ruysscher D, Kempen GI. Impact of fatigue on overall quality of life in lung and breast cancer patients selected for high-dose radiotherapy. Ann Oncol. 2007;18:940-944.

26. Beijer S, Kempen GI, Pijls-Johannesma MC, de Graeff A, Dagnelie PC. Determinants of overall quality of life in preterminal cancer patients. Int J Cancer. 2008;123:232-235.

27. Minderhoud IM, Oldenburg B, van Dam PS, van Berge Henegouwen GP. High prevalence of fatigue in quiescent inflammatory bowel disease is not related to adrenocortical insufficiency. Am J Gastroenterol. 2003;98:1088-1093.

28. Romberg-Camps MJ, Bol Y, Dagnelie PC, Hesselink-van de Kruijs MA, Kester A, Engels LG, van Deursen C, Hameeteman W, Pierik M, Wolters F, Russel M, Stockbrugger R. Fatigue in Inflammatory Bowel Disease, results of a population based study in the Netherlands; the IBD South Limburg cohort. Gut. 2009;58(Suppl II):A311.

29. Romberg-Camps MJ, Bol Y, Dagnelie PC, Hesselink-van de Kruijs MA, Kester A, Engels LG, van Deursen C, Hameeteman W, Pierik M, Wolters F, Russel M, Stockbrugger R. Fatigue and Health Related Quality of Life in Inflammatory Bowel Disease. Results from a population based study in the Netherlands: The IBD-South Limburg Cohort. Inflamm Bowel Dis. 2010:epub ahead of print.

30. Romberg-Camps MJ, Bol Y, Dagnelie PC, Hesselink-van de Kruijs MA, Kester A, Engels LG, van Deursen C, Hameeteman W, Pierik M, Wolters F, Russel M, Stockbrugger R. The influence of fatigue on the Health Related Quality of Life in Inflammatory Bowel Disease, results of a population based study in the Netherlands: the IBD South Limburg cohort. Gut. 2009;58(Suppl II):A310.

31. Kos D, Kerckhofs $E$, Nagels G, D'Hooghe M B, Ilsbroukx S. Origin of fatigue in multiple sclerosis: review of the literature. Neurorehabil Neural Repair. 2008;22:91-100.

32. Kojima T, Ishiguro N, Oguchi T, Oba M, Tsuchiya H, Sugiura F, Furukawa TA, Suzuki S, Tokudome S. Psychosocial factors, disease status, and quality of life in patients with rheumatoid arthritis. J Psychosom Res. 2009;67:425-431.

33. Russel M. Data management of the South Limburg Inflammatory Bowel Disease Registry 'IBD South Limburg'. Thesis Incidence, risk factors and quality of life in IBD. 1997;ISBN 90-9010684-7:49-57.

34. http://statline.cbs.nl/StatWeb/start.asp?lp=Search/Search.

35. Lennard Jones JE. Classification of inflammatory bowel disease. Scand J Gastroenterol. 1989;s170:2-6.

36. Geboes K, Colombel JF, Greenstein A, Jewell DP, Sandborn WJ, Vatn MH, Warren B, Riddell RH. Indeterminate colitis: a review of the concept--what's in a name? Inflamm Bowel Dis. 2008;14: 850-857.

37. Romberg-Camps MJ, Dagnelie PC, Kester AD, Hesselink-van de Kruijs MA, Cilissen M, Engels LG, Van Deursen C, Hameeteman WH, Wolters FL, Russel MG, Stockbrugger RW. Influence of phenotype at diagnosis and of other potential prognostic factors on the course of inflammatory bowel disease. Am J Gastroenterol. 2009;104:371-383.

38. Gasche C, Scholmerich J, Brynskov J, D'Haens G, Hanauer SB, Irvine EJ, Jewell DP, Rachmilewitz D, Sachar DB, Sandborn WJ, Sutherland LR. A simple classification of Crohn's disease: report of the Working Party for the World Congresses of Gastroenterology, Vienna 1998. Inflamm Bowel Dis. 2000;6:8-15. 
39. Wolters FL, Russel MG, Sijbrandij J, Ambergen T, Odes S, Riis L, Langholz E, Politi P, Qasim A, Koutroubakis I, Tsianos E, Vermeire S, Freitas J, van Zeijl G, Hoie O, Bernklev T, Beltrami M, Rodriguez D, Stockbrugger RW, Moum B. Phenotype at diagnosis predicts recurrence rates in Crohn's disease. Gut. 2006;55:1124-1130.

40. Hoie O, Wolters F, Riis L, Aamodt G, Solberg C, Bernklev T, Odes S, Mouzas IA, Beltrami M, Langholz E, Stockbrugger R, Vatn M, Moum B. Ulcerative colitis: patient characteristics may predict 10-yr disease recurrence in a European-wide population-based cohort. Am J Gastroenterol. 2007;102:1692-1701.

41. Harvey RF, Bradshaw JM. A simple index of Crohn's-disease activity. Lancet. 1980;1:514.

42. Sandler RS, Jordan MC, Kupper LL. Development of a Crohn's index for survey research. J Clin Epidemiol. 1988;41:451-458.

43. Lichtiger S, Present DH, Kornbluth A, Gelernt I, Bauer J, Galler G, Michelassi F, Hanauer S. Cyclosporine in severe ulcerative colitis refractory to steroid therapy. N Engl J Med. 1994;330:1841-1845.

44. Smets EM, Garssen B, Bonke B, De Haes JC. The Multidimensional Fatigue Inventory (MFI) psychometric qualities of an instrument to assess fatigue. J Psychosom Res. 1995;39:315-325.

45. Smets EM, Garssen B, Cull A, de Haes JC. Application of the multidimensional fatigue inventory (MFI20 ) in cancer patients receiving radiotherapy. $\mathrm{Br} J$ Cancer. 1996;73:241-245.

46. Guyatt G, Mitchell A, Irvine EJ, Singer J, Williams N, Goodacre R, Tompkins C. A new measure of health status for clinical trials in inflammatory bowel disease. Gastroenterology. 1989;96:804-810.

47. Russel MG, Pastoor CJ, Brandon S, Rijken J, Engels LG, van der Heijde DM, Stockbrugger RW. Validation of the Dutch translation of the Inflammatory Bowel Disease Questionnaire (IBDQ): a health-related quality of life questionnaire in inflammatory bowel disease. Digestion. 1997;58:282-288.

48. Ware JE, Jr., Sherbourne CD. The MOS 36-item short-form health survey (SF-36). I. Conceptual framework and item selection. Med Care. 1992;30:473-483.

49. McHorney CA, Ware JE, Jr., Lu JF, Sherbourne CD. The MOS 36-item Short-Form Health Survey (SF-36): III. Tests of data quality, scaling assumptions, and reliability across diverse patient groups. Med Care. 1994;32:40-66.

50. van Tulder MW, Aaronson NK, Bruning PF. The quality of life of long-term survivors of Hodgkin's disease. Ann Oncol. 1994;5:153-158.

51. Statacorp. Stata Statistical Software: Release 8.2. Stata corperation: College Station, TX, 2005.

52. Loftus EV, Feagan BG, Colombel JF, Rubin DT, Wu EQ, Yu AP, Pollack PF, Chao J, Mulani P. Effects of adalimumab maintenance therapy on health-related quality of life of patients with Crohn's disease: patient-reported outcomes of the CHARM trial. Am J Gastroenterol. 2008;103:3132-3141.

53. Gibson PR, Weston AR, Shann A, Florin TH, Lawrance IC, Macrae FA, Radford-Smith G. Relationship between disease severity, quality of life and health-care resource use in a cross-section of Australian patients with Crohn's disease. J Gastroenterol Hepatol. 2007;22:1306-1312.

54. Graff LA, Walker JR, Lix L, Clara I, Rawsthorne P, Rogala L, Miller N, Jakul L, McPhail C, Ediger J, Bernstein $\mathrm{CN}$. The relationship of inflammatory bowel disease type and activity to psychological functioning and quality of life. Clin Gastroenterol Hepatol. 2006;4:1491-1501.

55. Blondel-Kucharski F, Chircop C, Marquis P, Cortot A, Baron F, Gendre JP, Colombel JF. Health-related quality of life in Crohn's disease: a prospective longitudinal study in 231 patients. Am J Gastroenterol. 2001;96:2915-2920.

56. Petrak F, Hardt J, Clement T, Borner N, Egle UT, Hoffmann SO. Impaired health-related quality of life in inflammatory bowel diseases: psychosocial impact and coping styles in a national German sample. Scand J Gastroenterol. 2001;36:375-382.

57. Hjortswang $\mathrm{H}$, Strom M, Almer S. Health-related quality of life in Swedish patients with ulcerative colitis. Am J Gastroenterol. 1998;93:2203-2211.

58. Irvine EJ, Feagan B, Rochon J, Archambault A, Fedorak RN, Groll A, Kinnear D, Saibil F, McDonald JW. Quality of life: a valid and reliable measure of therapeutic efficacy in the treatment of inflammatory bowel disease. Canadian Crohn's Relapse Prevention Trial Study Group. Gastroenterology. 1994;106:287-296.

59. Mitchell A, Guyatt G, Singer J, Irvine EJ, Goodacre R, Tompkins C, Williams N, Wagner F. Quality of life in patients with inflammatory bowel disease. J Clin Gastroenterol. 1988;10:306-310.

60. Irvine EJ. Quality of Life--measurement in inflammatory bowel disease. Scand J Gastroenterol Suppl. 1993;199:36-39. 
61. Reinisch W, Sandborn WJ, Bala M, Yan S, Feagan BG, Rutgeerts P, Radford-Smith G, Xu S, Eisenberg D, Olson A, Colombel JF. Response and remission are associated with improved quality of life, employment and disability status, hours worked, and productivity of patients with ulcerative colitis. Inflamm Bowel Dis. 2007;13:1135-1140.

62. Feagan BG, Sandborn WJ, Hass S, Niecko T, White J. Health-related quality of life during natalizumab maintenance therapy for Crohn's disease. Am J Gastroenterol. 2007;102:2737-2746.

63. Casellas F, Rodrigo L, Nino P, Pantiga C, Riestra S, Malagelada JR. Sustained improvement of healthrelated quality of life in Crohn's disease patients treated with infliximab and azathioprine for 4 years. Inflamm Bowel Dis. 2007;13:1395-1400.

64. Feagan BG, Coteur G, Tan S, Keininger DL, Schreiber S. Clinically meaningful improvement in healthrelated quality of life in a randomized controlled trial of certolizumab pegol maintenance therapy for Crohn's disease. Am J Gastroenterol. 2009;104:1976-1983.

65. Sainsbury A, Heatley RV. Review article: psychosocial factors in the quality of life of patients with inflammatory bowel disease. Aliment Pharmacol Ther. 2005;21:499-508.

66. van Wijk CM, Kolk AM. Sex differences in physical symptoms: the contribution of symptom perception theory. Soc Sci Med. 1997;45:231-246.

67. Cathebras PJ, Robbins JM, Kirmayer LJ, Hayton BC. Fatigue in primary care: prevalence, psychiatric comorbidity, illness behavior, and outcome. J Gen Intern Med. 1992;7:276-286.

68. Kirk J, Douglass R, Nelson E, Jaffe J, Lopez A, Ohler J, Blanchard C, Chapman R, McHugo G, Stone K. Chief complaint of fatigue: a prospective study. J Fam Pract. 1990;30:33-39; discussion 39-41.

69. Chen MK. The epidemiology of self-perceived fatigue among adults. Prev Med. 1986;15:74-81.

70. Jason LA, Richman JA, Rademaker AW, Jordan KM, Plioplys AV, Taylor RR, McCready W, Huang CF, Plioplys S. A community-based study of chronic fatigue syndrome. Arch Intern Med. 1999;159: 2129-2137.

71. Pawlikowska T, Chalder T, Hirsch SR, Wallace P, Wright DJ, Wessely SC. Population based study of fatigue and psychological distress. Bmj. 1994;308:763-766.

72. Clauw DJ, Chrousos GP. Chronic pain and fatigue syndromes: overlapping clinical and neuroendocrine features and potential pathogenic mechanisms. Neuroimmunomodulation. 1997;4:134-153.

73. Van Houdenhove B, Van Den Eede F, Luyten P. Does hypothalamic-pituitary-adrenal axis hypofunction in chronic fatigue syndrome reflect a 'crash' in the stress system? Med Hypotheses. 2009;72:701-705.

74. Kapsimalis F, Basta M, Varouchakis G, Gourgoulianis K, Vgontzas A, Kryger M. Cytokines and pathological sleep. Sleep Med. 2008;9:603-614.

75. Ranjbaran Z, Keefer L, Stepanski E, Farhadi A, Keshavarzian A. The relevance of sleep abnormalities to chronic inflammatory conditions. Inflamm Res. 2007;56:51-57.

76. Minderhoud IM, Samsom M, Oldenburg B. Crohn's disease, fatigue, and infliximab: is there a role for cytokines in the pathogenesis of fatigue? World J Gastroenterol. 2007;13:2089-2093.

77. Margolis KG, Gershon MD. Neuropeptides and inflammatory bowel disease. Curr Opin Gastroenterol. 2009;25:503-511.

78. Walker JR, Ediger JP, Graff LA, Greenfeld JM, Clara I, Lix L, Rawsthorne P, Miller N, Rogala L, McPhail $\mathrm{CM}$, Bernstein CN. The Manitoba IBD cohort study: a population-based study of the prevalence of lifetime and 12-month anxiety and mood disorders. Am J Gastroenterol. 2008;103:1989-1997.

79. Vidal A, Gomez-Gil E, Sans M, Portella MJ, Salamero M, Pique JM, Panes J. Health-related quality of life in inflammatory bowel disease patients: the role of psychopathology and personality. Inflamm Bowe Dis. 2008;14:977-983.

80. Turnbull GK, Vallis TM. Quality of life in inflammatory bowel disease: the interaction of disease activity with psychosocial function. Am J Gastroenterol. 1995;90:1450-1454.

81. Guthrie E, Jackson J, Shaffer J, Thompson D, Tomenson B, Creed F. Psychological disorder and severity of inflammatory bowel disease predict health-related quality of life in ulcerative colitis and Crohn's disease. Am J Gastroenterol. 2002;97:1994-1999.

82. Nordin K, Pahlman L, Larsson K, Sundberg-Hjelm M, Loof L. Health-related quality of life and psychological distress in a population-based sample of Swedish patients with inflammatory bowel disease. Scand J Gastroenterol. 2002;37:450-457.

83. Janke KH, Klump B, Gregor M, Meisner C, Haeuser W. Determinants of life satisfaction in inflammatory bowel disease. Inflamm Bowel Dis. 2005;11:272-286. 
84. Bjornsson E, Simren M, Olsson R, Chapman RW. Fatigue in patients with primary sclerosing cholangitis. Scand J Gastroenterol. 2004;39:961-968.

85. Ondersma SJ, Lumley MA, Corlis ME, Tojek TM, Tolia V. Adolescents with inflammatory bowel disease: the roles of negative affectivity and hostility in subjective versus objective health. J Pediatr Psychol. 1997;22:723-738.

86. Engstrom I, Lindquist BL. Inflammatory bowel disease in children and adolescents: a somatic and psychiatric investigation. Acta Paediatr Scand. 1991;80:640-647.

87. Tarter RE, Switala J, Carra J, Edwards KL, Van Thiel DH. Inflammatory bowel disease: psychiatric status of patients before and after disease onset. Int J Psychiatry Med. 1987;17:173-181.

88. Helzer JE, Chammas S, Norland CC, Stillings WA, Alpers DH. A study of the association between Crohn's disease and psychiatric illness. Gastroenterology. 1984;86:324-330.

89. Walker EA, Gelfand MD, Gelfand AN, Creed F, Katon WJ. The relationship of current psychiatric disorder to functional disability and distress in patients with inflammatory bowel disease. Gen Hosp Psychiatry. 1996;18:220-229.

90. Moreno-Jimenez B, Lopez Blanco B, Rodriguez-Munoz A, Garrosa Hernandez E. The influence of personality factors on health-related quality of life of patients with inflammatory bowel disease. J Psychosom Res. 2007;62:39-46.

91. Grootenhuis MA, Maurice-Stam H, Derkx BH, Last BF. Evaluation of a psychoeducational intervention for adolescents with inflammatory bowel disease. Eur J Gastroenterol Hepatol. 2009;21:430-435.

92. van der Zaag-Loonen HJ, Grootenhuis MA, Last BF, Derkx HH. Coping strategies and quality of life of adolescents with inflammatory bowel disease. Qual Life Res. 2004;13:1011-1019.

93. von Wietersheim J, Kessler $\mathrm{H}$. Psychotherapy with chronic inflammatory bowel disease patients: a review. Inflamm Bowel Dis. 2006;12:1175-1184.

94. Khan F, Turner-Stokes L, Ng L, Kilpatrick T. Multidisciplinary rehabilitation for adults with multiple sclerosis. Cochrane Database Syst Rev. 2007:CD006036.

95. Rupp I, Boshuizen HC, Jacobi CE, Dinant HJ, van den Bos GA. Impact of fatigue on health-related quality of life in rheumatoid arthritis. Arthritis Rheum. 2004;51:578-585.

96. Vriezekolk J, Eijsbouts A, Evers A, Stenger A, Van Den Hoogen F, van Lankveld W. Poor psychological health status among patients with inflammatory rheumatic diseases and osteoarthritis in multidisciplinary rehabilitation: Need for a routine psychological assessment. Disabil Rehabil. 2009;32: 836-844.

97. Cullen DL, Stiffler D. Long-term oxygen therapy: review from the patients' perspective. Chron Respir Dis. 2009;6:141-147.

98. Blinderman CD, Homel P, Billings JA, Tennstedt S, Portenoy RK. Symptom distress and quality of life in patients with advanced chronic obstructive pulmonary disease. J Pain Symptom Manage. 2009;38: 115-123.

99. Hill K, Geist R, Goldstein RS, Lacasse Y. Anxiety and depression in end-stage COPD. Eur Respir J. 2008;31:667-677. 


\section{.}




\section{Chapter 7}

General discussion and conclusions 
136 Chapter 7 


\section{Introduction}

The exact cause of IBD is still unknown. Apart from genetic predispositions, environmental factors probably also play a significant role in its aetiology and pathogenesis. Studies of population based, prospectively and uniformly diagnosed regional inception cohorts are of great importance, as they can provide incidence figures and clues about intrinsic and extrinsic risk factors. Moreover, possible differences in disease outcome can be illustrated with respect to the combined effect of "natural course" and "therapeutic" interventions. In Inflammatory Bowel Disease (IBD), most data on aetiology, clinical manifestation, disease course and outcome originate from referral centres with special interest in these disorders. Updating the existing knowledge - using population based cohorts - therefore remains important as changes in environmental conditions, life styles and therapies are continuously ongoing.

IBD has important socio-economic consequences as it is mainly afflicts young adults in their most productive years, potentially resulting in long-term productivity loss or even inability to work. In daily clinical practice fatigue is frequently reported as an important symptom in IBD, often independently of disease activity. Despite the frequent presence of this "invalidating" symptom not much is known about fatigue in IBD. This is surprising as in other chronic inflammatory disorders the impact of fatigue on Health Related Quality of Life (HRQoL) is increasingly acknowledged.

The main focus of studies presented in this thesis was to provide information on possible changes over time in incidence rates, mortality risks, factors determining disease course, but also evaluating the prevalence of fatigue and to investigate determinants on the level of fatigue and HRQoL.

\section{The IBD South Limburg cohort}

The studies presented in this thesis were performed within the IBD South Limburg (IBD-SL) cohort. This population based IBD registry was established in 1991. All three hospitals in South Limburg, i.e. the Maastricht University Medical Center and the general district hospitals of Heerlen and Sittard participated in the study. As the number of hospitals in the region is small, contact during the study was optimal and resulted in a high ascertainment of completeness of prevalent cases. ${ }^{1}$ Furthermore, migration in and out of the area is low. ${ }^{2}$ Registration within the IBD-SL registry is currently still ongoing. In the future, a change from the paper based medical files to electronical patient charts will make it easier to register disease course in the IBD cohort and to perform checks whether any IBD patient was missed out in the IBD-SL registration. A prospective online data registration on phenotype and genotype could lead to new insights in aetiology and disease behaviour in this complex disorder. 


\section{Main findings}

- The incidence of IBD in the South Limburg region was high, but no significant increase was found in the total incidence of CD, UC and IC during the 11 years' study period (chapter 2).

- No seasonal influence on the onset of symptomatic IBD was found, and despite the introduction of new diagnostic techniques, diagnostic lag time of IBD had not changed (chapter 2).

- Overall mortality rates in CD, UC and IC were similar compared to the background population. However, disease-specific mortality risk by gastrointestinal causes was significantly increased both in CD and UC, probably reflecting complicated disease course (chapter 3).

- In general, in this cohort, disease course was relatively benign (chapter 4).

- In CD patients, young age at diagnosis and terminal ileum location were the most prominent predictors of disease recurrence. Small bowel location was associated with a significantly increased risk for surgery, as did stricturing and combined stricturing and penetrating disease. In UC, extensive colitis at diagnosis was related to increased risk for colectomy and older age at diagnosis initially increased recurrence risk, but subsequently was protective (chapter 4).

- The prevalence of fatigue was high, even when patients with current disease activity were excluded. Moreover, fatigue was associated with impaired HRQoL, with CD patients suffering significantly more than UC patients (chapter 5).

- In CD and UC, a more severe disease course (even when excluding patients with current disease activity) was associated with a higher degree of fatigue and an impaired HRQoL (chapter 6).

\section{Incidence, seasonality and diagnostic lag time}

\section{Incidence}

Information on IBD incidence rates are conflicting. Recent publications show that the incidence of Inflammatory Bowel Diseases (IBD) is still increasing in the adult European population $^{3-6}$ The reported increase of IBD incidence over the last decades in different European countries supports the idea that environmental factors play an important role in the aetiology and pathogenesis of IBD. A change to Westernized lifestyle ${ }^{7}$ and improved hygienic circumstances ${ }^{8,9}$ have also been implicated for the pathogenesis of IBD. Possibly other factors with impact on incidence figures are the improvement of diagnostic measures and an easier access to health care facilities. The stable incidence rates in the South Limburg cohort during the present study suggest that such factors have been levelling out in the past 15 years in this area. Registration of incidence rates of diseases depends mainly on the completeness of case collection in a well-defined 
geographic or political area, and on the accuracy of information available from the background population. An important potential cause of differences in crude incidence rates between different studies is variation in age distribution of the populations assessed. Therefore, age standardization has to be applied when studying time trends, as age distributions can change over time. Also for incidence comparison between countries age standardisation is necessary. It is however still the minority of European IBD incidence studies that have used age correction. ${ }^{3-5,10-15}$

In the future, continuing quality control of data in the IBD-SL region needs to be performed. With the electronical patient files and the hospital disease diagnosis registration in the Netherlands (Diagnose Behandeling Combinatie [DBC]), control options will extend. However, verification of the exact IBD diagnosis by the managing physician still is the most important requirement.

\section{Seasonality}

Although the cause of Inflammatory Bowel Diseases is still not elucidated, genetic and environmental factors are thought to play an important role in the aetiology. ${ }^{16-19}$ Data increasingly implicate that there is a dysfunctional mucosal immune response to intestinal bacteria in the pathogenesis of IBD, especially in the case of $C D{ }^{20,21}$ Chronic inflammatory response is possibly triggered by infections with bacterial or viral pathogens and/or is due to a defective mucosal barrier. The search for causative or modulating risk factors in the environmental field is ongoing, some of them possibly connected with public and personal hygienic circumstances. ${ }^{8,9}$ The risk of infections might be subject to climate, changes of biorhythm or other environmental events, thereby secondarily influencing IBD onset. This could potentially result in seasonal variation of incidence rates. However, until now, published data on seasonal variation of incidence rates show conflicting results. ${ }^{22-25}$ We could not confirm seasonal influences on the incidence of IBD. This is probably due to the fact that IBD patients often present with quite a long history of symptoms before diagnosis (lag time), which makes it difficult to exactly determine when symptoms began. Moreover, extrinsic pathogenic factors can act in different ways, as the time interval and size of the relation between environmental influences and the reaction of the patient can be highly variable (for example an acute reaction to a triggering infection versus a slow alteration of the patient's immune system by repeated exposition). Conditions useful or necessary for the study of seasonality in IBD have recently been discussed ${ }^{26}$ but will remain difficult to fulfil, also in future research.

\section{Diagnostic lag time}

As during recent years the health care organisation and diagnostic options in the field of IBD have significantly improved, we expected this to positively influence the duration of time from first complaints until the diagnosis, i.e. the diagnostic lag time, possibly indicating disease already in a sub-clinical state. But even in the patients most 
recently incepted in our cohort (2000-2002), only in 81\% IBD was diagnosed within one year after the start of complaints, which is comparable to other recent studies. ${ }^{6,27}$ Probably, it remains of great importance to enhance patients' and doctors' awareness with regard to IBD. ${ }^{6}$ Also improvement of information on IBD given through the Internet ${ }^{28}$, television and IBD patient organization activities ${ }^{29}$ could improve patient awareness. However, caution is advised as information, especially through the internet, can greatly vary in quality. ${ }^{30,31}$

\section{Risk stratification in IBD patients}

\section{Mortality}

In literature the debate whether IBD carries an increased mortality risk is still ongoing. But the numerous studies reporting on IBD mortality often differ in terms of patient selection, patient inception, follow-up rates and duration of disease.

In the present study we found similar overall mortality rates in CD, UC and IC patients when compared with the background population. However, disease-specific mortality risk was significantly increased for gastrointestinal (GI) causes of death both in $C D$ and UC, a finding previously reported by others ${ }^{32-34}$, suggesting that mortality might be the consequence of disease severity and phenotype at diagnosis.

From the healthcare viewpoint, it would be highly relevant to identify patients who are at increased risk, either already at diagnosis or during disease course, and therefore would need a different, more intensive, follow-up strategy.

We found that CD- as well as UC-related deaths occurred relatively early after diagnosis and were mostly due to severe attacks of inflammation and/or to postoperative complications. This finding confirms earlier reports in literature. ${ }^{35-48}$ The increased early mortality appears to concern a subgroup of patients with a more aggressive disease course, which might benefit from an aggressive early treatment regime. However, optimal treatment strategies early in the disease course are still under debate. ${ }^{49-52}$ The access to infliximab therapy has improved clinical outcome ${ }^{53}$ and consequently HRQoL. ${ }^{54}$ It has also diminished the need for surgery in IBD. ${ }^{49,55}$ However, a lack of clinically useful predictors of a debilitating disease course hinders the selection of patients eligible for early biological intervention. ${ }^{49}$ Moreover, early interventions with biologicals (the "top-down" treatment strategy) have not yet been evaluated regarding long-term effects. In addition, there is a risk of over-treating those $1030 \%$ of patients that will have a more benign course of the disease. ${ }^{56}$

Another confirmed mortality risk factor from gastrointestinal causes in CD patients was an age $<40$ years at diagnosis. ${ }^{32,33,39-42}$ In contrast, in literature an increased risk was also reported in patients above 50 years at diagnosis. ${ }^{32,33,39,40,57}$ As young age at diagnosis appears to be an independent risk factor for disease recurrence ${ }^{58-60}$, the high mortality risk of young $C D$ patients could also be a sign of a more severe disease 
course. In old patients, the increased mortality risk may be due to co-morbidity and/or effects of disease- and therapy-related complications. In our UC population, mortality was significantly increased in a U-shaped manner, with higher mortality in the age groups $<19$ years and $>80$ years, whereas others reported an excess mortality only in UC patients of older age at diagnosis. ${ }^{36,44,61}$ Thus, young UC-patients in addition to elderly patients seem to be at risk.

Reports on phenotype at diagnosis and SMR in CD are conflicting. ${ }^{32,37-39,43-45}$ This may be due to patient selection at inclusion or to differences in phenotypic classification. As we found that all CD phenotypes within the GI category had an increased SMR, disease location at diagnosis did not show to be helpful to identify a patient having an increased mortality risk at diagnosis. In UC, as only "unknown" disease location at diagnosis (overall and in female patients) was found to have an increased SMR, we expect that this could be as well a result of selection bias if patients were too ill for extensive diagnostic evaluation at first presentation. As also found by Hoie et al. in an European wide cohort study ${ }^{61}$ we could not confirm most earlier reports which indicated that the extent of disease in UC was associated with excess mortality. ${ }^{36-}$ $38,44,46,48$

In the present study, the previously reported increase in mortality from colon carcinoma in $C D$ and $U C^{62-66}$ could not be confirmed. The median follow up period of seven years from diagnosis in this study may have been too short to observe this effect, as colorectal cancer is known to have a long latency period. ${ }^{37,38,63,67-69}$ Risk factors for the development of colon carcinoma in IBD reported in literature are treatment in referral centres ${ }^{70-72}$, coexisting of primary sclerosing cholangitis ${ }^{73,74}$, long periods with disease activity ${ }^{73}$, the presence of extensive colitis ${ }^{74,75}$ and a positive family history for colon carcinoma. ${ }^{74}$ As chronic medication with 5-ASA is considered protective, the reported incidence in literature of colon carcinoma in both UC and CD may decline further over the coming years. ${ }^{76-78}$ In the present cohort, the cumulative use of 5-ASA and the percentage of patients that used 5-ASA during follow-up was very high in $C D$ patients, nearly equalling the frequency of its use by UC patients. ${ }^{79}$ However, as already mentioned, longer follow-up is needed to detect a possible beneficial effect of such treatment in our cohort.

To assess mortality risks, further studies will be necessary to identify high-risk patients based on initial disease characteristics, considering in addition the treatment regiments patients were subjected to. Until then, based on our findings, we suggest that some IBD sub-groups need intensive follow-up, in order to achieve a further decrease of the mortality. Especially newly diagnosed IBD patients in the first year after diagnosis as well as IBD patients very young or elderly at diagnosis should be regarded as individuals at higher risk. 


\section{Disease course}

In IBD, the main goal of all therapeutic efforts is to achieve quick disease remission after onset and to prevent relapses and disease related complications in order to improve or maintain the HRQoL. As important finding presented in this thesis, in CD, small bowel location, stricturing disease, young age and smoking were predictive for disease recurrence. In UC, extensive colitis was a negative prognostic predictor with regard to the need for a surgical intervention. Older age at diagnosis in UC initially increased recurrence risk, but appeared to be protective after more than 2.4 years of follow-up. We speculate that possibly the vulnerability in older patients diagnosed with UC is higher and that, with time evolving, they might develop a more benign disease course, as older patients could be more willing to follow the physicians' therapeutic advice.

Overall disease course was relatively benign in this cohort over a mean follow-up period of seven years: $10 \%$ of patients experienced no recurrence at all and around $40 \%$ of the patients did not use any medication at the end of the study period, an observation also made by Wolters et al. ${ }^{59}$ Possible explanations for this benign disease course might be intrinsic (e.g. natural disease course, adaptation immune system) or extrinsic (e.g. early intensive treatment and care, protecting factors in the environment).

Identifying patients at risk for a more severe disease course is increasingly important as data on new treatment strategies (for example with "biologicals") suggest that treatment early in the disease course, "top-down", might change the natural history of the disease $\mathrm{s}^{50,53,55,80}$ and improve outcome. Even with the relatively short follow-up time of this study, a significant increase was noticed in the use of immune modulating therapy in $C D$ and $U C$ and of infliximab use in $C D$ during the recent years of follow-up. Although phenotypic classification according to the Vienna ${ }^{81}$ or the recent Montreal classification $^{82,83}$ might be helpful to predict disease course, it remains difficult to provide clear answers due to differences between cohorts, case definition, definition of disease recurrence and the inclusion of milder cases due to increased awareness and better diagnostic tools. Moreover, phenotypic behaviour may change during the course of the disease. ${ }^{84}$

As information on IBD associated genotypes becomes increasingly available ${ }^{85-89}$, future prognostic research should focus on the combination of phenotypic and genotypic data, to establish valid risk factor profiles for the disease course in individual patients, in need of a more aggressive treatment strategy. 


\section{Fatique and health related quality of life}

\section{Summary of results on fatigue and HRQoL in IBD}

\section{Fatigue}

Persistent fatigue from chronic illness involves ongoing exhaustion that is disproportionate to exertion and not alleviated by rest. ${ }^{90}$ Fatigue is often the most debilitating part of the disease ${ }^{90,91}$, but frequently does not correlate with disease status or clinical findings. ${ }^{90,92-98}$ Despite the fact that, in clinical IBD practice, fatigue is a common complaint, very little is known about its origin and treatment. We confirmed the high prevalence of fatigue (nearly $40 \%)^{92}$ in a cross-sectional study, compared to 6$8.5 \%$ reported in the general population. ${ }^{99-101}$ Fatigue scores in our IBD population were comparable with values found in rheumatic disease ${ }^{102,103}$, systemic sclerosis ${ }^{104}$, Sjogren's syndrome ${ }^{105}$, chronic liver disease ${ }^{106}$ and cancer. ${ }^{107-109}$ Anaemia and active disease in our IBD population were independent contributors to the level of fatigue, as also was shown by few other studies. ${ }^{92,110}$ In CD as well as in UC, a more severe disease course resulted in worse fatigue scores. In multivariate analysis, only infliximab use in $\mathrm{CD}$ was associated with less fatigue and better HRQoL scores.

\section{Health Related Quality of Life}

Similar to results presented in this thesis, numerous reports show that HRQoL in IBD patients is impaired compared to the general population. ${ }^{111-117}$ However, in remission, similar HRQoL scores have been reported. ${ }^{118-120}$ The most frequently reported contributing factor to a low HRQoL is active disease. ${ }^{111,112,114,115,117-129}$ Other unfavourable factors reported in literature are female gender ${ }^{111,113,122,130}$, higher age ${ }^{114}$, anaemia $^{110}$, corticosteroid $^{111,131,132}$ or immunosuppressive drug use ${ }^{131}$, hospitalization $^{111}$, short bowel syndrome ${ }^{133,134}$, extra-intestinal manifestations ${ }^{113,118,131,135}$, IBS-like symptoms ${ }^{116,136}$, and maladaptive coping behaviour. ${ }^{137-140}$

Factors favourably influencing $\mathrm{HRQ}$ oL in $C D$ were use of immunosuppressives (after one year of follow-up) $)^{111}$, post-surgery situation ${ }^{130,141,142}$, and having a partner ${ }^{114}$ or social support of a different kind after a surgical intervention. ${ }^{137}$ The relationship between HRQoL and disease course is little investigated. The present study confirmed results obtained by others regarding $C D^{131,143}$ and $U C^{131,143,144}$, that a more severe (relapsing) disease course, use of corticosteroids, immunosuppressives and infliximab, and extra-intestinal manifestations negatively affect HRQoL. In a multivariate analysis, we found fatigue to be an independent contributor to the impaired HRQoL in IBD, as was previously reported in two other studies. ${ }^{92,110}$ 


\section{How to explain the high level of fatigue and its influence on HRQOL?}

As summarized above, most attributing factors to the level of fatigue and HRQoL are directly or indirectly related to active disease. This, does however not explain why the prevalence of fatigue remains high during quiescent disease, or why a more severe disease course (without current disease activity) leads to a higher level of fatigue and subsequently to an impaired HRQoL. In the search for causes, three different approaches are possible:

\section{Biological approach}

The origin of fatigue is often split up into "central" and"peripheral", with peripheral fatigue resulting from neuromuscular dysfunction outside the central nervous system (CNS) and being related to impaired neurotransmission in peripheral nerves and/or defects in muscular contraction..$^{90}$ In chronic disease, central fatigue appears to be the most relevant, however, the relative contribution of peripheral and central fatigue in patients may vary significantly between diseases. Peripheral fatigue, for example, is observed in chronic diseases associated with muscle wasting and inflammation and/or joint abnormalities, as often occurs in rheumatoid arthritis (RA) and systemic lupus erythematosus (SLE). To elucidate the aetiology of central fatigue, many studies have been performed within the patient group with the chronic fatigue syndrome (CFS). ${ }^{145}$ It has been suggested that the hypothalamic-pituitary-adrenal axis (HPA-axis) may not be functioning appropriately in CFS and moreover, the dysfunction of the HPA-axis may be associated with depressive disorders and associated fatigue. ${ }^{90,146,147}$ However, in a heterogeneous group of IBD patients (with patients having active disease and patients being in remission) this could not be confirmed. ${ }^{92}$

Other possible influence may derive from circulating cytokines which are often elevated in chronic disease. ${ }^{90,148}$ The mechanism whereby elevations in cytokine levels outside the CNS may induce alterations in behaviour are unclear, but may either involve direct actions across the blood brain-barrier cells into the brain (reviewed by Swain90) or be secondary, as alterations in cytokine levels can also induce sleep disorders149, a symptom which is also highly prevalent in IBD patients even during quiescent disease.150

A proposed biological pathway in the CFS resulting in secondary depression is the presence of a chronic gut-derived inflammation due to weakened tight junction resulting in a "leaky gut" for mainly gram-negative bacteria, secondarily activating the inflammatory response system in which pro-inflammatory cytokines and lipopolysacharides play an important role. ${ }^{151,152}$ However, psychological stress might also increase bowel permeability, and thereby worsen the prognosis for a relapse-free course of $\mathrm{IBD}^{153}$ and possibly contribute to depression and secondary fatigue. 
The neurotransmitter serotonin has also been investigated in the aetiology of CFS and depression. Although a recent review on the role of neuropeptides in IBD was not conclusive, clarification of their mechanisms of action may lead to new treatment options in the future. ${ }^{154}$

\section{Psychological approach}

\section{Personality}

Studies on personality factors within the IBD population have shown conflicting results. High levels of neuroticism (negative emotional reactivity) are found more frequently in CD compared to UC patients ${ }^{155,156}$, however, when correcting data for demographic (age, gender) and behavioural factors (smoking) differences did not remain significant ${ }^{157}$, a finding confirmed by others more recently. ${ }^{158}$ In a study on personality characteristics prior to development of IBD, no significant differences were found with regard to personality traits. ${ }^{159}$ Taking this into account, the available data suggest that primary personality differences are unlikely to be a direct cause of IBD, but might have secondary impact on the course of disease.

\section{Coping}

Coping has been defined as the cognitive and behavioural efforts to manage stress, with the latter characterized as specific external and/or internal demands that are exceeding the resources of the individual. Coping strategies can be categorised in several dimensions, for example: emotion-focused/problem-focused, active/passive, flexible/inflexible and adaptive/maladaptive. These dimensions can overlap. The adaptive/maladaptive categorization is most broadly used as it can be useful for evaluation of coping in clinical settings, as it encompasses part of the other dimensions. Adaptive coping allows the individual to manage the situation more effectively, for example by focussing on the most important life goals, self management of health (diet, exercise), recruitment of social support and acceptance of symptoms. In a maladaptive coping situation a patient could withdraw himself from social activities and social involvement, use addictive substances or evolve to catastrophic thinking. ${ }^{160}$ Another form of maladaptive coping, 'depressive' coping (self pity, social withdrawal and feeling of helplessness) was found to be related to a higher level of disease concerns and psychological distress in IBD. ${ }^{137,161}$ Although most patients with IBD manage to cope well with their disease, maintaining a remarkable level of psychological well-being and an intact life style ${ }^{162,163}$, there is a sub-group of IBD patients with relatively quiescent disease in which psychological characteristics profoundly affect HRQoL. ${ }^{161}$ Patients' self-rated health status was as strongly determined by their habitual coping mechanisms as by their disease activity, and the presence of depressive coping patterns was much more important than disease characteristics in predicting patients' disease-related concerns. ${ }^{161}$ This suggests that 
psychologically orientated interventions could have a major effect on some patients' HRQoL by helping them to cope better with stressors related or unrelated to their disease. Trials in this respect have shown only a limited success but were performed during the advanced disease course ${ }^{164-169}$, whereas one might presume that improving coping strategies early in the disease course would have a greater impact on the long term.

Supposed that the development of coping mechanisms takes place early in the disease course, early intervention against depression and anxiety might secondarily improve fatigue and $\mathrm{HRQ}$ oL outcome, and perhaps thereby even change the course of IBD. ${ }^{170}$ Maladaptive coping disorders could be targeted with interventions such as cognitive behavioural therapy. Some older studies have assessed the effects of psychological interventions in IBD randomizing usual treatment either with or without sessions of group training regarding education, problem solving, relaxation, communication and cognitive strategies. Results indicated favourable effects of these interventions on outcome, especially with regard to coping and a reduction in depression, stress and pain perception. ${ }^{164,171,172}$ Results from more recent studies showed less evident effects in the short term, with no differences in outcome after one and after two years of therapeutic sessions with regard to HRQoL, anxiety and depressive symptoms. ${ }^{165,173-175}$ A recent intervention study focussing on skills and behaviour change to reduce distress showed reductions in disease related concerns, in particular for female participants, which were stable after 3 and 9 months of follow-up. ${ }^{167}$

\section{Mood disorders}

To what extent the presence of an anxiety or depressive disorder influences the level of fatigue remains difficult to understand as fatigue can be a symptom, but also a cause of depressive symptoms. The presence of a chronic medical condition has been found to be associated with higher rates of anxiety and mood disorders. ${ }^{176,177}$ Disease activity in IBD is strongly related to psychological anxiety as well as depressive symptoms ${ }^{126,178,179}$, however results are conflicting ${ }^{129,130,180}$ and the presence of a mood disorder is not always associated with disease severity ${ }^{181}$ or a firm diagnosis of depression. $^{182-185}$

Depression and anxiety are also thought to be able to exacerbate chronic health conditions, through a number of mechanisms including decreased behavioural compliance ${ }^{186,187}$ or an impaired functioning of the immune system. ${ }^{188}$ The presence of depression could also influence the effectiveness of treatment; in a prospective study of $C D$ patients treated with infliximab an earlier re-treatment was needed. ${ }^{189}$ Thus, disease activity and psychological distress probably have a reciprocal relationship, potentially exacerbating or triggering each other.

Within the IBD population, higher levels of anxiety and depressive symptoms are found in CD compared to UC patients ${ }^{116,129,130}$, however those differences are often the result of disease activity. ${ }^{128,190}$ Moreover, depression rates were higher among female patients, patients without partners, younger respondents, those who reported greater 
pain, and those who had functional limitations. ${ }^{191}$ The subjective needs of patients for psychological interventions has been shown to be mainly disease- or anxietyrelated. ${ }^{192}$

Of course the period around diagnosis can also influence the presence of anxiety and depressive disorders as much higher need for treatment of anxiety and depression is reported in the first year following diagnosis of IBD. ${ }^{180}$ As gastrointestinal symptoms often are present some time before the IBD diagnosis ${ }^{6,27,193}$ the question can be raised whether psychiatric morbidity actually precedes the IBD or is secondary to the condition. In a large population based sample, depression was identified as a moderate risk factor for UC, even when it occurred more than five years prior to the UC diagnosis. $^{180}$

\section{Social approach}

\section{Social support}

Social support was found to be very important for patients, improving coping mechanisms and resulting in a better quality of life. ${ }^{117,127,194-197}$ Having a partner was also found to improve $\mathrm{HRQOL}^{114}$ as it reduced the presence of depression ${ }^{191}$, similar to social support after surgical interventions. ${ }^{137}$ Support resulting from patients' trust in their physicians also improved adherence to medical management. ${ }^{198}$ Trust could be improved by increasing contact time with the treating physician and by extending the amount of information on new drugs. ${ }^{187,199}$ For chronic diseases, optimal management involves a partnership between the patient and physician. This facilitates the active involvement of the patient in their own care.

\section{Quality of care}

In earlier studies, HRQoL was also found to be influenced by the quality of care (particularly with regard to the parameters of "providing information", "costs", and "courtesy"). ${ }^{196,200}$ The assessment of the quality of health care, based on patients' perception, also revealed quality problems with respect to accommodation, accessibility to health care facilities and information received. In subgroup analysis, disease type, educational status, age and disease duration played an important role in the formation of patients' expectations from the health care system. ${ }^{200}$

It might even be speculated that patients who are not satisfied with the health care and treatment facilities could experience more stress potentially resulting in a more severe disease course.

\section{Patient education}

Patients with chronic conditions need support from health care providers in the supply of accurate and clear information, ideally, in a way that offers patients the possibility to develop a partial self-management strategy. In this perspective a useful link could 
be made between information offered and a patient's past experience. The use of information (how it is provided, by whom, and at what time point) is a key factor in this concept. ${ }^{201,202}$ Many patients report that they do not know enough about their disease, and would like more information. ${ }^{203,204}$ The information on IBD given through the Internet ${ }^{28}$, television, and IBD patient organizations ${ }^{29}$ could however still be improved as, especially on the internet, regarding the accuracy of information provided. $^{30,31}$

\section{Limitations}

A strength of the presented studies is their population based setting and the prospective inclusion of uniformly diagnosed IBD patients in the cohort, all in a well characterized geographical area. There are however some limitations. Despite the thorough registration at all study sites, there are probably still missing patients. Also, as data collection regarding disease course was mainly performed retrospectively by a limited group of persons, patient classification by disease location and behaviour at diagnosis could have been influenced by the information available. Moreover, definitions of outcome (disease course) based on treatment parameters such as surgery and/or medication change (as they were used in this study) could be biased by the fact that treatment methods may systematically differ between clinical centres, even in limited geographic areas.

Questionnaire response rates were high (65\%). However, more female than male patients responded, which might have influenced the results as it appears that women may be more likely to report fatigue, to report more severe fatigue, and are more likely to seek medical help for their fatigue, all of these factors influencing the final outcome. ${ }^{205-207}$ However, we adjusted for gender in multiple regression analysis.

Disease activity score calculation was performed using the assumption that abdominal palpation was normal, as not all patients could undergo physical examination for practical reasons. Therefore, in a sub-group of CD patients, disease activity was also measured using the validated questionnaire from Sandler et $a l^{208}$; the correlation, compared with results from the Harvey Bradshaw score ${ }^{209}$, was high $(r=0.80)$.

Finally, in a minority of patients we had no actual haemoglobin results available at the censoring time, as the indication for blood tests was given by the managing physicians. As fatigue and HRQoL scores in the patients with no haemoglobin level determined were comparable with those patients having quiescent disease and/or a normal haemoglobin level, we may assume it seems most likely that these patients were in remission and had no anaemia at the moment of filling in the questionnaire. 


\section{Conclusions and future perspectives}

In the present thesis, we studied disease course in IBD in a regional inception cohort in South Limburg, the Netherlands. Furthermore, we were able to enlarge the current knowledge on IBD related fatigue and its influence on the HRQoL, a common problem in clinical practice.

Regarding lag time to diagnosis of IBD, to our knowledge there is no evidence that in IBD a shorter lag-time between start of symptoms and diagnosis can influence disease course. However, trying to reduce it would be a logical first step to possibly improve outcome in IBD.

The stable IBD incidence over time in South Limburg would suggest that aetiological factors are levelling out in our region, although the incidence is still high compared to especially the Southern European countries. Future uniformly defined (with regard to patient selection, patient inception, follow-up, etcetera), population based research will be of major importance to understand factors contributing to the onset and development of this chronic disorder. In line with this, continuing quality control of included data need to be performed. Only in that way differing results from prospective and comparable registrations of IBD patients in an (inter-)national context can lead to possible clarifications.

Although, in our results, the disease course overall appeared to be mild with no increased overall mortality rate, we did identify patients at risk for recurrent disease and early mortality. Future research should therefore focus on factors contributing to these risks. Questions arising may be related to current IBD treatment (e.g. biologicals and their timing in the treatment schedule) or quality of care (treatment in low versus high volume IBD centres, numbers of gastroenterologists per hospital, presence of specialized IBD nurses, et cetera). Furthermore, in the complex disorder of IBD, knowledge about the genetic background is increasing. In future research one should therefore also focus on the combination of phenotypic and genotypic data, in order to establish possible aetiological factors and potentially a reliable risk factor profile for the disease course in an individual patient, identifying "tailor made" treatment strategies.

We reported that the prevalence of fatigue in our cohort was very high, independently of disease activity and/or anaemia. Moreover, a more severe disease course in the past was an independent predictor for currently increased fatigue and a lower HRQoL independent of actual disease activity and/or anaemia. Our results imply that patients with repeated exacerbations in the past, who have required more intensive drug treatment, are at risk of developing fatigue and a decrease in HRQoL. Only infliximab use during the previous severe disease course could improve current HRQoL.

As the presence of fatigue has a major impact on HRQoL, among treating physicians a high awareness of the prevalence and impact of fatigue is warranted. Future longitudinal, psychological and biological research is necessary to gain more insight in the concept of fatigue in chronic recurrent inflammation such as IBD. Hopefully, early 
detection and adequate intervention will lead to improved HRQoL. In the short term, in clinical practice, studies could focus on the usefulness of screening methods for fatigue, maladaptive coping strategies and the presence of anxiety and depression in order to identify patients at risk. Furthermore, the possible role of specialized IBD nurses could be considered as they could play a major role in assessing patients' wellbeing and in detecting early signs of mood disorders, coping problems and socially related factors. Finally, the possible benefit of early consultation of a medical psychologist or participation in a rehabilitation program could be investigated.

We conclude that there is strong accumulating evidence for a close interplay between disease course, fatigue, HRQoL and associated psychological factors, indicating the relevance of an IBD management based on an integrated "bio-psycho-social" longterm approach of patient care. 


\section{References}

1. Russel MG, Dorant E, Volovics A, Brummer RJ, Pop P, Muris JW, Bos LP, Limonard CB, Stockbrugger RW. High incidence of inflammatory bowel disease in The Netherlands: results of a prospective study. The South Limburg IBD Study Group. Dis Colon Rectum. 1998;41: 33-40.

2. http://statline.cbs.nl/StatWeb/start.asp?!p=Search/Search.

3. Arin Letamendia A, Borda Celaya F, Burusco Paternain MJ, Prieto Martinez C, Martinez Echeverria A, Elizalde Apestegui I, Laiglesia Izquierdo M, Macias Mendizabal E, Tamburri Moso P, Sanchez Valverde F. [High incidence rates of inflammatory bowel disease in Navarra (Spain). Results of a prospective, population-based study]. Gastroenterol Hepatol. 2008;31:111-116.

4. Economou M, Filis G, Tsianou Z, Alamanos J, Kogevinas A, Masalas K, Petrou A, Tsianos EV. Crohn's disease incidence evolution in North-western Greece is not associated with alteration of NOD2/CARD15 variants. World J Gastroenterol. 2007;13:5116-5120.

5. Sincic BM, Vucelic B, Persic M, Brncic N, Erzen DJ, Radakovic B, Micovic V, Stimac D. Incidence of inflammatory bowel disease in Primorsko-goranska County, Croatia, 2000-2004: A prospective population-based study. Scand J Gastroenterol. 2006;41:437-444.

6. Vind I, Riis L, Jess T, Knudsen E, Pedersen N, Elkjaer M, Bak Andersen I, Wewer V, Norregaard P, Moesgaard F, Bendtsen F, Munkholm P. Increasing incidences of inflammatory bowel disease and decreasing surgery rates in Copenhagen City and County, 2003-2005: a population-based study from the Danish Crohn colitis database. Am J Gastroenterol. 2006;101:1274-1282.

7. Russel MG, Engels LG, Muris JW, Limonard CB, Volovics A, Brummer RJ, Stockbrugger RW. Modern life' in the epidemiology of inflammatory bowel disease: a case-control study with special emphasis on nutritional factors. Eur J Gastroenterol Hepatol. 1998;10:243-249.

8. Koloski NA, Bret L, Radford-Smith G. Hygiene hypothesis in inflammatory bowel disease: a critical review of the literature. World J Gastroenterol. 2008;14:165-173.

9. Amre DK, Lambrette P, Law L, Krupoves A, Chotard V, Costea F, Grimard G, Israel D, Mack D, Seidman EG. Investigating the hygiene hypothesis as a risk factor in pediatric onset Crohn's disease: a casecontrol study. Am J Gastroenterol. 2006;101:1005-1011.

10. Gower Rousseau C, Salomez JL, Dupas JL, Marti R, Nuttens MC, Votte A, Lemahieu M, Lemaire B, Colombel JF, Cortot A. Incidence of inflammatory bowel disease in northern France (1988-1990). Gut. 1994;35:1433-1438.

11. Shivananda S, Lennard Jones J, Logan R, Fear N, Price A, Carpenter L, van Blankenstein M. Incidence of inflammatory bowel disease across Europe: is there a difference between north and south? Results of the European Collaborative Study on Inflammatory Bowel Disease (EC-IBD). Gut. 1996;39:690-697.

12. Timmer A, Breuer-Katschinski B, Goebell H. Time trends in the incidence and disease location of Crohn's disease 1980-1995: a prospective analysis in an urban population in Germany. Inflamm Bowel Dis. 1999;5:79-84.

13. Rodrigo L, Riestra S, Nino P, Cadahia V, Tojo R, Fuentes D, Moreno M, Gonzalez Ballina E, Fernandez E. A population-based study on the incidence of inflammatory bowel disease in Oviedo (Northern Spain). Rev Esp Enferm Dig. 2004;96:296-305.

14. Cachia E, Calleja N, Aakeroy R, Degaetano J, Vassallo M. Incidence of inflammatory bowel disease in Malta between 1993 and 2005: a retrospective study. Inflamm Bowel Dis. 2008; 14:550-553.

15. Manousos ON, Giannadaki E, Mouzas IA, Tzardi M, Koutroubakis I, Skordilis P, Vassilakis S, Kouroumalis E, Vlachonikolis IG. Ulcerative colitis is as common in Crete as in northern Europe: a 5-year prospective study. Eur J Gastroenterol Hepatol. 1996;8:893-898.

16. Kucharzik T, Maaser C, Lugering A, Kagnoff M, Mayer L, Targan S, Domschke W. Recent understanding of IBD pathogenesis: implications for future therapies. Inflamm Bowel Dis. 2006;12:1068-1083.

17. Feeney MA, Murphy F, Clegg AJ, Trebble TM, Sharer NM, Snook JA. A case-control study of childhood environmental risk factors for the development of inflammatory bowel disease. Eur J Gastroenterol Hepatol. 2002;14:529-534.

18. Joossens M, Simoens M, Vermeire S, Bossuyt X, Geboes K, Rutgeerts P. Contribution of genetic and environmental factors in the pathogenesis of Crohn's disease in a large family with multiple cases. Inflamm Bowel Dis. 2007;13:580-584. 
19. Van Kruiningen HJ, Joossens M, Vermeire S, Joossens S, Debeugny S, Gower-Rousseau C, Cortot A, Colombel JF, Rutgeerts P, Vlietinck R. Familial Crohn's disease in Belgium: pedigrees, temporal relationships among cases, and family histories. J Clin Gastroenterol. 2007;41:583-590.

20. Hanauer SB. Inflammatory bowel disease: epidemiology, pathogenesis, and therapeutic opportunities. Inflamm Bowel Dis. 2006;12 Suppl 1:S3-9.

21. Shiobara N, Suzuki Y, Aoki H, Gotoh A, Fujii Y, Hamada Y, Suzuki S, Fukui N, Kurane I, Itoh T, Suzuki R. Bacterial superantigens and $T$ cell receptor beta-chain-bearing $T$ cells in the immunopathogenesis of ulcerative colitis. Clin Exp Immunol. 2007;150:13-21.

22. Aratari A, Papi C, Galletti B, Angelucci E, Viscido A, D'Ovidio V, Ciaco A, Abdullahi M, Caprilli R. Seasonal variations in onset of symptoms in Crohn's disease. Dig Liver Dis. 2006;38: 319-323.

23. Moum B, Aadland E, Ekbom A, Vatn MH. Seasonal variations in the onset of ulcerative colitis. Gut. 1996;38:376-378.

24. Evans JG, Acheson ED. An epidemiological study of ulcerative colitis and regional enteritis in the Oxford area. Gut. 1965;6:311-324.

25. Cave D, Freedman L. Seasonal variations in the clinical presentation of Crohn's disease and ulcerative colitis. Int J Epidemiol. 1975:317-320.

26. Stockbrugger RW. Seasonality in IBD: Do we really know about it? Dig Liver Dis. 2006;38: 323-325.

27. Abakar-Mahamat A, Filippi J, Pradier C, Dozol A, Hebuterne X. Incidence of inflammatory bowel disease in Corsica from 2002 to 2003. Gastroenterol Clin Biol. 2007;31:1098-1103.

28. Angelucci E, Orlando A, Ardizzone S, Guidi L, Sorrentino D, Fries W, Astegiano M, Sociale O, Cesarini M, Renna S, Cassinotti A, Marzo M, Quaglia A, Sergi MD, Simondi D, Vernia P, Malesci A, Danese S. Internet use among inflammatory bowel disease patients: an Italian multicenter survey. Eur J Gastroenterol Hepatol. 2009;21:1036-1041.

29. Bodini P, Politi P, Mortilla MG. Communication for IBD patients: Present status and future perspectives. gastroenterology. 2005;128.

30. van der Marel S, Duijvestein M, Hardwick JC, van den Brink GR, Veenendaal R, Hommes DW, Fidder $\mathrm{HH}$. Quality of web-based information on inflammatory bowel diseases. Inflamm Bowel Dis. 2009.

31. Bernard A, Langille M, Hughes S, Rose C, Leddin D, Veldhuyzen van Zanten S. A systematic review of patient inflammatory bowel disease information resources on the World Wide Web. Am J Gastroenterol. 2007;102:2070-2077.

32. Wolters FL, Russel MG, Sijbrandij J, Schouten L, Odes S, Riis L, Munkholm P, Bodini P, O'Morain C, Mouzas IA, Tsianos E, Vermeire S, Monteiro E, Limonard C, Vatn M, Fornaciari G, Pereira S, Moum B, Stockbrugger RW. Crohn's disease: increased mortality 10 years after diagnosis in a Europe-wide population based cohort. Gut. 2006;55:510-518.

33. Canavan C, Abrams KR, Hawthorne B, Mayberry JF. Long-term prognosis in Crohn's disease: An epidemiological study of patients diagnosed more than 20 years ago in Cardiff. Aliment Pharmacol Ther. 2007; 25:59-65.

34. Jess T, Riis L, Vind I, Winther KV, Borg S, Binder V, Langholz E, Thomsen OO, Munkholm P. Changes in clinical characteristics, course, and prognosis of inflammatory bowel disease during the last 5 decades: a population-based study from Copenhagen, Denmark. Inflamm Bowel Dis. 2007;13:481-489.

35. Palli D, Trallori G, Saieva C, Tarantino O, Edili E, D'Albasio G, Pacini F, Masala G. General and cancer specific mortality of a population based cohort of patients with inflammatory bowel disease: the Florence Study. Gut. 1998;42:175-179.

36. Winther KV, Jess T, Langholz E, Munkholm P, Binder V. Survival and cause-specific mortality in ulcerative colitis: follow-up of a population-based cohort in Copenhagen County. Gastroenterology. 2003;125:1576-1582.

37. Ekbom A, Helmick CG, Zack M, Holmberg L, Adami HO. Survival and causes of death in patients with inflammatory bowel disease: a population-based study. Gastroenterology. 1992;103:954-960.

38. Persson PG, Bernell O, Leijonmarck CE, Farahmand BY, Hellers G, Ahlbom A. Survival and cause-specific mortality in inflammatory bowel disease: a population-based cohort study. Gastroenterology. 1996;110:1339-1345.

39. Jess T, Winther KV, Munkholm P, Langholz E, Binder V. Mortality and causes of death in Crohn's disease: follow-up of a population-based cohort in Copenhagen County, Denmark. Gastroenterology. 2002;122:1808-1814.

40. Mayberry JF, Newcombe RG, Rhodes J. Mortality in Crohn's disease. Q J Med. 1980;49: 63-68. 
41. Prior P, Gyde S, Cooke WT, Waterhouse JA, Allan RN. Mortality in Crohn's disease. Gastroenterology. 1981;80:307-312.

42. Weterman IT, Biemond I, Pena AS. Mortality and causes of death in Crohn's disease. Review of 50 years' experience in Leiden University Hospital. Gut. 1990;31:1387-1390.

43. Probert CS, Jayanthi V, Wicks AC, Mayberry JF. Mortality from Crohn's disease in Leicestershire, 19721989: an epidemiological community based study. Gut. 1992;33: 1226-1228.

44. Farrokhyar F, Swarbrick ET, Grace RH, Hellier MD, Gent AE, Irvine EJ. Low mortality in ulcerative colitis and Crohn's disease in three regional centers in England. Am J Gastroenterol. 2001;96:501-507.

45. Cottone M, Rosselli M, Casa A. Smoking, azathioprine, and clinical course in Crohn's disease. Gastroenterology. 1996;111:1161-1162.

46. Brostrom O, Monsen U, Nordenwall B, Sorstad J, Hellers G. Prognosis and mortality of ulcerative colitis in Stockholm County, 1955-1979. Scand J Gastroenterol. 1987;22:907-913.

47. Gyde S, Prior P, Dew MJ, Saunders V, Waterhouse JA, Allan RN. Mortality in ulcerative colitis. Gastroenterology. 1982;83:36-43.

48. Jess T, Gamborg M, Munkholm P, Sorensen TI. Overall and cause-specific mortality in ulcerative colitis: meta-analysis of population-based inception cohort studies. Am J Gastroenterol. 2007;102:609-617.

49. Van Assche G, Vermeire S, Rutgeerts P. Infliximab therapy for patients with inflammatory bowel disease: 10years on. Eur J Pharmacol. 2009.

50. Van Assche G, Vermeire S, Rutgeerts P. Immunosuppression in inflammatory bowel disease: traditional, biological or both? Curr Opin Gastroenterol. 2009;25:323-328.

51. van der Woude CJ, Hommes DW. Are we ready for top-down therapy for inflammatory bowel diseases: pro. Expert Rev Gastroenterol Hepatol. 2007;1:243-248.

52. Rutgeerts P, Vermeire S, Van Assche G. Biological therapies for inflammatory bowel diseases. Gastroenterology. 2009;136:1182-1197.

53. Hanauer SB, Feagan BG, Lichtenstein GR, Mayer LF, Schreiber S, Colombel JF, Rachmilewitz D, Wolf DC, Olson A, Bao W, Rutgeerts P. Maintenance infliximab for Crohn's disease: the ACCENT I randomised trial. Lancet. 2002;359:1541-1549.

54. van Balkom BP, Schoon EJ, Stockbrugger RW, Wolters FL, van Hogezand RA, van Deventer SJ, Oldenburg B, van Dullemen HM, Russel MG. Effects of anti-tumour necrosis factor-alpha therapy on the quality of life in Crohn's disease. Aliment Pharmacol Ther. 2002;16:1101-1107.

55. Baert F, Caprilli R, Angelucci E. Medical therapy for Crohn's disease: top-down or step-up? Dig Dis. 2007;25:260-266.

56. Domenech E, Manosa M, Cabre E. Top-down therapy: is the evidence strong enough? Dig Dis. 2009;27:306-311.

57. Loftus EV, Jr., Silverstein MD, Sandborn WJ, Tremaine WJ, Harmsen WS, Zinsmeister AR. Crohn's disease in Olmsted County, Minnesota, 1940-1993: incidence, prevalence, and survival. Gastroenterology. 1998;114:1161-1168.

58. Veloso FT, Ferreira JT, Barros L, Almeida S. Clinical outcome of Crohn's disease: analysis according to the vienna classification and clinical activity. Inflamm Bowel Dis. 2001;7:306-313.

59. Wolters FL, Russel MG, Sijbrandij J, Ambergen T, Odes S, Riis L, Langholz E, Politi P, Qasim A, Koutroubakis I, Tsianos E, Vermeire S, Freitas J, van Zeijl G, Hoie O, Bernklev T, Beltrami M, Rodriguez D, Stockbrugger RW, Moum B. Phenotype at diagnosis predicts recurrence rates in Crohn's disease. Gut. 2006;55:1124-1130.

60. D'Haens G, Rutgeerts P. Postoperative recurrence of Crohn's disease: pathophysiology and prevention. Inflamm Bowel Dis. 1999;5:295-303.

61. Hoie O, Schouten L, Wolters FL, Solberg IC, Riis L, Mouzas IA, Politi P, Odes S, Langholz E, Vatn M, Stockbrugger RW, Moum B. Ulcerative colitis: no rise in mortality in a European-wide population based cohort 10 years after diagnosis. Gut. 2007;56:497-503.

62. Ekbom A, Helmick C, Zack M, Adami HO. Increased risk of large-bowel cancer in Crohn's disease with colonic involvement. Lancet. 1990;336:357-359.

63. Bernstein $\mathrm{CN}$, Blanchard JF, Kliewer E, Wajda A. Cancer risk in patients with inflammatory bowel disease: a population-based study. Cancer. 2001;91:854-862.

64. Jess T, Loftus EV, Jr., Harmsen WS, Zinsmeister AR, Tremaine WJ, Melton LJ, 3rd, Munkholm P, Sandborn WJ. Survival and cause specific mortality in patients with inflammatory bowel disease: a long term outcome study in Olmsted County, Minnesota, 1940-2004. Gut. 2006;55:1248-1254. 
65. Masala G, Bagnoli S, Ceroti M, Saieva C, Trallori G, Zanna I, D'Albasio G, Palli D. Divergent patterns of total and cancer mortality in ulcerative colitis and Crohn's disease patients: the Florence IBD study 1978-2001. Gut. 2004;53:1309-1313.

66. Cottone M, Magliocco A, Rosselli M, Pinzone F, Oliva L, Orlando A, Aiala MR, Cipolla C, Pagliaro L. Mortality in patients with Crohn's disease. Scand J Gastroenterol. 1996;31: 372-375.

67. Stewenius J, Adnerhill I, Anderson H, Ekelund GR, Floren CH, Fork FT, Janzon L, Lindstrom C, Ogren M. Incidence of colorectal cancer and all cause mortality in non-selected patients with ulcerative colitis and indeterminate colitis in Malmo, Sweden. Int J Colorectal Dis. 1995;10:117-122.

68. Mellemkjaer L, Johansen C, Gridley G, Linet MS, Kjaer SK, Olsen JH. Crohn's disease and cancer risk (Denmark). Cancer causes and control CCC. 2000;11:145-150.

69. Karlen P, Lofberg R, Brostrom O, Leijonmarck CE, Hellers G, Persson PG. Increased risk of cancer in ulcerative colitis: a population-based cohort study. Am J Gastroenterol. 1999;94:1047-1052.

70. Prior P, Gyde S, Allan RN. Mortality in ulcerative colitis: methods of analysis. Gastroenterology. 1982;83:524-525.

71. Gyde SN, Prior P, Allan RN, Stevens A, Jewell DP, Truelove SC, Lofberg R, Brostrom O, Hellers G. Colorectal cancer in ulcerative colitis: a cohort study of primary referrals from three centres. Gut. 1988;29:206-217.

72. Kvist N, Jacobsen O, Kvist HK, Norgaard P, Ockelmann HH, Schou G, Jarnum S. Malignancy in ulcerative colitis. Scand J Gastroenterol. 1989;24:497-506.

73. Jess T, Loftus EV, Jr., Velayos FS, Winther KV, Tremaine WJ, Zinsmeister AR, Scott Harmsen W, Langholz E, Binder V, Munkholm P, Sandborn WJ. Risk factors for colorectal neoplasia in inflammatory bowel disease: a nested case-control study from Copenhagen county, Denmark and Olmsted county, Minnesota. Am J Gastroenterol. 2007;102:829-836.

74. Sharan R, Schoen RE. Cancer in inflammatory bowel disease. An evidence-based analysis and guide for physicians and patients. Gastroenterol Clin North Am. 2002;31:237-254.

75. Gillen CD, Walmsley RS, Prior P, Andrews HA, Allan RN. Ulcerative colitis and Crohn's disease: a comparison of the colorectal cancer risk in extensive colitis. Gut. 1994;35: 1590-1592.

76. Ryan BM, Russel MG, Langholz E, Stockbrugger RW. Aminosalicylates and colorectal cancer in IBD: a not-so bitter pill to swallow. Am J Gastroenterol. 2003;98:1682-1687.

77. Cheng Y, Desreumaux P. 5-aminosalicylic acid is an attractive candidate agent for chemoprevention of colon cancer in patients with inflammatory bowel disease. World J Gastroenterol. 2005;11:309-314.

78. Munkholm P. Review article: the incidence and prevalence of colorectal cancer in inflammatory bowel disease. Aliment Pharmacol Ther. 2003;18 Suppl 2:1-5.

79. Romberg-Camps MJ, Dagnelie PC, Kester AD, Hesselink-van de Kruijs MA, Cilissen M, Engels LG, Van Deursen C, Hameeteman WH, Wolters FL, Russel MG, Stockbrugger RW. Influence of phenotype at diagnosis and of other potential prognostic factors on the course of inflammatory bowel disease. Am J Gastroenterol. 2009;104:371-383.

80. Waldner MJ, Neurath MF. Novel cytokine-targeted therapies and intestinal inflammation. Curr Opin Pharmacol. 2009.

81. Gasche C, Scholmerich J, Brynskov J, D'Haens G, Hanauer SB, Irvine EJ, Jewell DP, Rachmilewitz D, Sachar DB, Sandborn WJ, Sutherland LR. A simple classification of Crohn's disease: report of the Working Party for the World Congresses of Gastroenterology, Vienna 1998. Inflamm Bowel Dis. 2000;6:8-15.

82. Satsangi J, Silverberg MS, Vermeire S, Colombel JF. The Montreal classification of inflammatory bowel disease: controversies, consensus, and implications. Gut. 2006;55: 749-753.

83. Silverberg MS, Satsangi J, Ahmad T, Arnott ID, Bernstein CN, Brant SR, Caprilli R, Colombel JF, Gasche C, Geboes K, Jewell DP, Karban A, Loftus Jr EV, Pena AS, Riddell RH, Sachar DB, Schreiber S, Steinhart $\mathrm{AH}$, Targan SR, Vermeire S, Warren BF. Toward an integrated clinical, molecular and serological classification of inflammatory bowel disease: Report of a Working Party of the 2005 Montreal World Congress of Gastroenterology. Can J Gastroenterol. 2005;19 Suppl A:5-36.

84. Louis E, Collard A, Oger AF, Degroote E, Aboul Nasr El Yafi FA, Belaiche J. Behaviour of Crohn's disease according to the Vienna classification: changing pattern over the course of the disease. Gut. 2001;49:777-782.

85. Noomen CG, Hommes DW, Fidder HH. Update on genetics in inflammatory disease. Best Pract Res Clin Gastroenterol. 2009;23:233-243. 
86. Bhat M, Nguyen GC, Pare P, Lahaie R, Deslandres C, Bernard EJ, Aumais G, Jobin G, Wild G, Cohen A, Langelier D, Brant S, Dassopoulos T, McGovern D, Torres E, Duerr R, Regueiro M, Silverberg MS, Steinhart H, Griffiths AM, Elkadri A, Cho J, Proctor D, Goyette P, Rioux J, Bitton A. Phenotypic and genotypic characteristics of inflammatory bowel disease in French Canadians: comparison with a large North American repository. Am J Gastroenterol. 2009;104:2233-2240.

87. Russell RK, Drummond HE, Nimmo EE, Anderson N, Smith L, Wilson DC, Gillett PM, McGrogan P, Hassan K, Weaver LT, Bisset M, Mahdi G, Satsangi J. Genotype-phenotype Analysis in Childhood-onset Crohn's Disease: NOD2/CARD15 Variants Consistently Predict Phenotypic Characteristics of Severe Disease. Inflamm Bowel Dis. 2005;11:955-964.

88. Helio T, Halme L, Lappalainen M, Fodstad H, Paavola-Sakki P, Turunen U, Farkkila M, Krusius T, Kontula K. CARD15/NOD2 gene variants are associated with familially occurring and complicated forms of Crohn's disease. Gut. 2003;52:558-562.

89. Hampe J, Grebe J, Nikolaus S, Solberg C, Croucher PJ, Mascheretti S, Jahnsen J, Moum B, Klump B, Krawczak M, Mirza MM, Foelsch UR, Vatn M, Schreiber S. Association of NOD2 (CARD 15) genotype with clinical course of Crohn's disease: a cohort study. Lancet. 2002;359:1661-1665.

90. Swain MG. Fatigue in chronic disease. Clin Sci (Lond). 2000;99:1-8.

91. Dagnelie PC, Pijls-Johannesma MC, Lambin P, Beijer S, De Ruysscher D, Kempen GI. Impact of fatigue on overall quality of life in lung and breast cancer patients selected for high-dose radiotherapy. Ann Oncol. 2007;18:940-944.

92. Minderhoud IM, Oldenburg B, van Dam PS, van Berge Henegouwen GP. High prevalence of fatigue in quiescent inflammatory bowel disease is not related to adrenocortical insufficiency. Am J Gastroenterol. 2003;98:1088-1093.

93. Kos D, Kerckhofs E, Nagels G, D'Hooghe M B, Ilsbroukx S. Origin of fatigue in multiple sclerosis: review of the literature. Neurorehabil Neural Repair. 2008;22:91-100.

94. Kojima T, Ishiguro N, Oguchi T, Oba M, Tsuchiya H, Sugiura F, Furukawa TA, Suzuki S, Tokudome S. Psychosocial factors, disease status, and quality of life in patients with rheumatoid arthritis. J Psychosom Res. 2009;67:425-431.

95. Krupp LB. Fatigue in multiple sclerosis: definition, pathophysiology and treatment. CNS Drugs. 2003;17:225-234.

96. Denburg SD, Carbotte RM, Denburg JA. Psychological aspects of systemic lupus erythematosus: cognitive function, mood, and self-report. J Rheumatol. 1997;24:998-1003.

97. Wolfe F, Michaud K. Predicting depression in rheumatoid arthritis: the signal importance of pain extent and fatigue, and comorbidity. Arthritis Rheum. 2009;61:667-673.

98. Huyser BA, Parker JC, Thoreson R, Smarr KL, Johnson JC, Hoffman R. Predictors of subjective fatigue among individuals with rheumatoid arthritis. Arthritis Rheum. 1998;41: 2230-2237.

99. Walker EA, Katon WJ, Jemelka RP. Psychiatric disorders and medical care utilization among people in the general population who report fatigue. J Gen Intern Med. 1993;8:436-440.

100. Bates DW, Schmitt W, Buchwald D, Ware NC, Lee J, Thoyer E, Kornish RJ, Komaroff AL. Prevalence of fatigue and chronic fatigue syndrome in a primary care practice. Arch Intern Med. 1993;153: 2759-2765.

101. Lawrie SM, Manders DN, Geddes JR, Pelosi AJ. A population-based incidence study of chronic fatigue. Psychol Med. 1997;27:343-353.

102. Rupp I, Boshuizen HC, Jacobi CE, Dinant HJ, van den Bos GA. Impact of fatigue on health-related quality of life in rheumatoid arthritis. Arthritis Rheum. 2004;51:578-585.

103. van Tubergen A, Coenen J, Landewe R, Spoorenberg A, Chorus A, Boonen A, van der Linden S, van der Heijde D. Assessment of fatigue in patients with ankylosing spondylitis: a psychometric analysis. Arthritis Rheum. 2002;47:8-16.

104. Thombs BD, Bassel M, McGuire L, Smith MT, Hudson M, Haythornthwaite JA. A systematic comparison of fatigue levels in systemic sclerosis with general population, cancer and rheumatic disease samples. Rheumatology (Oxford). 2008;47:1559-1563.

105. Barendregt PJ, Visser MR, Smets EM, Tulen JH, van den Meiracker AH, Boomsma F, Markusse HM. Fatigue in primary Sjogren's syndrome. Ann Rheum Dis. 1998;57:291-295.

106. Unal G, de Boer JB, Borsboom GJ, Brouwer JT, Essink-Bot M, de Man RA. A psychometric comparison of health-related quality of life measures in chronic liver disease. J Clin Epidemiol. 2001;54:587-596. 
107. Visser MR, Smets EM. Fatigue, depression and quality of life in cancer patients: how are they related? Support Care Cancer. 1998;6:101-108.

108. Hagelin CL, Wengstrom $\mathrm{Y}$, Runesdotter S, Furst CJ. The psychometric properties of the Swedish Multidimensional Fatigue Inventory MFI-20 in four different populations. Acta Oncol. 2007;46:97-104.

109. Holzner B, Kemmler G, Greil R, Kopp M, Zeimet A, Raderer M, Hejna M, Zochbauer S, Krajnik G, Huber $\mathrm{H}$, Fleischhacker WW, Sperner-Unterweger B. The impact of hemoglobin levels on fatigue and quality of life in cancer patients. Ann Oncol. 2002;13:965-973.

110. Gasche C, Lomer MC, Cavill I, Weiss G. Iron, anaemia, and inflammatory bowel diseases. Gut. 2004;53:1190-1197.

111. Blondel-Kucharski F, Chircop C, Marquis P, Cortot A, Baron F, Gendre JP, Colombel JF. Health-related quality of life in Crohn's disease: a prospective longitudinal study in 231 patients. Am J Gastroenterol. 2001;96:2915-2920.

112. Janke $\mathrm{KH}$, Raible A, Bauer M, Clemens $\mathrm{P}$, Meisner C, Hauser W, Steder-Neukamm U, Henrich G, Herschbach P, Gregor M, Klump B. Questions on life satisfaction (FLZM) in inflammatory bowel disease. Int J Colorectal Dis. 2004;19:343-353.

113. Bernklev T, Jahnsen J, Aadland E, Sauar J, Schulz T, Lygren I, Henriksen M, Stray N, Kjellevold O, Vatn $M$, Moum B. Health-related quality of life in patients with inflammatory bowel disease five years after the initial diagnosis. Scand J Gastroenterol. 2004;39:365-373.

114. Bernklev T, Jahnsen J, Lygren I, Henriksen M, Vatn M, Moum B. Health-related quality of life in patients with inflammatory bowel disease measured with the short form-36: psychometric assessments and a comparison with general population norms. Inflamm Bowel Dis. 2005;11:909-918.

115. Petrak F, Hardt J, Clement T, Borner N, Egle UT, Hoffmann SO. Impaired health-related quality of life in inflammatory bowel diseases: psychosocial impact and coping styles in a national German sample. Scand J Gastroenterol. 2001;36:375-382.

116. Simren M, Axelsson J, Gillberg R, Abrahamsson H, Svedlund J, Bjornsson ES. Quality of life in inflammatory bowel disease in remission: the impact of IBS-like symptoms and associated psychological factors. Am J Gastroenterol. 2002;97:389-396.

117. Graff LA, Walker JR, Lix L, Clara I, Rawsthorne P, Rogala L, Miller N, Jakul L, McPhail C, Ediger J, Bernstein $\mathrm{CN}$. The relationship of inflammatory bowel disease type and activity to psychological functioning and quality of life. Clin Gastroenterol Hepatol. 2006;4:1491-1501.

118. Hjortswang H, Jarnerot G, Curman B, Sandberg-Gertzen H, Tysk C, Blomberg B, Almer S, Strom M. The influence of demographic and disease-related factors on health-related quality of life in patients with ulcerative colitis. Eur J Gastroenterol Hepatol. 2003;15:1011-1020.

119. Casellas F, Arenas JI, Baudet JS, Fabregas S, Garcia N, Gelabert J, Medina C, Ochotorena I, Papo M, Rodrigo L, Malagelada JR. Impairment of health-related quality of life in patients with inflammatory bowel disease: a Spanish multicenter study. Inflamm Bowel Dis. 2005;11: 488-496.

120. Andersson P, Olaison G, Bendtsen P, Myrelid P, Sjodahl R. Health related quality of life in Crohn's proctocolitis does not differ from a general population when in remission. Colorectal Dis. 2003;5: 56-62.

121. Pizzi LT, Weston CM, Goldfarb NI, Moretti D, Cobb N, Howell JB, Infantolino A, Dimarino AJ, Cohen S. Impact of chronic conditions on quality of life in patients with inflammatory bowel disease. Inflamm Bowel Dis. 2006;12:47-52.

122. Casellas F, Lopez-Vivancos J, Badia X, Vilaseca J, Malagelada JR. Influence of inflammatory bowel disease on different dimensions of quality of life. Eur J Gastroenterol Hepatol. 2001;13:567-572.

123. Han SW, McColl E, Barton JR, James P, Steen IN, Welfare MR. Predictors of quality of life in ulcerative colitis: the importance of symptoms and illness representations. Inflamm Bowel Dis. 2005;11:24-34.

124. Casellas F, Lopez-Vivancos J, Casado A, Malagelada JR. Factors affecting health related quality of life of patients with inflammatory bowel disease. Qual Life Res. 2002;11:775-781.

125. Saibeni S, Cortinovis I, Beretta L, Tatarella M, Ferraris L, Rondonotti E, Corbellini A, Bortoli A, Colombo E, Alvisi C, Imperiali G, de Franchis R. Gender and disease activity influence health-related quality of life in inflammatory bowel diseases. Hepatogastroenterology. 2005;52: 509-515.

126. Porcelli P, Leoci C, Guerra V. A prospective study of the relationship between disease activity and psychologic distress in patients with inflammatory bowel disease. Scand J Gastroenterol. 1996;31: 792-796. 
127. Sewitch MJ, Abrahamowicz M, Bitton A, Daly D, Wild GE, Cohen A, Katz S, Szego PL, Dobkin PL. Psychological distress, social support, and disease activity in patients with inflammatory bowel disease. Am J Gastroenterol. 2001;96:1470-1479.

128. Walker EA, Gelfand AN, Gelfand MD, Katon WJ. Psychiatric diagnoses, sexual and physical victimization, and disability in patients with irritable bowel syndrome or inflammatory bowel disease. Psychol Med. 1995;25:1259-1267.

129. Guthrie E, Jackson J, Shaffer J, Thompson D, Tomenson B, Creed F. Psychological disorder and severity of inflammatory bowel disease predict health-related quality of life in ulcerative colitis and Crohn's disease. Am J Gastroenterol. 2002;97:1994-1999.

130. Nordin K, Pahlman L, Larsson K, Sundberg-Hjelm M, Loof L. Health-related quality of life and psychological distress in a population-based sample of Swedish patients with inflammatory bowel disease. Scand J Gastroenterol. 2002;37:450-457.

131. Bernklev T, Jahnsen J, Schulz T, Sauar J, Lygren I, Henriksen M, Stray N, Kjellevold O, Aadland E, Vatn $M$, Moum B. Course of disease, drug treatment and health-related quality of life in patients with inflammatory bowel disease 5 years after initial diagnosis. Eur J Gastroenterol Hepatol. 2005;17: 1037-1045.

132. Faubion WA, Jr., Loftus EV, Jr., Harmsen WS, Zinsmeister AR, Sandborn WJ. The natural history of corticosteroid therapy for inflammatory bowel disease: a population-based study. Gastroenterology. 2001;121:255-260.

133. Carlsson E, Bosaeus I, Nordgren S. Quality of life and concerns in patients with short bowel syndrome. Clin Nutr. 2003;22:445-452.

134. Kalaitzakis E, Carlsson E, Josefsson A, Bosaeus I. Quality of life in short-bowel syndrome: impact of fatigue and gastrointestinal symptoms. Scand J Gastroenterol. 2008;43:1057-1065.

135. Hauser W, Dietz N, Steder-Neukamm U, Janke KH, Stallmach A. Biopsychosocial determinants of health-related quality of life after ileal pouch anal anastomosis for ulcerative colitis. Inflamm Bowel Dis. 2004;10:399-407.

136. Minderhoud IM, Oldenburg B, Wismeijer JA, van Berge Henegouwen GP, Smout AJ. IBS-like symptoms in patients with inflammatory bowel disease in remission; relationships with quality of life and coping behavior. Dig Dis Sci. 2004;49:469-474.

137. Moskovitz DN, Maunder RG, Cohen Z, McLeod RS, MacRae H. Coping behavior and social support contribute independently to quality of life after surgery for inflammatory bowel disease. Dis Colon Rectum. 2000;43:517-521.

138. Smolen DM, Topp R. Coping methods of patients with inflammatory bowel disease and prediction of perceived health, functional status, and well-being. Gastroenterol Nurs. 1998;21:112-118.

139. Tanaka M, Kazuma K. Ulcerative colitis: factors affecting difficulties of life and psychological well being of patients in remission. J Clin Nurs. 2005;14:65-73.

140. van der Zaag-Loonen HJ, Grootenhuis MA, Last BF, Derkx HH. Coping strategies and quality of life of adolescents with inflammatory bowel disease. Qual Life Res. 2004;13:1011-1019.

141. Thirlby RC, Land JC, Fenster LF, Lonborg R. Effect of surgery on health-related quality of life in patients with inflammatory bowel disease: a prospective study. Arch Surg. 1998;133: 826-832.

142. Thirlby RC, Sobrino MA, Randall JB. The long-term benefit of surgery on health-related quality of life in patients with inflammatory bowel disease. Arch Surg. 2001;136:521-527.

143. Lix LM, Graff LA, Walker JR, Clara I, Rawsthorne P, Rogala L, Miller N, Ediger J, Pretorius T, Bernstein $\mathrm{CN}$. Longitudinal study of quality of life and psychological functioning for active, fluctuating, and inactive disease patterns in inflammatory bowel disease. Inflamm Bowel Dis. 2008;14:1575-1584.

144. Hjortswang $\mathrm{H}$, Strom M, Almer S. Health-related quality of life in Swedish patients with ulcerative colitis. Am J Gastroenterol. 1998;93:2203-2211.

145. Chen R, Liang FX, Moriya J, Yamakawa J, Sumino H, Kanda T, Takahashi T. Chronic fatigue syndrome and the central nervous system. J Int Med Res. 2008;36:867-874.

146. Clauw DJ, Chrousos GP. Chronic pain and fatigue syndromes: overlapping clinical and neuroendocrine features and potential pathogenic mechanisms. Neuroimmunomodulation. 1997;4:134-153.

147. Van Houdenhove B, Van Den Eede F, Luyten P. Does hypothalamic-pituitary-adrenal axis hypofunction in chronic fatigue syndrome reflect a 'crash' in the stress system? Med Hypotheses. 2009;72:701-705. 
148. Leon AJ, Gomez E, Garrote JA, Bernardo D, Barrera A, Marcos JL, Fernandez-Salazar L, Velayos B, Blanco-Quiros A, Arranz E. High levels of proinflammatory cytokines, but not markers of tissue injury, in unaffected intestinal areas from patients with IBD. Mediators Inflamm. 2009;2009:580450.

149. Kapsimalis F, Basta M, Varouchakis G, Gourgoulianis K, Vgontzas A, Kryger M. Cytokines and pathological sleep. Sleep Med. 2008;9:603-614.

150. Ranjbaran Z, Keefer L, Stepanski E, Farhadi A, Keshavarzian A. The relevance of sleep abnormalities to chronic inflammatory conditions. Inflamm Res. 2007;56:51-57.

151. Maes M, Leunis JC. Normalization of leaky gut in chronic fatigue syndrome (CFS) is accompanied by a clinical improvement: effects of age, duration of illness and the translocation of LPS from gramnegative bacteria. Neuro Endocrinol Lett. 2008;29:902-910.

152. Maes M. Inflammatory and oxidative and nitrosative stress pathways underpinning chronic fatigue, somatization and psychosomatic symptoms. Curr Opin Psychiatry. 2009;22:75-83.

153. Meddings JB, Swain MG. Environmental stress-induced gastrointestinal permeability is mediated by endogenous glucocorticoids in the rat. Gastroenterology. 2000;119:1019-1028.

154. Margolis KG, Gershon MD. Neuropeptides and inflammatory bowel disease. Curr Opin Gastroenterol. 2009;25:503-511.

155. Andrews H, Barczak P, Allan RN. Psychiatric illness in patients with inflammatory bowel disease. Gut. 1987;28:1600-1604.

156. Robertson DA, Ray J, Diamond I, Edwards JG. Personality profile and affective state of patients with inflammatory bowel disease. Gut. 1989;30:623-626.

157. Barrett SM, Standen PJ, Lee AS, Hawkey CJ, Logan RF. Personality, smoking and inflammatory bowel disease. Eur J Gastroenterol Hepatol. 1996;8:651-655.

158. Vidal A, Gomez-Gil E, Sans M, Portella MJ, Salamero M, Pique JM, Panes J. Health-related quality of life in inflammatory bowel disease patients: the role of psychopathology and personality. Inflamm Bowel Dis. 2008;14:977-983.

159. Siegler IC, Levenstein S, Feaganes JR. Personality before and after illness onset among patients with inflammatory bowel disease: a controlled, prospective study. Psychosom Med. 2000;62:151 (abstract).

160. Drossman DA, Leserman J, Li Z, Keefe F, Hu YJ, Toomey TC. Effects of coping on health outcome among women with gastrointestinal disorders. Psychosom Med. 2000;62:309-317.

161. Mussell M, Bocker U, Nagel N, Singer MV. Predictors of disease-related concerns and other aspects of health-related quality of life in outpatients with inflammatory bowel disease. Eur J Gastroenterol Hepatol. 2004;16:1273-1280.

162. Hendriksen C, Binder V. Social prognosis in patients with ulcerative colitis. $\mathrm{Br}$ Med J. 1980;281: 581-583.

163. Walker EA, Roy-Byrne PP, Katon WJ, Li L, Amos D, Jiranek G. Psychiatric illness and irritable bowel syndrome: a comparison with inflammatory bowel disease. Am J Psychiatry. 1990;147:1656-1661.

164. Schwarz SP, Blanchard EB. Evaluation of a psychological treatment for inflammatory bowel disease. Behav Res Ther. 1991;29:167-177.

165. Jantschek G, Zeitz M, Pritsch M, Wirsching M, Klor HU, Studt HH, Rasenack J, Deter HC, Riecken EO, Feiereis $\mathrm{H}$, Keller W. Effect of psychotherapy on the course of Crohn's disease. Results of the German prospective multicenter psychotherapy treatment study on Crohn's disease. German Study Group on Psychosocial Intervention in Crohn's Disease. Scand J Gastroenterol. 1998;33:1289-1296.

166. Deter HC, Keller W, von Wietersheim J, Jantschek G, Duchmann R, Zeitz M. Psychological treatment may reduce the need for healthcare in patients with Crohn's disease. Inflamm Bowel Dis. 2007;13: 745-752.

167. Mussell M, Bocker U, Nagel N, Olbrich R, Singer MV. Reducing psychological distress in patients with inflammatory bowel disease by cognitive-behavioural treatment: exploratory study of effectiveness. Scand J Gastroenterol. 2003;38:755-762.

168. von Wietersheim J, Kessler H. Psychotherapy with chronic inflammatory bowel disease patients: a review. Inflamm Bowel Dis. 2006;12:1175-1184.

169. Grootenhuis MA, Maurice-Stam H, Derkx BH, Last BF. Evaluation of a psychoeducational intervention for adolescents with inflammatory bowel disease. Eur J Gastroenterol Hepatol. 2009;21:430-435.

170. Wahed M, Corser M, Goodhand JR, Rampton DS. Does psychological counseling alter the natural history of inflammatory bowel disease? Inflamm Bowel Dis. 2009. 
171. Milne B, Joachim G, Niedhardt J. A stress management programme for inflammatory bowel disease patients. J Adv Nurs. 1986;11:561-567.

172. Shaw L, Ehrlich A. Relaxation training as a treatment for chronic pain caused by ulcerative colitis. Pain. 1987;29:287-293.

173. Smith GD, Watson R, Roger D, McRorie E, Hurst N, Luman W, Palmer KR. Impact of a nurse-led counselling service on quality of life in patients with inflammatory bowel disease. J Adv Nurs. 2002;38:152-160.

174. Maunder RG, Esplen MJ. Supportive-expressive group psychotherapy for persons with inflammatory bowel disease. Can J Psychiatry. 2001;46:622-626.

175. Keller W, Pritsch M, Von Wietersheim J, Scheib P, Osborn W, Balck F, Dilg R, Schmelz-Schumacher E, Doppl W, Jantschek G, Deter HC. Effect of psychotherapy and relaxation on the psychosocial and somatic course of Crohn's disease: main results of the German Prospective Multicenter Psychotherapy Treatment study on Crohn's Disease. J Psychosom Res. 2004;56:687-696.

176. Katon W, Ciechanowski P. Impact of major depression on chronic medical illness. J Psychosom Res. 2002;53:859-863.

177. Patten SB, Beck CA, Kassam A, Williams JV, Barbui C, Metz LM. Long-term medical conditions and major depression: strength of association for specific conditions in the general population. Can J Psychiatry. 2005;50:195-202.

178. Mittermaier C, Dejaco C, Waldhoer T, Oefferlbauer-Ernst A, Miehsler W, Beier M, Tillinger W, Gangl A, Moser G. Impact of depressive mood on relapse in patients with inflammatory bowel disease: a prospective 18-month follow-up study. Psychosom Med. 2004;66:79-84.

179. Mardini HE, Kip KE, Wilson JW. Crohn's disease: a two-year prospective study of the association between psychological distress and disease activity. Dig Dis Sci. 2004;49: 492-497.

180. Kurina LM, Goldacre MJ, Yeates D, Gill LE. Depression and anxiety in people with inflammatory bowel disease. J Epidemiol Community Health. 2001;55:716-720.

181. Ondersma SJ, Lumley MA, Corlis ME, Tojek TM, Tolia V. Adolescents with inflammatory bowel disease: the roles of negative affectivity and hostility in subjective versus objective health. J Pediatr Psychol. 1997;22:723-738.

182. Engstrom I, Lindquist BL. Inflammatory bowel disease in children and adolescents: a somatic and psychiatric investigation. Acta Paediatr Scand. 1991;80:640-647.

183. Tarter RE, Switala J, Carra J, Edwards KL, Van Thiel DH. Inflammatory bowel disease: psychiatric status of patients before and after disease onset. Int J Psychiatry Med. 1987;17:173-181.

184. Helzer JE, Chammas S, Norland CC, Stillings WA, Alpers DH. A study of the association between Crohn's disease and psychiatric illness. Gastroenterology. 1984;86:324-330.

185. Walker EA, Gelfand MD, Gelfand AN, Creed F, Katon WJ. The relationship of current psychiatric disorder to functional disability and distress in patients with inflammatory bowel disease. Gen Hosp Psychiatry. 1996;18:220-229.

186. Nigro G, Angelini G, Grosso SB, Caula G, Sategna-Guidetti C. Psychiatric predictors of noncompliance in inflammatory bowel disease: psychiatry and compliance. J Clin Gastroenterol. 2001;32:66-68.

187. Husain A, Triadafilopoulos G. Communicating with patients with inflammatory bowel disease. Inflamm Bowel Dis. 2004;10:444-450; discussion 451.

188. Maunder RG, Levenstein S. The role of stress in the development and clinical course of inflammatory bowel disease: epidemiological evidence. Curr Mol Med. 2008;8:247-252.

189. Persoons $P$, Vermeire S, Demyttenaere K, Fischler B, Vandenberghe J, Van Oudenhove L, Pierik M, Hlavaty $T$, Van Assche $G$, Noman M, Rutgeerts $P$. The impact of major depressive disorder on the shortand long-term outcome of Crohn's disease treatment with infliximab. Aliment Pharmacol Ther. 2005;22:101-110.

190. Drossman DA, Leserman J, Mitchell CM, Li ZM, Zagami EA, Patrick DL. Health status and health care use in persons with inflammatory bowel disease. A national sample. Dig Dis Sci. 1991;36:1746-1755.

191. Fuller-Thomson E, Sulman J. Depression and inflammatory bowel disease: findings from two nationally representative Canadian surveys. Inflamm Bowel Dis. 2006;12:697-707.

192. Miehsler W, Weichselberger M, Offerlbauer-Ernst A, Dejaco C, Reinisch W, Vogelsang H, Machold K, Stamm T, Gangl A, Moser G. Which patients with IBD need psychological interventions? A controlled study. Inflamm Bowel Dis. 2008;14:1273-1280. 
193. Pimentel M, Chang M, Chow EJ, Tabibzadeh S, Kirit-Kiriak V, Targan SR, Lin HC. Identification of a prodromal period in Crohn's disease but not ulcerative colitis. Am J Gastroenterol. 2000;95:3458-3462.

194. Drossman DA, Patrick DL, Mitchell CM, Zagami EA, Appelbaum MI. Health-related quality of life in inflammatory bowel disease. Functional status and patient worries and concerns. Dig Dis Sci. 1989;34:1379-1386.

195. Casellas F, Fontanet G, Borruel N, Malagelada JR. The opinion of patients with inflammatory bowel disease on healthcare received. Rev Esp Enferm Dig. 2004;96:174-184.

196. van der Eijk I, Vlachonikolis IG, Munkholm P, Nijman J, Bernklev T, Politi P, Odes S, Tsianos EV, Stockbrugger RW, Russel MG. The role of quality of care in health-related quality of life in patients with IBD. Inflamm Bowel Dis. 2004;10:392-398.

197. Janke KH, Klump B, Gregor M, Meisner C, Haeuser W. Determinants of life satisfaction in inflammatory bowel disease. Inflamm Bowel Dis. 2005;11:272-286.

198. Nguyen GC, LaVeist TA, Harris ML, Datta LW, Bayless TM, Brant SR. Patient trust-in-physician and race are predictors of adherence to medical management in inflammatory bowel disease. Inflamm Bowel Dis. 2009;15:1233-1239.

199. Magro F, Portela F, Lago P, Deus J, Cotter J, Cremers I, Vieira A, Peixe P, Caldeira P, Lopes H, Goncalves R, Reis J, Cravo M, Barros L, Ministro P, Lurdes Tavares M, Duarte A, Campos M, Carvalho L. Inflammatory Bowel Disease: A Patient's and Caregiver's Perspective. Dig Dis Sci. 2009.

200. Pallis AG, Kostagiolas PA, Mouzas IA, Niakas D. Patients' perceptions as an indicator of quality of care, in Greek patients with inflammatory bowel disease. Scand J Caring Sci. 2009;23:93-99.

201. Hall NJ, Rubin GP, Hungin AP, Dougall A. Medication beliefs among patients with inflammatory bowel disease who report low quality of life: a qualitative study. BMC Gastroenterol. 2007;7:20.

202. Protheroe J, Rogers A, Kennedy AP, Macdonald W, Lee V. Promoting patient engagement with selfmanagement support information: a qualitative meta-synthesis of processes influencing uptake. Implement Sci. 2008;3:44.

203. Martin A, Leone L, Castagliuolo I, Di Mario F, Naccarato R. What do patients want to know about their inflammatory bowel disease? Ital J Gastroenterol. 1992;24:477-480.

204. Bregenzer N, Lange A, Furst A, Gross V, Scholmerich J, Andus T. Patient education in inflammatory bowel disease does not influence patients knowledge and long-term psychosocial well-being. Z Gastroenterol. 2005;43:367-371.

205. Chen MK. The epidemiology of self-perceived fatigue among adults. Prev Med. 1986;15: 74-81.

206. Jason LA, Richman JA, Rademaker AW, Jordan KM, Plioplys AV, Taylor RR, McCready W, Huang CF, Plioplys S. A community-based study of chronic fatigue syndrome. Arch Intern Med. 1999;159: 2129-2137.

207. Pawlikowska T, Chalder T, Hirsch SR, Wallace P, Wright DJ, Wessely SC. Population based study of fatigue and psychological distress. Bmj. 1994;308:763-766.

208. Sandler RS, Jordan MC, Kupper LL. Development of a Crohn's index for survey research. J Clin Epidemiol. 1988;41:451-458.

209. Harvey RF, Bradshaw JM. A simple index of Crohn's-disease activity. Lancet. 1980;1:514. 
Summary 


\section{Summary}

Inflammatory Bowel Disease (IBD) comprises a group of inflammatory conditions of the intestine. The major types of IBD are Crohn's Disease (CD) and Ulcerative Colitis (UC). The main difference between $C D, U C$ and IBDU is the location and nature of the inflammatory changes. In some IBD patients, even after careful investigation, the differential diagnosis between $C D$ and $U C$ remains uncertain, this group of patients is referred to as IBD unclassified (IBDU). In this thesis, results regarding disease course, fatigue and Health Related Quality of Life (HRQoL), are reported from a population based IBD cohort located in the South East of the Netherlands, South Limburg (IBD-SL). All IBD patients newly diagnosed between January $1^{\text {st }}, 1991$ and January $1^{\text {st }}, 2003$ $(\mathrm{N}=1187)$ in the IBD-SL region were included in this study.

Main focus of the studies presented was to detect changes in diagnostic lag time and incidence rates (including possible seasonal influences) over time in our region (chapter 2), to identify predictive factors at diagnosis and during disease course for the course of disease and outcome in IBD with regard to mortality and recurrences (chapter 3 and 4), to investigate the prevalence and severity of fatigue (chapter 5) and to identify determinants of fatigue and HRQoL in this IBD population (chapter 5 and 6). In chapter $\mathbf{2}$ we have shown that there was no significant increase in the total incidence of $C D, U C$ and IBDU in the IBD-SL region during the observation period. However, compared to earlier reports from the central part of the Netherlands and other European countries, the incidence found was relatively high. No seasonal influence was found on rates of incidence, and despite the introduction of new diagnostic techniques, diagnostic lag time did not change. We concluded that the stable incidence rates found could indicate that extrinsic influences, which have modified the epidemiology of IBD in recent years, might have stabilised in the study area. However, continued studies with prospective and comparable registrations of IBD will remain to be extremely important for the understanding of factors contributing to the onset and development of IBD.

In chapter 3 we report standardized mortality rates (SMR) within the IBD-SL region in the period 1991-2002. Overall mortality in CD, UC and IBDU was comparable to the background population. This was an important observation, as at least in $C D$ an increased SMR has been reported in the majority of other studies. However, diseasespecific mortality risk was significantly increased for gastrointestinal causes of death in both CD and UC. We found that CD as well as UC related deaths occurred relatively early after diagnosis and were mostly due to severe attacks of inflammation and/or postoperative complications a finding that confirmed earlier reports in literature. Based on these findings, we suggested that some IBD sub-groups might need intensive follow-up in order to achieve a further decrease of the mortality risk. This regards especially newly diagnosed IBD patients the first year after diagnosis and IBD patients very young or elderly at diagnosis. 
In chapter 4 surgical and non-surgical disease recurrences are described in correlation to phenotypic characteristics at diagnosis. Even though a relatively benign disease course was observed with $10 \%$ of patients experiencing no recurrence after diagnosis and around $40 \%$ of the patients not using any medication at the end of follow-up (approximately 7 years), we found high recurrence rates especially in the first year after diagnosis for CD, UC as well as IBDU. In CD, small bowel location, stricturing disease, young age at diagnosis and current smoking were all negative predictors for disease recurrence. In UC, with a mean follow-up of 7 years, the colectomy rate was 8.3\%. UC patients having an extensive colitis were at risk for recurrent disease and colectomy. Moreover in UC, a high age at diagnosis increased the risk for recurrent disease in the first year, whereas after $\mathbf{2 . 4}$ or more years of follow-up, an older age at diagnosis was protective. We concluded that it is of utmost importance to recognize potential negative risk factors for the disease course, helping to identify patients who could profit from early intervention and possibly early aggressive treatment.

In chapter $\mathbf{5}$ we investigated the prevalence and severity of fatigue and the impact on HRQoL in IBD patients. Fatigue was assessed by the Multidimensional Fatigue Inventory (MFI), a validated instrument dedicated to measure fatigue in an objective manner. HRQoL was measured using the validated Inflammatory Bowel Disease Questionnaire (IBDQ) and the Short Form health survey (SF-36). The prevalence of fatigue was very high, resulting in a lowered HRQoL, in which $C D$ patients were affected more than UC patients. Even in patients having quiescent disease, the prevalence of fatigue in CD and UC was $38 \%$ and $36 \%$ respectively, using the upper $95^{\text {th }}$ percentile of the general population as a reference value. In UC, disease activity and anaemia were independent contributors to the level of fatigue, whereas in CD fatigue was mainly influenced by disease activity. In our opinion these findings imply that, in IBD patients, physicians need to be aware of fatigue in order to better understand its impact on the patients and to find means of improving the HRQoL.

In chapter 6 determinants of fatigue and HRQoL occurring from diagnosis onwards during the disease course were evaluated. Results showed that, even after exclusion of patients with current disease activity and/or anaemia, a more severe disease course independently resulted in worse fatigue scores and lower HRQoL. Especially the number of "all type" recurrences had a negative impact, whereas surgical interventions alone showed almost no effect on fatigue and HRQoL. The use of corticosteroids and immunosuppressives resulted in worse fatigue and HRQoL scores. This implies that patients with repeated exacerbations in the past, who have required more intensive drug treatment, are at risk of developing fatigue and a decreased HRQoL. A clear exception in this was the use of infliximab in CD which ameliorated the outcome. As the presence of fatigue has a major impact on personal functioning and satisfaction, attention on its presence has to be advised even in patients with no current disease activity.

Chapter 7 provides a general discussion of the implications of the results presented in this thesis and their interrelationship in the context of current literature. An opinion 
regarding the follow-up and treatment strategy in a sub-group of patients at risk for a worse outcome is given. Based on the observations in this thesis, one would advise to intensively guard the young and elderly diagnosed IBD patients, those recently diagnosed, and patients having a disease location with high risk for recurrent disease, such as small bowel location with or without stricturing or penetrating disease in CD and extensive colitis in UC. Perhaps in these sub-groups a more aggressive treatment strategy is warranted. Furthermore, a summary regarding fatigue and HRQoL in IBD is provided, with special attention to possible causative mechanisms for the sub-group of patients that have high fatigue scores and impaired HRQoL without current active disease and/or anaemia. Concluding, we hypothesise that there is strong accumulating evidence for a close interplay between disease course, fatigue, HRQoL and social and psychological factors, indicating the relevance of an IBD management based on an integrated "bio-psycho-social" long-term approach. 

167

Samenvatting 


\section{Samenvatting}

Inflammatoire darmziekten, in het engels "Inflammatory Bowel Disease" (IBD) genoemd, worden gekenmerkt door ontstekingen van de darm. De exacte oorzaak van IBD is niet bekend maar is waarschijnlijk multifactoriëel met zowel genetisch predisponerende factoren als omgevingsfactoren die een rol spelen. Binnen de inflammatoire darmziekten komen de ziekte van Crohn (CD) en Colitis Ulcerosa (UC) het meeste voor. Het belangrijkste verschil tussen CD en UC betreft de aard van de ontsteking en de locatie hiervan. Bij een aantal IBD patiënten kan er, zelfs na zorgvuldig en uitgebreid onderzoek, geen definitieve diagnose worden gesteld. Bij deze patiënten wordt de diagnose "IBD unclassified" (IBDU) oftewel niet-classificeerbare colitis vastgesteld.

Dit proefschrift beschrijft de ziekte uitkomst van patiënten met IBD in de regio ZuidLimburg, het "IBD-ZL" cohort. Er is bij alle tussen 1 januari 1991 en 1 januari 2003 nieuw gediagnosticeerde IBD patiënten ( $N=1187)$ gekeken naar het ziekte beloop, vermoeidheid en de kwaliteit van leven.

Belangrijkste doelen van de studie waren:

- het bestuderen van veranderingen in de incidentie tussen 1991 en 2002, waarbij eveneens gekeken is of de tijd tussen het ontstaan van klachten en het vaststellen van de diagnose is veranderd in de loop van de jaren en of er sprake was van een seizoensinvloed op de incidentie (hoofdstuk 2)

- het identificeren van factoren die de kans op overlijden en de kans op hernieuwde ziekteactiviteit beïnvloeden. Factoren aanwezig op het moment van het vaststellen van de diagnose dan wel aanwezig gedurende het ziektebeloop werden hiervoor geanalyseerd (hoofdstuk 3 en 4)

- de prevalentie en ernst van moeheidklachten bij IBD patiënten (hoofdstuk 5) en het identificeren van factoren die van invloed kunnen zijn op de vermoeidheid en kwaliteit van leven (hoofdstuk 5 en 6 )

In hoofdstuk 2 wordt beschreven dat er geen significante stijging is van de $C D, U C$ en IBDU incidentie in de IBD-ZL regio gedurende de observatie periode. Echter de incidentie is nog steeds relatief hoog ten opzichte van eerdere publicaties vanuit Leiden en vanuit andere Europese landen. Er bleek geen invloed van seizoenen te bestaan op de incidentie en ondanks de beschikbaarheid van steeds geavanceerdere technieken voor aanvullende diagnostiek bleek de tijdsduur tussen de start van de klachten en het vaststellen van de IBD diagnose niet te zijn veranderd. We hebben geconcludeerd dat de gevonden stabiele incidentie cijfers mogelijk het gevolg zijn van in de loop van de jaren gelijkblijvende dan wel afgenomen omgevingsfactoren die van invloed zijn op het ontstaan van IBD. Om ook in de toekomst meer over de etiologie en het beloop van IBD te weten te komen blijft het van groot belang om prospectieve, vergelijkbare IBD registraties te continueren.

In hoofdstuk 3 rapporteren we het gestandaardiseerde overlijdensrisico van patiënten met IBD in de IBD-ZL regio in de periode 1991-2002. Het algemene, totale, 
overlijdensrisico voor CD, UC en IBDU was niet verhoogd. Deze bevinding is zeer belangrijk gezien er met name voor $C D$ in de meerderheid van de publicaties een verhoogd risico op overlijden wordt beschreven. Bij nadere analyse bleek wel dat zowel bij CD als bij UC een verhoogd risico bestaat om te overlijden aan een maag/darm gerelateerde oorzaak. Bij de meeste patiënten die overleden door een maag/darm gerelateerde oorzaak was de diagnose IBD nog maar recent gesteld en was het ziektebeloop meestal gecompliceerd (ernstige aanvallen van ontsteking en veel complicaties na chirurgische ingrepen), een bevinding die ook bij eerdere onderzoeken werd vastgesteld. Naar aanleiding van onze uitkomsten zijn wij van mening dat bepaalde IBD subgroepen een intensieve controle behoeven om het risico op overlijden zo mogelijk verder te verminderen. Dit betreft met name de IBD patiënten waarbij de diagnose net is vastgesteld (eerste jaar na diagnose) en de patiënten die heel jong of juist heel oud zijn bij het vaststellen van de diagnose.

In hoofdstuk $\mathbf{4}$ is gekeken naar de voorspellende waarde van fenotypische kenmerken bij diagnose op de aanwezigheid van ziekteactiviteit gedurende het verder ziekte beloop, gemeten middels noodzaak tot aanpassen van medicatie (niet-chirurgische opvlamming) of een operatie (chirurgische opvlamming).

Vergeleken met eerder gepubliceerde data bleek in onze populatie over het algemeen het ziekte beloop goedaardig te zijn in termen van het risico op een opvlamming: $10 \%$ van de patiënten had geen klachten meer na het stellen van de diagnose en $40 \%$ van de patiënten gebruikte geen medicatie meer aan het einde van onze follow-up periode (ongeveer 7 jaar). De kans op een opvlamming was met name groot in het eerste jaar na de diagnose zowel bij CD, UC als IBDU patiënten. Bij CD patiënten bleek het risico op een opvlamming verhoogd bij ontstekingsactiviteit gelokaliseerd in de dunne darm, bij vernauwingen in de darm, bij jonge patiënten en bij patiënten die rookten gedurende het ziektebeloop.

Het percentage van UC patiënten waarbij de gehele dikke darm verwijderd werd gedurende het ziekte beloop was $8.3 \%$ (gemiddelde follow-up duur 7 jaar). Het risico op opvlammingen bij UC patiënten was met name aanwezig als de hele dikke darm ontstoken was. Een hoge leeftijd bij UC patiënten op het moment van de diagnose bleek in het eerste jaar een risicofactor te zijn voor het krijgen van een opvlamming, maar na gemiddeld 2.4 jaar follow-up verdween dit risico en bleek oudere leeftijd zelfs te "beschermen" tegen ziekteactiviteit. Het blijft van belang om deze vastgestelde negatieve prognostische factoren bij diagnose te onderkennen zodat patiënten met een potentieel ernstiger ziektebeloop mogelijk eerder dan wel een andere, mogelijk "agressievere", behandeling kunnen ondergaan.

In hoofdstuk 5 inventariseerden we hoe vaak vermoeidheid voorkwam in onze IBD populatie en hoe ernstig de vermoeidheidsklachten waren. Tevens hebben we onderzocht wat de invloed van de vermoeidheid was op de kwaliteit van leven van IBD patiënten. Vermoeidheid werd gemeten met behulp van een multidimensionele vermoeidheids index, een gevalideerde vragenlijst die het mogelijk maakt de vermoeidheid in een objectieve schaal weer te geven. De kwaliteit van leven werd met 
behulp van twee vragenlijsten vastgesteld, de gevalideerde IBD specifieke kwaliteit van leven vragenlijst (IBDQ) en een meer algemene vragenlijst om de gezondheidstoestand te meten (SF-36). De prevalentie van vermoeidheidsklachten bleek zeer hoog te zijn, resulterend in een lagere kwaliteit van leven. CD patiënten scoorden hierbij slechter dan de UC patiënten. Zelfs bij patiënten zonder ziekteactiviteit was de prevalentie van vermoeidheid bij CD patiënten $38 \%$ en bij UC patiënten $36 \%$, waarbij de $95^{\mathrm{e}}$ percentiel van de vermoeidheids score van de normale bevolking werd gebruikt als afkapwaarde voor abnormale vermoeidheid. Bij UC patiënten was zowel de ziekte activiteit als de aanwezigheid van een anemie een onafhankelijke bijdragende factor aan de ernst van de gemeten vermoeidheid. Bij CD patiënten werd vermoeidheid met name bepaald door de ernst van de ziekteactiviteit ten tijde van de meting. Het is van groot belang dat artsen zich bewust zijn van vermoeidheid als belangrijk en beperkend symptoom van IBD. Daardoor kunnen er strategieën ontwikkeld worden om de vermoeidheids klachten te verminderen en secundair de kwaliteit van leven van IBD patiënten verbeteren.

In hoofdstuk 6 is gekeken naar factoren die van invloed zijn op vermoeidheid en de kwaliteit van leven gedurende het gehele ziektebeloop. Zelfs na exclusie van IBD patiënten met ziekte activiteit en/of een anemie op het moment van de vragenlijst, blijkt een ernstiger ziekte beloop te resulteren in meer vermoeidheid en een lagere kwaliteit van leven. Met name het totaal aantal opvlammingen gedurende het ziektebeloop beïnvloedt de uitkomsten negatief, terwijl chirurgische interventies nagenoeg geen invloed hebben. Het gebruik van prednison en immuunsuppressiva resulteerde eveneens in een hogere vermoeidheidsscore en een lagere kwaliteit van leven. Deze bevinding impliceert dat het risico op vermoeidheid zeer hoog is voor een IBD patiënt met meer opvlammingen in het verleden en/of hierbij de noodzaak tot intensievere medicamenteuze behandeling. De enige door ons vastgestelde uitzondering hierop was het gebruik van infliximab gedurende het ziektebeloop bij CD. Gezien het feit dat de aanwezigheid van vermoeidheid van grote invloed is op het persoonlijk functioneren en welbevinden van patiënten, is het ook voor patiënten zonder ziekte activiteit of een anemie van belang hier aandacht aan te blijven besteden.

Ten slotte volgt in hoofdstuk 7 een discussie over de belangrijkste in dit proefschrift gepresenteerde uitkomsten en de samenhang met de recente literatuur over dit thema. Een mening wordt geponeerd met betrekking tot de follow-up en behandel strategie voor een subgroep van IBD patiënten met een verhoogd risico op een slechtere ziekte uitkomst. Gebaseerde op de bevindingen van dit proefschrift zou ons advies zijn om met name patiënten intensiever te vervolgen die een jonge of oudere leeftijd hebben ten tijde van het stellen van de diagnose, de patiënten die recent gediagnosticeerd zijn en de groep van IBD patiënten met een ziekte locatie die een verhoogd risico geeft voor een opvlamming, zoals dunne darm locatie bij de CD met of zonder stenosering of fistelvorming en de patiënten met een uitgebreide (pan-colitis) bij UC. Misschien moeten deze "risico" patiënt groepen toch anders, "agressiever", 
behandeld worden. Tevens wordt er een samenvatting gegeven van de huidige kennis omtrent vermoeidheid en kwaliteit van leven bij IBD patiënten. Speciaal wordt hier ingegaan op mogelijk oorzakelijke mechanismen van vermoeidheids symptomen bij IBD patiënten die geen ziekteactiviteit of anemie hebben. Concluderend speculeren we dat er waarschijnlijk een zeer sterke interactie bestaat tussen het ziektebeloop, de kwaliteit van leven, sociale factoren en psychologische factoren. Dit benadrukt het belang van een langdurige, geïntegreerde IBD behandeling gebaseerd op een "biopsycho-sociaal" model. 
Dankwoord 
174 


\section{Dankwoord}

Graag wil ik iedereen bedanken die heeft bijgedragen aan de voltooiing van dit proefschrift. Een aantal hiervan wil ik echter toch in het bijzonder noemen.

Allereerst wil ik alle patiënten bedanken die deel hebben genomen aan dit onderzoek. Ondanks de zeer uitgebreide enquête was er een goede respons en kwamen er vele positieve reacties. Zonder jullie medewerking komt de wetenschap niet verder.

Reinhold Stockbrügger, de hoeveelheid energie die van je uitgaat kan niet anders dan aanstekelijk werken. Kennis en kunde worden door jou overgebracht op een manier die ik maar zelden ben tegengekomen. Ik heb nooit kritiek ontvangen zonder dat deze ingeleid werd door een positieve zin, dat heeft me op de been gehouden en is hoe een ware opleider hoort te zijn. Je hebt al die jaren onvoorwaardelijk veel tijd in mij en dit onderzoek gestoken met de instelling "dit gaat helemaal goed komen". Vanuit de hele wereld heb ik feedback van je gekregen op de manuscripten en was er jouw persoonlijke interesse in mij. Lang leve Skype ${ }^{\circledR}$, hierdoor ben je voor mij nooit ver weg geweest!

Pieter Dagnelie, mijn "stok achter de deur". Door het plannen van de afspraken met jou de afgelopen twee jaar was er telkens een deadline te halen. Je kritische visie op de analyses en manuscripten hebben het resultaat beter en beter gemaakt. Het enthousiasme en de felicitaties als er weer een artikel was geaccepteerd zijn ongeëvenaard gebleven, dit als uiting van jouw persoonlijke betrokkenheid en interesse. Hartelijk dank voor alle hulp en het vertrouwen de afgelopen jaren.

Maurice Russel, jij hebt de basis gelegd voor dit hele proefschrift. Door jouw inzet en enthousiasme is deze IBD registratie geworden tot wat het nu is. Een feit waar ik dankbaar gebruik van heb gemaakt. Je hebt me geïntroduceerd bij alle betrokkenen en behoed voor de potentiële valkuilen van een beginnende onderzoeker. Van jouw begeleiding en bijsturing waar nodig, zowel klinisch als wetenschappelijk, heb ik enorm veel geleerd.

De leden van de beoordelingscommissie, prof. dr. M.H. Prins, prof. dr. J.M.J.P. van der Linden, dr. B. Oldenburg en prof. dr. J.J. van Os bedank ik voor hun bereidwilligheid het manuscript te lezen en het geven van waardevolle adviezen. I would like to express my gratitude to prof. dr. C. O' Morain for his willingness to review the manuscript and for his willingness to participate in the corona.

Martine Hesselink - van de Kruijs, dank je wel voor het uit handen nemen van al die praktische zaken. Maar nog veel belangrijker is het voor mij geweest dat je er altijd een persoonlijke noot aan toe hebt gevoegd, het was gezellig! Daarnaast kwamen er vele 
goede suggesties en voorstellen van jouw kant en werd er gestaag doorgewerkt waarna ik ook weer verder kon met uiteindelijk dit als resultaat. We hebben heel wat uurtjes samen gezeten. Ik ben er bijzonder blij mee dat jij aan mijn zijde staat als paranimf. Daisy Jonkers, als kamergenoot van Martine en begeleidster van vele onderzoekers die mij zijn voorgegaan, ik kon altijd met mijn vragen bij jou terecht. Dank voor al je tips en adviezen, ik heb ze dankbaar in ontvangst genomen.

Arnold Kester, ik ben enorm dankbaar dat ik bij jou terecht ben gekomen. Ik heb je al mijn domme vragen kunnen stellen. Je hebt je met een enorm enthousiasme op de data geworpen resulterend in dit proefschrift. Ik durf te zeggen dat het zonder jou nog lang niet af zou zijn geweest. Het was natuurlijk voor jou ook een roerige en verdrietige tijd maar desondanks ben je blijven roepen, "stuur maar, het houdt me van de straat en op andere gedachten". Het heeft enorm veel voor me betekend, nogmaals dank.

Leo Schouten, dank je wel voor al je hartelijkheid en hulp bij de statische analyses van de incidentie en mortaliteit. Ik ben ook hier weer heel veel wijzer van geworden.

Frank Wolters, onze gezamenlijke tijd start al in het Catharina Ziekenhuis in Eindhoven. Onder andere door jou ben ik enthousiast geworden voor het MDL vak. In Maastricht is de samenwerking tot mijn vreugde alleen maar groter geworden. De EC-IBD bijeenkomsten resulterend in jouw proefschrift waren altijd zeer geslaagd en een basis voor het huidige onderzoek. Alle adviezen, hulp en steun in de breedste zin van het woord heb ik zeer gewaardeerd.

Yvonne Bol, ik ben met een korte vraag over de vermoeidheids vragenlijst bij jou terecht gekomen, maar we zijn al snel aan elkaar blijven "plakken". De wederzijdse interesse met betrekking tot moeheid en beïnvloedende factoren vanuit het medische en psychologische perspectief heeft ook bij jou geleid tot een prachtig proefschrift. Ik hoop dat we deze samenwerking nog langdurig kunnen voortzetten.

Alle MDL artsen, op dit moment of in het recente verleden werkzaam in de IBD-ZL regio, dank jullie wel voor de tijd die is gestoken in de inclusie van de deelnemende patiënten en de bereidwilligheid om patiëntendossiers ter inzage ter beschikking te stellen. Wat mij betreft gaan we ervoor om dit waardevolle project zo te behouden.

Charles Limonard, graag wil ik jou en je medewerkers van het MEMIC danken voor de ondersteuning en opzet van de gebruikte database om de gegevens te verzamelen. Waarbij ik met name Jack Berben en Anita Legtenberg nog zou willen noemen. Ik heb al jullie inspanningen zeer gewaardeerd. 
Mia Cilissen, dank voor al je hulp tijdens dit hele project. Dank voor het meedenken en het mee verzamelen van de gegevens. Het was tevens een genot om de IBD spreekuren samen met je te doen. Daarnaast denk ik ook met veel plezier terug aan de gezelligheid van onze etentjes en de EC-IBD uitstapjes.

Mitsie Thijssens en Elly Mares, dank voor alle secretariële ondersteuning en vooral dank voor de "peptalks" op het secretariaat even tussendoor tijdens mijn periode in Maastricht.

Emy Heijnen, Niels Koopman, Edith Kuiper en Guy Raven dank ik vanwege de enorme steun bij de datavergaring.

Tiny Wouters, voor jou was de hoofdrol weggelegd in de laatste fase van dit proefschrift. Met een flink tempo kreeg ik de stukken weer retour, netjes in het gareel en klaar voor de drukpers. De tijd die je hierin enthousiast en onvoorwaardelijk steekt is goud waard. Daardoor is het toch nog gelukt hier enigszins ontspannen doorheen te komen.

Alice Wielinga, jij hebt perfect aangevoeld wat ik wilde met de omslag van dit proefschrift. De inhoud van dit proefschrift wordt symbolisch weergegeven. Daarnaast is het voor mij persoonlijk een uiting van de band die ik had met mijn veel te jong gestorven vader. Ik vind het prachtig!

Rens Bos, Leopold Engels, Frans Erdkamp, Frans de Heer, Roel van Kampen, Eric Keulen, Mariëlle Krekels, Bert-Jan Looij, Heidrun Pawlowski, Frank Peters, Walther Sipers, Frank Stifft, Herman Verhoeven, Gaico Verseput, Chantal de Weerd-Spaetgens en Harro van Westreenen, bij elkaar de voltallige vakgroep interne geneeskunde, MDL en geriatrie. Dank voor al jullie steun en mogelijkheden om dit proefschrift tot een goed einde te kunnen brengen. Ik ben in een "warm nest" terecht gekomen en hoop er samen met jullie nog heel wat prettige jaartjes door te brengen.

Geraline Leusink, Hanny Pijnenborg, Nicolette Verduin en Gera de Vries mijn geneeskunde studiemaatjes vanaf het eerste begin. Dank voor jullie vriendschap en interesse de afgelopen jaren. Het liefste had ik jullie allemaal aan mijn zijde gehad tijdens de verdediging.

Mam, dank voor al je liefde, aanhoudende interesse en het feit dat je er altijd voor mij, Steven en de kinderen bent. Bert, "de tijd geeft mooie momenten, herinneringen, met blijdschap maar helaas ook verdriet", wat had ik graag gezien dat je aan mijn moeders zijde had gestaan. Mijn schoonouders Henk en Ingrid, dank voor jullie steun en de vele gesprekken onder het genot van een goed glas wijn. Johan en Mariëlle, Frank en Ellen, Ingrid en Marcel dank voor alle getoonde interesse de afgelopen jaren. 
Tot slot, maar het belangrijkste, Steven en de meisjes, Isa, Eline en Sofie. Woorden kunnen nooit genoeg zeggen hoe blij ik met jullie ben. Zonder jullie geen SMIES om gezamenlijk te kunnen genieten. Ik hoop dat we in goede gezondheid nog heel veel jaren samen kunnen doorbrengen! 
179

Curriculum Vitae 


\section{Curriculum Vitae}

Mariëlle Romberg-Camps werd geboren op 29 Januari 1970 te Tienray. In 1988 behaalde zij haar V.W.O. diploma aan de R.K. Scholengemeenschap Jerusalem te Venray (sinds 1995 opgeheven en ondergebracht in het huidige Dendroncollege te Horst). Aansluitend startte haar studie geneeskunde aan de Universiteit van Maastricht. In juni 1995 behaalde zij het artsexamen. Zij ging als arts-assistent niet in opleiding werken op de intensive care en de multidisciplinaire oncologie afdeling van het Catharina Ziekenhuis te Eindhoven en kon daar aansluitend in april 1997 haar opleiding tot internist starten (opleider: dr. W. Breed, later dr. S.J. Hoorntje). In april 2001 werd deze opleiding voortgezet in het Academisch Ziekenhuis te Maastricht (opleider: prof. dr. H. Hillen, later prof. dr. K.M.L. Leunissen). De registratie als internist vond plaats op 1 april 2003. Hierna volgde zij, eveneens in het Academisch Ziekenhuis Maastricht, de opleiding tot maag-darm-lever arts (opleider: prof. dr. R.W. Stockbrügger). Haar registratie als maag-darm-lever arts vond plaats in juni 2006. In 2004 begon ze met het wetenschappelijk onderzoek dat heeft geleid tot de resultaten beschreven in dit proefschrift. Na een korte periode als staflid bij de werkgroep maagdarm-leverziekten in het Academisch Ziekenhuis te Maastricht, is ze sinds juli 2006 werkzaam als maag-darm-lever arts in het Orbis Medisch Centrum te Sittard (voorheen Maaslandziekenhuis).

In 1999 is zij getrouwd met Steven Romberg. Samen hebben ze drie dochters, Isa (10 jaar), Eline (8 jaar) en Sofie (6 jaar). 

Appendix

Patient questionnaire 


\section{IBD * ZL}

Inflammatory Bowel Disease (IBD)

onderzoekscentrum Zuid-Limburg

\section{Ziektebeloop en Moeheid \\ na het stellen van de diagnose IBD}

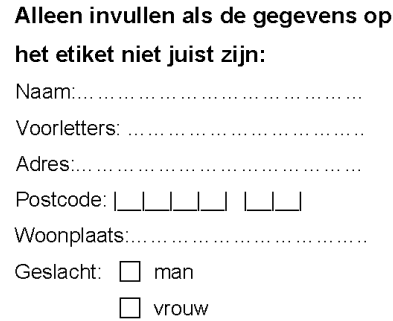


Inleiding

Voor u ligt de vragenlijst 'Ziektebeloop en Moeheid na het stellen van de diagnose IBD'. In deze vragenlijst worden vragen gesteld over uzelf, uw gezondheid sinds bij u de diagnose IBD is gesteld en over vermoeidheid.

We willen u vragen om alle vragen te beantwoorden. Per vraag kunt $u$ aankruisen wat voor $u$ van toepassing is. Per vraag kruist $u$ één antwoord aan. Bij sommige vragen zijn meer antwoorden mogelijk. Dit wordt apart aangegeven. Bij een aantal vragen is het wellicht moeilijk te kiezen uit de antwoordmogelijkheden. Indien u twijfelt over een antwoord, kruist $u$ het antwoord aan dat het meest bij uw persoonlijke situatie past.

Invulvoorbeeld

Had u de afgelopen week klachten die verband houden met uw darmziekte?

凶 nee $\square$ ja

Indien u zich vergist bij het aankruisen van een hokje, kunt $\mathrm{u}$ dit verbeteren door dat hokje helemaal zwart te maken en het juiste hokje aan te kruisen.

nee

区 ja

Graag gebruik maken van een zwarte of blauwe pen bij het invullen

$\mathrm{Na}$ het invullen van de vragenlijst kunt $u$ deze terugzenden met de retourenveloppe. Een postzegel is hierbij niet nodig.

Voor de volledigheid willen wij hierbij vermelden dat de resultaten niet terug te voeren zullen zijn op individuele personen.

\section{Alvast hartelijk bedankt voor uw medewerking!!}




\section{Persoonlijke gegevens}

1 Wat is de datum van vandaag?

2

Wat is uw geslacht?

$\square$ man

$\square$ vrouw

3

Wat is uw geboortedatum?

$4 \quad$ Wat is uw huidige burgerlijke staat?

$\square$ gehuwd of samenwonend

$\square$ nooit gehuwd of samenwonend geweest

$\square$ gescheiden na huwelijk of langdurige relatie

$\square$ weduwe / weduwnaar

Wat is uw hoogst voltooide opleiding?

$\square \quad$ Geen opleiding

$\square \quad$ Lager algemeen onderwijs

$\square$ Lager beroepsonderwijs

$\square \quad$ Middelbaar algemeen onderwijs

$\square$ Middelbaar beroepsonderwijs

$\square$ Voortgezet algemeen onderwijs

$\square$ Hoger beroepsonderwijs

$\square$ Wetenschappelijk onderwijs

\section{L_L__L}

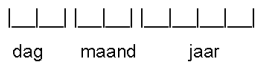

dag maand jaar

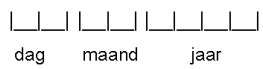
(bijv. basisonderwijs)
(bijv. LTS, ambachtsschool, LEAO, LHNO)
(bijv. MAVO, MULO, 3-jarig HBS)
(bijv. VMBO, MBO, MTS, MEAO)
(bijv. HAVO, WWO, HBS)
(bijv. HBO, HTS, HEAO)
(Universiteit) 


\section{Darmziekte}

6 Is bij u de diagnose colitis ulcerosa, de ziekte van Crohn of aspecifieke colitis gesteld, zo ja wanneer? (aspecifieke colitis is een chronische ontsteking van de darm waarbij geen duidelijk onderscheid gemaakt kan worden tussen de ziekte van Crohn en colitis uicerosa)

$\begin{array}{lll}\square & \text { ziekte van Crohn } & \text { in het jaar } \\ \square & \text { colitis ulcerosa } & \text { in het jaar } \\ \square & \text { aspecifieke colitis } & \text { in het jaar }\end{array}$

7 Hoe zou u het beloop van uw ziekte willen beschrijven sinds de diagnose in termen van klachten?
$\square \quad$ Inactief gebleven in alle jaren sinds de diagnose
$\square \quad$ Klachten in een minderheid van de jaren sinds de diagnose
$\square \quad$ Klachten in een meerderheid van de jaren (maar niet elk jaar) sinds de diagnose
Klachten in elk jaar sinds de diagnose

8 Bent u geopereerd aan uw blinde darm, zo ja wanneer?

$\square$ nee

$\square \mathrm{ja}, \quad$ in (maand/jaar) $\left.\right|_{\perp}$

9 Wat voor operaties heeft u sinds het stellen van de diagnose voor uw chronische inflammatoire darmziekte ondergaan? (Meerdere antwoorden mogelijk. Indien bekend tevens maand en jaar invullen waarin operaties plaatsvonden)

$\square$ geen operatie ondergaan

$\square$ dunne darm (gedeeltelijk) verwijderd

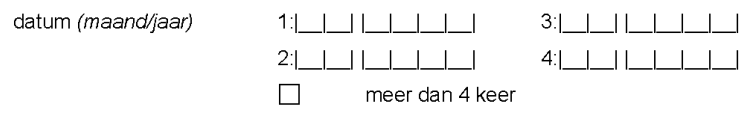

dikke darm (gedeeltelijk) verwijderd

datum (maand/jaar)
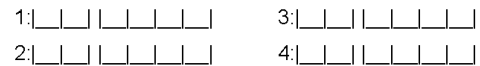

stoma aangelegd/ opgeheven

datum (maand/jaar)
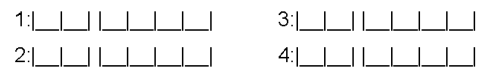

fistel / abces operatie

datum (maand/jaar)

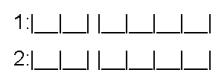

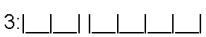

anale pouch

andere operatie $\mathrm{nl}$ 
10 Heeft u momenteel een stoma?

$\square$ nee

$\square$ ja

11 Wat vindt $u$, over het algemeen genomen, van uw gezondheid?
$\square$ heel slech
$\square$ slecht
$\square$ matig
$\square$ goed
$\square$ zeer goed
$\square$ uitstekend

12 Wat vindt u van uw gezondheid op dit moment?
$\square$ zeer goed
$\square$ goed
$\square$ matig
$\square$ slecht
$\square$ zeer slecht

13 Heeft u gisteren diarree gehad, zo ja hoe vaak?

$\square$ nee

$\square$ ja, namelijk |___ keer

14 Heeft u vannacht last van diarree gehad?
$\square$ nee
$\square$ ja

15 Heeft u gisteren last van buikpijn of krampen gehad?
$\square$ ja, ernstig
$\square$ ja, matig
$\square$ ja, mild
$\square$ nee

16 Heeft u gisteren bloed bij uw ontlasting gehad?
$\square \mathrm{ja}$, de hele tijd
$\square$ ja, bij meer dan $50 \%$ van mijn ontlasting
$\square$ ja, bij minder dan $50 \%$ van mijn ontlasting
$\square$ nee 
17 Heeft u gisteren ongewild ontlasting verloren?

$\square$ nee

$\square$ ja

18 Heeft u gisteren specifieke medicijnen tegen diarree gebruikt?

(b.v. Imodium $B$, Diacure $B$, Loperamide( $)$

$\square$ nee

$\square$ ja

19 Uit welke categorie gebruikt u op dit moment medicatie (tabletten, capsules, zetpillen, klysma's) in verband met IBD? (Meerdere antwoorden zijn mogelijk)

$\square$ geen medicijnen

$\square$ 5- ASA medicatie

Bijvoorbeeld: Sulfasalazine (Salazopyrine $\circledast$ ), Mesalazine (Asacol(B), Pentasa $\left(\Theta^{\circ}\right.$, Salofalk $\Theta$ ) Osalazine (Dipentum $\Theta$ )

corticosteroïden Bijvoorbeeld: Prednis(ol)on, Budesonide (Entocort@ of Budenofalk(B), beclometason klysma

antibiotica Bijvoorbeeld: Metronidazol (Flagyl@), Ciprofloxacine (Ciproxin的)

immunomodulatoren Bijvoorbeeld: Azathioprine (Imuran@), 6- Mercaptopurine (Purinethol@), Tioguanine (Lanvis $\Theta$ ), Cyclosporine (Neoral( $\Theta$ ), Methotrexaat (Ledertrexaat $\Theta$ )

kalk/vitamine $D$

overige vitamines

osteoporose medicatie

anti-diarree

Bijvoorbeeld: vitamine D (Devaron $@$ ), kalk (Calcit@), Calcios $\otimes$; Calci-chew(B)/met of zonder vit D)

Bijvoorbeeld: Foliumzuur, vitamine B12

(Hydroxycobalamine ${ }^{\circledR}$ )

Bijvoorbeeld: Risedroninezuur (Actonel@), Alendroninezuur (Fosamax@), APD®, Didrokit@

anti-diarree

ijzersupplementen

nieuw geneesmiddel

zuurremmer voor maag

Bijvoorbeeld: Loperamide (Imodium(, Diarem( Diacure®), Loperamide-oxide (Arestal(B)), Colestyramine (Questran(B)), ursodeoxycholzuur (Ursochol@), Ursofalk@)

Bijvoorbeeld: (Ferrofumuraat $\Theta$ ), (Ferrogradumet $\Theta$ ),

Ferrioxidesaccharaat (Venofer(i))

Bijvoorbeeld: Anti-TNF-alfa of infliximab (Remicade(B)

Bijvoorbeeld: Omeprazol (Losec(®), Esomeprazol (Nexium(B), Lansoprazol (Prezal@), Pantoprazol (Pantozol(B), Rabeprazol (Pariet巴)

anders $\mathrm{nl}$ 
Indien u sinds het stellen van de diagnose Anti -TNF-alfa of infliximab (Remicade $\odot$ ) toegediend heeft gekregen? In welke periode en hoe vaak was dit?

$\square$ nooit Anti-TNF-alfa of infliximab (Remicade( $\mathrm{B}$ ) toegediend gekregen

$\square \operatorname{van} \mid$

$\square$ aantal $\quad \square 1$ keer

$\square 2$ keer

$\square 3 \mathrm{keer}$

$\square 4$ keer

$\square 5$ keer

$\square$ vaker dan 5 keer

21 Indien u nu Azathioprine (Imuran $\otimes$ ), 6- Mercaptopurine (Purinethol®) of Tioguanine

(Lanvis $\otimes$ ) gebruikt, sinds wanneer?

$\square$ sinds

|____ا________ (maand-jaar)

$\square$ niet van toepassing

22 Indien u Methotrexaat (Ledertrexaat $\left.{ }^{\circledR}\right)$ gebruikt, sinds wanneer?

$\square$ sinds I_L__l_L_____ (maand-jaar)

$\square$ niet van toepassing

23 Bent u nog bij een maag-darm-leverarts onder controle in verband met uw darmziekte?

$\square$ ja

$\square$ nee, ik ben helemaal niet meer bij een arts onder controle sinds $\mid$

maand jaar

nee, ik ben niet meer bij een maag-darm-leverarts maar wel bij

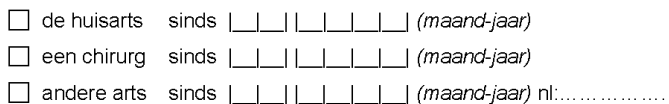

24 Bent u momenteel in de ziektewet in verband met darmziekten of andere reden? (belangrijkste reden invullen, slechts 1 antwoord mogelijk)

nee

ja, in verband met darmziekten

ja, andere reden

25 Bent u momenteel in de WAO in verband met darmziekten of andere reden? (belangrijkste reden invullen, slechts 1 antwoord mogelijk)

nee

ja, in verband met darmziekten

ja, andere reden

$+$ 
$\square$ nee

$\square \mathrm{ja}$,

$$
\text { in het jaar I________ werd dit vastgesteld }
$$

27 Gebruikt u momenteel bloedverdunners, pijnstillers of ontstekingsremmers zoals bijvoorbeeld Ascal $\AA$, Aspirine, Acetosal $\circledast$, Diclofenac $\Theta$, Ibuprofen $\circledast$, Naproxen $\circledast$, Viox $\circledast$, Celebrex®?

$\square$ nee

$\square$ ja, namelijk

28 Heeft u ooit last van aften in de mond, zo ja hoe vaak? (Onder aften, ook wel stomatitis aftosa genoemd verstaan wij pijnlijke witte blaasjes in de mond)

$\square$ nee

$\square$ ja, dit werd voor het eerst vastgesteld in het jaar

$\rightarrow$ hoe vaak hebt $u$ hiervan last? $\square$ minder dan 1 periode per maand

$\square 1$ periode per maand
$\square 2$ periodes per maand
$\square 3$ periodes per maand
$\square$ vaker namelijk $\downarrow$ __ $\_$periodes per maand

29 Heeft u ooit pijnlijke ontstekingen aan uw oog of ogen gehad waarvoor u medische hulp heeft gezocht? (Met de cogontstekingen zijn bedoeld: episcleritis, keratitis en uveitis)

$\square$ nee

$\square \mathrm{ja}$, dit werd voor het eerst vastgesteld in het jaar

oor huisarts
$\square$ oogarts
$\square$ maag darm lever arts
$\square$ overig $\mathrm{nl} . . . \ldots \ldots \ldots \ldots \ldots \ldots$

\section{Heeft u gewrichtsaandoeningen waarvoor u medische hulp heeft gezocht?}

(Met de gewrichtsziekten zijn bedoeld: spondylitis, sacro-ilëtis, ziekte van Bechterew en artritis)

$\square$ nee

$\square$ ja, dit werd voor het eerst vastgesteld in het jaar

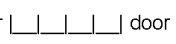
huisarts

$\square$ reumatoloog

maag darm lever arts

overig $\mathrm{nl}$ 
$\square$ nee

$\square \mathrm{ja}, \rightarrow$

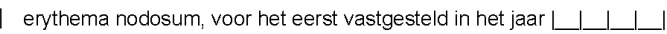
door wie is de diagnose gesteld?

$\square$ huisarts

$\square$ huidarts / dermatoloog

$\square$ maag darm lever arts

$\square$ overig $\mathrm{nl}$

$\rightarrow$

pyoderma gangrenosum, voor het eerst vastgesteld in het jaar | _ _ _ _ _ _ _ door wie is de diagnose gesteld?

$\square$ huisarts

$\square$ huidarts / dermatoloog

$\square$ maag darm lever arts

$\square$ overig nl

32 Heeft u ooit niet door galsteenveroorzaakte problemen met de galwegen gehad? (b.v. scleroserende cholangitis, (PSC)

$\square$ nee

$\square$ ja, dit werd voor het eerst vastgesteld in het jaar $\mid \_\_$___ _ d door $\square$ huisarts

$\square$ maag darm lever arts

$\square$ overig $\mathrm{nl}$.

\section{Heeft u ooit een fistel, een abces of een fissuur gehad?}

$\square$ nee

ja, $\rightarrow \quad \square$ fistel, (een "kanaal " dat twee lichaam sholten met elkaar verbindt Ook kan een fistel een verbinding zijn tussen een holte en de huid)

dit werd voor het eerst vastgesteld in het jaar L_______ door

$\square$ huisarts

$\square$ chirurg

$\square$ maag darm lever arts

$\square$ overig $\mathrm{nl}$

$\rightarrow \quad \square$ abces, (ook wel etterbuilgenaamd, is een met pus gevulde holte) dit werd voor het eerst vastgesteld in het jaar $\_\_\_\_$_ door $\square$ huisarts

$\square$ chirurg

$\square$ maag darm lever arts

$\square$ overig $\mathrm{nl}$

$\rightarrow \quad \square$ fissuur, (een hardnekkig spleetvormig zweertje in de plooien rond de anus) dit werd voor het eerst vastgesteld in het jaar |_______ door $\square$ huisarts 


\section{Roken}

34 Rookt u momenteel sigaretten?

$\square$ nee, ik heb nooit sigaretten gerookt

$\square$ nee, ik ben gestopt met roken

$\square$ ja, ik rook sinds het jaar

35 In welk jaar bent u begonnen en eventueel gestopt met roken van sigaretten?

$\square$ niet van toepassing, nooit gerookt

Begonnen

$$
\text { in het jaar I_________ }
$$

Definitief gestopt.

in het jaar

36 Vertoeft u dagelijks in een rokerige omgeving (in uw gezin of werkplek)?

$\square$ nee, nooit

$\square$ nee, momenteel niet maar in het verleden wel

$\square$ ja

37 Vanaf welk jaar en tot wanneer vertoefde u dagelijks in een rokerige omgeving (in uw gezin of werkplek)?

$\square$ niet van toepassing, nooit dagelijks in rokerige omgeving

Begonnen

in het jaar

Gestopt.

in het jaar 


\section{De familie}

Komt bij $\mathrm{u}$ in de familie de ziekte van Crohn voor?

$\square$ nee

$\square$ ja (meerdere antwoorden mogelijk) bij

$$
\begin{aligned}
& \square \text { ouder(s) } \\
& \square \text { kind(eren) } \\
& \square \text { tweelingbroer of tweelingzus } \\
& \square \text { zus(sen) of broer(s) } \\
& \square \text { opa(s) of oma(s) } \\
& \square \text { oom(s) of tante(s) } \\
& \square \text { neven of nichten }
\end{aligned}
$$

$39 \quad$ Komt bij u in de familie de colitis ulcerosa voor?

$\square$ nee

ja (meerdere antwoorden mogelijk) bij

$$
\begin{aligned}
& \square \text { ouder(s) } \\
& \square \text { kind(eren) } \\
& \square \text { tweelingbroer of tweelingzus } \\
& \square \text { zus(sen) of broer(s) } \\
& \square \text { opa(s) of oma(s) } \\
& \square \text { oom(s) of tante(s) } \\
& \square \text { neven of nichten }
\end{aligned}
$$

40 Heeft uw echtgeno(o)t(e) / levensgezel(lin) IBD?

$\square$ nee

$\square$ ja, ziekte van Crohn

$\square$ ja, Colitis Ulcerosa

$\square$ ja, Aspecifieke Colitis

41 Heeft één van uw eerstegraads familieleden darmkanker gehad? Zo ja, op welke leeftijd? (Indien het meerdere personen betreft kunt u de verschillende leeftijden invullen)

$\square$ niemand
$\square$ moeder
$\square$ vader
$\square$ kind(eren)
$\square$ zus(sen) of broer(s)

$+$

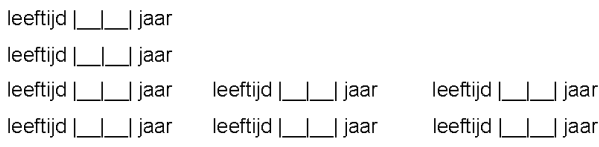




\section{Vermoeidheid}

42 Op deze pagina staan 4 uitspraken waarmee $u$ kunt aangeven hoe $u$ zich de laatste 2 weken heeft gevoeld. U kunt elke vraag beantwoorden door in één van de zeven hokjes een kruisje te zetten. De plaats van het kruisje geeft aan in weke mate $u$ vindt dat de uitspraak op u van toepassing is

\section{VOORBEELD:}

Wanneer $u$ vindt dat de uitspraak helemaal klopt, zet dan een kruisje in het linker hokje, dus zo

\begin{tabular}{l|l|l|l|l|l|l|l|}
$\begin{array}{l}\text { Ja, dat } \\
\text { klopt }\end{array}$ & $\mathbf{X}$ & & & & & & \\
$\begin{array}{l}\text { nee, dat } \\
\text { klopt niet }\end{array}$
\end{tabular}

Wanneer u vindt dat het antwoord niet 'ja, dat klopt', maar ook niet 'nee, dat klopt niet' is, zet dan een kruisje in het hokje dat het meest overeenkomt met uw gevoel. Bijvoorbeeld zo:

\begin{tabular}{l|l|l|l|l|l|l|l|}
$\begin{array}{l}\text { Ja, dat } \\
\text { klopt }\end{array}$ & & & & & $\mathbf{X}$ & & $\begin{array}{l}\text { nee, dat } \\
\text { klopt niet }\end{array}$ \\
\hline
\end{tabular}

Beantwoord alle vier de uitspraken en plaats telkens één kruisje bij iedere uitspraak

a Ik voel me moe

b Ik ben gauw moe

c Ik voel me fit

d Lichamelijk voel ik me uitgeput
Ja, dat

klopt

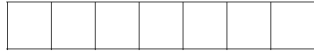

Ja, dat

klopt

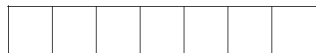

nee dat klopt niet

Ja, dat

klopt

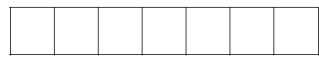

nee, dat klopt niet

Ja, dat klopt

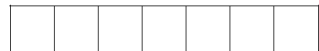

nee, dat klopt niet 


\title{
VOORBEELD:
}

\author{
'IK VOEL ME ONTSPANNEN.'
}

Wanneer u vindt dat het helemaal klopt dat u zich de laatste dagen ontspannen voelt, plaatst u een kruisje in het linker hokje; dus zo:
ja, dat klopt

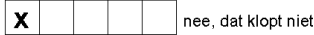

Hoe minder $u$ de uitspraak van toepassing vindt, hoe meer $u$ het kruisje naar rechts, richting 'nee, dat klopt niet' kunt plaatsen. Sla alstublieft geen uitspraken over en plaats telkens één kruisje bij iedere uitspraak. Er zijn geen foute antwoorden. Het gaat om uw eerste indruk

$1 \quad$ Ik voel me fit

2 Lichamelijk voel ik me tot weinig in staat

$3 \quad$ Ik zit vol activiteit

$4 \quad$ Ik heb zin om allerlei leuke dingen te gaan doen

$5 \quad$ Ik voel me moe

$6 \quad$ Ik vind dat ik veel doe op een dag

$7 \quad$ Als ik ergens mee bezig ben, kan ik mijn gedachten er goed bijhouden

8 Lichamelijk kan ik veel aan

$9 \quad$ Ik zie er tegen op om iets te doen

10 Ik vind dat ik weinig doe op een dag

11 Ik kan me goed concentreren

12 Ik voel me uitgerust

13 Het kost me moeite ergens mijn aandacht bij te houden

14 Lichamelijk voel ik me in een slechte conditie

15 Ik zit vol plannen

$16 \mathrm{lk}$ ben gauw moe

17 Er komt weinig uit mijn handen

18 De zin om dingen te ondernemen ontbreekt mi

19 Mijn gedachten dwalen gemakkelijk af

20 Lichamelijk voel ik me in een uitstekende conditie

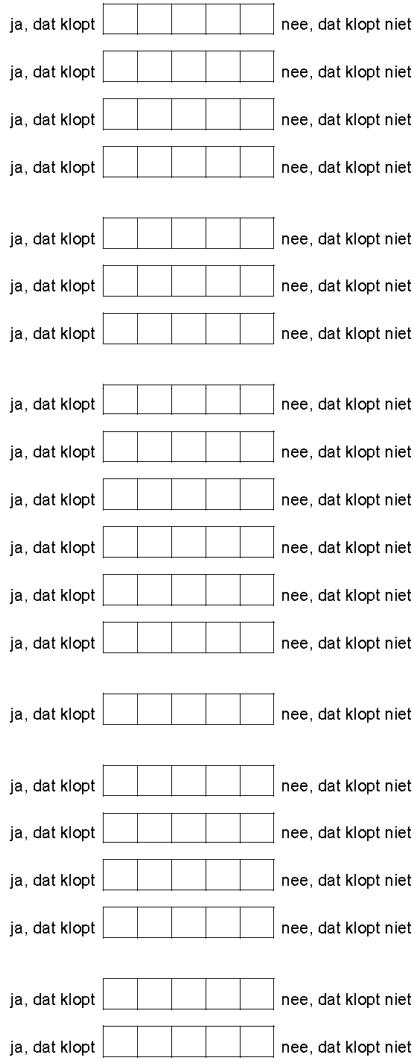

13 
44 Lees elke vraag aandachtig door. Zet een kruisje in het vierkantje bij het antwoord dat het beste weergeeft hoe $u$ zich gedurende afgelopen week gevoeld heeft. Denk niet te lang na. Uw eerste reactie is waarschijnlijk de meest nauwkeurige

1 Ik voel me gespannen
$\square$ bijna altijd
$\square$ vaak
$\square$ soms
$\square$ nooit

2 Ik geniet nog steeds van de dingen waar ik gewoonlijk van kon genieten

$\square$ zeker zo veel

$\square$ wat minder

$\square$ duidelijk minder

$\square$ nauwelijks nog

3 Ik heb een angstig gevoel alsof er iets vreselijks gaat gebeuren

$\square$ zeer zeker

$\square$ zeker

$\square$ een beetje

$\square$ helemaal niet

4 I k kan lachen en de dingen van de vrolijke kant zien

$\square$ net zoveel als gewoonlijk

$\square$ nu wat minder

$\square$ nu duidelijk minder

$\square$ helemaal niet meer

5 Ik maak me zorgen

$\square$ heel vaak

$\square$ vaak

$\square$ niet zo vaak

$\square$ heel soms

6 Ik voel me opgewekt

$\square$ nooit

$\square$ heel af en toe

$\square$ soms

$\square$ meestal

$7 \quad$ Ik kan me ontspannen

altijd

$\square$ meestal

$\square$ af en toe

$\square$ nooit

8 Ik heb het gevoel dat bij mij alles moeizamer gaat

$\square$ bijna altijd

$\square$ heel vaak

$\square$ soms

$\square$ nooit 
9 Ik heb een angstig, gespannen gevoel in mijn buik

$\square$ nooit

$\square$ soms

$\square$ vrij vaak

$\square$ heel vaak

10 Het interesseert me niet meer hoe ik eruit

$\square$ inderdaad, helemaal niet meer zi

$\square$ ik besteed minder aandacht aan mezelf

$\square$ ik besteed misschien iets minder aandacht aan mijzelf

$\square$ ik besteed net zoveel aandacht aan mijzelf als gewoonlijk

11 Ik voel me onrustig

$\square$ inderdaad, zeer vaak

$\square$ tamelijk vaak

$\square$ soms

$\square$ nooit

12 lk kijk met plezier uit naar dingen

net zoveel als gewoonlijk

$\square$ iets minder dan gewoonlijk

$\square$ veel minder dan gewoonlijk

$\square$ nauwelijks

13 Ik raak plotseling in paniek

$\square$ inderdaad, zeer vaak

$\square$ tamelijk vaak

$\square$ soms

$\square$ nooit

14 I k kan genieten van een goed boek of een

$\square$ vaak radio- of televisieprogramma

$\square$ regelmatig

$\square$ af en toe

$\square$ zelden

45 Hoe zou u over het algemeen uw gezondheid noemen?

$\square$ uitstekend

$\square$ zeer goed

$\square$ goed

$\square$ matig

$\square$ slecht 

geleden?

$\square$ veel beter nu dan een jaar geleden

$\square$ wat beter nu dan een jaar geleden

$\square$ ongeveer hetzelfde nu als een jaar geleden

$\square$ wat slechter nu dan een jaar geleden

$\square$ veel slechter nu dan een jaar geleden

47 De volgende vragen gaan over bezigheden die u misschien doet op een doorsnee dag. Wordt u door uw gezondheid op dit moment beperkt bij deze bezigheden? Zo ja, in welke mate?

\section{BEZIGHEDEN}

Ja

ernstig beperkt een beetje beperkt

Nee

helemaal niet beperkt

a Forse inspanning zoals hardlopen, tillen van zware voorwerpen, een veeleisende sport beoefenen

b Matige inspanning zoals een tafel verplaatsen, stofzuigen, zwemmen of fietsen

c Tillen of boodschappen dragen

d Een paar trappen oplopen

e Één trap oplopen

f Bukken, knielen of hurken

g Meer dan een kilometer lopen

h Een paar honderd meter lopen

i Ongeveer honderd meter lopen

j Uzelf wassen of aankleden 
Heeft $u$ in de afgelopen 4 weken, een van de volgende problemen bij uw werk of andere dagelijkse bezigheden gehad, ten gevolge van uw lichamelijke gezondheid?

a $U$ besteedde minder tijd aan werk of andere bezigheden

b $U$ heeft minder bereikt dan u zou willen

c $U$ was beperkt in het soort werk of andere bezigheden

d $U$ had moeite om uw werk of andere bezigheden uit te voeren (het kostte $u$ bijvoorbeeld extra inspanning)

49 Heeft $u$ in de afgelopen 4 weken, een van de volgende problemen ondervonden bij uw werk of andere dagelijkse bezigheden ten gevolge van emotionele problemen (zoals depressieve of angstige gevoelens?

Ja Nee

a $U$ besteedde minder tijd aan werk of andere bezigheden

b U heeft minder bereikt dan u zou willen

c $U$ deed uw werk of andere bezigheden niet zo zorgvuldig als gewoonlijk

50 In hoeverre hebben uw lichamelijke gezondheid of emotionele problemen u gedurende de afgelopen 4 weken gehinderd in uw normale omgang met familie, vrienden of buren, bij activiteiten in groepsverband?

$\square$ helemaal niet

$\square$ enigszins

$\square$ nogal

$\square$ veel

$\square$ heel erg veel

51 Hoeveel lichamelijke pijn heeft u de afgelopen 4 weken gehad?
$\square$ geen
$\square$ heel licht
$\square$ licht
$\square$ nogal
$\square$ ernstig
$\square$ heel ernstig 
52 In welke mate bent u de afgelopen 4 weken door pijn gehinderd in uw normale werk (zowel werk buitenshuis als huishoudelijk werk)?

$\square$ helemaal niet

$\square$ een klein beetje

$\square$ nogal

$\square$ veel

$\square$ heel erg veel

53 Deze vragen gaan over hoe u zich voelt en hoe het met u ging in de afgelopen 4 weken. Wilt $u$ a.u.b. bij elke vraag het antwoord aangeven dat het best benadert hoe u zich voelde.

a Voelde uzich levenslustig?

b Was u erg zenuwachtig?

c Zat u zo in de put dat niets $u$ kon opvrolijken?

d Voelde u zich rustig en tevreden?

e Had u veel energie?

f Voelde u zich somber en neerslachtig?

g Voelde u zich uitgeput?

h Was u een gelukkig mens?

i Voelde u zich moe?

54 Hoe vaak hebben uw lichameliike gezondheid of emotionele problemen u gedurende de afgelopen $\mathbf{4}$ weken gehinderd bij uw sociale activiteiten (zoals vrienden of familie bezoeken, etc)?

$\square$ altijd

$\square$ meestal

$\square$ soms

$\square$ zelden

$\square$ nooit 
Hoe JUIST of ONJUIST is elk van de volgende uitspraken voor u?

$\begin{array}{lccccc} & \begin{array}{c}\text { Volkomen } \\ \text { juist }\end{array} & \begin{array}{c}\text { Groten- } \\ \text { deels } \\ \text { juist }\end{array} & \begin{array}{c}\text { Weet ik } \\ \text { niet }\end{array} & \begin{array}{c}\text { Groten- } \\ \text { deels } \\ \text { onjuist }\end{array} & \begin{array}{c}\text { Volkomen } \\ \text { onjuist }\end{array} \\ \begin{array}{l}\text { Ik lijk wat gemakkelijker ziek te } \\ \text { worden dan andere mensen }\end{array} & \square & \square & \square & \square & \square \\ \begin{array}{l}\text { Ik ben even gezond als andere } \\ \text { mensen die ik ken }\end{array} & \square & \square & \square & \square & \square \\ \text { Ik verwacht dat mijn gezondheid } & \square & \square & \square & \square & \square \\ \text { achteruit zal gaan } & \square & \square & \square & \square \\ \text { Mijn gezondheid is uitstekend } & \square & \square & \square & \square & \square\end{array}$


De volgende vragen zijn opgenomen om een idee te krijgen hoe $u$ zich gedurende de afgelopen twee weken heeft gevoeld. Er wordt gevraagd naar klachten die kunnen behoren bij uw darmziekte, maar ook zijn vragen opgenomen over algemeen welbevinden en stemming. Kruis telkens het meest toepasselijke antwoord aan.

56 Hoe vaak was moeheid of het gevoel

$\begin{array}{clcccc}\text { de hele grootste } & \text { een } & \text { een } & \text { een } & \text { bijna } & \text { hele- } \\ \text { tijd } & \begin{array}{l}\text { deel van } \\ \text { de tijd }\end{array} & \text { groot deel van deel van deel van deel van } & \text { maal } \\ \text { de tijd } & \text { de tijd } & \text { detijd } & \text { de tijd } & \end{array}$
"uitgeblust te zijn" de afgelopen twee weken voor u een probleem?

57 Hoe vaak was $u$ de afgelopen twee weken gefrustreerd, ongeduldig of rusteloos?

58 Hoe vaak heeft $u$ de afgelopen twee weken school moeten missen of uw werk niet kunnen doen als gevolg van uw darmklachten?

59 Hoe vaak heeft $u$ de afgelopen twee weken dunne ontlasting gehad?

60 Hoe vaak bent $u$ in de afgelopen twee weken ongerust geweest over een eventueel noodzakelijke operatie voor uw darmziekte?

61 Hoe vaak heeft u de afgelopen twee weken een afspraak moeten uitstellen of afzeggen in verband met uw darmziekte?

62 Hoe vaak heeft $u$ de afgelopen twee weken last gehad van buikkrampen?

63 Hoe vaak heeft $u$ zich de afgelopen twee weken niet lekker gevoeld ("algemeen onwel zijn")?

64 Hoe vaak heeft $u$ zich de aflopen twee weken zorgen gemaakt om niet op tijd bij het toilet te kunnen komen?

65 Hoe vaak heeft $u$ de afgelopen weken last gehad van buikpijn?

66 Hoe vaak heeft u gedurende de afgelopen twee weken problemen gehad een goede nachtrust te krijgen of had $u$ last van 's nachts wakker worden?

67 Hoe vaak voelde $u$ zich de afgelopen twee weken depressief of teneergeslagen? 
68 Hoe vaak heeft $u$ de afgelopen twee weken gelegenheden vermeden waarvan u niet zeker wist dat er een toilet in de buurt was?

69 Hoe vaak heeft u gedurende de afgelopen twee weken last gehad van veel winderigheid?

70 Hoe vaak heeft $u$ zich de afgelopen twee weken zorgen gemaakt over het behouden of verkrijgen van het gewicht dat u nastreeft?

71 Veel patiënten met chronische darmziekte maken zich vaak zorgen of hebben angsten die te maken hebben met hun ziekte. Onder andere zorgen om kanker te krijgen, zich nooit beter te voelen en angsten om weer veel last van hun darmziekte te krijgen. Hoe vaak heeft u dergelijke zorgen gehad gedurende de afgelopen twee weken?

72 Hoe vaak heeft u gedurende de afgelopen twee weken last gehad van een opgeblazen gevoel?

73 Hoe vaak heeft $u$ de afgelopen twee weken last gehad van bloedverlies bij de ontlasting?

74 Hoe vaak heeft u zich gedurende de afgelopen twee weken opgelaten gevoeld door uw darmprobleem?

75 Hoe vaak heeft $u$ de afgelopen twee weken het gevoel gehad dat $\mathrm{u}$ naar het toilet moest gaan waarbij dan echter geen ontlasting kwam?

76 Hoe vaak heeft $u$ zich de afgelopen twee weken verdrietig of van streek gevoeld?

77 Hoe vaak heeft $\mathrm{u}$ zich de afgelopen twee weken kwaad gemaakt vanwege uw darmziekte?

78 Hoe vaak heeft u zich gedurende de afgelopen twee weken misselijk gevoeld?

79 Hoe vaak was u gedurende de afgelopen twee weken geïrriteerd?

\begin{tabular}{|c|c|c|c|c|c|}
\hline hele & $\begin{array}{l}\text { Grootste } \\
\text { deel van } \\
\text { de tijd }\end{array}$ & $\begin{array}{c}\text { Een } \\
\text { groot } \\
\text { deel van } \\
\text { de tijd }\end{array}$ & $\begin{array}{c}\text { Een } \\
\text { matig } \\
\text { deel van } \\
\text { de tijd }\end{array}$ & $\begin{array}{c}\text { Een } \\
\text { Klein } \\
\text { deel van } \\
\text { de tijd }\end{array}$ & $\begin{array}{l}\text { Bijna } \\
\text { geen } \\
\text { deel van } \\
\text { de tijd }\end{array}$ \\
\hline
\end{tabular}
de tijd de tijd de tijd de tijd

niet 
80 Hoe vaak heeft $u$ in de afgelopen twee weken ontlasting gehad in vergelijking met een rustige fase van uw darmziekte?

$\square$ ontlasting vaker dan ooit

$\square$ extreem vaak

$\square$ erg vaak

$\square$ matige verhoging in vergelijking met rustige fase

$\square$ enige verhoging in vergelijking met rustige fase

$\square$ lichte verhoging in vergelijking met rustige fase

$\square$ geen verhoging in vergelijking met rustige fase

81 Hoeveel energie had u de afgelopen twee weken?
$\square$ totaal geen energie
$\square$ heel erg weinig energie
$\square$ weinig energie
$\square$ enige energie
$\square$ matige hoeveelheid energie
$\square$ veel energie
$\square$ zeer veel energie

82 Hoeveel moeite heeft het u de afgelopen twee weken gekost, door uw darmproblemen, om tijd te besteden aan ontspanning of sport?

$\square$ zeer veel moeite, ontspanning en sport waren niet mogelijk

$\square$ veel moeite

$\square$ best wel moeite

$\square$ enige moeite

$\square$ weinig moeite

$\square$ praktisch geen moeite

$\square$ helemaal geen moeite, geen beperking van sport / ontspanning door darmproblemen

83 Hoe vaak heeft u zich gedurende de afgelopen twee weken relaxed en ontspannen gevoeld?

$\square$ nooit

$\square$ een klein deel van de tijd

$\square$ enig deel van de tijd

$\square$ een matig deel van de tijd

$\square$ grootste deel van de tijd

$\square$ bijna de hele tijd

$\square$ de hele tijd 
Hoe groot was het probleem voor u gedurende de afgelopen twee weken dat per ongeluk wat ontlasting werd verloren?

$\square$ een ernstig probleem

$\square$ een belangrijk probleem

$\square$ een matig probleem

$\square$ enige last

$\square$ weinig last

$\square$ bijna geen last

$\square$ geen last

In welke mate heeft uw darmprobleem gedurende de afgelopen twee weken ertoe bijgedragen dat er een beperking was in uw seksuele leven?

$\square$ geen seksuele activiteit door darmproblemen

$\square$ zeer grote beperking door darmproblemen

$\square$ grote beperking door darmproblemen

$\square$ matige beperking door darmproblemen

$\square$ enige beperking door darmproblemen

$\square$ nauwelijks beperking door darmproblemen

$\square$ geen beperking door darmproblemen

86 Hoe vaak had u gedurende de afgelopen twee weken het gevoel niet door uw omgeving te worden begrepen?

$\square$ de hele tijd

$\square$ bijna de hele tijd

$\square$ grootste deel van de tijd

$\square$ een matig deel van de tijd

$\square$ enig deel van de tijd

$\square$ een klein deel van de tijd

$\square$ nooit

87 Hoe tevreden, gelukkig of blij was u gedurende de afgelopen twee weken met uzelf?

$\square$ zeer ontevreden, grootste deel van de tijd ongelukkig

over het algemeen ontevreden, ongelukkig

$\square$ iets ontevreden, ongelukkig

$\square$ over het algemeen tevreden, blij

$\square$ tevreden, meeste deel van de tijd gelukkig

$\square$ zeer tevreden, meeste deel van de tijd gelukkig

$\square$ extreem tevreden, kon niet gelukkiger of blijer zijn 